\title{
Baumwoll-Anbau, \\ -Handel und -Industrie in den \\ Vereinigten Staaten von Nordamerika
}

\author{
Von
}

Moritz Schanz

Neubearbeitete zweite Ausgabe 

Return this book on or before the Latest Date stamped below. A charge is made on all overdue books.

University of Illinois Library

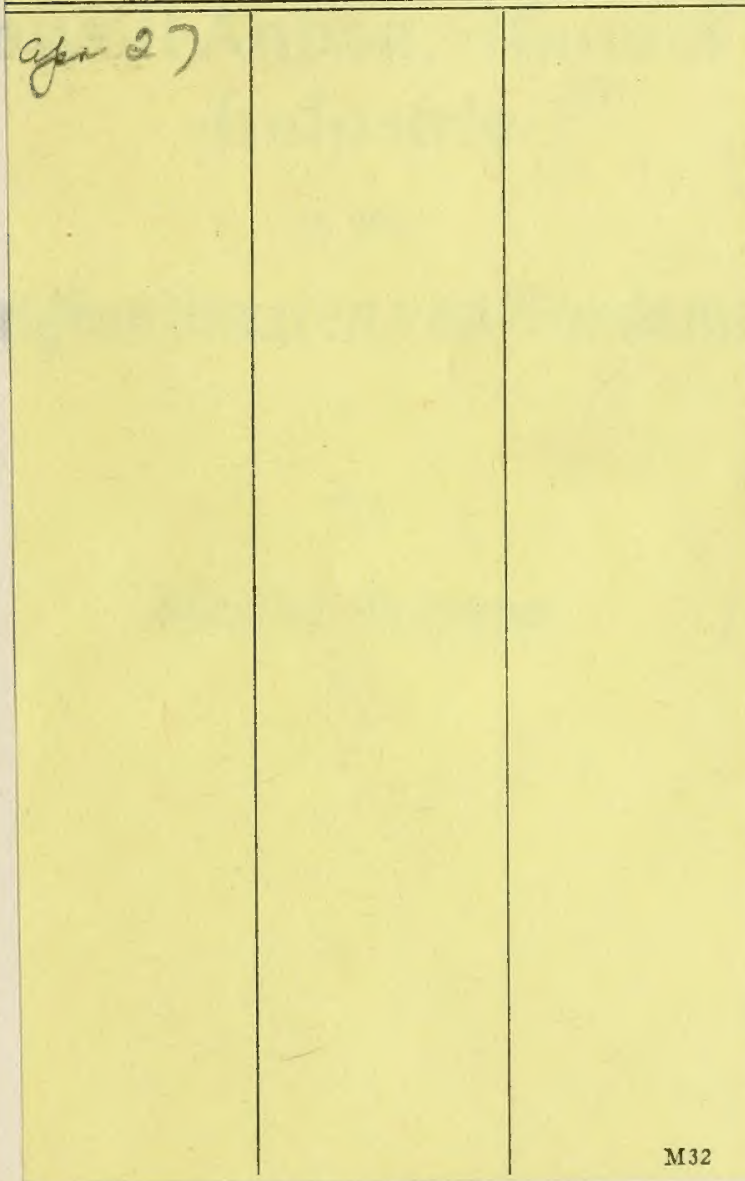


Digitized by the Internet Archive in 2011 with funding from University of Illinois Urbana-Champaign 


\title{
Sonderabdruck
}

aus „Beihefte zum Tropenpflanzer“ Jahrg. 1914/15, Nr. 6.

\section{Baumwoll-Anbau, -Handel und -Industrie}

in den

\section{Vereinigten Staaten von Nordamerika}

\author{
Von
}

\section{Moritz Schanz}

Neubearbeitete zweite Ausgabe. 
Yeffetis

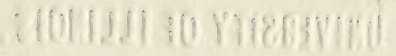

absisere

$++\ldots$ 


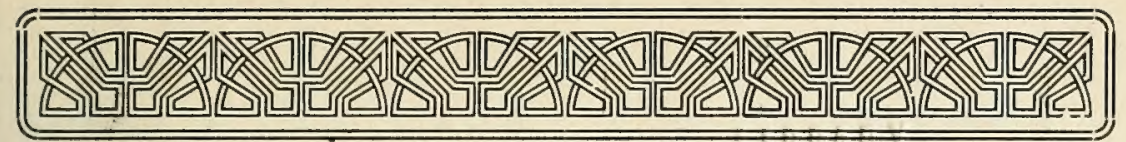

\section{1 \\ schl6bi \\ cop. 4}

\section{Vorwort.}

Die Redaktion des „Tropenpflanzer“ hat mich ersucht, meinen nordamerikanischen Reisebericht vom Sommer 1907, den sie seinerzeit veröffentlichte, bis zur Jetztzeit fortzuführen und in erweiterter Form nach demselben Plane auszuarbeiten, den ich in meinen inzwischen erschienenen Abhandlungen über Baumwolle in Ägypten und dem Englisch-Ägyptischen Sudan, in Ostindien und in RussischAsien befolgte.

Die Arbeit ist bereits im Sommer 1914 vollendet gewesen, ihre Veröffentlichung erlitt aber durch die Kriegsereignisse einige Verzögerung.

Ich schließe damit meine Serie von Berichten über die Hauptgebiete des Baumwollanbaues ab.

Chemnitz, Sommer I9I 5.

\section{Moritz Schanz,}

stellvertretender Vorsitzender der Baumwollkommission des Kolonial-Wirtschaftlichen Komitees.

\section{1}


Heffone

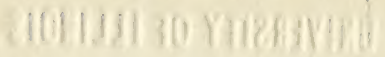

An:Bano

\section{.}




\section{Inhalt.}

Geld, Maße und Gewichte

Die Landwirtschaft in den Vereinigten Staaten.

Allgemeines S. 7. Grundbesitzverteilung und Pachtwesen S. 9. Landpreise S. II. Arbeiterfrage und Löhne S. II. Ländliches Kreditwesen S. I2. Genossenschaften S. I3. Staatliche Förderung S. 13. Ackerbau-Amt S. I3. Versuchsstationen S, I4. Wanderlehrer S. I 5. Landwirtschaftliches Unterrichtswesen S. 16. Landwirtschaftsgesellschaften S. I 7.

Der Baumwollgürtel .

Geographische Grenzen S. 17. Baumwollböden S. i8. Klima S. 20. Künstliche Be- und Entwässerung S. 22. Wirtschaftsformen bei Weißen und Farbigen S. 23. Pflanzervereinigungen S, 32 .

Baumwollsorten

Botanische S. 35 . Uplands S. 35. Sea Island S. 37. Ägyptische

S. 38. Handelssorten S. 39

Saatwahl und Saatzucht

Baumwollanbau

Fruchtfolge S. 44. Ackergeräte und Tiere S. 45. Zurichtung des Bodens S. 47. Düngung S. 49. Mulching S. 52. Aussaat S. 52. Pflege während des Wachstums S. 54. Ernte S. 56.

Baumwollkrankheiten und -schädlinge.

Bureau of Entomology S. 62. Farmers Cooperative Demonstration Work S. 63. Erprobte Kulturmethoden S. 63.

Anbauflächen, Erträge und Durchschnittspreise

Einzelgebiete

Amtliche Statistik und Ernteschätzung . . . . . . . . . . . . . 70

Ernteaufbereitung. . . . . . . . . . . . . . . . . 73

Entkernen S. 74. Pressen und Packen S. 79. Compress S. 8o. Gin-Compress S. 82. Rundballen S. 82, Feuchtigkeit in Baumwolle S. 83 .

Produktionskosten und Rentabilität . . . . . . . . . . . . . . . 84

Baumwollsaat und Produkte daraus . . . . . . . . . . . . . . . 87

Die Ölmühlen S. 89. Linters S. 93. Baumwollsaatschalen S. 94. Ölgewinnung, hydraulischer Prozeß S. 95. Kalter Prozeß S. 97. Baumwollsaatkuchen und -mehl S. 99. Baumwollsaatöl S. 10I. 
Baumwollaufkauf und -handel S. Io6. Baumwollbörsen in Nordamerika S. I Io. Preise für middling S. I Io. United States Cotton Futures Act S. III.

Versand

Landstraßen S. Ir 3. Wasserstraßen S. Ir3. Eisenbahnen S. Ir3. Ausfuhrplätze S. II 5 .

Baumwollexport Mengen und Werte S. II7. Bestimmungsländer S. I19. Baumwollbörsen in Europa S. II9. Arbitrage S, I2I.

Baumwollverbrauch in den Vereinigten Staaten

Geschichtliches S. 122. Statistisches S. 124. Spinnerei S. 124. Weberei S. 125. Arbeiter S. 126. Betriebskraft S. I28. Baumwollverbrauch einheimischer und importierter Baumwolle S. 129. Absatz S. I29. Export von Baumwollwaren S. I29. Import von Baumwollwaren S. r30.

Zukunft des amerikanischen Baumwollbaus Rückblick und Ausblick S. I30.

Quellenverzeichnis

\section{Geld, Maße und Gewichte.}

I Dollar $=$ Ioo Cents . . . . . . . . . . . . . $=4,20 \mathrm{M}$.

I Cent. . . . . . . . . . . . . . . . . $=4$ Pfennige

I amerikanische Township $=6 \times 6$ Miles $=36$ Square Miles oder

Sections . . . . . . . . . . . . . . $=93,247 \mathrm{qkm}$

I Section $=$ I Square Mile $=640$ Acres . . . . . . . . . $=2,59$

I Lot $=1 / 8$ Section $=80$ Acres . . . . . . . . . . $=32,368$ ha

I Acre $=4840$ Quadratyards . . . . . . . . . . . . . $=0,4046$,

I englische Landmeile $=1760$ Yards . . . . . . . . . $=1609 \mathrm{~m}$

I Yard $=3$ Fuß . . . . . . . . . . . . . = $9 \mathrm{I} 4 \mathrm{~mm}$

I Fuß = I2 Zoll . . . . . . . . . . . . . . . = 305 "

I Zoll (Inch) . . . . . . . . . . . . . . . . . . . . = 25,4 ",

I amerikanische short ton $=$ Tonne (für Baumwollsaat) $=2000$ Pfund $=907 \mathrm{~kg}$

I amerikanischer Zentner (Cwt.) $=$ II2 Pfund . . . . . . . = $50^{3 / 4}$,

I amerikanisch-englisches Pfund (lb.) . . . . . . . . . . = $453.5 \mathrm{~g}$

I amerikanisches Bushel $=4$ Pecks ... . . . . . . . 35,238 I

1 Peck . . . . . . . . . . . . . . . . . . . 8,8 "

I amerikanische Gallon . . . . . . . . . . . . = 3.785 , 


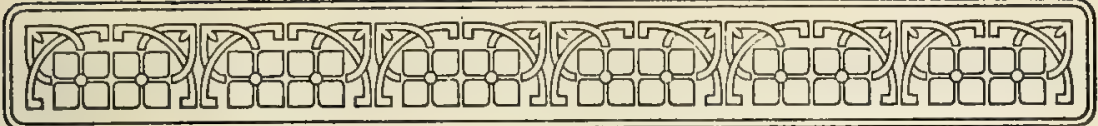

\section{Geschichtliches.}

Schon die ersten Entdecker Amerikas trafen die Baumwolle dort an vielen Stellen an. Kolumbus fand auf seiner Entdeckungsfahrt 1492 Baumwolle wild wachsend auf Guanahani, und er und seine Nachfolger trafen die Pflanze dann auch vielfach auf dem amerikanischen Festlande an, wo sie von den Eingeborenen mit bemerkenswerter Kunstfertigkeit zu Geweben verwandt wurde. Besonders in M exiko lieferte Baumwolle die alleinige Grundlage der Kleidung, und Baumwollstoffe bildeten einen Teil der von Cortez an Kaiser Karl V. gesandten Geschenke. Dem Beispiel der Azteken folgend, polsterte auch Cortez die Wämser seiner Soldaten, um sie vor den feindlichen Pfenlen zu schützen, mit Baumwolle. Baumwolle und Gewebe daraus wurden weiterhin 1522 von Pizarro in P e r u angetroffen, die wildwachsende Pflanze von Cabeça de Vaca I536 im heutigen Gebiete der Un i o n, am unteren Mississippi, im südlichen Louisiana, in Texas und in Kalifornien. Auch die B r a silianer brauchten die Faser der wildwachsenden Pflanze zu Stricken, Netzen, Hängematten und sogar zu Kleidungsstücken, Proben brasilianischer Baumwolle kamen schon 1570 auf den Ulmer Markt - kurz, überall zwischen dem 35. nördlichen und südlichen Breitengrad war Baumwolle zur Zeit der Entdeckung Amerikas wildwachsend oder kultiviert vorhanden und ihre Verwendbarkeit bekannt. Bald trugen auch die europäischen Einwanderer zur Ausbreitung der Baumwollkultur bei.

Die englischen Kolonisten Virginias brachten Sämereien aus allen Teilen der Erde, darunter auch Baumwollsaat mit, die I 607 bei Jamestown versucht und erfolgreich angebaut wurde; im Jahre $162 \mathrm{I}$ wird auf einem Verzeichnis der in Virginia gezogenen 'rodukte Baumwolle mit 8 Pence für das Pfund aufgeführt. Die Saat stammte aus Westindien und der Levante. Wenn der Export von Virginia zunächst auch fast ausschließlich auf Tabak zugeschnitten war, so wurde Baumwolle, im Anbau von einigen der 
ersten Gouverneure begünstigt, doch für den Heimbedarf gezogen und verarbeitet.

Im Jahre 1664 ließ sich eine Anzahl von Kolonisten von der Insel Barbados aus in $\mathrm{Ca}$ rolin a nieder und brachten neben anderen Kulturpflanzen auch Baumwolle mit. 1666 wurden große Mengen levantinischer Baumwollsaat aus Cypern und Smyrna nach Carolina gesandt, und zu Anfang des 18. Jahrhunderts hatte der Baumwollbau dort bereits einen solchen Umfang angenommen, daß cin Fünftel der Bevölkerung mit dem Ertrag bekleidet werden konnte. Freilich erlangte an dieser südlichen Küste der I693 durch Zufall in Charleston eingeführte Reis bald eine ähnliche überragende Bedeutung wie der Tabak im Norden.

Auch das ab, 1683 von den Franzosen kolonisierte Louisiana, damals die heutigen Staten Mississippi und A 1 ab a ma mit umfassend, führte mit Negerarbeit betriebenen Baumwollbau ein. Ab 1734 wurde Baumwolle in $\mathrm{G} \mathrm{c}$ o r g i a angepflanzt, und wenn auch nur als Gartenpflanze, drang sie ab 1736 bis an die Chesapeake-Bai in $\mathrm{M}$ a $\mathrm{r}$ y 1 a $\mathrm{n}$ d vor. Im Jahre $\mathrm{I} 754$ berichtet man über Baumwolle in Flo rida. $175^{8}$ führten dic Franzosen weiße siamesische Baumwolle in Louisiana ein. Der Notstand während des Revolutionskrieges ließ Baumwolle für den Bedarf des Heeres sogar in Dela a a re und in $\mathrm{New} \mathrm{J}$ e r s e y anbauen und P e n ns y lva nien deckte den heimischen Bedarf des Staates selbst.

Im ganzen aber spielte Baumwolle im amerikanischen Wirtschaftsleben vor dem Unabhängigkeitskrieg nur eine recht nebensächliche Rolle, und der Anbau beschränkte sich überwiegend nur auf kleine Flächen. Das größte um 1776 erwähnte Baumwollfeld in der Nähe von Savannah umfaßte nur 30 Acres, auf denen kaum 3000 bis 4000 Pfund Baumwolle gezogen sein mögen. Mit der Entstehung des Plantagen-Großbetriebes im Süden und der Einführung der Negersklaverei hat Baumwolle also nichts zu tun gehabt, dafür waren vielmehr die Kulturen von Tabak, Reis und Indigo verant. wortlich.

I 786 wurde die langstapelige Se a I s I a n d-Baumwolle von den Bahama-Inseln aus in Georgia eingeführt, und ihr Anbau dehnte sich an den Gestaden von Georgia und Carolina mehr und mehr aus. Sonst scheint man bis dahin mehr die kurzstapeligen Sorten angebaut zu haben.

Die Gesamternte im Jahre I790/9 I belicf sich auf 8800 Ballen von je 225 Pfund netto, und man fing an, darunter auch George Washington, der Baumwolle eine grofe Zukunft zuzuschreiben. 
Die Ernte von 179I/92 belief sich auf 13300 Ballen, davon kamen $75 \%$ auf Süd-Carolina und die restlichen $25 \%$ fast ganz auf Georgia. Allmählich übernahm dort die Baumwolle die Stelle des Indigos, und man baute an der Küste Sea Island, während man im Hinterland Nanking-Baumwolle von Malta, Nierenbaumwolle von Pernambuco und die feine Bourbon-Baumwolle probierte.

Im Laufe des 18. Jahrhunderts begann man auch Baumwolle auszuführen, allerdings in sehr bescheidenem Umfang, und zwar scheint die erste Baumwolle im Jahre 1739 durch den in Georgia ansässigen Kolonisten Samuel Augspurger nach England gebracht worden $z u$ sein, das seinen damals nicht großen Bedarf darin in Westindien, der Levante, Brasilien, Bourbon und Ostindien deckte. Von da ab bis zum Jahre 1784 werden nur in sieben Jahren kleine nordamerikanische Baumwollverschiffungen nach England erwähnt; von 1784 an aber beginnen, mit zunächst 14 Ballen, die jährlichen regelmäßigen Verschiffungen, und gleichzeitig steigen die Mengen; I786 gelangten 900 Pfund nach Liverpool, I793 schon 487600 und 1794 , in dem Jahre der Patentierung von Whitneys Sägegin, I 600000 Pfund.

Nachdem in England Hargreaves 1767 die Spinnmaschine und Cartwright 1785 den mechanischen Webstuhl erfunden und damit den Grund zu der modernen Baumwollindustrie gelegt hatten, beantragte auf der anderen Seite des Atlantik ein stellenloser Lehrer, Eli Whitney in Savannah, 1793 das Patent auf seine Sägegin, welche die bislang überaus zeitraubende und mühsame Entkernung der Baumwolle mit der Hand durch eine ebenso sinnreiche wie einfache Maschine ersetzte und die Baumwoll-Großkultur eigentlich erst ermöglicht hat. Die etwa gleichzeitigen Erfindungen ergänzten sich trefflich: Auf der einen Seite, zunächst in England, stark steigende Zunahme des Bedarfs an Rohmaterial, auf der anderen Seite die Möglichkeit leichterer Produktion mit Hilfe der Sägegin und größeren Absatzes.

Die erste mit Wasserkraft betriebene Gin-Anlage wurde 1795 in Süd-Carolina errichtet, und mit der bald eintretenden Verbesserung der Maschine und steigender. Sklaveneinfuhr nahm der Baumwollbau so schnell zu, dals die Pflanzer eine Uberproduktion befürchteten. Während noch im Jahre I79I die Gesamtproduktion der Vereinigten Staaten nur 2 Millionen Pfund ausmachte, war sie 180 I bereits auf 40 Millionen Pfund gestiegen, und die Union eroberte bereits zu Anfang des 19. Jahrhunderts unter den Baumwoll-Ausfuhrländern die erste Stelle, die sie seitdem behauptet hat. Die 
Baumwollkultur fordert keine kostspielige Maschinerie oder große Kapitalanlage in Meliorationen und konnte sich also leicht ausdehnen in einem Gebiet mit idealen Vorbedingungen dafür.

Als neue Anbaugebiete traten I80I Tennessee und 1839 Arkansas hinzu, im letzteren Jahre wurde Baumwolle auch in Maryland, Delaware, Indiana und Illinois angebaut; seit 1845 tritt $T$ exas hinzu, das bald einen riesigen Aufschwung nahm und Ende der 8oer Jahre an die Spitze sämtlicher Baumwollstaaten trat, nachdem I79I bis I82 I Süd-Carolina, vorübergehend Georgia, ab 1839 Mississippi die größte Baumwollmenge geliefert hatte. Nur durch Anwendung künstlichen Düngers konnten auch die Atlantischen Staaten Areal und Ertrag des Baumwollbaus ausdehnen.

Im Jahre 1825 erreichte die Ernte zum ersten Male I Million Ballen zu 3 I 2 Pfund, und im Jahre 1861 , vor Ausbruch des Bürgerkrieges, war sie auf 41/2 Millionen Ballen zu 477 Pfund gestiegen.

Baumwolle war die solide. Basis für die Pflanzeraristokratie des Südens. Neben den mit Sklaven betriebenen Pflanzungen, welche den Kern des Baumwollbaus bildeten, pflanzten hier und da atuch sklavenlose ,arme Weiße“, unwissende kleine Farmer im Oberland und in den Gebirgszügen, wohin sich die Negerwirtschaften nicht ausgedehnt hatten, auf armem Boden etwas Baumwolle. Der tiichtige, aber kapitallose kleine Squatter jedoch fühlte sich durch die ,schwarze Mauer" vom Vordringen nach dem Westen abgeschreckt, trat nur in Texas und Arkansas in Erscheinung, und es hat lange gedauert, ehe die fremde Einwanderung sich dahin wandte. Erst die deutschen Einwanderer in Texas gaben den Südstaaten das lehrreiche Beispiel, daß man auch in dieser allersüdlichsten Lage der Union mit we i Ber Arbeit in verständiger Landwirtschaft quantitativ und qualitativ befriedigende Erträge erzielen könne.

Der mit so großer Erbitterung geführte Sezessionskrieg von I86 I bis I865 schlug dem Süden auch wirtschaftlich die schwersten Wunden. Fast das ganze öffentliche Kapital war in Papiergeld der Konföderation angelegt und verloren; beträchtliche Mengen des privaten Produktivkapitals waren aufgezehrt und aufgenutzt; die Sklaven hörten auf Privatkapital zu sein; Staaten und Private waren stark verschuldet, die Leistungsfähigkeit des Pflanzers war vermindert. Die verarmten Leute in dem verarmten Lande mußten sich, um weiterzuwirtschaften, Geld zu riesigen Zinssätzen, oder Waren zu ungeheuren Preisen auf Kredit suchen und gerieten in Abhängigkeit von diesen Zustand nach Kräften ausnutzenden Bankiers, Kaufleuten und Faktoren. Um auch nur diesen drückenden 
Kredit schaffen zu können, führte man das Pfandrecht an die Ernte auf dem Halm (Crop Lien) ein, das für die wirtschaftliche Zukunft und Machtverteilung auf eine ganze Generation hinaus von entscheidender Bedeutung wurde. Aber der Preis des Geldes war und blieb enorm hoch, 75 bis $80 \%$ werden als nicht ungewöhnlich bezeichnet; für vollkommen sichere Kredite berechneten die Banken I 8 bis $30 \%$, bei auf Kredit genommenen Waren wurden für das Risiko $100 \%$ und mehr aufgeschlagen.

Der gesamte Baumwollexport der vier Jahre I 862 bis I 865 war, trotz einer großartig organisicrten Blockadebrechung, auf 70 oos Ballen gesunken, und wenn die damaligen hohen Preise vorübergehend auch die Staaten West-Virginia, Nevada, Kalifornien, Illinois und Utah zur Aufnahme der Baumwollkultur veranlaßten, so betrug die Gesamtproduktion der Union im Jahre 1865 doch nur 300000 Ballen, und die Arbeiter- und Kreditverhältnisse waren nach der plötzlichen Aufhebung der Sklaverei derart zerrüttet, daß es zehn Jahre dauerte, ehe man die Erntehöhe vor dem Kriege wieder erreichte.

Trotzdem die Tendenz der Baumwollpreise bis zu Ende des letzten Jahrhunderts im allgemeinen eine sinkende war, ist die weitere Entwicklung der Baumwollproduktion seit Mitte der zoer Jahre, mit einigen Schwankungen, eine stetige gewesen; I879 erscheint als neuer Baumwollproduzent $\mathrm{Oklahoma}$, das seit Anfang des 20. Jahrhunderts einen bedeutenden Aufschwung nahm, auch Neu-Mexiko und Kalifornien nahmen die Kultur wieder auf, dazu trat neuerdings, mit Zuhilfenahme künstlicher Bcwässerung, A rizon a.

Im Jahre 1890 überschritt die Baumwollernte zum ersten Male 8 Millionen Ballen, I894 erreichte sie Io Millionen, I9I I ihre bisherige Rekordhöhe von I61/4 Millionen Ballen, und dabei wiesen dic Baumwollpreise seit Anfang des Jahrhunderts eine sehr respektable Steigerung auf. Die wirtschaftliche Krisis der Südstaaten kann seit Ende des 19. Jahrhunderts als überwunden gelten, überall trifft man auf Zeichen wirtschaftlicher Blüte. Der "neue Süden" hat das Baumwollkönigreich industrialisiert, das Baumwollfeld in enge Bcziehungen zur Baumwollfabrik gebracht, Kohlen-, Eisen- und andere gewerbliche Großanlagen geschaffen. Welch hohes Selbstbewußtsein heute den amerikanischen Baumwollfarmer erfüllt, kam recht deutlich auf dem großen Baumwollkongreß in Atlanta, Georgia, zum Ausdruck, der im Oktober 1907 stattfand und einerseits von den amerikanischen Pflanzern, Händlern und Spinnern, anderseits von 
zahlreichen Vertretern der, ,Internationalen Vereinigung von Baumwollspinnern und Webern" besucht war. Die letzteren brachten dabei mancherlei alte Beschwerden, besonders wegen der schlechten Packung der amerikanischen Baumwolle, zur Sprache, die amerikanischen Farmer-Vereinigungen aber erklärten bei dieser Gelegenheit, daß sie nicht mehr geneigt seien, Baumwolle „billig“ zu verkaufen, sondern daß sie, ,im Interesse der Erziehung ihrer Kinder, eines menschenwürdigen Daseins" und aus anderen idealen Gründen einen zukünftigen Mindestpreis von I5 Cents für das Pfund Baumwolle verlangten; der Marktpreis Ende 1907 war II Cents.

Unter diesen Umständen tauchte bei den europäischen Spinnern der Gedanke auf, sich selbst am amerikanischen Baumwollbau zu beteiligen, und man nahm dafür zunächst den Ankauf der HeathmanFarm im Staate Mississippi in Aussicht. Dieser Plan realisierte sich nicht, doch kauften einige Jahre später sowohl die „Fine Cotton spinners and Doublers Association" in Manchester wie andere englische Kapitalisten Land im Staate Mississippi zum Zwecke des Baumwollbaus.

Baumwolle liefert heute nach Mais die wertvollste Ernte der Vereinigten Staaten iiberhaupt und wertete im bisherigen Rekordjahr I9IO nach amtlicher Schätzung 820 Millionen Dollar für LintBaumwolle und I 43 Millionen Dollar für unbearbeitete Batumwollsaat, zusammen 963 Millionen oder fast eine Milliarde Dollars. Der M e $\mathrm{n}$ g e nach steht bislang das Jahr I9I I mit I61/4 Millionen Ballen à 500 Pfund an der Spitze.

Auch im Export der Vereinigten Staaten steht Rohbaumwolle an der Spitze der Liste, lieferte im Fiskaljahr I9I2 mit 565 Millionen Dollars $26 \%$ des Gesamtexports und übertraf damit die Summe der nächsten drei großen Exportgruppen: Eisen- und Stahlerzeugnisse, Fleisch- und Molkereiprodukte und Brotstoffe. Neben England, dem Hauptabnehmer von Baumwolle, nahmen mit ihrer wachsenden Industrie auch die europäischen Kontinentalstaaten allmählich als Baumwollkonsumenten zu und überholten seit Ende des 19. Jahrhunderts in ihrer Gesamtmenge England. Anderseits entwickelte sich auch die Baumwollindustrie in den Vereinigten Staaten selbst derart, daß sie heute bereits reichlich ein Drittel der Ernte im Lande selbst verarbeitet.

Im allgemeinen hat der Batumollverbratuch der Welt schneller zugenommen als die Baumwollerzetugung, so daß innerhalb des letzten Jahrzehnts kleine Ernten und eine zügellose Spekulation wiederholt dis Gespenst einer $\mathrm{B}$ a $u \mathrm{~m}$ wo $11 \mathrm{not}$ und die wildesten 
Preisschwankungetl hervorriefen. Denkwürdig sind darunter besonders die Operationen der New lorker Spekulanten Daniel Sully in 1903/04 und Theodor H. Price in I9IO, und bei der letzten, schließlich auch zusammengebrochenen Schwänze, stieg Baumwolle an der Terminbörse vorübergehend auf 20 Cents, cinen l'reis, wie er seit dem Bürgerkrieg nicht dagewesen.

Diese Verhältnisse veranlaßten dịc curopäischen Mächte mit Kolonialbesitz, seit Anfang des 20. Jahrhunderts den Baumwollbau in eigenen Gebieten auszudehnen bzw. neu einzuführen, um so allmählich die drückende Abhängigkeit abzustreifen, in der man sich bislang Amerikas überwältigender Monopolstellung in Baumwolle gegeniiber befindet. Diese Bestrebungen können aber nur sehr allmähliche Fortschritte machen, und inzwischen ist „King Cotton“ die Hauptstuitze von Nordamerikas wirtschaftlicher Vormachtstellung.

\section{Die Landwirtschaft in den Vereinigten Staaten.}

Allgemeines. Nach der Verbreitung der Hauptkulturpflanzen teilt man Nordamerika in fünf verschiedene Produktionsgebiete ein, nämlich I. in das Hafergebiet der Nordstaaten, 2. das Weizengebict der Nordweststaaten, 3. den Maisgürtel der mittelatlantischen Staaten, 4. das Küstenland des Stillen Ozeans mit überwiegendem Weizenbau und 5. das Baumwollgebiet der Südstaaten, in dem Baumwolle und Mais die Hauptanbaupflanzen bilden, während alle anderen Kulturen, besonders unsere Getreidearten, dort völlig zurïcktreten; dagegen werden auf verhältnismäßig beschränkter Fläche auch noch Zuckerrohr und Reis gebaut.

Größe und Bevölkerungsdichte der fünf geographischen Sektionen weisen laut Zensus von I9Io folgende Zahlen auf:

\begin{tabular}{|c|c|c|c|c|c|}
\hline & \multicolumn{5}{|c|}{ Bevölkerung in Tausenden } \\
\hline & $\mathrm{qkm}$ & Weiße & Farbige & Total & auf I qkm \\
\hline Nord-Atlantische Staaten & 419837 & 25385 & 484 & 25869 & 61,6 \\
\hline Süd-Atlantische Staaten & 695710 & 8082 & $4 \operatorname{II} 2$ & 12194 & $\mathbf{I} 7,5$ \\
\hline Nördliche Zentralstaaten. & I 95 I $65 \mathrm{I}$ & 29345 & 544 & 29889 & I 5,3 \\
\hline Südliche Zentralstaaten & I $58042 \mathrm{I}$ & 12557 & 4637 & I 7 I94 & 10,9 \\
\hline Westliche Staaten . & 3044606 & 6775 & $5 I$ & 6826 & 2,2 \\
\hline & 7692225 & $82 \times 44$ & 9828 & 91972 & I I,96 \\
\hline
\end{tabular}

gegen I 20 Menschen auf den Quadratkilometer in Deutschland, gegen welches auch dic dichtest besiedelten Gegenden der Vereinigten 
Staaten mit 6I Menschen noch fast um die Hälfte zurückbleiben. Dabei ist die starke Bevölkerungszunahme Nordamerikas weit weniger auf die natürliche Vermehrung als auf die Einwanderung zurückzuführen, deren Güte mit der Abnahme germanischer Elemente zurückgeht. Auch heute noch ist die Union cin verhältnismäßig dünn besiedèltes Land.

Von den 7,69 Millionen Quadratkilometern $=1903$ Millionen Acres Flächenraum, etwa I 8 mal die Größe von Deutschland, nehnnen Wüsten, Gebirgs- und Steppenregionen, die nicht kultur- und besiedlungsfähig sind, ungefähr die Hälfte ein. Nach dem Zensus von 19 Io umfaßte das gesamte, heute schon fast gänzlich in Besitz genommene Farmland in 61/3 Millionen Farmen 879 Millionen Acres, darunter 478 Millionen Acres ,improved lands", d. h. landwirtschaftlich, zu Ackerbau und Viehzucht bereits genutzte Flächen, im Gesamtwerte des landwirtschaftlichen Eigentums von fI Milliarden Dollars. Die Durchschnittsgröße der Farm ist 138 Acres, wovon 75 Acres ,improved" sind, und zwar hat gerade der Baumwollgürtel die kleinste Durchschnittsgröße der Farmen, nämlich I 5 Acres total und 44 Acres improved lands.

Von den rund 478 Millionen Acres landwirtschaftlich genutzten Farmland entfallen

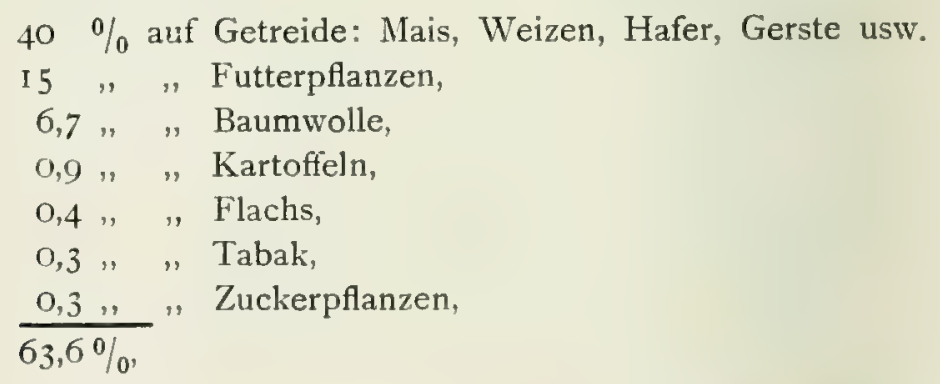

während der verbleibende Rest von $36,+$ \% zum größten Teil auf „Weideland" und die mit der Ausdehnung der Trockenfarmerei ständig zunehmende "Schwarzbrache“ entfällt.

Da der kultivierbare Boden fast völlig in Besitz genommen, so vollzieht sich in der heute noch als "Agrarstaat" zu bezeichnenden Union unter dem Einfluß der ungemein rasch anwachsenden Bcvölkerung der natürliche Umschwung, der mit zunchmender Wertsteigerung des Bodens und steigendem Inlandsbedarf zu einer Verkleinerung der Betriebe, intensiverer Wirtschaftsweise und Rückgang des Exports landwirtschaftlicher Produkte führt. 
Das Verhältnis von ländlicher zu städtischer Bevölkerung hat sich wie folgt entwickelt:

$1880 \quad 1900 \quad 1910$

$\begin{array}{llll}\text { Ländliche Bevölkerung - } 70,5 \% & 59,5 \% & 53,7 \% \\ \text { Städtische Bevölkerung } & 29,5 \% & 40,5 \% & 46,3 \%\end{array}$

wobci unter ,rural population“ sämtliche ländliche Gemeinwesen mit 2500 oder weniger Einwohnern begriffen sind, die durchaus nicht alle das landwirtschaftliche Gewerbe ausüben. Die industrielle und gewerbliche Bevölkerung der Union wächst also in erheblich stärkerem Maße als die landwirtschaftliche, und daher müssen die landwirtschaftlichen Erzeugnisse, ungeachtet der nur langsam folgenden Produktionssteigerung, in zunchmendem Maße zur Deckung des Inlandbedarfs dienen.

Trotz der glänzenden landwirtschaftlichen Entwicklung des letzten Jahrzehnts ist die nordamerikanische Landwirtschaft, im ganzen genommen, im Vergleich zur west- und mitteleuropäischen, auch heute noch als höchst extensiv zu bezeichnen, wenn die cinzelnen Staaten auch wesentlich verschieden sind. Im allgemeinen ist trotz günstigerer Bodenverhältnisse in Nordamerika der Ertrag an Ackerfrüchten dort nur ungefähr halb so hoch wie in Deutschland.

Der Farmerstand der Union setzt sich zum überwiegenden Teil aus geistig regsamen, lernbegierigen und geschäftstüchtigen Elementen zusammen. Gerade der Baumwollbau freilich ist noch vielfach in Händen von Negern und unwissenden weißen Pflanzern.

Grundbesitzverteilung und Pachtwesen. Unter Zugrundelegung des extensiven Charakters der nordamerikanischen Landwirtschaft und des verhältnismäßig noch niedrigen Bodenwertes unterscheidet man

a) Parzellenbesitz unter 20 Acres, der zur vollen Beschäftigung und Ernährung einer Familie nicht ausreicht;

b) Kleinbesitz von 20 bis Ioo Acres, der zur vollen Beschäftigung und Ernährung einer Familie ohne fremde Arbeitskräfte ausreicht;

c) mittlerer Besitz von 100 bis 1000 Acres gewährt einer Familic volle Beschäftigung und Ernährung unter Hinzuziehung fremder Arbeitskräfte;

d) Großbesitz von über Iooo Acres absorbiert die Arbeitskraft des Betriebsleiters vollkommen durch die Leitung und Aufsicht des Betriebs, event. unter Mithilfe von Verwaltern. 
Der Zensus von I9 Io gibt dafür folgende Zahlen:

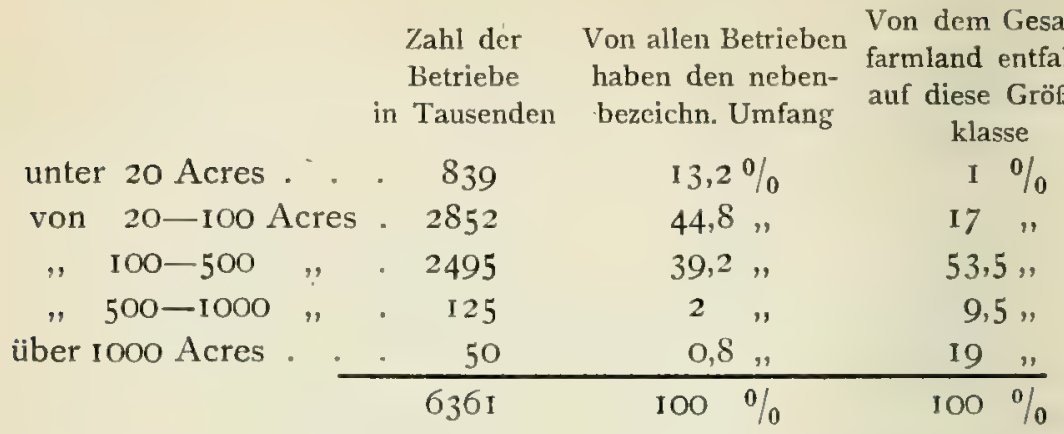

Das Schwergewicht der nordamerikanischen Landwirtschaft liegt im Klein- und Mittelbesitz, der $80 \%$ des Gesamtfarmlandes umfaßt und sich auf Kosten des Großgrundbesitzes auch weiter ausdehnt. Parzellenbesitz ist besonders stark vertreten in den Ostund Süd-Zentralstaaten, in denen nach dem Bürgerkrieg dic großen Plantagenbesitzer ihre zwangsweise befreiten Sklaven als kleine Pächter ansetzten. Klein- und Mittelbesitz herrscht in den Getreidegebieten vor. Großgrundbesitz überwiegt natürlicherweise in den trockenen Gebieten der westlichen Staaten, deren Weidewirtschaften bis zu $50 \%$ des gesamten Farmlands einnehmen.

Nach der Art der Betriebsleiter wurden im Jahre 19 Io verwaltet vom

Zahl der Farmen in Tausenden

Eigentümer

Pächter

Verwalter für den abwesenden

$$
\begin{array}{rlr}
58 & =\mathrm{I},, & 54=6, \\
\hline 636 \mathrm{I}=100 \% & 879=100 \%
\end{array}
$$

Acres in Millionen $599=68 \%$ $226=26$

Besitzer

Von der Gesamtzahl kamen $85,5 \%$ auf weiße und $14,5 \%$ auf farbige Besitzer, Pächter und Verwalter. Die $920000 \mathrm{f}$ a $\mathrm{r}$ big en Landwirte der Vereinigten Staaten im Jahre Igro verteilen sich auf $24 \mathrm{I}$ ooo Besitzer, 678 ooo Pächter und I500 Verwalter und finden sich fast ausschließlich im Süden der Union, wo sie $29 \%$ der sämtlichen Landwirte bilden; sie bewirtschaften im ganzen 46 Mill. Acres Farmland, wovon 29 Millionen ,improved".

Das Pachtwesen ist am stärksten vertreten in den Baumwollstaaten, nämlich mit $60 \%$ und mehr aller Farmen in Süd-Carolina, Georgia, Alabama und Mississippi, mit 50 bis $60 \%$ in Louisiana, 


\section{Arkansas, Texas und Oklahoma, mit 40 bis $50 \%$ in Nord-Carolina}

und Tennessee.

Die starke Ausdehnung des Pachtwesens fällt auf in einem jungen Lande mit ungeheurem Reichtum an billigem Boden, und dabei nimmt der Prozentsatz der Pachtbetriebe in regelmäßiger Ausdehnung zu, trotzdem in der Union durchgehends ziemlich harte Pachtbedingungen gelten. Die Pachtungen laufen allgemein auf kurze Termine, bieten keine Ermunterung zu Meliorationen und gewähren fast nie ein wirkliches Heim. Besonders vorherrschend ist der Pachtbetrieb unter dem Parzellen- und Kleinbetrieb mit 49 bzw. $40 \%$ der betreffenden Größenklassen im Jahre I900. Die stärkste und noch ständig wachsende Ausdehnung der Pachtwirtschaft weisen die südlichen Staatengruppen mit rund $50 \%$ aller Betriebe und rund einem Drittel des Farmlandes auf, weil nach Aufhebung der Sklaverei die Plantagenbesitzer durch Kapital- und Arbeitermangel zur Aufteilung ihres Groligrundbesitzes in einzelne Farmen gezwungen wurden.

Der Ankauf und die Verpachtung von Grundbesitz in Nordamerika ist nicht nur eine sichere, sondern bei den hohen Pachten und der raschen Steigerung des Bodenwertes auch sehr rentable Kapitalsanlage. Außerdem lohnt in vielen Distrikten der Kleinbetrieb im allgemeinen besser als der Großbetrieb.

Die Landpreise sind, hauptsächlich wegen der durch die allgemeine Preissteigerung für landwirtschaftliche Erzeugnisse bewirkten erhöhten Rentabilität der Landwirtschaft, im letzten Jahrzehnt sprunghaft von durchschnittlich 15,57 Dollars pro Acre in Igoo auf 32,40 Dollars in 19 Io gestiegen, in den Baumwollstaaten während des gleichen Zeitraums von durchschnittlich $51 / 2$ bis $83 / 4$ Dollars auf I6 bis i 8 Dollars.

Arbeiter. Die Lage des Arbeitsmarktes auf dem Gebiet der nordamerikanischen Landwirtschaft läßt sich mit dem Schlagwort charakterisieren: ,Mangel an landwirtschaftlichen Arbeitern herrscht in den ganzen Vereinigten Staaten." Dieser von Jahr zu Jahr wachsende Arbeitermangel auf dem Lande ist cinerseits verursacht durch das ungemeine Wachstum von Industrie und Handel, anderseits durch den Umstand, daß neuerdings die Masse der Einwanderer nicht mit der ausgesprochenen Absicht herüberkommt, sich der Landwirtschaft zu widmen, sondern als Industriearbeiter in den Städten zu leben. Der Umfang der Landflucht in den Vereinigten Staaten ist geradezu erschreckend, und dementsprechend sind die ländlichen Arbeitslöhne gestiegen. 
Bei Io stündiger Arbeitszeit erhielten ländliche $J$ ah resarbeiter an Monatslöhnen :

Ohne Verptlegung
I 880 I $890 \quad 1909$
D o 11 a rs

Nord-Atlantische Staaten Süd-Atlantische Staaten . Nord-Zentralstaaten . . Süd-Zentralstaaten . . Westliche Staaten
$22,5 \quad 24,7 \quad 30,8$

I $2,8 \quad 13,9 \quad 18,7$

$22,8 \quad 22,2 \quad 30,5$

$16,3 \quad 16,1 \quad 20,2$
Mit voller Verpflegung I880 I890 I 1909 Dollars

$\begin{array}{rrr}13,7 & 16,3 & 20,7 \\ 8,7 & 9,3 & 13,1 \\ 15,2 & 15,8 & 22,2 \\ 11,1 & \text { I I,3 } & 14,2 \\ 23,7 & 21,8 & 31,3\end{array}$

ferner $\mathrm{S}$ aisonarbeiter an $\mathrm{Tagel}$ ohn:

$\begin{array}{lllllll}\text { Nord-Atlantische Staaten } & \text { I,6 } & \text { I,7 } & \text { I,9 } & \text { I,2 } & \text { I,3 } & \text { 1,6 } \\ \text { Süd-Atlantische Staaten . } & \text { I, 1 } & \text { I,0 } & \text { I,2 } & \text { O,8 } & \text { 0,8 } & \text { 1,0 } \\ \text { Nord-Zentralstaaten . . } & \text { I,9 } & \text { I,6 } & 2,2 & \text { I,5 } & \text { I,2 } & \text { 1,8 } \\ \text { Süd-Zentralstaaten . . } & \text { I,2 } & \text { I,2 } & \text { I,3 } & 0,9 & 0,8 & 1,0 \\ \text { Westliche Staaten . . } & \text { I,9 } & \text { I,9 } & 2,5 & \text { I,5 } & \text { I,5 } & 2,0\end{array}$

Akkordlöhne werden selten vereinbart und hauptsächlich bei Negern und Chinesen gelegentlich der Ernteeinbringung.

Neben der Lohnsteigerung tritt neuerdings auch eine starke Bewegung der ländlichen Arbeiterbevölkerung nach einer Verkürzung der Arbeitszeit hervor, und so drängen alle Verhältnisse auf eine weitergehende Steigerung der Produktionskosten für landwirtschaftliche Erzeugnisse hin.

Kreditwesen. Das ländliche Kreditwesen in Nordamerika ist gänzlich unorganisiert, und die üblichen Zinssätze sind deshalb hohe. Im Durchschnitt sind zwei Drittel sämtlicher Farmen hypothekarisch nicht belastet, der Anteil der Schuld vom Werte von Land und Gebäuden beträgt nur $27 \%$, und überdies ist ein großcr Teil der Hypotheken nur für Meliorationszwecke, Bauten, Maschinen usw. aufgenommen, so daß diese Belastung nicht eine Verschlechterung der Besitzlage des Farmers darstellt, sondern eine durch Steigerung von Wert und Reinertrag des Besitzers begründete Belastung. Die finanzielle Grundlage ist also eine durchaus gesunde. Kreditorganisationen für langfristigen ländlichen Hypothekenkredit fehlen in den Vereinigten Staaten gänzlich. Der Durchschnittsfarmer erhält von sciner Bank nur Kredit, wenn er zwei bis vier sichere Bürgen stellt oder ein Pfand, sei es in Mobilien (chattel mortgage), sei es in Immobilien (mortgage), gibt. Die auf Hypotheken leihenden Banken zählen in Nordamerika nach Tausenden, aber sie entsprechen insofern wenig den besonderen landwirtschaftlichen Bedürfnissen, 
als die Hypotheken gewöhnlich nur zu hohen Zinssätzen für einige Jahre, von dem Gläubiger mit kurzer Frist kündbar und ohne Möglichkeit der Amortisation, gegeben werden.

Unter dem Präsidenten Taft hat man deshalb die Frage des ländlichen Kredits eingehend studiert und empfohlen, das deutsche System nach dem Muster der deutschen Landschaften, Raiffeisenbanken und Hypothekenbanken unter Regierungskontrolle einzuführen, das zunächst allerdings wohl nur für wenige dichtbesicdelte Bezirke der östlichen Staaten in Frage kommen könnte.

Der Durchschnittszinsfub für landwirtschaftliche Darlehen beträgt jetzt $81 / 2 \%$ p. a.

Das Genossenschaftswesen in den Vereinigten Staaten ist mangels eines besonderen Genossenschaftsgesetzes, das auf besonderer Rechtsgrundlage den Betrieb gesetzlich kontrolliert, nur in Form von ,freien Vercinigungen“, „landwirtschaftlichen kooperativen Urganisationen“, zu einem geringen Teil auch als ,Aktiengesellschaften" organisiert. Im ganzen zählte man im Jahre I908 rund 85000 landwirtschaftliche Genossenschaften der verschiedensten Betätigungszweige mit zusammen etwa $31 \%$ Millionen Mitgliedern und teilweise vorbildlich entwickelt und organisiert.

Staatliche Förderung der Landwirtschaft erfolgt in erster Linie durch das Department of Agriculture oder AckerbauAmt in Washington, früher dem Patent Office angehörig, seit 1862 cine selbständige Behörde, die sich allmählich zu einer großartigen Organisation entwickelt hat, mit etwa $\mathbf{4} 000$ Angestellten, darunter die Mehrzahl mit wissenschaftlicher Ausbildung, deren Aufgabe es ist, als Beamte der Zentrale, Leiter von Versuchsstationen, Lehrer und Wanderlehrer im Dienste der Landwirtschaft tätig zu sein und den Fortschritt durch Popularisation neuer Forschungsergebnisse mit unterstützen zu helfen. Der leitende Gesichtspunkt für die Gewährung der reichen Mittel, die seitens der Bundesregierung für landwirtschaftliche Zwecke zur Verfügung gestellt werden, ist die Auffassung, ,daß die Wohlfahrt des Volkes so sehr von der Verbesserung der landwirtschaftlichen Zustände abhängig ist, daß es weise erscheint, entgegen den sonstigen verfassungsmäßigen Bestimmungen, die Wohlfahrtsklausel der Verfassung zu benutzen, um die Bundesausgaben für die Verbesserung der landwirtschaftlichen Ausbildung $z u$ rechtfertigen und den Einzelstaaten und Privatunternehmungen die allgemeine und sonstige Berufsbildung zu überlassen".

Von den etwa 12 verschiedenen Unterabteilungen des Amtes interessieren uns hier die folgenden: 
I. Das statis t is che B u rea u sammelt und veröffentlicht Ernteberichte, worüber unter dem Kapitel „Statistik“ Näheres mitgeteilt werden wird.

2. Das $W$ et te $r-B$ u r e a mit etwa I50 ihm unterstehenden, über das ganze Gebiet der Union verstreuten meteorologischen Stationen veröffentlicht wöchentliche Berichte über Regenfall und Temperatur und während der Wachszeit der Baumwolle auch über den Stand der Kultur.

3. Das Bureau of Plant Industry und

4. das Burea of Biological Survey sind die wissenschaftlichen Zentralen für alle Studien und Erfahrungen betreffs Saatwahl, Verbesserung der Qualitäten und der Kultur im allgemeinen.

- 5. Das Burea uf Soils behandelt die Boden- und Düngerkunde.

6. Dem Office of Experiment $\mathrm{Stat}$ i ons unterstehen die staatlichen Versuchsanstalten.

7. Das Entomologische Burea u, von dessen Tätigkeit bei dem Kapitel „Baumwoll-Schädlinge“ zu berichten sein wird.

8. Das Offic of $\mathrm{Public} \mathrm{Roads}$, zur Beratung in Bau und Verbesserung von Landstraßen.

Die Veröffentlichungen der verschiedenen Bureaus sind sehr zahlreich und werden in großen Mengen, besonders unter den Farmern, verbreitet.

Uber die wertvollen. Berichte des Cen sus-Burea us in Washington wird bei dem Kapitel ,Statistik" gesprochen werden.

Eine hervorragende Stelle nehmen die State Agricultura 1 Experiment Stations ein, deren erste 1875 in Connecticut errichtet wurde und die einen großen Aufschwung nahmen, nachdem dic Bundesregierung 1886 beschloß, jedem Staat und Territorium jährlich I5 ooo Dollars zur Unterhaltung einer landwirtschaftlichen Versuchsanstalt zu gewähren, und im Jahre is88 zur Kontrolle und zur Sammlung, Sichtung und Bearbeitung der gewonnenen Einzelresultate als Zentrale das Office of Experiment Stations beim Ackerbau-Amt in Washington einrichtete. Heute existieren 6I solcher Versuchsstationen, von denen 55 Bundesunterstützung genießen; diese Stationen haben eigene entomologische Institute, stehen teilweise mit den landwirtschaftlichen Schulen und den Staatsuniversitäten in Verbindung und, um ihre Forschertätigkeit zu fördern, ist der jährliche Bundeszuschuß für jede derselben für diesen ausschließlichen Zweck seit I9I I auf 
30000 Dollars erhöht. Der Rest der Kosten wird von den Einzelstaaten aufgebracht, welche auch die Leiter der Anstalten ernennen. Häufig ist der Direktor der staatlichen Landwirtschafts-Schule gleichzeitig Direktor der Versuchsstation, und auf vielen derselben arbeitet unter dem Direktor eine Anzahl jüngerer wissenschaftlicher Sachverständiger in den verschiedenen Gebieten der Stationstätigkeit. In den Baumwollstaten gibt es als Zweigstellen der Ackerbaustationen besondere "B a u $\mathrm{mwo} 11-\mathrm{V}$ ersuchs farme $\mathbf{n}^{\text {", }}$, je nach der Verschiedenheit der Böden auch mehrere solcher in cinem Staate. Dieselben umfassen etwa je Ioo bis 300 Acres, werden je nachdem mit Schülem oder mit Tagelöhnern, stellenweise auch mit Sträflingsarbeit bestellt und unterstehen der Aufsicht eines von der Regierung ernannten Sachverständigen, der in seiner Person theoretische Kenntnis mit lokaler praktischer Erfahrung vereinigt und dadurch die bestmöglichen Resultate erzielen hilft. Tatsächlich erhalten sich diese staatlichen Versuchsfarmen vielfach aus ihren Erträgen selbst, andere bedürfen nur eines kleinen staatlichen Zuschusses. Die Versuchsstationen betreiben Sortenzucht, Düngungs- und Bodenbearbeitungsversuche und bekämpfen die Pflanzenkrankheiten und Schädlinge, sie verwenden bei ihrer Arbeit bewährte moderne Ackergeräte und landwirtschaftliche Maschinen, aber nur insoweit solche tatsächlich für den gewöhnlichen Farmbetrieb als brauchbar erwiesen sind. Die Laboratorien sind mit den neuesten Instrumenten und Apparaten für Chemic, Bakterienkunde usw. ausgestattet. Soweit Versuche in Gemeinschaft mit Farmern ausgeführt werden, was in nennenswertem Umfang geschieht, so liefert die Versuchsstation Arbeitsplan, Saat, Düngemittel usw. und übernimmt die Bodenanalyse und Prüfung der Resultate, während der Farmer Land und Arbeitskräfte zur Verfügung stellt. Gewisse Spezialfragen werden außerdem für Rechnung des Bundes und durch dessen Beamte aus Washington auf geeigneten Staatsfarmen bearbeitet, und sodann läßt das AckerbauAmt in Washington in jedem Staate durch dafür bezahlte Farmer besondere Landfächen nach seinen Anweisungen bestellen. Die Gesamtkosten der Versuchsanstalten beliefen sich I9I2 auf $3 \frac{3}{4}$ Millionen Dollars.

Sehr erfolgreich wirken auch die von der Bundesregierung entsandten Wanderlehrer, welche jahraus jahrein in den einzelnen Staaten herumreisen, die Farmer über die neuesten und besten Methoden unterrichten und ihrerseits dazu beitragen, daß die Fortschritte wissenschaftlicher Forschung möglichst populär ge- 
macht werden und bis in die Hütte des kleinsten Farmers dringen.

Auch das 1 andwirtschaftliche Unterrichtswese $n$ ist gut entwickelt. Das erste Agricultural College wurde I857 errichtet, und neben den Universitäten beträgt die Zahl der Colleges mit Ackerbau-Kursen heute 66, wovon 30 in den Baumwollstaaten. Daneben leisten zahlreiche Sekundärinstitute und Farmschulen gute Dienste, und selbst in den Volksschulen ländlicher Distrikte werden Ackerbau-Demonstrationen betrieben.

Die I862 durch Kongreßbeschluß von Landschenkungen vorbereiteten, von den Einzelstaaten mit Unterstützung der Bundesregierung seit $\mathrm{I} 867$ geschaffenen und unterhaltenen und seit I888 mit den Versuchsanstalten in Verbindung gebrachten Agricultural and Mechanical Colleges bieten als Fortbildungsschulen jungen Leuten im Alter von $\mathrm{I}_{4}$ bis 18 Jahren in meist vierjährigem Kursus Gelegenheit zur Ausbildung in Ackerbau und Handwerk. Der Unterricht ist für Staatsangehörige ganz. frei, und zwar stehen jeder Grafschaft und Stadt im Staate eine bestimmte Anzahl von Freistellen zu. Die Spesen für Lebensunterhalt schwanken zwischen I25 und 300 Dollars im Jahre, doch ist den Schülern überall Gelegenheit geboten, durch eigene Arbeit einen Teil dieser Kosten verdienen zu können. Das College im Clemson, SüdCarolina, z. B. zählt nicht weniger als 700 Schüler und besitzt u. a. auch eine besondere Textilabteilung. Die Kosten dieser Anstalten werden zum guten Teile aufgebracht durch die für chemische Untersuchung des Handelsdüngers erhobenen staatlichen Abgaben, welche in allen Baumwollstaaten und auch in einigen nördlichen Staaten eingeführt sind. Diese Lehranstalten sind nur für Weiße bestimmt, und man zählte im Jahre I9r2 im ganzen 53 ooo weiße Schüler. Daneben existieren in I6 Staaten aber auch ähnliche Institute für Farbige, von denen das 1868 gegründete Hampton Normal and Agricultural Institute in Virginia und das I88 I von dem berühmten Booker T. Washington errichtete Tuskegee Normal and Industrial Institute in Alabama mit seinen zahlreichen Tochteranstalten, sowie die Schule in Houston besonders genannt seien. Die Gesamtzahl der farbigen Schüler im Jahre 1912 betrug 8500 .

Die Zahl der an den Ackerbauschulen und Versuchsstationen tätigen Lehrer und Beamten betrug im Jahre I9 12: 7660.

Die Ausgaben, welche das Ackerbau-Amt in Washington und die staatlichen Organisationen jährlich im Interesse des Baumwollbaus leisten, indem sie ihre Dienste dem Farmer unentgeltich zur 
Verfügung stellen, belaufen sich ausschlieBlich der Unterrichtskosten auf rund I Million Dollars, wovon je ein Drittel auf die Versuchsstationen, auf die Statistik und auf Spezialfragen der Pflanze und ihrer Feinde entfällt.

Die ersten privaten Landwirtschaftsgesell$\mathrm{s} \mathrm{ch}$ a f ten wurden gegen Ende des 18 . Jahrhunderts gebildet, und die 1785 in Süd-Carolina gegründete Gesellschaft hatte als einen ihrer Zwecke bereits die Anlage einer landwirtschaftlichen Versuchsanstalt. Die Zahl der lokalen Farmer's Clubs und Farmer's Institutes, welche sich bestreben, theoretische und praktische Kenntnisse zu vertiefen, ist sehr groß.

\section{Der Baumwollgürtel.}

Geographische Grenzen. Dic Baumwolle ist cine Tieflandpflanze, die eine möglichst gleichmäßige 'Temperatur verlangt, wie solche vorzugsweise in Küstenländern zu finden ist. Das für einen lohnenden Baumwollbau in Nordamerika in Betracht kommende Gebiet liegt im allgemeinen südlich des 37 . Breitengrades und wird im Norden begrenzt durch eine Linie, die bei Norfolk in Virginia beginnt und im Zickzack nach der Grenzecke zwischen Texas, Colorado und Neu-Mexiko führt. Nur in wenigen, besonders begünstigten Lagen nördlich des 37. Grades wird noch etwas Baumwollbau betrieben; die Grafschaft mit der nördlichsten Stelle der Baumwollkultur in den Vereinigten Staaten liegt unter dem $40^{\circ}$ und nördlich des Missouri im gleichnamigen Staate. Wir haben in der geschichtlichen Einleitung gesehen, daß unter besonderen Unständen Baumwolle bis nach New Jersey hinauf gebaut wurde, aber sie ist in diesen nördlichen Lagen längst durch sicherere und lohnendere Ernten ersetzt. Im Süden und Osten erstreckt sich der Baumwollbau fast überall bis an das Meer, und im Südwesten bildet der Rio Grande del Norte die Grenze des Baumwollgürtels, der sich etwa I500 englische Meilen von Ost nach West erstreckt und 500 Meilen breit ist. In der "Gebirgsrcgion“ von Süd-Carolina wird Baumwolle bis zu einer Meereshöhe von $500 \mathrm{~m}$ gebaut.

Die zehn Hauptbaumwollstaaten, nach ihrer heutigen Erntemenge geordnet, sind Texas, Georgia, Alabama, Süd-Carolina, Mississippi, Oklahoma, Nord-Carolina, Arkansas, Louisiana und Tennessee, während die acht weiteren: Missouri, Florida, Virginia, Arizona, California, Kansas, Kentucky und Neu-Mexiko zusammen nur wenig über I \% der Gesamternte liefern. Im ganzen gibt es 
rund $\mathrm{I} 3 / 1$ Millionen Baumwollfarmen in etwa 900 Grafschaften, und das Zentrum des Baumwollertrags, das sich 1850 in Alabama befand, ist mit zunehmender Bedeutung des Westens allmählich durch den Staat Mississippi hindurch nach der Südostecke von Arkansas vorgerückt.

Die zehn Hauptbaumwollstaaten, dazu Florida und Virginia, laben 822 ooo Quadratmeilen $=562$ Millionen Acres Areai und wiesen I9 Io eine Bevölkerung von 24 Millionen, davon $43 / 4$ Millionen städtisch und 191/4 Millionen ländlich auf, d. h. etwa drei arbeitsfähige Männer für landwirtschaftliche Arbeiten auf die englische Quadratmeile.

Das Land, wo Boden und Klima Baumwollbau lohnend machen, wird mit 533 Millionen Acres angegeben; davon sind erst 328 Millionen $=6 \mathrm{I} \%$ in Farmen angelegt und davon wieder erst I38 Millionen Acres $=42 \%$ kultiviert. Etwa ein Viertel der kultivierten Fläche und etwa ein Zehntel der totalen Farmfläche ist mit Baumwolle bestellt. Millionen Acres vom jetzigen Farmland können noch zum Baumwollbau herangezogen werden und ohne die geringste Kulturverbesserung die jetzige Baumwollproduktion verdoppeln; andere Millionen, die noch nie unter den Pflug genommen wurden, sind außerdem verfügbar. Im unteren Mississippidelta existieren 30 ooo Quadratmeilen sumpfigen Alluviallands, die nach Entwässerung den fruchtbarsten Baumwollboden liefern werden, und Texas allein besitzt genug Land, um jährlich an Stelle der jetzigen 5 Millionen 30 Millionen Ballen liefern zu können. Eine Gesamternte von 60 bis 7o Millionen Ballen wäre, soweit das nötige Land in Betracht kommt, also durchaus möglich.

Baumwollböden. Baumwolle verlangt einen hinreichend tiefgründigen, trockenen, gut durchlüfteten Boden, bedarf freilich zeitweiliger Anfeuchtung, ist aber sehr empfindlich gegen stagnierendes Grundwasser und gegen Luftmangel des Bodens. Vor 1860 wurde Baumwolle auf fast allen Plantagen des Südens, hauptsächlich aber auf den tiefen fruchtbaren Lehmböden gebaut, die sich erfahrungsgemäB am besten dafür eigneten. Heutigentags baut man Baumwolle innerhalb der geeigneten Klimazone auf ungefähr a 11 en Arten von Böden und korrigiert deren Mängel durch künstliche Düngung. Wenn auch der Boden für Baumwolle fruchtbar sein soll, so braucht er doch weder an mineralischen noch organischen Nährstoffen reich zu sein. Einige der reichsten amerikanischen Böden liefern nur Mittelernten, während ärmere Böden der Nachbarschaft, unter gleichen ïbrigen Verhältnissen, hohe Erträge 
liefern. Humusreiche Böden eignen sich deshalb nicht zum Baumwollbau, weil sie die Stauden auf Kosten der Früchte stark ins Kraut schießen lassen. Am besten empfiehlt sich ein Boden, in dem Kieselsäure vorherrscht, der nicht arm an Kali- und Phosphorsäure ist und nur so viel organische Stoffe enthält, als zu einem mäßigen Wachstum des Holzes nötig ist.

Die Böden innerhalb des Baumwollgürtels sind nun von sehr verschiedener Zusammensetzung, und man unterscheidet zunächst zwei Hauptklassen, nämlich „Uplands“ mit sandigem und Klaieboden und ,low lands" oder "flat lands" mit den Prärien und den Flußtälern. Baumwolle wird gepflanzt: I, auf leichtem, sandigem Boden, der gewöhnlich nur einen sehr geringen Ertrag gibt, aber besonders für Sea Island geeignet ist. 2. Auf schwerem Ton(Klaie-)Boden, der große Pflanzen, aber verhältnismäßig wenig Lint erzeugt. 3. Auf Schwemmland, das sich ähnlich verhält; die Ernten sind hier in guten Saisons allerdings sehr grob, aber nicht so sicher, und in schlechten Saisons den Angriffen von Schädlingen und Krankheiten stark ausgesetzt. 4. Auf lehmigem Boden, welcher die sichersten Ernten liefert, besonders auf feinem sandigen Lehm mit Unterlage von Klaie-Boden, welcher während der Wachszeit eine gleichmäßige Feuchtigkeit hält.

Im einzelnen unterscheidet man außerhalb der Gebirgsregion, welche sich von Alabama und Georgia aus in den Appalachen von Südwesten nach Nordosten zieht und in Nord-Carolina mit $2040 \mathrm{~m}$ ihre höchste Erhebung erreicht, folgende Bodengebiete: Das „A 1 $1 \mathrm{uvia} l \mathrm{gebiet}$ " umfaBt 30 Millionen Acres und ist mehr oder weniger in allen Baumwollstaaten, am stärksten aber in Louisiana, Texas, Mississippi und Arkansas vertreten. Der „u n t e r e $\mathrm{K}$ i e f e rg ürt e l" mit 34 Millionen Acres zieht im östlichen Baumwollgürtel von Nord-Carolina bis Florida und weist in der Hauptsache sandige Lehme mit verschiedenartigem Untergrund auf. Westlich davon folgt in einem Gürtel von fast gleicher Breite und von Nord-Carolina bis Mississippi das 39 Millionen Acres umfassende ,H ügelige Ki ef erngebie t", das neben überwiegendem Lehm viele Sumpfstrecken aufweist. In einem schmalen geschweiften Streifen, der sich von Tennessee durch Alabama und Georgia nach den Carolinas zieht, folgt das 6 Millionen Acres große ,S a ndhügelgebi e t“. Daran stößt westlich, in den Carolinas und in Georgia, das 32 Millionen Acres umfassende „P i e dmont-Gse bi e t“, die Region der Granitfelsen. Das „Eich enund $\mathrm{Hickory}-\mathrm{Gebiet"mit} 43$ Millionen Acres und sandigen, 
lehmigen Böden findet sich hauptsächlich in der Westhälfte des Baumwollgürtels in den Staaten Alabama, Mississippi, Louisiana, Arkansas und Texas. Die Hauptfäche mit 65 Millionen Acres nimmt das „Prä ri e-G e b i e t" ein, das, in seiner Mehrheit westlich vom Mississippistrom gelegen, die schwarze Prärie von Alabama, Mississippi und Texas, die Küstenprärie von Texas, dic Grauschlammprärie von Arkansas und dic Rotlehmprärie von Texas umfaßt. Die „R o t 1 e h m 1 än d e r" mit I3 Millionen Acres finden sich besonders in Arkansas. Die „B $1 \mathrm{uffs}$ " endlich, mit II Millionen Acres, bilden ein schmales Hügelband östlich vom Mississippi von Kentucky bis Louisiana und weisen in ihrem wohl dränierten Alluvialland vorzügliche Bedingungen für Baumwollbau auf.

Im allgemeinen ist für die nordamerikanischen Baumwollböden ein beträchtlicher Kaligehalt und ein geringer Phosphorsäuregehalt charakteristisch. Vielfach sind sie bereits stark ausgewaschen und bedürfen einer besseren Pflege als bislang.

Klima. Mehr als alle anderen Feldfrüchte hängt Baumwolle von günstiger Witterung ab. Sie braucht zunächst zu ihrer Entwicklung verhältnismäßig hohe Temperatur und Feuchtigkeit, während der Reifezeit aber Trockenheit, Bedingungen, wie sie mit geringen jährlichen Temperaturschwankungen die Südstaaten der Union im allgemeinen bieten. Hohe Luft- und Bodenwärme und reicher Sonnenschein sind wesentlichste Erfordernisse für das Gedeihen der Baumwolle, heiterer Himmel bei Tage, starker Tau bei Nacht sind während der Entwicklung der Pflanze besonders günstig. Man hat sie mit Recht ,ein Kind der Sonne“ genannt, und in der Tat verlangt sie mindestens sechs Monate warmen Sonnenscheins.

Wichtig für die Entwicklung der Pflanze ist in erster Linie, daß der letzte Frost im Frühjahr nicht zu spät und der erste Frost im Herbst nicht zu bald eintritt, denn die Wachs- und Reifezeit der Baumwolle ist eine ziemlich lange, sechs bis sieben Monate umfassend, und die Pflanze kann in keinem Stadium ihrer Entwicklung Fröste vertragen. Mehrjährige Baumwolle ist deshalb in den Vereinigten Staaten ausgeschlossen, sie ist hier vielmehr eine einjährige Pflanze, wenn auch nach warmen Wintern der alte Wurzelstock zuweilen neue Triebe schießen läßt. Das Pflücken der Baumwolle zieht sich oft bis weit in den Winter hinein, der erste starke Frost aber hebt das weitere Wachstum der Pflanze auf, und die noch anstehenden Knospen oder jungen Kapseln entwickeln sich n̨icht mehr zur reifen Frucht. 
Die mittlere Jahrestemperatur des Baumwollgürtels schwankt, von Norden nach Siiden hin, zwischen 13 und $22^{\circ}$, im Januar zwischen $-0,5^{\circ}$ and $+13,8^{\circ}$, im Julimittel zwischen 23,9 und $29,2^{\circ} \mathrm{C}$. In der Hauptanbauregion: Süd-Carolina, Georgia, Alabama, Mississippi, Louisiana und Texas beträgt die mittlere Jahrestemperatur $18^{\circ}$, mit einer mittleren Januartemperatur von $9^{\circ}$ und einer mittleren Juliwärme von $27^{\circ} \mathrm{C}$. Der Sommer erreicht seine größte Wärme im Juli mit 27 bis $28^{\circ}$ in Mittel, bei einem Minimum von etwa $I 8^{\circ} \mathrm{im}$ nördlichen Teile und einem Maximum von etwa $37^{\circ} \mathrm{im}$ südlichsten Texas. Die tägliche Durchschnittstemperatur im Baumwollgürtel nimmt von der Aussaat bis Anfang August zu, und bis dahin sollte sich die Pfanze voll entwickelt und alle ihr nötigen Nährmittel aufgespeichert haben. Die ersten tödlichen Herbst $\mathrm{f} r$ ös te im Baumwollgürtel treten mit der ersten Oktoberwoche ein, dic letzten Fröste reichen bis Anfang Mai hinein. Der Winter sonst ist hier selten streng und sinkt nur ausnahmsweise bis auf $-18^{\circ} \mathrm{C}$. Die größte wirklich beobachtete Kälte betrug - $30^{\circ}$, die grölte Wärme $+42^{\circ} \mathrm{C}$. Wie Frost, so kommt auch Schneefa $11 \mathrm{im}$ ganzen Baumwollgürtel vor; nur der südlichste Teil Floridas ist frostfrei. Aber im allgemeinen kann man sagen, daß das Klima des Baumwollgürtels „Freiluftleben“ während des ganzen Jahres erlaubt.

Baumwolle wird noch erfolgreich angepflanzt bei nur 20 inch jährlichem $R$ egenfall. Die meisten Baumwollstaten aber weisen etwa 50 inch auf, so z. B. Alabama, Arkansas und Georgia, Mississippi zeigt 52 inch, Florida 57 inch, dagegen Oklahoma nur $3 \mathrm{I}$ bis 37 inch und Texas $2 \mathrm{I}$ bis 27 inch. Als Regel nimmt in den Südstaten der Regen vom Frühjahr bis zur Sommermitte, also bis zur vollen Entwicklung der Baumwollpflanze, leicht $z u$, und schwankt von Mai bis September etwa zwischen $3 \frac{3}{4}$ und $53 \%$ inch im Monat, während die Zahl der bewölkten Tage im Monat während Juni bis September im Durchschnitt Io bis I5 aufweist. Lange anhaltende Regen, namentlich bei kühler Temperatur, sind in jeder Periode der Entwicklung schädlich; vor der Blüte wirkt auch eine lang anhaltende Dürre nachteilig. Im ersten Falle wird auf Kosten der Frucht Holz gebildet, im zweiten kommt die Entwicklung der Stauden zum Stocken, die Reife tritt vorzeitig ein, und die leichte Ernte ist kurzstapeliger als gewöhnlich. Gegen die Dürren kann man sich unter Umständen durch künstliche Bewässerung schützen, nicht so gegen anhaltende Regen, welche deshalb in höherem Maße zu fürchten 
sind. Nach Westen zu nehmen die regelmäßigen Regen ab, und im südlichen und westlichen Texas ist infolge der wenig ergiebigen Frühlingsregen Baumwollbau meist nicht gut möglich ohne künstliche Bewässerung, welche mit Hilfe von Flußkanälen, Staubecken und artesischen Brunnen von Ioo bis Iooo Fuß Tiefe erfolgt. Sehr wertvoll erweist sich besonders in trockenen Gebieten, wie Texas, der nächtliche reichliche $T$ a u, welcher Blätter und Wurzeln erquickt.

Die Wetterbedingungen eines Jahres sind selbst innerhalb desselben Staates, melir noch zwischen den verschiedenen Staaten des Baumwollgürtels, oft wesentlich verschieden, und deshalb sind schlechte Ernteaussichten in cinem Distrikt keineswegs für die Gesamternte ausschlaggebend. Anderseits wird es auch kaum ein Jahr geben, welches im $\mathrm{g}$ a $\mathrm{n} z$ e n Baumwollgürtel ideales Wetter aufwiese.

Im ganzen aber bieten Boden und Klima des Baumwollgürtels der Vereinigten Staaten auf einer Riesenfläche die denkbar günstigsten Vorbedingungen für Baumwollbau. Dem in der Regel nicht allzu feuchten Frühling folgt ein noch weniger feuchter, heißer Sommer mit gelegentlichen Regenschauern und ein warmer, regenarmer Herbst, und damit sind nahezu ideale Verhältnisse gegeben.

Künstliche Be- und Entwässerung. Seit einer Reihe von Jahren werden seitens der Bundesregierung und privater Erwerbsgesellschaften große Anstrengungen gemacht, durch Bewässerungsarbeiten größten Stiles umfangreiche Ländereien in den regenarmen Distrikten für landwirtschaftliche Zwecke nutzbar zu machen; diese Ländereien liegen überwiegend in der regenarmen Zone der Weststaaten mit weniger als 12 inch Niederschlägen, und nur ein geringer Teil befindet sich in dem semi-ariden Gebiet mit 12 bis 20 inch. Dic Aufteilung des Neulandes, das zum größten Teil der Regierung gehört, erfolgt in Familienlosen von ıo bis гбо Acres derart, daß die Selbstkosten innerhalb von zehn Jahren zurückzuzahlen sind. Das Problem, genügende Ansiedler auf das Land zu bringen, ist aber nicht leicht zu lösen. Die Wasserverteilung wird von Verbrauchsgesellschaften besorgt, denen die öffentliche Nützlichkeit zuerkannt wurde. Der Schwerpunkt dieser amerikanischen Bewässerungswirtschaft liegt im Futterbau (I909: $73 \%$ des Bewässerungslandes), der dem UUbergang von der wilden Steppen-Viehzucht zu intensiverer Viehhaltung mit Winterfütterung Rechnung trägt. Aber auch der Baumwollbau in Texas profitiert von künstlicher Bewässerung, und die Versuche mit ägyptischer Baumwolle sind ausschließlich auf künstliche Bewässerung eingestellt. In Neu-Mexiko, Arizona und Kalifornien sind freilich die Arbeitslöhne reichlich 
teuer für Baumwollbau, und dic Konkurrenz des besonders in Gunst stehenden Luzerne- und Obstbaus wirft riesige Erträge bei sehr geringer Arbeit ab.

Ist auf der einen Seite künstliche Bewässerung nötig, so ist an anderen Stellen wieder eine gute D rän a ge sehr wichtig, da stchendes Wasser den Boden kiihlt und versauert, während gut dräniertes Land die nötige Feuchtigkeit besser zurückhält und man durch eine gute Entwässerung die Erträge unter Umständen verdoppeln kann. Man wendet sie deshalb neuerdings auch im Baumwollbau mehr und mehr an und verhindert damit auch die sonst so häufigen Auswaschungen des Bodens. Die Kosten für Dränierröhren, welche den Wasserhaushalt regeln, sind sehr verschieden, aber meist wohl angewandt.

Wirtschaftsformen. Baumwolle wurde lange Zeit fast ausschließlich mit Sklavenarbeit gezogen; für die ab Anfang des 19. Jahrhunderts so rapide zunehmende Baumwollkultur war der Neger unerläßlich, und noch hente erblickt dic Mehrzahl der Farbigen in den Vereinigten Staaten ihren Hauptunterhalt im Baumwollbau. Von den 9,8 Millionen Farbigen der Union (Census Ig Io) leben $83 / 4$ Millionen oder $89 \%$ in den Südstaaten, wo sie noch heute in Süd-Carolina und in Mississippi die Zahl der dortigen Weißen übertreffen, trotzdem im letzten Jahrzehnt die weiße Bevölkerung in den Südstaaten um $24 \%$, die farbige aber nur um Io \% zugenommen hat. Im Durchschnitt der Südstaaten bildeten die Neger I910 noch immer $30 \%$ der Gesamtbevölkerung gegen $36 \%$ im Jahre I 880 .

Während der Sklavenzeit waren die Plantagen in der Regel unter direkter Verwaltung des Besitzers, und zwar umfaßten diese einzelnen Pflanzungen bis zu 20000 Acres mit Iooo Sklaven. Eine Farm von 3000 Acres mit roo Sklaven und 25 Maultieren repräsentierte einen Wert von Ioo ooo Dollars, lieferte, neben allen für den Unterhalt von Mensch und Vieh nötigen Farmerzeugnissen, als Verkaufsprodukt etwa ioo Ballen Baumwolle in der Saison und warf einen Jahresverdienst von Io 000 bis 20 ooo Dollars ab. Die Durchschnittsgröße der Farm in den Baumwollstaaten betrug in Jahre 1860 aber nur 37 I Acres, und zwar kamen

auf die Größen von $1-100 \quad 100-500 \quad 500-1000$ Acres und mehr in den verschiedenen

Staaten . . 50-80 $12-50 \quad \mathrm{I}-9 \%$

und die Zahl der Sklaven verteilte sich im gleichen Jahre auf

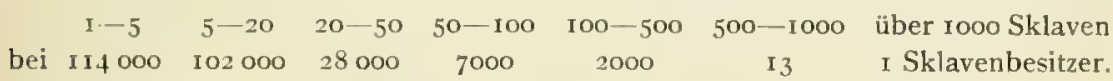


$\mathrm{N}$ a ch der Sklavenbefreiung wurde der Anbau von Lebensmitteln und Futterpflanzen zunächst meist ganz eingestellt; für den durch den Krieg tief verschuldeten Pflanzer bildete Baumwolle die cinzige Basis des ihm nötigen Kredits, und auf Anbau von Baumwolle konzentrierten sich deshalb alle verfügbaren Kräfte. Um die Schwarzen als Arbeiter zu gewinnen, führte man nunmehr das $\mathrm{Pach} \mathrm{tsys} \mathrm{tem}$ ein, wobei diese Leute freilich nur so viel arbeiteten, als für ihren bescheidenen Lebensunterhalt unumgänglich notwendig war. Die Schwierigkeit, genügende Arbeiter zu beschaffen, war besonders während der Pflückzeit stellenweise sehr groß, und unter diesen Verhältnissen vollzog sich mehr und mehr Verkauf und Aufteilung der großen ,Ilantagen" in einzelne kleine „Farmen“, wobei man soliden Käufern gem lange Abzahlungsfristen gewährte. Diese Tendenz ist bis heute dic herrschende geblieben. Nur in den ungesunderen Lagen, wo die Arbeit fast ausschließlich von der niedrigsten Negerklasse geliefert wird, mag sich das Plantagensystem noch eine Zeitland halten; ganz vereinzelt gibt es auch heute noch Pflanzungen mit 23000 Acres und 5000 Arbeitern, meist aber umfassen sie nur 400 bis 1000 Acres, 5000 Acres gelten als ein gut abgerundeter Besitz, während ein großer Teil des Baumwollanbaus heute auf kleinen Negerfarmen von etwa 20 Acres von einer Familie mit einem Maultier erfolgt.

Der Census von I9Io weist I 7I4000 Baumwollfarmen $=27 \%$ aller Farmen der Union überhaupt auf, und da in diesem Jahre die Gesamtanbaufläche von Baumwolle 32,4 Millionen Acres betrug, so kamen auf die einzelne Farm knapp 20 Acres Baumwolland, d. h. ungefähr gerade die Fläche, welche eine Familie bestellen kann. Ein erwachsener Neger bearbeitet 6 Acres, eine Familie 15 bis 50, im Durchschnitt 20 bis 25 Acres. Ein Maultier pflügt bis 30 Acres.

Sehr vernünftigerweise herrscht heute aber meist nicht mehr das ,all cotton"-System, wie zunächst nach dem Bürgerkriege, sondern der Pflanzer baut vorab seine Bedürfnisse an Lebens- und Futtermitteln, zieht Gemüse und Obst, treibt Viehzucht und behandelt Baumwolle als "surplus crop". Die Entwicklung des Verkehrs, das Aufblühen von Städten und Industrien im Süden sichert dem Farmer jetzt auch lohnenden Absatz der verschiedensten anderen Produkte, während früher Baumwolle die einzige Geldernte repräsentierte, und aus dieser Entwicklung heraus erklärt es sich mit, daß die Anbaufläche von Baumwolle, trotz der guten Preise dafür, sich nicht in größerem Maße entwickelt hat. 
Die $L$ andpreisc in den Baumwollstaaten sind natïlich schr verschieden, schwanken zwischen I und I50 Dollars für den Acre und haben letzthin vielerorts eine stark steigende Tendenz gezeigt, ebenso wie Arbeitslöhne, Lebensmittel und künstliche Dünger. In Georgia z. B. bezahlt man für ungesundes Küstenland 5 bis Io Dollars, für Kulturland im Innern 50 Dollars und mehr; in Louisiana für ungerodetes Hügelland 5 Dollars, für gerodetes Io bis I5 Dollars, für Kulturland in den Alluvialgebieten 50 Dollars. Im Gebiet der Southern Railway wird im Jahre IgI4 ungerodetes Land, ohne Gebäude, mit 5 bis 25 Dollars, kulturfertiges Land, mit Gebäuden, zu 20 bis 75 Dollars der Acre angeboten. Ist die Möglichkeit billigen Transports gegeben, so macht allein der Wert des Holzes die Urbarmachung eines Waldgebietes reichlich bezahlt; freilich liegt solches Land meist wcit weg von der Eisenbahn, und es dauert volle drei Jahre, ehe das Land von Baumstïmpfen und Wurzeln befreit ist. Die Kosten der Urbarmachung betragen etwa I5 Dollars auf den Acre.

„Dörfer" sind im Baumwollbezirk unbekannt, und auch der weiße amerikanische Farmer, mit Ausnahme des Teutonen, haftet nicht an der Scholle, sondern wechselt leicht scine Umgebung, wenn ihm das vorteilhaft zu sein scheint.

Die Wirtschafts formen des Baumwollbaus teilen sich in vier verschiedene, durch Zwischenstufen verbundene Hauptklassen: Entweder der Besitzer bestellt seine Farm se $1 \mathrm{~b} \mathrm{~s} \mathrm{t}$, allein oder mit Hilfe von Tagelöhnern; oder der Besitzer läßt die Farm durch einen V e r w a $1 \mathrm{t}$ e r besorgen; oder er verpachtet seine Farm ganz oder in Teilen gegen $\mathrm{Gel} \mathrm{d} p \mathrm{ach} \mathrm{t}$ an Bebauer, die das Land auf eigene Rechnung und Gefahr nach ihrem Gutdünken bestellen; oder er verpachtet es, weit häufiger noch, gegen einen fest bestimmten oder prozentualen Anteil am Ertrag der Ernte.

Eine fünfte Art, das sogenannte „By lay-System“, besteht darin, daß der Eigentümer mit einem Arbeiter oder einer Familie akkordicrt, seine Baumwollfelder für eine bestimmte Summe pro Acre zu bestellen und bis zur Reifezeit in Pflege zu nehmen, in der Voraussetzung, daß der Besitzer imstande sein wird, genügende Pfüickkräfte zu dem Minimalsatz von 50 Cents für 100 Pfund s. Z. selbst stellen zu können. Da diese Erwartung aber nur zu oft getäuscht wurde, stirbt dieses ganze System aus.

Die Arbeiter bzw. Pächter, die dabei in Frage kommen, sind in erster Linie die $\mathrm{F}$ a $\mathrm{rbigen}$, welche zahlreich und billig sind, freilich in der Arbeit meist nicht ausdauern und oft 
nomadenhaft leicht weiterziehen. Der Neger bringt es in Zimmerhöfen leicht auf täglich I bis 2 Dollars, verdient in zwei bis drei Tagen das, was er für die Woche braucht, und bummelt dann nicht selten für den Rest der Woche. Ein İtaliener produziert im Vergleich zum Neger das Doppelte. Bei allen Klagen, die man mit mehr oder weniger Recht gegen den Farbigen vorbringen kann, bleibt aber die Tatsache bestehen, daß er sein Bestes in der Farmtätigkeit leistet und daß er noch heute der Hauptträger der Baumwollkultur ist. In den östlichen Baumwollstaaten wird die Feldarbeit fast a us chließ 1 i ch von Farbigen geleistet; auch in den M it te 1 staaten überwiegt noch der Neger; im Staate Mississippi z. B. kommen sieben bis neun farbige auf einen weißen Baumwollbauer, während im We s t c n, besonders in Texas, die w e i $B$ e $n$ Arbeiter vorherrschen; es sind dies meist eingewanderte Italiener, daneben auch Deutsche und Skandinavier, und im Süden von Texas stellenweise Mexikaner, meist Mischlinge von Spaniern und Indianern, die sich streng von den Negern absondern und in ihren Leistungen verschieden beurteilt werden.

Von der Gesamtzahl der Farmen werden von F a r bigen bewirtschaftet in den

$\begin{array}{llll}\text { Süd-Atlantischen Staaten . . . } & 32 \% \\ \text { Südost-Zentralstaaten . . . . . . } 3 \text { I " } \\ \text { Südwest-Zentralstaaten . . . } 22,\end{array}$

und zwar sind die Farbigen dabei vertreten in den

$\begin{array}{lcccc} & & \text { als Eigentümer } & \text { Pächter } & \text { Verwalter } \\ \text { Süd-Atlantischen Staaten mit } & \text {. I } & 50 & 8 \% \\ \text { Südost-Zentralstaaten } & \text { " * } & \text { I I } & 50 & 8 \% " \\ \text { Südwest-Zentralstaaten } & \text { " * } & \text { I } 3 & 30 & 5, "\end{array}$

Außerdem werden natürlich auch noch bei den weißen Farmern viele Neger als Hilfsarbeiter verwandt.

Der Prozentsatz der von Farbigen bestellten Farmen beträgt $60 \%$ und mehr in Mississippi, 50 bis $60 \%$ in Süd-Carolina, 40 bis $50 \%$ in Georgia, Alabama und Louisiana, 20 bis $30 \%$ in Arkansas, Nord-Carolina und Florida, Io bis $20 \%$ in Texas und Oklahoma.

Der Wert der von Farbigen bewirtschafteten Farmen in den Südstaaten beträgt

\begin{tabular}{|c|c|c|c|c|}
\hline bei & rbigen & Besitzern & 275 & en \\
\hline , & , & Teilbesitzern & 72 & , \\
\hline , & $"$ & Verwaltern . & 12 & ", \\
\hline " &, & Pächtern & 758 & " \\
\hline
\end{tabular}


An und für sich eignen sich auch $W$ e i he recht wohl zum Baumwollbau in Nordamerika, doch kann die noch aus der Sklavenzeit stammende Abneigung der eingeborenen Wcißen, im Felde zu arbeiten, nur allmählich überwunden werden; selbst dic,,armen Weißen" aus dem Bergland im nördlichen T'eile der Süđstaaten ziehen Fabrikarbeit dem Feldbau vor, und die naheliegende Idee, die f rem de E in wander ung mehr als bislang auch nach dem Süden der Union zu lenken, ist zwar in einigen Staaten aufgenommen worden, wird aber teilweise paralysiert durch die dort in weiten Kreisen, besonders unter den Kleingrundbesitzern herrschende Abneigung gegen jede Einwanderung von Fremden, die man in der Presse als „Abschaum der Menschheit" und als ,gottlos" schildert und als „Lohndrücker" fürchtet. Im Staate Georgia z. B. sind angeblich $90 \%$ der Bevölkerung gegen fremde Einwanderung und machen ihren Einfluß in der Gesetzgebung entsprechend geltend. Unter diesen Umständen ist es nicht zu verwundern, daß die weißen Einwanderer in Süden, meist Italiener, vielfach falsch, teilweisc schlechter als Neger behandelt werden, obgleich sic, gut behandelt, Resultate liefern, die beiderseits voll befriedigen. Eine italienische Familie, die in Pacht 20 bis 30 Acres Baumwolle bestellt, kann mit Leichtigkeit 200 bis 300 Dollars im Jahre dabei ersparen, und wenn trotz dieser für Italiener gewiß lockenden Lebensbedingungen ihr Zuzug nach den Baumwollstaaten kein größerer ist, so liegt der Grund dafür in der falschen Behandlung, die ihnen vielerorts zuteil wird.

Besser liegen die Verhältnisse in den Grenzstaaten und in den Neuland Texas, wo es eine Reihe erfolgreicher deutscher und skandinavischer Farmer gibt, die auch in der Baumwollkultur zu den tüchtigsten Pflanzern gehören. Deutsche und schwedische Kolonisten haben hier vielfach Land derart auf Abzahlung gekauft, daß sie jedes Jahr ein Vierzigstel des Wertes zusammen mit den Zinsen der Restschuld bezahlen, so daB das Land nach 40 Jahren in ihren vollen Besitz kommt.

Die Southern Railway, die ein begreifliches Interesse an einer möglichst dichten Besiedelung des von ihr bediențen südöstlichen Teiles der Union hat, schlägt zur Ermutigung der Einwanderung Parzellierung von Großfarmen in „Heimstätten“ von je 40 Acres vor, zahlbar in zehn Jahren, und mit dem Ziele, aus diesem Kolonistenstamm nicht nur Landbebauer, sondern auch Industriearbeiter zu gewinnen.

Inzwischen herrscht im Süden vielfach direkter Arbeitermangel, und es werden deshalb auch weiße und farbige Strä f- 
$1 \mathrm{ingc}$ hin und wieder in Baumwollpflanzungen verwandt; in Georgia z. B. wird deren Arbeit, It bis 20 Stunden am Tage, meistbietend auf fünf Jahre verkauft. In Texas werden farbige Sträflinge, deren Arbeit gelobt wird, zu 20 Dollars für den Mann und Monat verdingt, wobei die Farmer das Gefängnis und dic Wohnungen für die Aufseher - je einen für zehn Sträflinge - aber keine Kost zu liefern haben.

Tagelöhner werden in den Baumwollfeldern nach Tag, Woche oder Monat bezahlt, manchmal ganz in Bargeld, meist aber teils in Waren, teils in Geld; der von den meisten Pflanzungsbesitzern unterhaltene Verkaufsladen (store) bildet eine nicht zu unterschätzende Einnahmequelle, da die hier gelieferten Waren nicht selten einen Nutzen bis zu Ioo\% abwerfen. Der Tagelohn in bar schwankt zwischen 50 und I00, ja bis 125 Cents, der Monatslohn zwischen Io und I5 Dollars plus Rationen im Werte von ungefähr 3 Dollars, nämlich wöchentlich 3 Pfund Fleisch und I Peck $=9$ Liter Mehl. Der Eigentümer bietet dem Arbeiter außerdem gewöhnlich bescheidene Wohnung mit einem Stück Gemüseland, Dorfschule und Kirche.

Die Schwarzen empfangen für die von ihnen abgelieferte Baumwolle Scheckbücher mit cinzelnen kleinen, auf 5 bis Ioo Cents lautenden Abschnitten in Gesamtnominalwert von 20 Dollars, die ihnen mit 22 Dollars belastet werdeñ, und dic nur für im Store des Landherrn gekaufte Waren gültig sind; manche Artikel werden aber auch dort nur gegen Bargeld verkauft. Die Italiener ziehen aus Aluminium geprägte Zahlmarken vor, die gleichfalls nur im Store des Landbesitzers gegen Waren eingetauscht werden.

Die Pachtverträge binden den Pächter stets für ein Jahr an die Pflanzung und geben dem Besitzer ein erststelliges Vorzugsrecht auf alle Wertobjekte des Pächters.

Erfolgt die Verpachtung gegen eine bestimmte, ganz oder teilweise im voraus zu bezahlende B a r s u m m e für den Acre, so hat der Pächter absolute Freiheit im Anbau; nur ist auch dabei die Bestimmung getroffen, daß der Pächter die gezogene Baumwolle in der Entkernungsanstalt des Landbesitzers zu entkernen und seinen Bedarf an Lebensmitteln usw. im Store des Genannten zu entnehmen hat. Der jährliche P a c h t p r e is für den Acre kultivierten Landes geht in den Oststaaten bis unter 2 Dollars herab und steigt in den Mississippistaaten und bei den Schwarzböden von Texas auf 5 bis Io Dollars. Der Landbesitzer liefert dabei dem Pächter nur das Wohnhaus. 
Die Verpachtung gegen einen Ernteanteil statt Bargeld crfolgt teilweise in der Form, dab dic Ablieferung einer be st im m t e $n$ Menge - 20 bis 100 P'fund - Baumwolle vom Acre seitens des Pächters an den Landeigner verlangt wird; letzterer liefert dabei, außer der stets vorhandenen Wohnung, nichts, weder Saat, noch Geräte, noch Tiere, gibt für Ankauf derselben aber eincn mit $10 \%$ p. a. zu verzinsenden Vorschul. und verlangt, daß alles, was er in seinem Storc führt, dort gekauft werden muß. Diese l'achtform wird hin und wieder von Italienern eingegangen.

Die häufigste Pachtform ist aber dicjenige, bei welcher sich Landbesitzer und Bebauer den Ernteertrag in natura teilen, meist zu halb und halb (Halbscheidesystem), wobei der Besitzer Haus mit Gemüseland, Saatgut, Dünger, Wagen und alle Ackergeräte, Maulesel und Futter, der Bebauer die Arbeitskräfte stellt. Dieses System wird bei gutem Boden von dem Besitzer bevorzugt. Bekommt der Besitzer nur $1 / 4$ bis $1 / 3$ vom Enteertrag, der Bebauer $7 / 3$ bis $3 / 4$, so muß letzterer auch Dünger, Tiere und Gerätschaften stellen.

In beiden Fällen erhält der Vertrag bindende Bestimmungen hinsichtlich des Anbaus, so daß, wenn der Pächter mit der Aussaat usf. im Verzug ist, der Eigentümer mehr Arbeitskräfte auf Kosten des Pächters stellen kann. Der Eigentümer darf auch die Zeit für Pflügen, Aussaat usw. bestimmen. Soweit Barvorschüsse nötig werden, erfolgen sie am Ende jedes Monats, und die endgültige Abrechnung erfolgt am Schluß der Saison.

Seinen Ernteanteil kann jeder der Beteiligten zu der ihm konvenierenden Zeit realisieren; oft ist der Bebauer bei dem vom Besitzer gehaltenen Kaufladen gegen vorgeschossene Waren aber so tief in der Kreide, daß der Ernteertrag knapp ausreicht, die aufgelaufenen Schulden zu tilgen, und so behält der Landherr den Arbeiter, besonders wenn es sich um Farbige handelt, dauernd an der Hand und erzielt Extragewinne durch hohen Nutzen auf Waren und die auf Vorschüsse von Bargeld oder Waren berechneten Zinsen von 8 bis $25 \%$ p. a. Eventuelle Guthaben des Pächters genießen keine Zinsvergütung.

Noch heute ist man vielfach der Meinung, daß die einzige Art, den Neger zu regelmäßiger Arbeit zu zwingen, darin liege, ihn in Schulden zu halten. Im übrigen ist eine $r i c h t i g e ~ B e h a n d-$ $1 \mathrm{ung}$ auch bei dem Neger entscheidend dafür, ob man ein genügendes Angebot von Arbeitern hat oder nicht.

Sobald die Baumwolle entkernt ist, wird auch die Baumwollsaat an den Landherrn verkauft, meist un te $r$ Marktpreis. 
Als Beispiel eines Betriebes folgen hier einige Angaben über dic erfolgreich betriebene Baumwollpflanzung Heathman in der Sunflower Grafschaft bei Greenville im State Mississippi, welche 1908 den europäischen Spinnern angeboten wurde. Die Plantage umfaßt 7500 Acres, wovon 3500 Acres Baumwolland mit einem Ertrage des Acres von $3 / 4$ Ballen Baumwolle von I bis $I^{1 / 4}$ Zoll Stapellänge; ferner I 250 Acres Kulturland mit Mais, Zuckerrohr, Kartoffeln, Futterpflanzen und anderen für die Pächter nötigen Produkten bestellt; endlich 2500 Acres Wald von Eichen, Hickory, Walnuß, Esche, Ahorn u. a. Das Waldland wurde mit 25, das Baumwoll- und andere Feldland mit 50 bis 60 Dollars für den Acre bewertet. Als Arbeiter bzw. Pächter lebten auf der musterhaft gehaltenen Pflanzung 20 italienische und 180 bis 190 farbige Familien, im ganzen etwas über Iooo Personen, und an Gebäuden waren vorhanden: des Besitzers Villa, wie alles übrige in Holzbau, im Werte von 8000 Dollars, 2 Inspektorhäuser à 2000 Dollars, 30 vierzimmerige Häuser à 500 und 180 zweizimmerige à 300 Dollars, ferner eine Entkernungsanlage mit 8 Munger Gins und 2 gewöhnlichen Pressen, ein Verkaufsladen (Store), Scheunen, Ställe und die nötigen kleineren Nebenbauten. An Tieren waren 175 Maultiere und Pferde und 3 Milchkühe vorhanden, wofür 35 ooo Dollars eingesetzt waren. Der für das Ganze geforderte Kaufpreis von 350 ooo Dollars galt als angemessen.

Ein weiteres Beispiel liefere die Landwirtschaft der F a r b ige $n$ in der Macon-Grafschaft des Staates Alabama im Jahre I9II. Es kommen dabei vier Klassen in Betracht, nämlich:

I. Lohnarbeiter, und zwar zunächst $\mathrm{T}$ agelöhner. Diese werden gestellt a) durch verheiratete Tagelöhner, welche bei to bis 50 Cents Tagelohn auch noch volle Verpflegung, bei 60 Cents und mehr gewöhnlich keine Verpflegung bekommen; b) Schulkinder für leichtere Arbeit bekommen 35 bis 40 Cents täglich; c) Witwen und geschiedene Frauen, welche nach Bestellung des eigenen Landes als Gelegenheitsarbeiter dienen, beziehen gleiche Lölne; d) für Gelegenheitsarbeiten dient endlich auch noch die fluktuierende Bevölkerung. - Monat $\mathrm{s}$ a $\mathrm{rb}$ e ite $\mathbf{r}$ bezichen für einen kräftigen Mann I 2 bis I3, selten bis 15 Dollars, Knaben lind Greise nur 5 bis 7 Dollars monatlich, dazu Wohnung und Kost, nämlich monatlich ein Bushel Maismehl und I4 Pfund Fleisch. Einen Ubergang zur nächsten Gruppe bildet bereits das ,part-standing wage system“; der Lohnarbeiter bezieht dabei einen Monatslohn von selten unter 5 bis 7 Dollars, bei Úberlassung von 3 bis 4 Acres Land zur Be- 
stellung für scinen eigenen Nutzen, wozu ihm Sonnabends Gespann und Geräte des Farmbesitzers zur Verfügung stehen.

2. Share Croppers. Diese bewirtschaften das Land, im allgemeinen nur mit Baumwolle und Mais, gegen einen Teilertrag der Ernte, der mit den steigenden Bedürfnissen der Farbigen von $1 / 5,1 / 4,1 / 3$ und $2 / 5$ allmählich fast allgemein auf $1 / 2$ gestiegen ist. Der Landbesitzer liefert dabei Land, Wohnung, Ackergeräte, Tiere, Futter, Feuerholz und die halben Düngerkosten. Aller Ertrag, mit Ausnahme des einen Acre Gartenlands, wird geteilt. Bis zur Ernteabrechnung bezieht der Cropper in monatlichen Raten vorher festgesetzte Barsummen von im ganzen 50 bis 200 Dollars gegen mindestens ro bis $15 \%$ Zinsen $\mathrm{P}$. a., oder er entnimmt, was weniger beliebt ist, die nötigen Waren auf Kredit. Besonders Witwen mit ihren Kindern sind häufig erfolgreich bei diesem System. Nach zwei bis drei Jahren besitzt der erfolgreiche Cropper ganz oder teilweise ein Maultier, Futter dafür, Wagen, Ackergerät, Saatgut, einige Schweine und Hühner und ctwas Bargeld und kann nun in die „Pächterklasse“ eintreten, ein sehr erstrebtes Ziel, un der lästigen Aufsicht zu entgehen und mehr lireiheit in der Leitung seiner eigenen Geschäfte zu haben.

3. Renters. Genießt der Pächter bei dem Landherrn Vertrauen, so kann er die Pacht auch antreten, ohne im Besitz des vorstehend aufgeführten Eigentums zu sein, und sein Landherr schießt ihm dann gegen Verzinsung das Nötige vor, bis die Ernteertrïge Rückzahlung gestatten. Eine Art vermögensloser Pächter findet sich auf großen Pflanzungen neben Lohnarbeitern und Share Croppers und ist im allgemeinen denselben Bedingungen wie letztere unterworfen, nur daß der Ertrag der Ernte nicht geteilt wird, sondern nach Abzug von Pacht, Kulturkesten und Barvorschiissen ganz dem Pächter verbleibt. Eine andere Art, gewöhnlich bemittelter Pächter pachtet Land abseits der großen l'achtungen und gibt davon oft klcinere Parzellen an Unterpächter ab gegen 2 bis $21 \%$ Ballen Baumwolle auf den Pflug; insoweit er keine Vorschüsse vom Landherrn bekommt, hat dieser Pächter nur eine Landpacht an ihn zu zahlen. Die Pachtsumme wird meist in Ba umwolle festgesetzt und beträgt dann etwa $1 / 2$ bis 2 Ballen à 500 Pfund Lint für eine Farm von 25 bis 30 Acres. Im Norden ist Geldpach t üblicher, und zwar etwa 75 bis 100 Dollars für eine Ein-Maultier-Farm. Gegen die Vorschüsse läßt sich der Landherr erststellige Hypothek auf Ente und oder persönliches Eigentum geben. 
Die Betriebsfähigkeit des Durchschnitts-Negerpächters erreicht ihre Grenze mit der Drei-Maultier-Farm; mit steigender Zahl der Pfïge nehmen Durchschnittsertrag und Nutzen ab. Prosperierende Pächter suchen ihr Pachtland, Vieh, Wagen und Geräte zu vermehren, daneben nehmen aber auch zu die

4. L a ndbesitzer. Die Farbigen in der Macon-Grafschaft begannen $u$ m I875 Land zu kaufen, das damals und zehn Jahre später 2 bis 5 Dollars für den Acre kostete. Heute bezahlt man dort für Waldland 8 bis 12, für gerodetes und ackerfähiges Land I 2 bis 20 Dollars für den Acre, und zwar finden Kleinkäufer die beste Kaufgelegenheit da, wo größere Landbesitze in Kleinfarmen von 40 Acres aufgeteilt werden. Die Tendenz, Land zu kaufen, ist besonders stark bei Familienhäuptern im Alter von 35 bis 40 Jahren, da die Verantwortlichkeit für Familie und Alter den IVunsch nach einem eigenen Heim bestärkt. Daß vor I880 Farbige keinen größeren Landerwerb anstrebten, lag an drei Gründen: I. besaßen sie keine Geschäftsgewandtheit; 2. hatten sie noch kein Zutrauen zu der Rechtsbeständigkeit ihrer Landtitel; 3. hofften sie noch auf Erfüllung des Regierungsprogramms: ,Jedem Ex-Sklaven 40 Acres Land und ein Maultier". Einzelne unternehmende Farbige gingen trotzdem frühzeitig an Landkauf, der dann von farbigen Farmer-Klubs und der vom Tuskegee Institute gegrïndeten Bau- und Leihgesellschaft gefördert wurde. Da, wo Negergemeinden entstehen, ist das erste, eine Schule zu gründen, und die Gemeinde trägt ihren Namen nach der Schule, Kirche oder Postanstalt. In Macon County schwankt die Farmgröße der Farbigen zwischen 3 und Iooo Acres; neben dem eigenen Landbesitz pachten und bewirtschaften Farbige aber häufig auch noch das Vielfache an weiterem Land. Moderne landwirtschaftliche Maschinen kommen auch bei ihnen mehr und mehr in Aufnahme. I.eihgeld gegen Verpfändung von Land, Ernte, Vieh nsw. kostet ihnen Io bis $15 \%$ p. a.

Pflanzervereinigungen in den Südstaaten sind verhältnismäßig junge Organisationen, die aber einen großen und steigenden Einfluß ausüben. Die sehr rührige

Farmers Educationaland Cooperative Union of America, gegründet 1902 mit dem Hauptsitz Dallas in Texas, Geschäftsstelle I9I4 in Union City, Georgia, ist eine der in Nordamerika so beliebten Geheimgesellschaften, etwas sozialdemokratisch angehaucht, umfaßt nur $\mathrm{kle}$ inere Pflanzer und Pächter, nicht nur Baumwollbauer, schließt Bankiers, Händler und Rechtsanwälte aus und zählt etwa 300000 Mitglieder. 
Die im Januar 1905 aus der „Cotton Growers Protection Association" hervorgegangene, weit weniger zahlreiche

Southern Cotton Association mit Hauptsitz in Atlanta, Georgia, vereinigte Pflanzer, meist Großfarmer, Bankiers und Händler in sich, trug unter ihrem eifrigen Präsidenten Harvie Jordan mehr politischen Charakter, ging Igo8 in die "National Cotton Association" mit Sitz in Atlanta über, welche die Einführung besserer Methoden in der Handhabung der Baumwollernten bezweckte, konnte das dafür nötige grolic Kapital aber nicht aufbringen und existiert heute nicht mehr.

Den ersten Anlaß zu dem agitatorischen Auftreten der I'flanzervereinigungen gaben die starken Schwankungen der Baumwollpreise, welche zwischen 5 Cents in 1898 und 18 Cents in 1904 variierten, ja innerhalb von nur acht Monaten infolge eines wahnsinnigen Spekulationsfiebers in New York von über I7 Cents im Mai ryot auf unter 7 Cents in Januar 5905 fielen und damit atuch vielen Farmern schwere Verluste oder zum mindesten entgehende Gewinne verursachten.

Eine Bewegung gegen die Auswüchse der Spekulation und im Interesse der Erziclung gleichmäligerer, die Arbeit des Pflanzers entsprechend lohnender Preise war durchaus berechtigt. Aber man ging sehr bald weiter und stellte nun seinerseits übertrieben hohe Ansprüche.

Man geht dabei von dem Standpunkt ans, daß die Welt amerikanische Baumwolle haben $m$ ï s s e, nirgendwo anders Ersatz dafiir sei und verlangt Monopolpreise.

Solange der Farmer gezwungen war, seine Baumwolle $\mathrm{schne} 11 \mathrm{mög} 1 \mathrm{ichst}$ zu verkaufen, um das dringend nötige Geld zu schaffen, half er selbst die Baumwoilpreise drücken. Nachdem sich aber der Suiden wirtschaftlich erholt und den auf den Bürgerkrieg folgenden Bankrott überwunden hat, sieht er auf Grund seiner reichen und mannigfachen Naturschätze die Zukunft sehr rosig. Die Baumwollfarmer sind jetzt wohlhabend, haben nicht mehr nötig, ihre Baumwolle sofort zu verkaufen, sondern können den Verkauf über zwölf Monate ausdehnen und abwarten, bis man ihnen notgedrungen die geforderten hohen Preise zahlt. Die Pflanzervereinigungen beabsichtigen, den Zwischenhandel vom Feld bis zur Spinnerei auszuschalten. Sic wollen die Anbaumenge bestimmen, die Baumwolle selbst klassifizieren, Lagerhäuser errichten, um die Baumwolle bei niedrigen Preisen aufzustapeln und ähnlich, wie bei den Getreidespeichern, zu beleihen - kurz einen Riesentrust bilden, um Produktion und Preise zu beherrschen. 
Tatsächlich sind letzthin im Süden auf Veranlassung der Farmers Union Hunderte von praktisch eingerichteten $L$ a g e r h ä u s e rn geschaffen worden, und damit steht, von dem cigentlichen $\mathrm{f}$ in an zie 11 en Zweck ihrer Errichtung abgesehen, jedenfalls eine bessere Sicherung vor "country damage“ in Aussicht.

Der angestrebte Minimalpreis beträgt I $_{5}$ Cents für das Pfund Paumwolle und 20 Dollars für die Tonne Baumwollsaat, und zu deren Erzwingung hat man wiederholt eine wesentliche Reduktion der Anbaufläche angedroht, wobei es allerdings sein Bewenden hatte. Der erzielte Durchschnittspreis für das Pfund amerikanischer Baumwolle betrug laut Angaben des Census-Bureaus im Jahrzehnt $I 897$ bis 1906 8\% Cents, und daß diese Preise keine Hungerpreise waren, kann der flüchtigste Besucher der Südstaaten ersehen, die ihre l'rosperität in erster Linie auf die Erträgnisse des Baumwollbaus aufbauen. Seitdem sind die Preise weiter gestiegen; 15 Cents aber sind als extravagante Forderung zu bezeichnen.

Die Pflanzervereinigungen wünschen ferner, alle $\mathrm{Z}$ w is ch c n lı än $\mathrm{d} \mathrm{l} \mathrm{er}$, besonders die amerikanischen, ebenso wie die S p e k u $1 \mathrm{at}$ ion in Baumwolle auszuschalten, und erstreben einen möglichst direkten Verkehr zwischen Pflanzer und Spinner unter Festsetzung eines von letzteren zu garantierenden, die ,Selbstkosten" deckenden Minimalpreises. I5 Cents! T e r m i n geschäfte in Ackerbauprodukten, also auch in Baumwolle, sollen iiberall in der ganzen Welt als ungesetzlich erklärt werden, wie das die Farmervereinigungen seit Igo6 tatsächlich in einer Reihe von Baumwollstaaten der Union, nämlich den beiden Carolinas, Georgia, Alabama, Arkansas und Texas, durch anti-futures laws bereits durchgedrückt haben.

Dagegen ist anzuführen, daß die Baumwoll-Zwischenhändler für Zusammenbringen, Klassifizieren und Bemustern größerer Quantitäten, aus denen der Spinner wăhlen kann, zur Zeit wenigstens unentbehrlich sind. Ebenso wird übersehen, daß die Baumwollbörsen nicht nur bedauerliche und zu bekämpfende Auswüchse zeitigen, die in den heftigen Preisschwankungen der letzten Jahre zum Ausdruck kamen, sondern überwiegend der Sicherung des soliden Geschäftes dienen, das auf Basis von Terminnotierungen für Rohbaumwolle entsprechend langfristige Abschlïsse in Garnen und Geweben macht.

Die Organisationen der Farmer und ihre Freunde haben durch iibertriebene Vorschläge, wie Verbrennen übergroßer Ernten, zwangsweise Einschränkung der Anbauflächen, Forderung exorbi- 
tanter Preise und Beantragung der ,Valorisation" der Baumwolle von Staats wegen zwar hin und wieder zur Satire herausgefordert, aber mit ihren Bestrebungen, Preise hoch zu halten, wird mehr und mehr zu rechnen sein.

\section{Baumwollsorten.}

Botanische Sorten. Dic Kultur der Baumwolle in Nordamerika ist ïberwiegend von der importierten levantinischen Baumwolle, Gossypium herbaceum ausgegangen; daneben wurde die mexikanische Gossypium hirsutum, seit i786 von Westindien die hochklassige Sea Island-Sorte eingeführt, und im Laufe der Zeit haben sich dann in den Vereinigten Staten etwa 600 verschiedene Spielarten ausgebildet, die manches botanische Rätsel aufgeben, heute aber auf zwei Grundformen zurückzuführen sind, nänlich die meist geptlanzte „Upland“ oder Gossypium hirsutum, welche weitaus die Hauptmasse der amerikanischen Baumwolle liefert, und die wertvollere, aber an Ertragsmenge weit zurückstehende Sea Island oder Gossypium barbadense.

a) Up 1 a nds. Es ist möglich, daß Gossypium punctatum in Alabama einheimisch war und die grünfilzige Upland-Baumwolle eine spätere Kulturform von ihr ist. Die Upland vermischte sich dann mehr oder weniger mit der levantinischen und wahrscheinlich auch mit der später importierten mexikanischen Baumwolle und bildete mit det Zeit eine Masse von Sorten. Gossypium hirsutum in den Suidstaaten ist ein 2 bis 7 , im Durchschnitt 3 bis 5 fiub hoher, vielfach verzweigter einjähriger Strauch, dessen jüngere Zweige, Blatt- und Blütenstiele ziemlich dicht behaart sind. Die vom holzigen Hauptstamm abgehenden Zweige nehmen nach oben hin an Länge und sitärke ab. Die Blumenblätter sind weiß, meist reinweiB, nur selten am Grunde nit purpurnem Fleck; beim Verbliihen, das ebenso rasch erfolgt wie die Entfaltung der Blüten, werden sie rötlich. Die Fruchtkapseln sind glatt, erreichen die Größe eines kleinen Hühnereis und enthalten in jedem ihrer drei bis fünf Fächer 5 bis I 2 Samen; welche außer den reinweißen oder gelblichen Fasern, der „Baumwolle“, noch einen ziemlich fest anhaftenden grünlichgrauen Filz, eine Grundwolle, tragen. Die Zahl der Kapseln an einem Strauch wechselt von einigen wenigen Stück bis zu mehreren Hunderten; ich sah in Texarkana cine Staude mit 4 Io Kapseln. Aber nicht alle Kapseln reifen, ein großer Teil leidet unter Insekten, Trockenheit, Regengüssen $11 \mathrm{sw}$; 30 bis 50 reife Kapseln auf die 
Staude gelten als guter Durchschnitt und ergeben vom Acre $3 / 4$ bis I Ballen Baumwolle. Die Stape 11 änge der Faser schwankt 2 wischen $3 / 1$ und $I \% / 8$ inch. In bezug auf Stapel unterscheidet man drei Klassen und bezeichnet die bis $25 \mathrm{~mm}$ langen als kurzstapelig, die von 25 bis $30 \mathrm{~mm}$ langen als mittelstapelig und die über $30 \mathrm{~mm}$ langen als langstapelig. Mit der größeren Faserlänge geht gewöhnlich auch größere Feinheit Hand in Hand. Man sucht neuerdings, besonders in den Staaten Mississippi, Texas, Arkansas und Süd-Carolina, durch geeignete Saatzucht die Stapellänge zu heben. Diese long staple-Uplands kommen in Länge an die Sea Island heran, geben aber vom Acre einen bis zu dreifach höheren Ertrag als diese und verursachen überdies geringere Produktionskosten. Der Hauptbedarf Lancashires ist für Baumwolle von $\mathrm{T} / \mathrm{s}$ bis I $1 / 4$ inch Stapellänge; Stapel über $I \frac{1}{4}$ inch kann nur für feinere Garnnummern verwendet werden, zu denen man gewöhnlich ägyptische Baumwolle nimmt, und ist also nur in guter und gleichmäBiger Qualität zu brauchen, andernfalls aber fast unverkäuflich. Nach der $R$ e if eze it gibt es früh-, mittel- und spätreifende Sorten. Nach der Z w e i g b i l d $\mathrm{ung}$ unterscheidet man lang- und kurzzweigige Arten. Erstere haben große Kapseln und langen Stapel, aber geringen Ertrag; letztere haben zwar nur kleine oder mittelgroße Kapseln und kurzen Stapel, geben aber hohen Ertrag und reifen früh. Nach dem Fa serertrag unterscheidet man drei Gruppen, nämlich solche mit weniger als $30 \%$ Lint vom Gesamtgewicht der unentkernten oder Samenbaumwolle, solche mit 30 bis $34 \%$ und solche mit über $34 \%$.

Professor J. F. Duggar in Alabama unterscheidet nach ihren charakteristischen Eigenschaften folgende sieben Gruppen von Uplands; es sind dies keine verschiedenen, ,botanischen" Sorten, sondern Anbau-Spielarten:

I. Cluster oder Dickson-Typ: Hohe, dünne Pflanzen, Kapseln gern in Büscheln wachsend, kleine Samen, frühreif, 32 bis $34 \%$ Lint. Hauptarten: Dickson, Jackson, Wellborn.

2. Semi-Cluster oder Peerless-Typ: Kurze Zweige, Kapseln mehr oder weniger in Büscheln, Samen mittelgroß, früh- bis mittelreif, 29 bis $35 \%$ Lint. Hauptarten: Peerless, Boyd, Dearing, Drake, Hawkins, Herlong.

3. Rio Grande oder Peterkin-Typ: Mittelgroße, dichtbezweigte Pflanzen, kleine Kapseln, glatte, scliwarze Samen, nur an der Spitze befilzt, mittlere Reifezeit, $35 \%$ Lint. Hauptarten: Peterkin, Dixie Wilt Resistant, Excelsior, Texas Oak, Toole. 
4. Slort Limb oder King-Typ: Kleine, gut bezweigte Pflanzen, kleine Kapseln, mittelgroße Samen, ganz früh reifend, 32 bis $34 \%$ Lint. Hauptarten: King, Lowry, Simpkins.

5. Big Boll oder Duncan-Typ: Große, starke Pflanzen, gut bezweigt, sehr große Kapseln, große, dicke Samen, gewöhnlich späte Reife, 29 bis $34 \%$ Lint. Hauptarten: Duncan, Cleveland, Lce, Russell, Triumph, Truitt.

6. Lang Limb Upland- oder Petit Gulf-Typ: Sehr große l'flanzen mit langen Zweigen, mittelgrolien Kapseln, spätreifend, 30 bis $32 \%$ Lint. Hauptarten: Petit Gulf, Ellis, Gunn.

7. Long Staple Upland- oder Allen-Typ: Große schwere Pflanzen, die guten feuchten Boden verlangen, untere Zweige sehr lang, mittelgrolie Kapseln, mittelgroße bis große Samen, späte Reife. langer Stapel, 25 bis $29 \%$ Lint. Hauptarten: Allens Improved, Columbia, Cook, Griffin, Hartwell, Matthews, Sunflower.

b) Sea Is land-Ba umolle oder Gossypium barbadense, ursprünglich auf den Kleinen Antillen und den BahamaInseln einheimisch, heute durch Anbau in allen Weltteilen vertreten, wurde durch die Kolonisten auch in Nordamerika angepflanzt und wird besonders in den Staaten Georgia und Florida, zum Teil auch in Süd-Carolina, an den Küsten und auf den vorliegenden Inseln gebaut, während sie im Innern dieser drei Staaten nur mit häufigem Samenwechsel gezogen verden kann und cine geringere Qualität liefert. In Innern Georgias importiert man Saat von der Küste, benutzt diese aber nicht direkt zur Nutzsaat, sondern zieht daraus netien Samen und gewinnt erst daraus eine Ernte, deren Samenkörner aber bereits wieder so weit entartet sind, dal. sic zu weiterem Anbau nicht mehr verwendet werden. In einer Entfernung von $80 \mathrm{~km}$ von der Küste ist Seal Island-Baumwolle sclten lohnend. Man hat zwar während einiger Jahrzehnte Seat Island in kleinem Maßstab auch in Texas angebaut und damit im Jahre I896/97 2597 Ballen erziclt, dic Kultur aber seitdem wieder aufgegeben. Im ganzen hefert Sea Island mit rund Ioo ooo kleinen Ballen im Jahre nur einen verschwindenden 'Teil der Gesamternte, nämlich etwa $1 / 2 \%$.

Gossypium barbadense ist eine bis zweijährige, krautartige, etwa 3 Fub hohe Pflanze mit unbeharten Stengeln, die Blumenblätter sind gelb oder schwefelfarbig mit einem purpurnen Fleck versehen, später rötlich. Die eiförmige, etwas zugespitzte Kapsel, kleiner als die durchschnittliche Upland, weist meist drei, seltener vier oder fünf Fächer auf mil je 6 bis 9 schwarzen, glatten Samen- 
kernen, die eine I5, bis 216 inch lange, weiße bis schwach cremefarbige, seidenartige Faser, aber darunter keinen Filz tragen. Gossypium barbadense liefert die wertvollste aller Baumwollsorten überhaupt, ist fein, kräftig, seidig und gleichmäßig, und der dafür erzielte hohe Preis, der auf den Süd-Carolina-Inseln bis zu 75 Cents für das Pfund erreicht, entschädigt für den kleinen Lintertrag, der mit $25 \%$ niedriger als bei irgendeiner anderen nordamerikanischen Sorte ist. und für die ganz besondere Sorgfalt, die bei ihrer Saatwahl und Kultur zu beobachten ist. Sca Island-Baumwolle ist nie ein Artikel des Massenkonsums geworden, sondern stets nur für Erzeugung beschränkter Mengen allerfeinster Warensorten in Frage gekommen.

Im letzten Jahrzehnt ist der Sea Island-Baumwolle der Vercinigten Staten übrigens eine ernstliche Konkurrenz im britischen Westindien entstanden. Nachdem diese feinste aller Baumwollen schon in früheren Zeiten dort angebaut worden war, wurde sie I903/0t durch die British Cotton Growing Association erneut eingeführt und ergab in Güte und Menge des Ertrags ausgezeichnete Resultate. Im Fruchtwechsel mit Zuckerrohr angebaut, waren dort im Jahre I9Io bereits 30000 Acres mit einem Jahresertrag von nahe an 3 Millionen Pfund Lint unter Baumwollkultur, und die Inselgruppe ist heute in der Lage, den gesamten Bedarf in Sea IslandBaumwolle decken zu können.

Mit der Sea Island-Baumwolle verwandt ist die

Ägyptische Ba $u \mathrm{~m}$ wolle. Im allgemeinen haben die verschiedenen Versuche mit fremden Baumwollsorten in den Vercinigten Staaten keine besseren Resultate als das jetzt dort cinheimische Naterial ergeben. Angesichts der sich verfeinernden amerikanischen Textilindustrie und des damit schnell wachsenden Redarfs an ägyptischer Baumwolle, der im Durchschnitt der letzten zehn Jahre etwa I fo ooo Ballen betrug, hat das Ackerbau-Amt seit 1892 begonnen, in den südwest-Staaten Kreuzungen zwischen ägyptischen und amerikanischen Varietäten vorzunehmen, und mit Hilfe künstlicher Bewässerung Anbauversuche sowohl in den Trockengebieten von Arizona und dem südöstlichen Kalifornien, als auch auf Alluvialböden in Texas gemacht, welche befriedigende Resultate und einen Ertrag bis zu 700 Pfund Lint vom Acre lieferten. Waren in Arizona die Ergebnisse der von Ägypien cingeführten Mitafifi-Saat selbst auch wenig crmutigend, so führte der Zufall oder die Saatzucht doch zu einer in Amerika netgebildeten, widerstandsfähigen Spielart, die der besten ägyptischen Sakellaridis chenso ïberlegen ist, wic diese allen anderen ägyptischen Sorten. 
Bewährt haben sich besonders dic beiden Sorten luma und Somerton.

Handelssorten. Bei der Beurteilung seitens des Handels kommen besonders in Betracht: Feinheit, Länge, Gleichheit, Glätte, Widerstandsfähigkeit, Elastizität, Färbung und Reinheit.

Nach ihrer Stapellänge eingeteilt, zerfällt die nordamerikanische Baumwolle in folgende vier Sorten:

L in ters sind die beim zweiten Ginprozeß abfallenden kurzen Flaumhaare der Saat, welche im Maximum 1/2 inch lang, also sehr kurz, dabei unregelmäßig, matt in Farbe und ölfleckig sind, nur zu Garnen von $\mathrm{Nr} .8$ bis Io spinnbar, sonst zu. Bindfaden, Stricken, Polstermaterial, Filz und Zellulose verwandt.

Upland ordinary staple, weiße, weiche und ziemlich kräftige Ware von $3 / 4$ bis $1 \frac{1}{s}$ inch Stapel, die charakteristischste und am meisten gebrauchte Sorte, dient zum Spinnen der Garnnummern bis 36 und 40 .

Upland long staple, mit einem Stapel von $I^{3} / 10$ bis $1 \% / 8$ inch, meist gut weiß, seltener rahmfarbig, ist in der Allen-Sorte bis $\mathrm{Nr} .50$ und 60 , in der kräftigen Benders bis $\mathrm{Nr} .60$, in der seidigen, feinen Peeler bis $\mathrm{Nr} .60$ und 80 spinnbar.

Se a Is land, nach Stapellänge in "low" unter $15 \% / 8$ inch, „medium" von $15 / 8$ bis $1 \% / 8$ inch und ,superior" von 2 bis $21 \%$ inch eingeteilt, dient besonders zu Nähzwirn, Spitzen, Automobilreifendecken und anderen Verwendungen, wo es auf Stärke und Feinheit ankommt. Sea Island ist bis zu Nr. 2000 gesponnen worden. Den längsten Stapel hat die Süd-Carolina-Sorte, welche für Garne Nr. 300 bis 400 dient, während die geringeren Floridas und Georgias für die Nr. I5o bis 300 verwendet werden.

Dic Liverpool Cotton Association unterscheidet amerikanische Baumwolle nach fünf Gebicten in Sea Island, Florida Sea Island, Upland, Texas und New Orleans. „Texas“ ist im Mittel etwas .kurzstapeliger als dic in Mississippi und Louisiana gebauten „Orleans" und dic aus Georgia, den Carolinas usw. stammenden "Uplands", die $\mathrm{I}^{1} / 10$ inch messen. "Mobile" aus Alabama und den angrenzenden Staaten haben durchschnittlich $I^{1} / 20$ inch Stapellänge.

$\mathrm{Se}$ a I s l and zerfallen nach ihrem Aussehen in: dogs, fine, extra fine, extra choice und fancy, während die übrigen Hauptsorten die folgenden sieben Hauptklassen, gleichfalls in steigender Güte, aufweisen:

ordinary, good ordinary, low middling, middling, good middling, middling fair und fair. Davon zerfallen die Klassen 2 bis 7 noch 
in halbe und viertel Grade, erstere mit "strict“, letztere mit ",barely“ und "fully" bezeichnet. Ordinary wird nur in strict und fully gehandelt, darunter gibt es aber noch die Sorten fully low ordinary; low ordinary und inferior. Dic Gradeinteilung bezieht sich stets nur auf gutfarbige ,weiße Baumwolle“, im Gegensatz zu derjenigen, welche durch Regen oder Frost gelitten und dadurch eine gelbliche bis rotgelbe Färbung erhalten hat. Man bezeichnet diese minderwertige, unter sich selbständige Klassen bildende Baumwolle mit „, t i n g e d“", wenn sie gering gefärbt, nur gelblich-weiß oder gelblich, mit ,h i g h color", wenn sie stark gelblich oder rötlich, und mit "s s t a in ed", wenn sie fleckig und mit rotfarbenen Flecken behaftet ist.

In Terminklassen unterscheidet man bei der gleichmäßigen Bedingung von "good staple" die fünf Farbenklassen: good, fair, tinged, high color und stained.

Die Preisrelationen zwischen den verschiedenen K̈lassen sind je nach Angebot und Nachfrage stark wechselnd.

Die von der Liverpool Cotton Association aufgestellten Klassen werden mit Ausnahme von Havre und Marseille in allen Handelsstädten beachtet, wenn auch mit gewissen Abweichungen. Die den verschiedenen Klassen entsprechenden Typen oder Standards werden jedes Jahr von den Liverpooler Maklern im Einvernehmen mit den maßgebenden überseeischen Faktoren mit großer Vorsicht ausgewählt, neu aufgestellt und darauf von den übrigen Börsenplätzen bezogen.

Eine im Frühjahr 1909 im Ackerbau-Amt zu Washington abgehaltene Konferenz führte zur Bestimmung von offiziellen „Nationalen Baumwoll-Standards", welche neun verschiedene Klassen zwischen good ordinary und middling fair umfassen, als Richtschnur für die Farmer dienen sollen und ab I. September I9 Io auch von den meisten Baumwollbörsen der Südstaaten angenommen wurden; ab I. April I9I5 wurden sie auch an der New Yorker Börse eingeführt.

Diese offizicllen amerikanischen Standards des Ackerbau-Amtes ziehen nur zwei Eigenschaften der Baumwolle in Betracht, nämlich Farbe und sodann die Menge von Unreinigkeiten und sichtbarem Abfall, der von $4 \%$ bei middling fair bis auf I $\%$ bei good ordinary steigt, nehmen aber keine Rücksicht auf die ebenso wichtigen Eigenschaften: Faserlänge, Stärke und Drehung der Faser und das Verhalten der Faser beim Bleichprozeß.

Erstrebt wird eine internationale, für die. ganze Welt gültige einheitliche Klassierung nordamerikanischer Baumwolle. 
Die Grundlage für alle Kontrakte ist ",niddling white cotton". Dieser Grad ist die allgemeine Norm, nach der sich alle anderen Grade bestimmen. „Middling" ist eine weiche (fleecy) Ware, die von Fremdkörpern, wie Samen, Blattresten, Schmutz usw., nahezu frei ist. Das größere oder geringere Vorhandensein von Fremdkörpern ist für die niederc oder höhcre Klassifikation ausschlaggebend. Jede Ernte hat in ihrer Gesamtlieit ihren eigenen Charakter; die eine fällt rein weiß, eine andere mehr „,creamy" oder "dingy" aus.

Die Bestimmung der verschiedenen Grade ist eine ziemlich schwierige. Da es kein technisches Hilfsmittel gibt, so kann nur langjährige Erfahrung und Ubung diese Kunstfertigkeit verleihen. Die Unterschiede in Reinheit, Farbe usw. sind für die einzelnen Grade nicht so augenfällig, daß nicht schon verschiedene Beleuchtung zu verschiedener Beurteilung führen kann. Es ist in Baumwollkreisen bekannt, daß kaum zwei Sachverständige dieselbe Baumwolle vollständig gleich klassifizicren, ja daß selbst derselbe Sachverständige die glciche Baumwolle bei einer zweiten Prüfung kaum ebenso wie das erste Mal zu klassifizieren vermag. In New York, wo die Börse amtliche Bescheinigungen über die Grade ausstellt, wird z. B. nur bei Nordlicht und nur während bestimmter Tagesstunden klassifiziert.

\section{Saatwahl und Saatzucht.}

Die bei der Wahl der Anbauart zu beobachtenden Eigenschaften sind: Anpassungsfähigkeit, Ertrag, Reifezcit, Wachsart, Länge und Stärke der Faser, Größe der Saat und Widerstandsfähigkeit gegen Krankheiten. Ein wünschenswerter Typ von Upland soll cinen starken kräftigen Stamm mit zahlreichen, bis ans Ende fruchttragenden Stengeln an der unteren Hälfte, große windbeständige Kapseln, hohe Lintprozente, mittelgroße Saat und starken, mindestens $\mathrm{I} 1 / \mathrm{s}$ inch langen Stapel aufweisen, die Pflanze soll widerstandsfähig, frühreifend und reichtragend sein.

Das Bestreben der amerikanischen Pflanzer ist fast stets darauf gerichtet gewesen, einen möglichst hohen Ertrag an Fasern zu erzielen und dabei zugleich den jeweiligen Forderungen der Marktlage gerecht zu werden. Durch die Ausbildung der Grundform von Gossypium hirsutum, welche ursprünglich nur 28 bis $30 \%$ Lint und einen Stapel von 20 bis $30 \mathrm{~mm}$ lieferte, ist es gelungen, den Ertrag an Lint stellenweise bis zu 36 bis $40 \%$, bei anderen Sorten dic 
Stapellänge wesentlich zu steigern. Aber nur bei wenigen Arten ist es gelungen, Lintertrag und Stapellänge gleichzeitig zu erhöhen. Selbst diese einzelnen verbesserten Eigenschaften können nur durch systematische und sorgfältige Weiterbehandlung und Samenauswahl erhalten werden, da Baumwolle eine starke Neigung besitzt, zu variieren und namentlich zur Urform zurückzukehren.

Die Heranzüchtung neuer Varietäten geschieht auch in Nordamerika entweder durch Auswahl der am besten entwickelten I'flanzen oder durch die Verbindung der guten Eigenschaften zweier Arten durch Kreuzung. Bei der weiteren Selbstzucht einer bewährten Spielart sucht man die Qualitäten nicht nur festzuhalten, sondern noch zu vervollkommnen durch Satwahl auf dem Stande selbst, eine Arbeit, die viel Sorgfalt und Gewissenhaftigkeit beansprucht, also keineswegs vom ersten besten Arbeiter ausgeführt werden kann und eine strenge Kontrolle erfordert. Die auszuwählenden und zu markierenden Stauden sollen von kräftigem, aufrechtem Wuchse und mit vielen, wagerecht laufenden und in gleichen Abständen stehenden Zweigen besetzt sein. Die Kapseln sollen zahlreich, groß und gut gerundet sein; je weniger Samenkerne sie haben, um so besser, diejenigen Kapseln, deren Samenmenge über den Durchschnitt zeigt, scheide man aus, ebenso solche Kapseln, deren Baumwolle hochgestellten Anforderungen nicht entspricht. Die natürlich in mehrmaligen Rundgängen zu sammelnde Samenbaumwolle muß auf einem besonderen Gestell mit besondercr Vorsicht getrocknet und dann separat geginnt werden.

Auf umsichtig geleiteten Pflanzungen läßt man bei der ersten und zweiten Pflücke eine geübte Hand vorweg gehen, welche die zur Neuaussaat bestimmten Kapseln von den stärksten Pflanzen wählt, und zwar davon wieder die größten Kapseln von den niedrigsten Zweigen, welche am frühesten blühen und welche dem Stamm am nächsten sitzen und in ihrer Wolle dem gewünschten Typ am besten entsprechen.

Die Samen sind dann in trockenen, gut gelüfteten und frostfreien Räumen aufzubewahren in nicht über $60 \mathrm{~cm}$ dicken Schichten, welche von Zeit zu Zeit umzuwenden sind.

Um eine möglichst gleichzeitige Reife des Feldes und damit eine einfachere und billigere Ernte zu erzielen, wird angeraten, nur die Samen von gle ichzeitig reifenden Blumen bzw. Kapseln zur Aussaat zu benutzen.

In jedem einzelnen Bezirk sollte ferner durch Ubereinkommen nur eine einzige, dort bewährte Sorte gezogen werden, denn der volle 
Wert einer ausgewählten neuen Sorte ist nur dann auszunutzen, wenn sie auf größeren Flächen im allgemeinen Gebrauch genommen und ihre Reinheit durch fortgesetzte Saatwahl aufrecht erhalten wird. Deshalb sollten die zu einer Genossenschaft zusammengeschlossenen Farmer eines Bezirks auch ihre Saat selbst ziehen und darin nicht von den Zufälligkeiten der Entkernungsanstalten als Saatlieferanten abhängig sein.

Im Einklang mit der wachsenden Nachfrage haben sich Regierung und Private in der Letztzeit bestrebt, den Anbau von 1 a $\mathrm{ng}$ st a peligen U p lands auszudehnen. Die früher besonders im Mississippi-Delta gezogenen langstapeligen Standard-Sorten sind durch den Kapselkäfer so gut wie vernichtet worden, und das Bureau of Plant Industry ist nunmehr bemüht, neue Sorten auszufinden und zu züchten, welche nach Güte und Ertrag den Wünschen der Praxis entsprechen. Vielfach ist es bislang allerdings schwierig gewesen, für die bessere Ware auch einen entsprechend höheren Preis zu erzielen. Im allgemeinen ist nämlich der Acre-Ertrag bei den kurzstapeligen Sorten größer als bei den langstapeligen, nicht selten beträgt er das Doppelte. Dazu kommt, daß letztere nicht nur einen reicheren Boden, sondern auch bessere Pflege verlangen und schwerer zu entsamen sind, überhaupt das höchste Geschick beim Pflanzer voraussetzen. Endlich reifen sie durchschnittlich später als die kurzstapeligen, was besonders für die Gegenden nördlich vom 32. Grad, wo man zuweilen mit sehr frühen Frösten zu rechnen hat, sehr ins Gewicht fällt. Der Pflanzer erleidet stets einen Verlust, wenn nicht sein ganzes Feld zur Reife gelangt. Daher bieten für die nördlichen Gegenden diejenigen Sorten die größte Gewähr, welche frühzeitig reifen, wenn sie auch meist nur kurzen Stapel und im allgemeinen mäßig hohen Lint-Ertrag haben. In den mittleren und südlichen Teilen des Baumwollgürtels ist frühe Reife zwar nicht so ausschlaggebend, aber doch immerhin insofern wichtig, als sie dem Pflanzer erlaubt, seine ganze Ernte vor den schweren Regengüssen cinzuheimsen, welche namentlich dic Monate November und Dezember bringen. Hier in der Mitte und im Süden fragt es sich, welche Art den größten Lint-Ertrag gibt; die Länge des Stapels kommt kaum in Betracht, da zwischen 20 und $30 \mathrm{~mm}$ nur ein sehr geringer Preisunterschied besteht.

Man kann ruhig behaupten, daß die Spinnindustrie sich mehr bestrebt hat, die von Amerika gelieferte Baumwolle bestmöglich zu verarbeiten, als daß Amerika bemüht gewesen wäre, eine für die Spinnerei besonders geeignete Klasse Baumwolle zu entwickeln; 
cigentlich aber sollte sich der Farmer anstrengen, diejenige Baumwolle zu züchten, die der Spinner braucht, und vor allem ist für diesen $\mathrm{Gl}$ e i c h m ä Bigkeit von der größten Bedeutung.

\section{Der Baumwollanbau.}

Vorausgeschickt sei diesem Kapitel, daß die Einzelheiten des Baumwollbaus, der mehr eine Art Garten- als eine Feldkultur ist, in den verschiedenen Staaten und Distrikten von einander abweichen, hier also nur die Hauptzüge gegeben werden können. Uber das Richtige in allen einzelnen Phasen der Baumwollkultur herrschen bislang noch ziemliche Meinungsverschiedenheiten auch unter Sachverständigen und Gelehrten.

Vor Beginn einer Pflanzungsperiode wird sich der sorgsame Pflanzer zunächst darüber zu vergewissern haben, daß seine Arbeit gut geplant, der Stand des Unternehmens seinen Mitteln entsprechend ist, genügend tierische Kräfte und Geräte vorhanden sind, um die gestellte Aufgabe mit möglichster Schonung der teuren menschlichen Kräfte durchführen zu können, da $\dot{B}$ Dünger mit Einsicht und weiser Sparsamkeit eingekauft, die Feldeinteilung eine verständige ist. Diese einzelnen Punkte sollen im folgenden etwas näher betrachtet werden.

Fruchtfolge. Baumwolle entzieht dem Boden im allgemeinen wenig Nahrungsstoffe, wenn man ihm Stengel, Laub und Saat zurückgibt. Die bis zu $25 \mathrm{Fuß}$ tiefen Alluvialländer des MississippiDeltas tragen seit 60 Jahren ungedüngt langstapelige Baumwolle, und in Texas und Arkansas wird Baumwolle Jahr für Jahr auf demselben Felde gepflanzt für zehn Jahre und länger. Mehr und mehr sieht man aber doch die Wichtigkeit einer planmäBigen Fruchtfolge cin, und zwar empfiehlt sich am besten eine dreijährige etwa in der Weise, daß im ersten Jahr Baumwolle, im zweiten ein kleinkörniges Getreide (Weizen, Hafer, Gerste oder Sorghum) und im dritten Cow peas, die chinesische Tafelbohne vigna sinensis, oder Sojabohnen, oder im Süden Velvet Beans, oder Luzerne mit Mais gebaut werden, wobei die keiner Pflege bedürfenden Leguminosen mit ihren tief eindringenden Wurzeln zur Stickstoffanreicherung des Bodens dienen; man kann sie auf dem Felde vom Vieh abweiden lassen, oder macht Heu daraus zum Trockenfutter, oder man läßt sie auf dem Felde absterben und unterpflügen, wobei sie Humus liefern und den mechanischen Zustand des Bodens verbessern. Am belicbtesten sind die Cow peas, die in ihren Früchten nicht nur ein 
gutes Nahrungsmittel für dic farbigen Arbeiter, sondern auch ein wichtiges Futtermittel für den wertvollsten Nebenbetrieb ciner Baumwollfarm, die Schweinemast, liefern.

Manchenorts, z. B. in Mississippi und Texas, zieht man, schon um das Unkraut niederzuhalten, in zwei Jahren drei Ernten auf demselben Boden, indem man im ersten Jahr cin kleinkörniges Getreide mit nachfolgenden Kuherbsen, im zweiten Jahre Baumwolle anbaut. Klee wird häufig mit Baumwolle und Mais als Winterdeckfrucht gezogen. Bei Sea Island-Anbau in Süd-Carolina überläßt man den Boden nach einjährigem Baumwollbau auf ein Jahr der Weide für Rinder und Schafe. B ra $\mathrm{che}$ ist sonst im Baumwollgürtel selten.

Auf einer modernen I60-Acres-Farm bestellt man im Wechselbau je 40 Acres mit Baumwolle, Mais, kleinkörnigem Getreide und Futterpflanzen und überläßt das letzte Viertel der Weide, so daß jedes Stück Zeit zur Bodenerholung hat.

Ackergeräte und Tiere. Die ungünstigen Arbeiter- und hohen Lohnverhältnisse, sowie die stellenweise Unmöglichkeit, genügende Arbeitskräfte zu beschaffen, haben die amerikanischen Farmer der Nord- und Weststaaten schon von jeher dazu veranlabt, den weitestgehenden Gebrauch von landwirtschaftlichen Geräten und Maschinen zur Ersparnis menschlicher Arbeitskraft zu machen; dieses Bestreben wurde einerseits unterstützt durch die Größe der gut arrondierten Farmen und die riesenhaften Flächen gleichmäßigen, ebenen und steinfreien Bodens und anderseits erleichtert durch das gleichmäBig schöne Wetter in der Sommer-Erntezeit. Amerika verdankt die Erfolge seiner Landwirtschaft zum guten Teile der Verbesserung landwirtschaftlicher Geräte und Maschinen.

Anders lagen die Verhältnisse in den Südstaaten. Während der Sklavenzeit dachte man dort überhaupt kaum an Verbesserung der Arbeitsgeräte, auch weiterhin sind solche im Baumwollbau selten gewesen und langsam eingeführt worden, und erst neucrdings tritt darin allmählich ein Fortschritt ein, wenn auch heute diese Verhältnisse vielfach noch recht rückständig sind. Am modernsten ist darin Texas.

Bis zum Bürgerkrieg wurde die Feldarbeit im Süden stellenweise ausschließlich mit der Hacke besorgt, und erst seitdem der Pflug eingeführt, beides Instrumente, die leicht auf der Farm selbst repariert werden konnten. Das Universalgerät der „einspännigen“ Farm ist noch heute dieser einfache, einspännige Pflug, der mit Ausnahme der jetzt stählernen Schar ganz aus Holz besteht, etwa 
40 Pfund wiegt und mit seinen auswechselbaren Scharen verschicdener Form sowohl zum Aufbrechen und Zerkleinern der Erdkruste, als zum Jäten und zum Unterpflügen dient. Neben diesem Pflug war vor allem noch die Hacke notwendig. Jetzt gibt es aber auch schon im Baumwollbau zwei- und dreispännige, Scheibenpflüge, Untergrundpflüge, Ackerwalzen und Kultivatoren. Ein moderner Farmer weiß, wieviel ökonomischer ein zweispänniger als ein einspänniger Pflug ist.

Im heutigen Betrieb folgt dem Pfluge die Egge, zuweilen in Verbindung mit der Walze, um den Boden zu pulverisieren. Dann folgt der mechanische Düngerstreuer und der seit I 880 allgemeiner in Gebrauch gekommene Saatdrill, dessen Konstruktion noch nicht auf der Höhe ist. Das Auslichten der Pflanzen geschieht mit der Hacke oder besonderen Kultivatoren. Zur weiteren Lockerung des Bodens und zur Unkrautbekämpfung dienen gleichfalls die meist noch einspännigen Hackmaschinen (Kultivatoren). Die Baumwollstoppeln werden stellenweise mit dem Stalk Cutter geschnitten. Schwierig gemacht wird die Einführung moderner Geräte und Maschinen durch den geringen Umfang vieler Einzelfarmen.

Angesichts der Schwierigkeit, genügende und billige menschliche Arbeitskräfte zum Pflücken zu gewinnen, war es naheliegend, auch nach einer Pflü $\mathrm{ckm}$ a s chin e zu suchen, und in der Tat hat es an mannigfachen Anläufen zur Einführung einer solchen nicht gefehlt, schon 1855 wurde der erste Baumwollpflücker patentiert; praktisch bewährt hat sich aber bislang noch keine, hauptsächlich wegen der so verschiedenen Reifezeit im gleichen Fclde. Am nächsten der Lösung dieses schwierigen Problems scheint noch ein Canadier schottischer Abstammung, Angus Campbell, gekommen zu sein, der nach langjährigen, mühevollen Versuchen eine Pflückmaschine erfand, deren Patente vor einigen Jahren von cincr Ncw Yorker Gesellschaft mit dem bekannten Theodore Price an der Spitze, zur Ausnutzung erworben wurden. Die Maschine kostet 5000 Dollars und reduziert die Pflückkosten angeblich auf cin Achtel der bisherigen. Aber auch diese Pflückmaschine befindet sich noch im Versuchsstadium.

Als Arbeitstiere im Felde dienen bei den Weißen meist Pferde, bei den Farbigen überwiegend Maultiere. Ein I200 bis I300 Pfund ziehendes Maultier, das bisweilen 30 Jahre Dienste leistet, kostet etwa 200 Dollars; ein Pferd kostet und leistet dasselbe, liefert aber außerdem jedes Jahr ein wertvolles Füllen:

Praktische Pflanzer pflegen auch neben den Arbeitsticren noch 
einiges Vieh zu halten, und zwar sind in aufsteigender Reihenfolge am nutzbringendsten: Rinder, Ziegen, Schafe, Schweine und Hühner, die letzteren also am profitabelsten.

Zurichtung des Bodens. Um zu verhüten, daß die fruchtbare Ackerkrume durch Auswaschung weggeschwemmt werde, ist auf geneigtem Gelände zunächst die Terrassierung des Bodens nötig. Ferner sind die Felder gegen das vielfach frei herumlaufende Vieh einzuzäunen, was oft noch in primitiver Weise durch einfache Holzscheite geschieht, oder aber mit Draht und Holzplanken, was ziemliche Kosten verursacht.

Vorbereitung und Pflügung des Landes in rauhen Furchen sollten im allgemeinen möglichst spät im Frühjahr und nicht schon im Herbst erfolgen, wenn es auch Bedingungen gibt, unter denen das Herbstpflügen vorzuziehen ist, und das Pflügen selbst sollte, um der gewöhnlich 2 bis 3 , unter besonders günstigen Umständen aber bis 4 und 5 Fuß langen Pfahlwurzel der Baumwolle das Eindringen zu erleichtern, möglichst tief, etwa I2 Zoll erfolgen, soweit dadurch nicht unfruchtbares Erdreich an die Oberfläche gebracht wird. Bei der kurz bemessenen Wachstumsperiode der Baumwolle hat ihre Wurzel keine Zeit, allmählich vorzudringen, und man muß ihr deshalb das Eindringen möglichst erleichtern. Im allgemeinen pflügt man nur 4 bis 8 Zoll tief, nur zu häufig erfolgt das Pflügen mit den veralteten Geräten sehr oberflächlich und nur etwa 3 Zoll tief, was nicht genügt. Ein Mann mit einem Maultier pflügt etwa 3 Acres am Tage.

In den Vereinigten Staaten hat man zwei verschiedene Arten der Anlage von Baumwollfeldern: die Hügel- und die Reihenpflanzung.

Bei der $\mathrm{H}$ ügelpflanzung werden nach entsprechender Vorbereitung des Bodens zunächst die Pflanzlinien abgesteckt, deren Abstände je nach der Fruchtbarkeit des Bodens zivischen 3 und $3^{1} \frac{1}{2}$ FuB wechseln. Darauf fährt man an den markierten Linien mit dem Pfluge einmal hin und her, streut den Dünger in die doppelt breite Furche und pflügt diese schwach gehäufelt zu. Alsdann zieht man Querlinien in denselben Abständen der Längslinien und legt in die, die Pflanzstellen bildenden Schnittpunkte je 6 bis 8 Samenkerne, die man ein Zoll hoch mit Erde bedeckt. Wenn die Saat aufgegangen, entfernt man die Pflänzchen bis auf das kräftigste jeder Gruppe; manche Pflanzer lassen wohl auch je zwei Keimlinge stehen. Die Vorteile der Hügelpflanzung bestehen im Vergleich zur Reihenpflanzung darin, daß die Stauden zahlreichere und größere 
Kapseln ansetzen, höher und freier wachsen, weniger unter Rost und Schädlingen leiden und cndlich weniger Handarbeit erfordern, da man von beiden Seiten das Unkraut mit dem Kultivator umpflügen kann.

\section{Weit häufiger aber ist die}

Reihen-oder Kammpflanzung. Je nach der Bodengüte und der gewählten Anbausorte markiert man dabei die Saatfurchen in Abständen von 3 bis $6 \mathrm{FuB}$, öflnet sie durch einmaliges Hin- und Herpflügen, bestreut sie mit Dünger und wirft sie darauf von beiden Seiten mit dem Pfluge wieder derart $z \mathfrak{u}$, daß ein leicht gewölbter Kamm entsteht und zwischen je zwei Kämmen eine breite Furche bleibt, die zur Ableitung des Wassers dient; der Abstand der einzelnen Reihen soll etwas mehr als der durchschnittlichen Höhe der ausgewachsenen Baumwollstaude entsprechen. Die Höhe der Kämme beträgt im allgemeinen etwa ein Fuß, für Sea Island aber bereitet man bis $2 \mathrm{FuB}$ hohe Beete vor. In früheren Zeiten war es allgemein üblich, in die Scheitellinie eines jeden Kammes eine seichte Furche zu ziehen, in die man die Samenkörner mit der Hand einlegte und mit der Hacke zudeckte. Neuerdings verwendet man dazu vielfach besondere Sämaschinen, welche gleichzeitig eine etwa 3 Zoll tiefe Furche öffnen, die Samen, von denen viele nicht aufgehen, in der gewünschten Entfernung, etwa I Zoll auseinander, einzeln hineinfallen lassen und dann durch ein Strichbrett I bis 2 Zoll hoch mit Erde bedecken.

Auf ebenem, gut dräniertem Land, wo kein Wegwaschen des Bodens zu befürchten ist, wendet man auch $F 1$ a ch a us ä en an, und in semi-ariden Gegenden sät man auch in eine frischgezogene Furche $\mathrm{zw}$ ischen den Kämmen aus, um die Saat in feuchten Boden zu bringen.

Praktischerweise wechselt man jedes Jahr beim Pflügen derart, daß die neue Aussaat in die Mitte zwischen die vorjährigen Reihen kommt, womit der Boden wesentlich geschont wird; stellenweise sät man in diese Mittellinien, welche die Baumwolle im nächsten Jahre aufnehmen sollen, nachdem die gesamte Bodenbearbeitung im Sommer eingestellt, noch Kuherbsen als Zwischenfrucht.

Da das Unkraut sich schon im zeitigen Frühjahr einstellt, so wird es gleich mit untergepfügt, wenn man die zur Aussaat nötigen Furchen zieht; namentlich für die frühreifenden Sorten liegt hierin ein Vorteil.

Im allgemeinen legt man die Reihen gern in der Richtung Nord-Süd an, um dem Sonnenschein möglichst freien Zutritt zu 
gewähren und die gegenseitige Beschattung der Pflanzen auf das geringste $\mathrm{Maß}$ zu beschränken. In heißeren Gegenden, wo die Luft trocken und der Regen spärlich ist, empfiehlt es sich aber, falls nicht künstlich bewässert werden kann, die Reihen von Ost nach West zu legen, um durch die Beschattung der Verdunstung der Bodenfeuchtigkeit entgegenzuwirken.

Düngung. Eine sehr wichtige Frage spielt auch in Amerika schon die Düngung.

In den früheren Jahren des amerikanischen Baumwollbaues wurde die Hauptmenge ohne irgendwelche künstliche Düngung erzeugt; war das Land allmählich ausgesogen, so nahm man neues unter Kultur, denn es kostete ja fast nichts. Der einzige Dünger, über den man zur Sklavenzeit verfügte, war Stalldünger, und dieser war verhältnismäßig selten, da die Viehhaltung nicht immer umfangreich war und man die Tiere frei auf die Weide gehen ließ. Dagegen lieferte die in großen Massen vorhandene Baumwollsaat, die damals noch keinen Handels- und Fabrikationswert besaß, im verrotteten Zustand einen vorzüglichen, stickstoffreichen Dung, den man allerdings meist den Körnerfrüchten und anderen Kulturgewächsen, aber nicht dem Baumwollbau zugute kommen ließ. Als das Land allmählich teurer wurde, brachte man stellenweise Fruchtwechsel in Anwendung; aber in der Hauptsache wuchs Baumwolle bis zum Jahre 1860 auf jungfräulichem Boden und war auf dessen natürliche Fruchtbarkeit angewiesen. In der Tat erschöpft Baumwolle den Boden weit weniger als die meisten anderen Feldfrüchte, solange man ihm Stengel und Saat zurückgibt.

Peru-Guano war zwar schon 1845 in Nordamerika eingeführt worden, aber die mit seiner ausschlieblichen Verwendung verknüpften Übelstände hinderten seine stärkere Benutzung, und erst Liebigs bahnbrechende Untersuchungen und die Erschließung der deutschen Kaliläger brachten nach dem Sezessionskriege auch in dem Baumwollbau einen großen Umschwung. Die damals so ernsten Arbeiterschwierigkeiten einerseits, der vielfach ausgesogene Boden anderseits machten eine bequem $z \mathfrak{u}$ bewirkende Aufbesserung des Bodens durch konzentrierten künstlichen Dünger besonders zeitgemäB, und von da ab sind mit Ausnahme der Alluvialfächen an großen Flüssen und der frisch unter Kultur genommenen Ländereien - Texas z. B. wendet noch heute im allgemeinen weder Rotation noch Kunstdünger an - alle Baumwollfelder der Vereinigten Staaten mit konzentriertem Kunstdünger behandelt worden. Ausgesogenes Land wurde dadurch wieder kulturfähig, und überdies 
kürzte diese Düngung die Entwicklungsperiode der Pflanze ab und dehnte so die klimatischen Grenzen ihres Anbaues aus. Besonders seitdem die Baumwollsaat ab Ende der yoer Jahre mehr und mehr in die Olmühle wanderte, $\mathrm{mu} \beta \mathrm{te}$ für künstliche Düngung gesorgt werden, und neuerdings ist Kunstdünger auch auf der kleinsten Negerfarm üblich geworden.

Der Ge bra $\mathrm{c} \mathrm{ch}$ des Düngers ermangelte allerdings vielfach wissenschaftlicher Grundlage und war planlos; anderseits lieferten gewissenlose Händler unter allerlei Phantasienamen mehr oder weniger wertloses Material und diskreditierten dadurch künstliche Dungmittel überhaupt, so daß auch die meisten Baumwollstaaten, dem Beispiel einiger nördlicher Staaten folgend, ab I888 eine amtliche Kontrolle des Handelsdüngers einführten, Minimalsätze der wertvollen chemischen Bestandteile und genaue Bezeichnung derselben vorschrieben, so daß man Kunstdünger heute nach garantierten Analysen kauft. Falsche Angaben seitens der Händler werden mit sehr hohen Geldstrafen geahndet. Als Entgelt für die staatliche Untersuchung wird eine Abgabe erhoben, die allerdings einerseits die Landwirtschaft belastet, ihr aber indirekt dadurch wieder zugute kommt, daß diese Einnahmen zur Unterhaltung der Agricultural and Mechanical Colleges in den verschiedenen Bundesstaaten dienen.

Tiefe und sorgfältige Bodenbeackerung erzeugt starke Stengel und kräftigen Blattwuchs, aber an und für sich allein noch keinen reichen Fruchtansatz; dazu hilft vielmehr wesentlich eine geeignete Düngung; diese erfolgt heute durch folgende Stoffe: Stalldung; Kompost; getrocknetes Blut, Knochen und andere Abfälle des Schlachthofs; getrocknete Fischabfälle, Nebenprodukte der Fischtran- und Fischkonservenfabriken, ebenso wie die Schlachthofabfälle Stickstoff und Phosphor enthaltend; Baumwollsaat oder ihr Aquivalent in Baumwollsaatmehl; Baumwollstoppeln, welche vom Acre etwas über eine halbe Tonne Gewicht ergeben und etwa I5 Pfund Stickstoff enthalten; Gründüngung, wobei man Kuherbsen, Luzerne und Raigras bevorzugt; die Hauptsache aber bildet heute der Kunstdünger. Auswahl, Menge und Mischung dieser einzelnen Düngemittel sind je nach den Boden- und Klimaverhältnissen und den gewählten Anbausorten wesentlich verschieden und sehr sorgfältig abzuwägen; die Wissenschaft beschäftigt sich auch in Amerika eingehend mit diesen Problemen, um sie je nach lokalen Bedingungen und Bedürfnissen best- und billigstmöglich zu lösen. Die Hauptdungstoffe wirken folgendermaßen: 
Stickst of $f$ treibt die Pflanzen zu raschem Wachstum und $\mathrm{zu}$ zahlreicher Blattbildung an und fördert dadurch im allgemeinen auch eine Vermehrung der Erträge. Er wird geliefert durch Chilisalpeter, Baumwollsaatmehl, tierische Abfälle, Anpflanzung von Leguminosen und Gründüngung.

Phosphorsäure fördert reichen Fruchtansatz und beschleunigt die Reife der Kapseln; sie wird geliefert durch Thomasmehl und die Superphosphate im Lande selbst, das reiche Läger davon in den Staaten Süd-Carolina, Tennessee, Florida, Arkansas und Idaho besitzt.

$\mathrm{K}$ a $1 \mathrm{i}$ endlich vermehrt in Form von Kainit die Größe des Stengels, macht ihn kräftiger, bewirkt längere Verzweigungen und bringt die Frucht zu einer vollkommeneren Entwicklung. Lieferant der Kalisalze ist bislang Deutschland, man hofft aber in der Union, auch darin unabhängig vom Auslande zu werden, sei es durch Entdeckung von Kalilägern im eigenen Lande, von der in den letzten Jahren wiederholt die Rede war, oder durch eine wissenschaftlichpraktische Ausnutzung der Massen von Riesen-Tang pflanzen, welche die pazifische Küste von Mexiko bis Alaska begleiten, und deren reicher Gehalt an Kalisalzen für Ackerbauzwecke nutzbar gemacht werden soll.

Was die Z e it der Düngung anbetrifft, so erfolgt sie meist eben vor der Aussaat; gut vorbereitete Böden werden stellenweise zur Hälfte bei der Aussaat, zur anderen Hälfte des aufzuwendenden Gesamtquantums bei der zweiten Umackerung gedïngt. Im allgemeinen sollten die Düngemittel nicht tiefer als 2 bis 3 Zoll eingebracht werden, und nur bei trockenen Böden tiefer.

Gewöhnlich rechnet man in den Vereinigten Staaten auf den Acre Baumwolland 200 bis 500 Pfund Kunstdünger, geht aber auch bis zu rooo Pfund und mehr. Der Wert der Tonne schwankt zwischen 14 und 32 Dollars, und bei einem Durchschnittspreis von I8 Dollars stellen sich die Kosten des Kunstdüngers auf I bis 2 Cents für das Pfund erzeugter Baumwolle.

Bei reichlicher und sachgemäßer Düngung nimmt Baumwolle mit sehr nährstoffarmem Boden günstiger physikalischer Beschaffenheit vorlieb; inwieweit ihr Anbau unter solchen Verhältnissen noch lohnt, ist nur durch Berechnung zu entscheiden, und jeder Farmer probiert das am besten selbst durch sorgfältige Versuche aus.

Den stärksten Verbrauch an Kunstdünger in den Vereinigten Staaten überhaupt weisen gerade die Südstaaten auf, welche davon 
allein für Baumwolle im Jahre 19 Io nicht weniger als 2 I65 ooo $\mathrm{t}$ verbrauchten; davon kamen auf

\begin{tabular}{|c|c|c|c|c|}
\hline Süd-Carolina & Georgia & Alabaina & Nord-Carolina & Mississippi \\
\hline \multicolumn{5}{|c|}{ Tausend Tons } \\
\hline 687 & 567 & 500 & 189 & 93 \\
\hline Louisiana & $\mathrm{Arl}$ & s e n d & exas & rida \\
\hline
\end{tabular}
30

26

I7

Manche Sorten Kunstdünger werden dem Farmer unter dem sogenannten ,cotton option plan" verkauft, wonach er die IVare im Frühjahr bezieht und im Herbst entweder in bar oder in einer vorher bestimmten Menge Baumwolle bezahlt.

In den wasserarmen Staaten des Südens und Westens der Union wird seit Jahren das , $\mathrm{Mulch}$ in $\mathrm{g}^{\prime \prime}$ angewandt, d. h. das Bedecken des Bodens mit Laub und gemähtem Gras, und zwar die Bedeckung nicht zu dicht, damit das Regenwasser nicht verhindert wird, bis an die Wurzeln der Pflanzen zu gelangen. Das ,Mulching““ dient hauptsächlich zur Erhaltung der Humusschicht im Boden und zur Bodenbereicherung, da in subtropischen Gegenden die Assimilation pflanzlicher Reste schon recht schnell erfolgt, während dic Bodenbedeckung gleichzeitig die Wasserverdunstung des Bodens während der Trockenzeit verhindert.

Aussaat. Die richtige Auswahl der für die verschiedenen Gegenden passendsten Arten, worüber im Kapitel Saatwahl gesprochen, ist überaus wichtig, und man hat sich damit überall den lokalen Bedingungen anzupassen. Ist dann eine geeignete Sorte ausprobiert und bewährt, so hat man die Saat für die nächste Ernte immer von der ersten Pflücke der stärksten Pflanzen und von den größten, vollausgereiften Kapseln der gewünschten Art Baumwolle zu nehmen. Selbst von ausgereiften und sorgfältig behandelten Samen bleibt stets ein beträchtlicher Prozentsatz taub; bei nicht vollständig ausgereiften oder sonst minderwertigen Samen erhöht sich dieser Prozentsatz unter Umständen so bedeutend, daß das betreffende Feld umgepflügt und mit Mais oder einer anderen schnell wachsenden Sommerfrucht bestellt werden muB, falls es im laufenden Jahre überhaupt Nutzen gewähren soll. Leider lassen es aber noch immer, trotz Experimental Stations und Wanderlehrern, viele amerikanische Farmer bei Auswahl der Saat an der nötigen Sorgfalt fehlen, kaufen ihre Saatmengen bei der Entkernungsanstalt oder der Olmühle, wo keine Aussonderung nach Güte stattfindet 
und die Samen verschiedener Arten nicht selten durcheinanderkommen. Die von diesem Gemisch aufgehenden Pflanzen können natürlich kein gleichmäßiges Ergebnis liefern.

Die Aussaat erfolgt baldmöglichst, nachdem kein Frost mehr zu befürchten ist, beginnt in Süd-Texas schon gegen den 25. Februar, unter den Bergen Georgias erst am 20. Mai; auf den reichen Mississippi-Ländern gibt nach starken Uberschwemmungen erst spät im Juni ausgepflanzte Baumwolle auch noch eine gute Ente. Zur Aussaat benutzt man heute meist eine einfache Sämaschine, welche mit einem Arbeiter und einem Maultier 6 bis 8 Acres am Tage bestellt, während mit der früheren Handbestellung ein Acre am Tage eine gute Leistung bildete. Häufig ist es nötig, die Saat in Asche, Staub oder Kalk einzurühren, um ihr Zusammenballen zu verhindern. Bei je einem Samen auf den laufenden Zoll und bei $4 \mathrm{FuB}$ gegenseitigem Abstand der Reihen kommen etwa I3 I ooo Samen auf den Acre oder, da durchschnittlich 5000 Samen ein Pfund wiegen, auf den Acre 26 Pfund Saat, also fast I Bushel von $35^{1 / 4}$ Liter. Von Upland-Saat wiegt das Bushel 30 bis $33^{1 / 3}$ Pfund. Mancherorts braucht man aber bis zu 2 Bushel auf den Acre und lichtet dann stärker aus, während man andererorts wieder mit I 5 Pfund Saat auf den Acre auskommt. Baumwollsaat ist billig, und so geht man im allgemeinen verschwenderisch mit ihr um, besonders da ja auch viele Kerne nicht aufgehen.

Nach 3 bis Io Tagen erscheinen die beiden Keimblätter der aufgehenden Saat. Wenn sich in der zweiten bis vierten Woche das dritte Blatt zeigt und die Pflanze etwa 5 Zoll hoch ist, beginnt das A usdünnen (chopping), um die Pflanzen auf die gewünschte Standweite zu bringen; die Ansichten darüber, was dabei das Richtige ist, sind sehr verschieden, und die Entfernungen der einzelnen Pflanzen innerhalb der Reihen schwanken, je nach Bodengüte und der gewählten Anbauart, ungefähr zwischen 9 Zoll und 3 Fuß. Ein Abstand von 15 bis 24 Zoll scheint das Praktischste und eine Dichtigkeit von Io ooo Pflanzen auf den Acre etwa der Durchschnitt zu sein. In Nordamerika läßt man, im Gegensatz zu Ägypten, im allgemeinen in jedem Pflanzloch nur ein e Pflanze stehen, nur selten sieht man hier zwei Pflanzen in einem Busch zusammen. Das Chopping selbst erfolgt mit Jätemaschinen oder mit der Hacke, und ein Mann bearbeitet mit letzterer 2 Acres, mit ersterer etwa 8 Acres am Tage. Praktischerweise nimmt man das Ausdünnen nicht auf einmal vor, sondern verteilt es, der verschiedenzeitigen Entwicklung der Pflänzchen entsprechend, auf zwei Io bis 
I2 Tage voneinander getrennte Prozeduren. Bei diesen wie bei den folgenden Arbeiten gilt es besonders, die feinen, wagerechten Wurzeln der stehenbleibenden Pflanzen, welche sich in einer Tiefe von 2 bis 9 Zoll erstrecken, nicht zu beschädigen.

Weitere Pflege während des Wachstums. Es beginnt nämlich nunmehr, also von der dritten bis vierten Woche nach der Aussaat $a b$, eine Bodenbearbeitung, deren Zweck es ist, das Land locker und von Unkraut freizuhalten. Keine Kulturpflanze verlangt einen von Unkraut reineren Boden als Baumivolle; das Lockern des Bodens aber bricht die Kapillarität der Oberfläche und erschwert dadurch die Ausdünstung. Dabei sei das Motto: „Tief pflügen, aber seicht lockern“. Diese Bearbeitungen erfolgen je nach Bodenbeschaffenheit und Wetter etwa drei- bis fünfmal und öfters in Zeitabständen von je anderthalb bis drei Wochen, $d$. $h$. bei trockenem Wetter bis ungefähr Anfang August, und werden zwischen den Reihen in deren Längsrichtung von Kultivatoren verschiedener Systeme ausgeführt; daneben hält man es stellenweise noch für angebracht, auch den Boden zwischen den einzelnen Pflanzen in $\mathrm{n}$ e $\mathrm{rh}$ a $1 \mathrm{~b}$ der Reihen mit der Hacke zu reinigen, was mit besonderer Vorsicht zu geschehen hat.

Die hauptsächlich gefürchteten Unkräuter sind das böse Johnson-Gras oder Guinea-Gras (Sorghum halepense), das man am besten durch Abweiden mit Schafen niederhält, wodurch die fleischigen Wurzeln absterben; ferner das Coco- oder Nut-Gras (Cyperus rotundus) und das im ganzen Baumwollgürtel vorkommende Crab-Gras (Panicum sanguinale).

Nebenher gehen noch einige Eventualarbeiten.

Falls nach dem Ausdünnen später Frost oder Schneidewürmer die jungen Keimlinge so empfindlich stören, daß die oft noch mögliche Wiedererholung und Kräftigung ausgeschlossen scheint, so müssen die notleidenden Stellen nachgepflanzt werden. Als alle Aussaat noch mit der Hand erfolgte, geschah natürlich auch das Nachpflanzen mit der Hand. Heute besorgt es allgemein die Sämaschine, welche den ganzen Feldteil billiger frisch bestellt, als die Ausbesserung einzelner Stellen mit der Hand kosten würde.

Setzt späterhin die Pflanze mehr Holz als Frucht an, so wird die Wurzel vermittels eines Pfluges, der bis dicht an den Stamm pflügt, beschnitten, und ein Zusatz von Phosphaten kann die Ernteaussichten sehr verbessern. Ein Beweis für gute Kultur liegt weniger in der absoluten Höhe der Pflanze, als in der Gleichmäßigkeit der Höhe und des Wuchses. 
Sehr verschiedene Ansichten und Ergebnisse werden über das Entköpfen der Baumwollstaude berichtet. An manchen Orten bricht man weniger kräftig entwickelten Pflanzen die Triebspitze aus, um die seitliche Ausdehnung und damit reiche Verzweigung und Knospenansatz möglichst zu fördern; anderwärts hat sich dieses Verfahren gar nicht bewährt.

Nach der letzten Bodenlockerung ist die eigentliche Ackerarbeit beendet und nunmehr Ruhe bis zur Zeit der Ernte; diese stille Periode nennt man "lay by".

Inzwischen haben sich etwa einen Monat nach der Aussaat dic crsten Knospen gezeigt; ungefähr drei Wochen später öffnen sich an der jetzt I5 Zoll hohen Pflanze die ersten Blüten, welche am dritten Tag abfallen und einen erbsengroßen Samenknoten hinterlassen; nach weiteren etwa 45 bis 50 Tagen ist die Samenkapsel an der nunmelir durchschnittlich $4 \mathrm{FuB}$ hohen Staude voll entwickelt. Das Reifen der Kapsel beansprucht einen bis zwei Monate. Durchschnittlich dauert es I25 Tage von der Aussaat bis zum Öffnen der ersten Kapseln, aus denen dann die daunenartige weiße Umhüllung der Samenkerne, die „Baumwolle“, elastisch herausquillt.

Von der Aussaat bis zur Reife vergehen also ungefähr fünf Monate, und zwar rechnet man durchschnittlich bei

$$
\text { von Saat zur Blüte von Blüte zur Reife Total }
$$

$\begin{array}{lccc}\text { New Orleans-Baumwolle } & 80-90 & 70-80 & \text { I50-I70 Tage } \\ \text { Sea Island-Baumwolle } & 100-110 & 80 & \text { I } 80-190 ",\end{array}$

Wie alle Malvaceen, treibt auch die Baumwolle monatelang Blüten, so daß Knospen, Blüten und reife Kapseln meist gleichzcitig an derselben Staude zu sehen sind.

Die Entwicklung der $\mathrm{F}$ a se $\mathrm{r} \mathrm{n}$ beginnt an dem entgegengesetzten Ende, an dem die Samen innerhalb der Kapsel angeheftet sind, und breitet sich von da allmählich über die ganze Oberfläche aus. Die Baumwollfasern erscheinen eine beträchtliche Zeit, bevor die Samen ihre volle Größe erreicht haben und wachsen durch eine allmähliche Verlängerung der Zellen, bis die Samenkapsel schließlich mit einem Gewirr von jungen Baumwollfasern angefüllt ist, deren Wachstum und Vermehrung mit zunehmender Reife und Kräuselung der Faser das Öffnen der Kapselklappen unterstützt. Die Länge der Fasern zeigt an verschiedenen Stellen des Samens beträchtliche Verschiedenheiten, und es scheint zweifelhaft, ob sie ihre volle Länge erreichen, bevor sie nach Offnung der Kapseln der 
reifenden Wirkung von Luft und Sonne ausgesetzt sind. Als Regel werden die längsten Fascrn da gefunden, wo sich ihre ersten Zellen cntwickeln, nämlich am Scheitel des Samens; an seinem Grundc sitzen die kürzesten Fasern. Man unterscheidet unreife, vollreife und überreife Fasern, von denen die ,vollreifen“, welche die Farbstoffe am willigsten aufnehmen, als Grundform des Handels zu bezeichnen sind.

Ernte. Die Pflückzeit beginnt in Süd-Texas am 10. Juli, in Nordwest-Texas erst am I. Oktober und währt im allgemeinen bis Anfang Januar, erstreckt sich aber am Mississippi und am Red River zuweilen bis März hinein. Die Art der Kapselöffnung ist bei den verschiedenen Spielarten sehr verschieden; einige öffnen ihre Kapseln frei, andere in einer solchen Art, daß die Flocke fest anhaftet; das letztere ist beliebt in windigen Lagen oder wo man die Ernte nicht schnell vornehmen kann.

Die Ernte beginnt, wenn so viele Kapseln aufspringen, daß ein Arbeiter täglich mindestens 50 Pfund Saatbaumwolle sammeln kann. Das P f 1 ü $\mathrm{ck}$ en geschicht noch heute überall, wie in der Anfangszeit, mit der Hand, erfordert also eine große Zahl Arbeiter; während ein Mann leicht 20 bis 30 Acres bestellen kann, bedarf es vier bis fünf guter Arbeiter, um die Ernte davon rechtzeitig zu pflücken. Es ist unter diesen Umständen noch ein Glück, daß die Reife der einzelnen Pflanzen, ja der einzelnen Kapseln an derselben Staude, so ungleichmäbig erfolgt und die Ernteeinheimsung sich also über 90 bis Ioo Tage verteilt. Im allgemeinen wird die Ernte dreimal gepflückt, in Intervallen von je einem Monat; aber je nach der Reife und der Zahl der verfügbaren Arbeitskräfte gibt es zwci bis fünf Pflückperioden; bei Arbeitermangel bleibt die Baumwolle so lange im Felde, bis sie auf einmal gepflückt wird, und es kommt unter solchen Verhältnissen vor, daß die Ernte mangels genügender Pflücker überhaupt nicht ganz eingebracht werden kann. Der Amerikaner Hall soll neuerdings ein Mittel erfunden haben, um dic Baumwolle künstlich zur Reife zu bringen, was vor allem den Vortcil bringen würde, daß die Ernte auf einmal geschehen könntc. (?)

Nach der Höhe der Zweige unterscheidet man lower, middle und top crop; erstere ist die frühzeitigste und beste, letzterc gewöhnlich schon durch Regen und Frost gefärbt und fleckig, also minderwertig, wenn auch noch brauchbar.

Wichtig ist, daß die Saatbaumwolle möglichst $r$ e i n gesammelt werde, frei von Kapselteilen und Blättern und nicht feucht. Man pflückt also nur bei trockenem Wetter und möglichst bald nach 
Austreten der Flocke aus der Kapsel. Die Iceren Kapselschalen läßt man beim Pflücken stehen, weil sie leicht zerstückeln und sich dann schwer von der Baumwolle trennen.

Der aus den Kapseln hervordringende weiße Flaum wird in Säcken gesammelt, die auf der Schulter getragen werden; sorgsame Pflanzer lassen an jedem Sack eine Seitentasche anbringen, in welcher die Pflücker diejenige Baumwolle stecken müssen, die beschädigt oder sonstwie fehlerhaft ist. Die Säcke werden nach ihrer Füllung in Körbe geleert, die am Ende der Reihen stehen, und von hier aus erfolgt der Transport der Saatbaumwolle in Maultierkarren entweder nach dem Lagerhaus der Farm, meist aber direkt nach der Entkernungsanstalt, deren Tätigkeitsradius lohnenderweise bis ctwa $20 \mathrm{~km}$ Entfernung reicht. Auf den Boden gefallene und beschmutzte Baumwolle sollte separat cingesammelt und geginnt werden.

Das T a g e s $\dot{q} \mathfrak{u}$ a $\mathrm{n} t \mathfrak{u m}$, welches eine Person pflücken kann, ist sehr verschieden; viele bleiben $u n t$ e $r$ Ioo Pfund, bei günstigen Verhältnissen wird eine Leistung von 300 und 400 Pfund erreicht; als Durchschnittsertrag rechnet man für einen Erwachsenen etwa Ioo Pfund. Für die an und für sich nicht schwere Arbeit des Pflückens eignen sich Frauen und Kinder am besten, weil sie eine leichtere Hand haben und sich nicht so tief zu bücken brauchen.

Auch der Pflücklohn wird für je Ioo Pfund abgelieferter Saatbaumwolle berechnet, und zwar schwankt derselbe in den verschiedenen Staaten zwischen 40 und Ioo Cents. In Georgia bezahlte man in der Letztzeit 42 , in Mississippi 50 , in Texas 66 , in Oklahoma 75 Cents. Nimmt man den mittleren Lohn von 75 Cents für ıoo Pfund Saatbaumwolle $=33$ Pfund entkernter oder Lintbaumwolle an, so entfallen auf das Pfund verkaufsfertiger Baumwolle allein 2,2 Cents für das Pflücken, und dieses bildet mithin nicht nur den langwierigsten, sondern auch weitaus den kostspieligsten Teil des Baumwollbaus überhaupt. Boden und Klima ermöglichen z. B. auch in Kalifornien sehr wohl Baumwollbau; aber die dort üblichen Tagelöhne von $1 \frac{1}{2}$ bis $21 / 2$ Dollars belasten Baumwolle allein für das Pfücken mit $71 \%$ Cents für das Pfund, und damit entfällt vielfach die Möglichkeit einer lo hn en d en Kultur.

Die zahlreichen Kapseln, welche gegen Ende der Saison vom Froste beschädigt sich nicht öffnen, ließ man früher ganz unbeachtet. Nachdem zuerst ein Farmer in Texas, wo früher Frost sonst viele Kapseln ungeöffnet ließ, im Jahre 1903 erfolgreich den 
Versuch unternommen hatte, diese Kapseln durch die Dreschmaschine laufen zu lassen, haben die hohen Baumwollpreise der letzten Jahre zur Erfindung einer Maschine angeregt, welche die Saatkerne aus diesen Kapseln ausdrischt, worauf der sonstige Kapselinhalt in der Ginnerei genau so behandelt wird wie handgepflückte Baumwolle. Die Herstellung dieser, ,Bollies“ genannten Baumwolle nimmt besonders im Westen stark zu und der Wert dieses Produkts beträgt etwa $3 / 4$ vom Preise gewöhnlicher „,Linters“.

Tritt der erste starke Frost ein, so fallen die Blätter der Baumwollpflanze $a b$, und es bleiben bloß noch leere Gerippe stehen, deren Gewicht auf ein Stück Land mit $1 / 3$ bis I Ballen Ertrag etwa 600 bis I80o Pfund ausmacht. Gewöhnlich läßt man diese Reste, nach der letzten Pflückung, durch Vieh abweiden, welches die Äste und die leeren Kapselschalen abfrißt. Der übrig bleibende Teil wird durch fortgesetzte Fröste immer härter und brüchiger, und die Stoppeln werden dann entweder umgehauen oder ausgerissen und verbrannt, wonach man die Asche gleichmäßig über das Feld verteilt; oder man pflügt die Stoppeln unter, am besten, nachdem man sie vorher mit einem Stalk-Cutter, der Io Acres am Tage bearbeitet, in fußgroße Stücke geschnitten hat. Bei der letzteren Methode wird die beim Verbrennen eintretende Vergeudung von Nährstoffen vermieden; das Verbrennen ist aber überall da vorzuziehen, wo man auf Vernichtung vorhandener tierischer und pflanzlicher Schädlinge Bedacht nehmen muß.

\section{Baumwoll-Krankheiten und -Schädlinge.}

Die Baumwoll-Krankheiten sind dreierlei verschiedener Natur. Sie stammen

I. aus physiologischen Ursachen, durch Störungen in der Ernährung und Assimilation, wie: die Mosaikkrankheit oder der Gelbe Blattrost; der Rote Blattrost; die winklige Blattfleckenkrankheit und das Abfallen der Kapseln.

2. folgen die Pilzkrankheiten an Wurzeln, Stengeln, Blättern und Kapseln, darunter besonders die gefährliche WelkKrankheit (Wilt Disease). Endlich

3. die Wurzel-Gallen, die durch Wurzelälchen (Nematoden) verursacht werden.

Diese Krankheiten treten stellenweise recht bedenklich auf, richten im großen und ganzen aber doch nur verhältnismäßig wenig Schaden an. Ihre Bekämpfung besteht im wesentlichen darin, die 
Konstitution der Pflanzen zu stärken; so hat man z. B. gegen den Rost, die bedenklichste Krankheit, mit Èrfolg Kainit-Düngung angewandt.

Weit verhängnisvoller als dic Baumwoll-Krankheiten aber sind die tierischen

Baumwoll-Schädlinge. Die Beschädigungen können erfolgen an den:

Wurzeln durch Wurzelälchen, Grillen, Erdraupen, Drahtwürmer und Engerlinge;

Stämmen durch Stammringler, Stammbohrer, Stengelspitzenbohrer, Woll- und Schildläuse;

B 1 ättcrn durch Schnecken, Heuschrecken, Raupen, Käfer, Wanzen, Blattläuse und Milben;

$B I$ üt en durch Raupen und Käfer;

K a p s e 1 n durch „Kapselwürmer", d. h. Raupen, und durch die Kapselkäfer, die sich in die Kapseln einbohren und durch Fraß und Exkremente Wolle und Samen zerstören; ferner durch Wanzen, welche die Faser beschmutzen und den Samen aussaugen; endlich durch Eichhörnchen und Ratten, welche die Fasern herausreiben und die Kerne aus den Kapseln herausfressen.

Im ganzen sind in den amerikanischen Baumwollfeldern gegen 500 verschiedene Arten Insekten beobachtet worden, wovon viele auch andere Kulturen besuchen und nur wenige der Baumwollpflanze oder der Ernte wirklich gefährlich werden.

In der gesamten baumwollbauenden Welt sind am meisten gefürchtet diejenigen Tiere, welche in den Kapseln leben und so die Faser direkt vernichten, also die Kapselwürmer und die Kapselkäfer.

Bis in die goer Jahre des letzten Jahrhunderts kannte man in den Vereinigten Staaten nur zwei ernstliche Schädlinge, den „Cotton leaf worm" und den "Cotton Boll Worm“.

Die olivgraue Motte des

"Cotton leaf"worm" oder "Cotton Caterpil1ar" (Aletia argillacea) beginnt zwei bis vier Tage nach dem Auskriechen ihre Eier, im ganzen 300 bis 600 , an den Blättern abzulegen. Die Raupe erscheint nach wenigen Tagen, lebt eine bis drei Wochen, nährt sich besonders von den Blättern, benagt zuweilen aber auch zarte Triebe und Kapseln. Sie verpuppt sich oberirdisch und verbleibt in diesem Stadium eine bis vier Wochen. Das Insekt liefert in der Saison fünf bis sieben Generationen, stirbt in den nördlichen 
Staaten während des Winters ab, überwintert aber in erstarrtem Zustand an geschützten Plätzen der Südstaaten. Die Raupe ist erfolgreich mit Arsenikbehandlung bekämpft worden, und ihre Bedeutung ist sehr zurückgegangen mit der vergrößerten Mannigfaltigkeit der Anbaupflanzen.

Der "Cotton Boll Worm" (Heliothis armiger), die Kapselraupe, ist nicht, wie die Aletia, auf Amerika beschränkt, sondern in vielen anderen Weltgegenden und auf sehr verschiedenen Futterpflanzen vertreten. Die gelbliche Motte legt etwa 500 Eier an alle Teile der Baumwollpflanze, besonders aber an die Unterseite der Blätter. Die Raupen erscheinen in zwei bis sieben Tagen und nähren sich zunächst von den jungen Blättern, bis sie junge Knospen oder Kapseln antreffen, in die sie als Zerstörer eindringen. Sie leben zwei bis vier Wochen, verpuppen sich dann für eine bis vier Wochen Dauer im Boden und liefern im Jahre etwa fünf Generationen. Thre Bekämpfung erfolgt hauptsächlich durch Fangpflanzen in Zwischenkulturen von Mais.

Außer diesen beiden waren bis zum Auftreten des Boll-Weevils keine ernstlichen Baumwollinsekten in den Vereinigten Staaten vertreten. Schneidew ürmer, besonders der Arten Feltia und Agrotis, schädigen zuweilen am Anfang der Saison die jungen Pflänzlinge; man bekämpft sic crfolgreich durch Vergiftung mit Pariser Grün. B la t t 1 ä use, mcist Aphis gossypii, verursachen gelegentlich, meist zu derselben Zeit wie die Schneidewürmer, das Welken der jungen Endblätter. Mehrere Wanzen arten (Dysdercus) stechen die jungen Kapseln an, aber nie in großem Umfang. Eine Reihe von $\mathrm{Heuschrecken}$ arten und eine $\mathrm{Ame}$ isenart (Oecodoma fervens) verwüsten zuweilen die Blätter in Texas; man vernichtet die Ameisen durch Petroleum. Der Southern Grass Worm (Laphygma frugiperda) verursacht nach feuchtem Frühjahr nennenswerten Schaden durch Zerstörung von Blättern, Knospen und Kapseln, und daneben gibt es noch verschiedene andere sich von Blättern nährende Raupen und Stengelbohrer.

Kein Schädling hat bisher aber größere Verwüstungen angerichtet und steht so im Mittelpunkt des allgemeinen Interesses, wie der

Boll Weevil oder mexikanische Baumwollkapselkäfer (Anthonomus grandis), der zuerst 1862 in Mexiko beobachtet, I880 dort in Monclova als ernster Baumwollschädling beschrieben wurde, immer weiter nordwärts vordrang; spätestens 1892 über den Rio Grande del Norte bei Brownsville auch in das Gebict der Ver- 
cinigten Staaten eingedrungen war und sich in Texas bereits in Jahre I894 als gefährlicher Feind der Baumwolle erwies. Das entomologische Staatsbureau von Texas riet damals an, den Baumwollbau für einen Landstrich längs des Rio Grande zu verbieten, um der Weiterverbreitung des Kapselkäfers Schranken zu setzen. Es hat sich bitter gerächt, daß dieser Vorschlag unbeachtet blieb; denn nun machte das Vordringen des Insekts jedes Jahr reißende Fortschritte: I904 griff die Invasion auf Louisiana über, Igo6 erreichte sic Oklahoma und Arkansas, überschritt in 1907 den Mississippistrom, I9I I wurden Alabama und Florida erreicht, und der durch den Kapselkäfer verursachte Schaden wurde allein im Jahre I909 auf I 1/4 Millionen Ballen Baumwolle berchnet. Der Schädling sucht jetzt reichlich ein Drittel der gesamten Baumwollfäche der Union heim und reduziert, wo er auftritt, die Ernte stellenweise bis auf die Hälfte und noch weniger.

Der nur knapp 1/4 Zoll lange braune Käfer lebt ausschlieBlich auf Baumwolle, nährt sich zunächst nach seiner Uberwinterung von den jungen Triebspitzen, legt seine Eier außen an die Knospen und Kapseln $a b$, und die bald erscheinenden Raupen fressen sich entveder in die Knospen oder, wenn die Eier an den Kapseln abgelegt, mit Vorliebe in die Samenkerne ein. Die befallenen Knospen fallen gewöhnlich ab, die meisten beschädigten Kapseln aber bleiben sitzen und verkrüppeln, mit Ausnahme der Spätsaison, wo sie entweder eintrocknen oder verfaulen. Die Verpuppung findet innerhalb der Knospen oder Kapseln in einem festen Kokon statt, in dem die abgestreifte Haut, Exkremente und Baumwollfasern versponnen sind; sehr häufig ähneln die Kokons den Baumwollsamen in ihrer äußeren Erscheinung so sehr, daß sie damit verwechselt werden können. Es kommt auch vor, daß die Larve einen Saatkern vollständig aushöhlt und sich dann darin verpuppt. Das Puppenstadium dauert 2 bis 14 Tage, die Zeit vom Eierlegen bis zum Auskriechen des Käfers I5 bis 25 Tage, je nach der Wärme. Die Lebensdauer der erwachsenen Tiere unterliegt großen Schwanxungen, wurde im Maximum bis zu 335 Tagen, im Durchschnitt mit 62 Tagen ermittelt. Die Vermehrung des Käfers ist stark von der Witterung abhängig; heiße, trockene Sommer töten eine Unmasse Larven, da sie keine Widerstandsfähigkeit gegen intensive Sonnenstrahlung besitzen, in kalten Wintern gehen zahlreiche Käfer ein; feuchte Sommer dagegen und milde Winter sind der Vermehrung günstig. Durchschnittlich rechnet man drei bis fünf Generationen im Jahr, und jedes Weibchen legt etwa I40 Eier. 
Der Kampf gegen den Boll Weevil ist mit großer Energie und wissenschaftlicher Gründlichkeit aufgenommen worden, fängt nach vieler Arbeit aber erst allmählich an, greifbare Resultate zu zeigen. Das Bespritzen mit giftigen Brühen blieb erfolglos, da der Käfer sein Vernichtungswerk innerhalb der Kapseln ausübt, und ein Radikalmittel gegen das Insekt ist bislang iiberhaupt nicht gefunden worden. Dagegen erscheinen günstig alle Maßnahmen, welche auf Erzielung früher Reife und Kräftigung der Pflanze abzielen, also früher Beginn der Pflanzzeit, Wahl frühreifer Sorten, saubere Kultur, geeignete Düngung, Ermöglichung reichlicher Besonnung durch weiten Abstand der Pflanzreihen, daneben die Heranziehung von Parasiten und Raubinsekten durch Anbau von Futterpflanzen jener Wirte bei den Baumwollfeldern. Sodann sind vom Ackerbauamt in Washington bislang etwa 60 Vogelarten festgestellt worden, welche für die Vertilgung des Baumwollkapselkäfers in Frage kommen, und zwar kommen dabei in erster Linie Pirol, Schwalbe und Ziegenmelker in Betracht. Besonders wichtig ist auch die Vernichtung der abgefallenen, vom Kapselkäfer bewohnten Knospen und das Verbrennen der Baumwollstoppeln im Herbst, um damit zahlreiche Eicr, Raupen und Puppen zu töten und den Weibchen Futter- und Brutplätze zu nehmen.

Wichtige Dienste leistet bei der Insektenbekämpfung das im Jahre 1862 als Abteil des Ackerbaumamts geschaffene, I904 mit zunehmender Erkenntnis seiner Bedeutung zum Range eines Bureaus erhobene

Burea u f Entomology in Washington, das mit seinen acht Untersektionen im Jahre I9IO 623 Angestellte, darunter I3 I wissenschaftlich gebildete Entomologen und daneben etwa I2000 Korrespondenten im ganzen Lande zählte. Überall, wo es Schädlinge zu bekämpfen gilt, erscheinen Abgesandte des Bureaus am Platze, um den Kampf zu organisieren und in den heimgesuchten Gegenden selbst wissenschaftliche Arbeitsstätten, "field stations", "zu eröffnen. Die ,Section for southern field crop insect" umfaßt Baumwolle mit der Zentralarbeitsstelle Dallas in Texas.

Neben dieser Einrichtung des Bundes besitzen heute fast sämtliche Einzelstaaten ihre besonderen amtlichen entomologischen Experten und Stationen.

Die bekannten B ekämpfungsmethoden, teils mechanischer, teils biologischer Art, sind sämtlich auch in den Vercinigten Staaten ausprobiert worden und bestehen in: I. Giftwirkung, 2. Einsammeln und Vernichten mit der Hand, 3. Einfangen 
durch Fangpflanzen und Lichtfallen, 4. Bekämpfung durch natürliche Feinde und Krankheiten, 5. Züchtung immuner Rassen, 6. Änderung der Kulturmethoden (Zeitpunkt der Aussaat und Ernte, Zwischenkulturen, Beseitigung der Ernterückstände). Die letzte Methode ist im allgemeinen die aussichtstreichste.

Die Schädigung durch Insekten tritt übrigens nicht alljährlich im gleichen Umfang und nicht immer im ganzen Lande ein.

Wertvolle Mithilfe hat bei der Bekämpfung der Schädlinge auch das im Jahre 1904 im Auftrag des Ackerbau-Amts in Washington von dem bewährten Ackerbau-Sachverständigen, dem DeutschAmerikaner Dr. S e a m a n A. Kn a p p zunächst in Texas organisierte

Farmer's Cooperative Demonstration Work geleistet, welches den Farmern die Grundlehren darüber beibringt, wie man Baumwolle trotz des Kapselkäfers crfolgreich bauen kann. Spezialkundige „Agenten“ des Bureau of Plant Industry in Washington lehren den Farme $r$ a $f$ seiner eigenen F a rm, die nach Angabe und unter Aufsicht des Agenten zu bestellen ist, in gemischtem Betrieb Baumwolle, Mais und seinen eigenen Bedarf an Lebensmitteln zu batten. Saat und Dünger werden, soweit sie zu diesen Versuchen dienen, von den Händlern vielfach gratis geliefert, der Farmer stellt Land und Arbeit.

Diese von Texas ausgehende Organisation nahm bald einen großartigen Aufschwung, war, als Dr. Knapp 19II starb, fast über den ganzen Baumwollgürtel verbreitet, und im Jahre 1912 nahmen an dieser Arbeit 858 amtliche Agenten und 35000 Farmer teil, während 67000 weitere Farmer den Rat der Agenten nur gelegentlich einholten. Um das Werk auch schon der Jugend sympathisch zu machen, wurden besondere „Boys Corn Clubs" gegründet, welche im Jahre I9I2 bereits 60 ooo Mitglieder zählten.

Das Werk erfordert jährlich 600 ooo Dollars, wovon die Hälfte vom Ackerbau-Amt in Washington, dic andere Hälfte von Einzelstaaten und Privaten aufgebracht wird.

Als in Vordamerika erprobte Kulturmethoden für Baumwolle empfehlen sich besonders auch mit Rücksicht auf Baumwoll-Schädlinge und -Krankheiten, nach dem Anraten der Versuchsstationen und des Entomologischen Bureaus die folgenden:

I. Abbrennen und völliges Vernichten der Stengel der Baumwollpflanzen im Herbst, um das Uberwintern von Schädlingen zu verhindern.

2. Abeggen der Flächen im Winter. 
3. Tiefes Pflügen.

4. Möglichst frühzeitiger Beginn der Aussaat.

5. Benutzung frühreifer Saat.

6. Hinreichende Düngung.

7. Man gebe den einzelnen Reihen der Baumwollstauden einen etwas größeren Abstand, als die Höhe der reifen Pflanzen beträgt und lasse auch innerhalb der Reihen genügend große Zwischenräume.

8. Abeggen der Felder, sobald die jungen Pflanzen ungefähr zollhoch sind, um die Erdkruste zu lockern.

9. Befreiung der Pflanzenreihen von Unkraut, sowie Schütteln der Pflanzen, damit die Insekten herabfallen.

Io. Vernichtung der dabei herabfallenden Pflanzenteile durch Verbrennen.

II. Beschränkung des allzu raschen Wachstums durch Abpflügen des Beetrückens nach der Mitte zu.

I2. Auswahl der am frühesten reifen und besten Anbausorte.

13. Regelmäßige Pausen im Anbau von Baumwolle unter Anwendung eines angemessenen Fruchtwechsels, z. B. erst Baumwolle, dann Kuherbsen, dann Mais; niemals sollte Baumwolle unmittelbar auf Baumwolle folgen.

I4. Bepflanzen der Zwischenräume zwischen den Baumwollreihen mit Hülsenfrüchten.

\section{Anbauflächen und Erträge.}

Die Baumwollanbauflächen, Erträge und Preise für das Pfund geschätzter Durchschnittsqualität Upland weisen folgende Zahlen auf, die Ernten in Ballen à 500 Pfund brutto:

\begin{tabular}{|c|c|c|c|c|c|}
\hline Jahr & $\begin{array}{c}\text { Ernte } \\
\text { Tausend Ballen }\end{array}$ & $\begin{array}{l}\text { Durchschnitts- } \\
\text { preis } \\
\text { Cents das Pfund }\end{array}$ & Jahr & $\begin{array}{c}\text { Ernte } \\
\text { Tausend Ballen }\end{array}$ & $\begin{array}{l}\text { Durchschnitts- } \\
\text { preis } \\
\text { Cents das Ffund }\end{array}$ \\
\hline I 790 & 3 & 26 & I859. & 4309 & I I \\
\hline $1794 \ldots$ & 17 & 36 & 1860 & $384 r$ & $I_{3}$ \\
\hline I799... & $4 I$ & 28 & I861 . . & 4490 & 31 \\
\hline ISO0 ... & 73 & 44 & I862 . & I596 & 67 \\
\hline $1805 \ldots$ & 146 & 22 & $1863 \ldots$ & 449 & IOI \\
\hline I810... & 177 & I5 & I $864 \ldots$ & 299 & $8_{3}$ \\
\hline I $820 \ldots$ & 334 & $I_{4}$ & $1865 \ldots$ & 2093 & 43 \\
\hline I830 . . & 732 & IO & I 866 & 1948 & $3 I$ \\
\hline $1835 \ldots$ & $106 I$ & I6 & I 869. & 2409 & 24 \\
\hline 1839 & I653 & 9 & $1870 \ldots$ & 4024 & 17 \\
\hline 1848 & 2615 & 7 & & & \\
\hline
\end{tabular}


Zensusberichte über die Größe der Anbaufläche beginnen erst mit dem Jahre I879.

\begin{tabular}{|c|c|c|c|c|c|c|}
\hline \multirow[t]{2}{*}{ Jahr } & $\begin{array}{l}\text { Anbau- } \\
\text { fläche }\end{array}$ & Ernte & $\begin{array}{c}\text { Ertrag vom } \\
\text { Acre }\end{array}$ & $\begin{array}{c}\text { Durchschnitts- } \\
\text { preis }\end{array}$ & $\begin{array}{l}\text { Wert von } \\
\text { Lint }\end{array}$ & $\begin{array}{l}\text { Wert von } \\
\text { Saat }\end{array}$ \\
\hline & $\begin{array}{l}\text { Millionen } \\
\text { Acres }\end{array}$ & $\begin{array}{c}\text { Millionen } \\
\text { Ballen }\end{array}$ & Pfund & Cents das Pfund & $\begin{array}{l}\text { Millionen } \\
\text { Dollars }\end{array}$ & $\begin{array}{l}\text { Millionen } \\
\text { Dollars }\end{array}$ \\
\hline I879.. & I 4,4 & 5,46 & I95 & I2 & - & - \\
\hline I884 . & I 7,4 & 5,48 & 163 & 10 & 一 & 一 \\
\hline $1889 \ldots$ & 20,1 & 7,47 & 185 & II & - & - \\
\hline I894.. & 23,6 & 10,02 & 205 & 6 & - & 一 \\
\hline I900.. & 25,7 & 10,26 & 205 & 9 & 一 & - \\
\hline 1902. & $27, \mathrm{I}$ & Io, 82 & I95 & 8 & 422 & 8o \\
\hline $1904 \ldots$ & 30 & I 3,68 & 215 & 9 & $56 I$ & $9 I$ \\
\hline I906. . & $3 r, 3$ & 13,60 & 205 & IO & 640 & $8 \mathrm{r}$ \\
\hline Igo8.. & 32,4 & I 3,59 & I95 & 9 & 589 & 92 \\
\hline Ígro.. & 32,4 & 12 & 175 & 15 & 820 & I 43 \\
\hline IgII. . & 36 & 16,25 & 210 & 10 & 732 & 127 \\
\hline I9I2.. & 34 & 14,31 & 203 & 12 & 792 & I 28 \\
\hline
\end{tabular}

Verteilt auf die einzelnen Staaten ergaben die Ernten von:

1912

Millionen Ballen Proz.

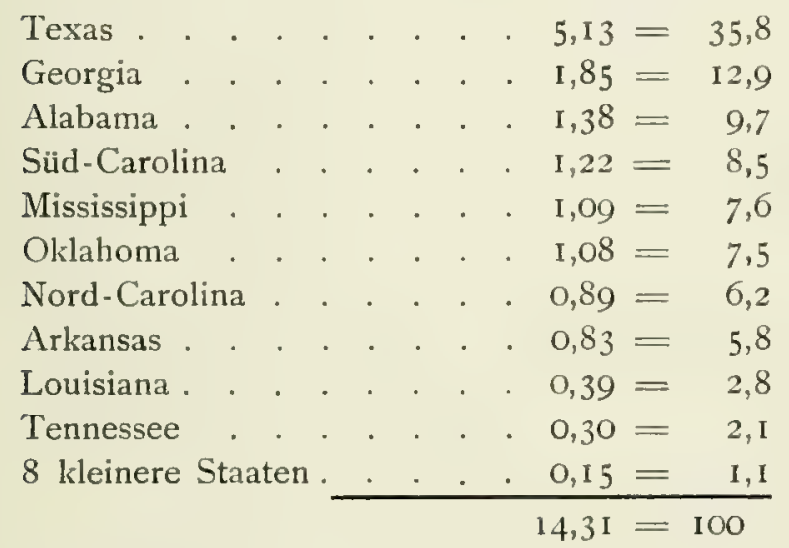

Die Produktion von Sea Island-Baumwolle wies auf in den Jahren . $1908 \quad 1909$ 1910 I9II 1912

Ernte . $94 \quad 95 \quad 90 \quad$ I19 74 Ballen à 500 Pfund.

Der Ertrag von Sea Island-Baumwolle schwankt zwischen 75 und 150 Pfund auf den Acre.

Der Ernteertrag ist je nach Charakter von Boden und Witterung, nach der Sorgfalt bei der Bestellung und entsprechend den auftretenden Pflanzenkrankheiten und Schädlingen natürlich 
sehr verschieden und beträgt im Durchschnitt für die einzelne Staude etwa ${ }^{1} / 10$ Pfund Saatbaumwolle. Von den kleinkapseligen Sorten ergeben 100 bis I20, von den großkapseligen 40 bis 60 Kapseln ein Pfund Saatbaumwolle. Die höchsten Erträge vom Acre gab im Jahre 19I2 Nord-Carolina mit durchschnittlich 267 Pfund Lint, es folgten Mississippi mit 260, Virginia 250, Süd-Carolina 209 und Texas mit 206 Pfund, alle anderen Staaten lieferten unter 200 Pfund, Georgia nur I59 Pfund.

Innerhalb der 20 Jahre 1874 bis 1894 schwankte der Durchschnittsertrag des gesamten Baumwollgürtels zwischen I39 Pfund in 1874 und 205 Pfund in 1894 , in den Einzelstaaten wiesen auf das Minimum mit I Io Pfund Alabama im Jahre I884, das Maximum mit 383 Pfund vom Acre Texas im Jahre 1894.

Im allgemeinen schwankt der Ertrag vom Acre zwischen 1/3 und I Ballen, ausnahmsweise werden bis $2 u 21 / 2$ Ballen erreicht, bei intensiver Kultur sind auf einer Farm in Nord-Carolina sogar 4 Ballen à 500 Pfund crzielt worden. Die reichen Alluvialländereien des Mississippi und die frischen schwarzen Prärieböden von Texas geben im allgemeinen bei weniger Arbeit höhere Erträge als die ariden „Uplands“ von Georgia.

Der Durchschnittsertrag amerikanischer Upland-Baumwolle ist durch verbesserte Kulturmethoden innerhalb der letzten Jahre langsam angestiegen, und mit wachsender Sorgfalt wird sich der Ertrag auch weiterhin noch steigern lassen, aber es wird damit keineswegs schnell gehen.

Zum Vergleich seien noch die Durchschnittserträge der beiden nächstwichtigen Baumwolländer angeführt: Das frostfreie Ägypten ergibt mit Bewässerungskultur 450 Pfund, Ostindien nur 80 Pfund vom Acre.

Die Durchschnitts qua litä ter Ernte fällt je nach dem Witterungsverlauf und sonstigen Bedingungen in den verschiedenen Jahren verschieden aus und schwankte in den letzten Io Jahren zwischen strict low middling und fully middling. In der Letztzeit beklagt man sich über den zunehmenden Mangel besserer Klassen, und die besonders in Lancashire viel begehrten Stapellängen von $I^{1} / 16$ bis $I^{3} / 10$ inch sind letzthin in Amerika sehr selten geworden. In der Regel ist eine quantitativ gute Ernte auch qualitativ befriedigend, da die der Entwicklıng günstigen Unıstände nach beiden Richtungen hin wirken. 


\section{Einzelgebiete.}

Es mögen hier einige kurze Notizen über die zehn Hauptbaumwollstaaten, von Osten nach Westen zu aufgeführt, folgen.

Nord-Carolin a ist vom Norden her der erste eigentliche Baumwollstaat, und mit Ausnahme von 24 im Gebirge gelegenen Grafschaften, die keine Baumwolle pflanzen, hat der schon im I7. Jahrhundert hier eingeführte Baumwollbau ständig zugenommen und spielt nach Mais die zweite Rolle im Ackerbau. Besonders das letzte Jahrzehnt weist eine erhebliche Zunahme auf, und dabei mit 267 I'fund den höchsten Durchschnittsertrag vom Acre. Haupthandelsplätze für Baumwolle sind Charlotte und Raleigh, Hafen dafür ist Wilmington.

Für S ü d-C a rolin a wird Baumwolle zuerst im Jahre 1664 erwähnt, und 1747 erfolgte ab Charleston die erste Ausfuhr mit sieben Packen. 1790 wurde von cinigen Irländern eine Spinnerei in Williamsburg eingerichtet, und seit der kurze Zeit darauf erfolgten Einführung der Sägegin wurde Baumwollbau die wichtigste Beschäftigung in Süd-Carolina und ist es bis heute geblieben. Sämtliche Grafschaften des Staates pflanzen Baumwolle an, und die hier I788 eingeführte Sea Island-Baumwolle gedeiht am besten auf den der Küste vorgelagerten Inseln, welche die besten Sea Island-Sorten überhaupt liefern. Haupthandelsplätze für Baumwolle sind Columbia und der Hafen Charleston.

Ge orgia berichtet über Baumwolle zuerst im Jahre 1735, und die Pflanze ist heute mit Ausnahme von sechs Grafschaften als crste Feldfrucht im ganzen Staate angebaut, dessen Baumwollernte nur derjenigen von Texas nachsteht. Georgia ist auch der größte Produzent von Sea Island-Baumwolle, ohne allerdings darin die hohe Qualität von Süd-Carolina zu erreichen. Hauptaufkaufsmärkte sind Augusta und Atlanta, Häfen Savannah und Brunswick.

A 1 a b a m a, um die Mitte des 19. Jahrhunderts an der Spitze der Baumwollstaaten stehend, ist seitdem im Vergleich zu anderen Staaten etwas zurückgeblieben und nahm im Jahre I9I2 die dritte Stelle ein. Baumwolle wird in sämtlichen Grafschaften des Staates gebaut, und zwar in ungefähr gleich großem Umfang mit Mais. Aufkaufsmärkte sind Montgomery und Selma, Hafen ist Mobile.

Lo u is ia na baut Baumwolle schon seit Ende des I7. Jahrhunderts, erreichte seine Höhepunkte 1859 und I904, ist von I9o6 bis 19 IO aber auf ein Viertel seines Ertrages zurückgegangen durch die starken Verwüstungen des Kapselkäfers und den dadurch ver- 
ursachten Ubergang von Baumwolle zu Reis, Zuckerrohr und anderen Kulturen. Letzthin ist der Baumwollbau wieder etwas gestiegen. Aufkaufsmärkte sind Shreveport und der Hafen New Orleans.

M is sissippi baut Baumwolle in sämtlichen Grafschaften mit Ausnahme von dreien in der Südost-Ecke, hatte I839 sämtliche älteren Baumwollstaaten überholt und diese erste Stelle bis $188_{4}$ meist behauptet. Dann lief ihm Texas den Rang ab. Trotzdem der Kapselkäfer auch hier letzthin einen Rückgang verursacht hat, bildet Baumwolle auch heute noch die wichtigste Feldfrucht. Aufkaufsmärkte sind Vicksburg, Yazoo City und Natchez.

Tennessee, zuerst im Jahre I80I unter den Baumwollstaaten aufgeführt, baut Baumwolle, die hier nach Mais rangiert, nur im westlichen Teil und nimmt unter den Hauptbaumwollstaaten die letzte Stelle ein. Aufkaufsmärkte sind Memphis, der zweitgrößte Binnenplatz für Baumwolle, und Nashville.

A rkansas, zuerst 1839 als Baumwollstaat erwähnt, nahm einen raschen Aufschwung, baut Baumwolle als zweitwichtigste Feldfrucht nach Mais heute in allen Grafschaften, mit Ausnahme von vieren in der Nordwest-Ecke. Aufkaufsmärkte sind Little Rock und Helena.

Texas, der heutige Champion, erscheint fast am spätesten in der Reihe der Baumwollstaaten, wird als solcher zuerst im Census von 1849 mit 58 ooo Ballen erwähnt, hat seitdem, wenn auch nicht ohne starke Schwankungen, einen raschen Aufstieg erlebt, nimmt seit I884 die erste Stelle ein und lieferte im Jahre I9I2 5, I3 Millionen Ballen $=35 \%$ der gesamten Baumwollernte Nordamerikas oder fast ein Viertel der ganzen Welthandelsernte. Texas übertrifft alle anderen Staaten weit an Umfang und besitzt einen großen Reichtum an geeignetem Land für Baumwollbau, der alle anderen Kulturen weit überragt. Mit Ausnahme des Nord- und des Westrands, wo das Land allmählich ansteigt und gleichzeitig steiniger und dürrer wird, baut man Baumwolle überall im Staate, stellenweise mit der nötigen künstlichen Bewässerung. Aufkaufsmärkte sind Houston, der größte Birnenplatz für Baumwolle, Dallas und Fort Worth; Häfen Galveston, der größte Baumwollhafen der Welt, Port Arthur und Texas City.

Oklahoma, im Jahre 1879 zuerst mit I700o Ballen aufgeführt, hat seit Anfang dieses Jahrhunderts einen starken Aufschwung genommen und steht bereits an sechster Stelle. Sämtliche Grafschaften, mit Ausnahme der I4 am Nordrand gelegenen, 
bauen Baumwolle, und der Baumwollbau gibt dem ganzen Süden des Staates das landwirtschaftliche Gepräge.

Das sind die zehn Hauptstaaten.

Nun noch einen Blick auf diejenigen Staaten, die Baumwolle nur im. Nebenamt ziehen.

Virginia, das älteste Gebiet innerhalb der Vereinigten Staaten, in dem Baumwollanbauversuche gemacht wurden, erreichte seine größte Produktion im Jahre 1826 mit 25 Millionen Pfund; Baumwolle spielt heute hier hinter Mais, Weizen und Hafer aber nur noch eine sehr geringe Rolle, und weist von allen Anbaugebieten den geringsten Ertrag vom Acre auf. Im Jahre I9II wurden 3 I ooo Ballen geerntet. Haupthafen ist Norfolk.

F 1 o r i d a baut Baumwolle seit der ersten Hälfte des I8. Jahrhunderts, erreichte die Höhe seiner Produktion im Jahre I9I I mit 96000 Ballen, und produziert seit den 5oer Jahren des 19. Jahrhunderts auch Sea Island-Baumwolle; ehe es Gcorgia überholte, nahm es eine Zeitlang sogar die erste Stelle darin ein, während es jetzt an zweiter Stelle betreffs Produktionsmenge darin steht. Der Boden Floridas ist größtenteils sumpfig und für Baumwollbau ungeeignet; dieser findet sich nur im Nordwestteil. Hafen des Staates ist Pensacola.

Von den mittleren Zentralstaaten $\mathrm{Kent} \mathrm{ucky}$, M is souri und $\mathrm{K}$ ansas, die auch zu den Baumwollstaaten gehören, spielt eine etwas nennenswerte Rolle nur

Missouri mit dem Hauptplatz St. Louis, das seit 1839 unter den Baumwollstaaten aufgeführt, den Baumwollbau in den Vereinigten Staaten am weitesten nach Norden getragen hat; die Baumwollgrafschaften liegen im Süden des Staates an der Grenze von Arkansas, liefern eine hervorragende Qualität und einen sehr hohen Ertrag vom Acre. Die größte Ernte war diejenige vom Jahre I9I I mit II 8 ooo Ballen.

- Schließlich kommen auch noch die Weststaaten in Betracht, wovon

$\mathrm{N}$ è $\mathrm{u}-\mathrm{Mexiko}$ für Baumwollbau recht unbedeutend ist.

Arizona macht Versuche mit ägyptischer Baumwolle unter Zuhilfenahme künstlicher Bewässerung. Es waren damit I9I3 im Salt River-Tal 2000 bis 3000 Acres bestellt, die durchschnittlich einen Ballen vom Acre trugen, eine Stapellänge von $I 1 / 2$ bis $I 3 / 4$ inch ergaben, und im Januar I9I4 einen Preis von 30 Cents für das I'fund erreichten. Von den geernteten 2000 bis 2500 Ballen wurden erstmalig 500 Ballen über Galveston nach Liverpool ausgeführt. 
In Califor $\mathrm{nia}$ endlich begann man Baumwollbau, durch Prämien angeregt, um 1865 im Tale des San Joaquin in Süd-Californien und erzielte eine vorzügliche Qualität, konnte 1873 eine kleine Ladung nach Liverpool senden und eröftnete 1883 eine Baumwollfabrik in Oakland, die bis heute die einzige westlich von Oklahoma geblieben ist. Mangel an Arbeitskräften ließ den Baumwollbau in Californien aber wieder eingehen, und erst die Anfang dieses Jahrhunderts erfolgte Erschließung des Imperial Vailcy des Colorado-Flusses in Süd-Californien durch künstliche Bewässerung regte auch den Baumwollbau wieder an. Im Jahre 1909 betrug die Anbaufläche darin 800 Acres, im Jahre I9I3 II 000 Acres mit 9000 Ballen Ertrag, im Jahre 19I4 rechnete man mit 16000 Acres. Bislang zieht man meist zwei Uplandsorten. Daneben macht man auch Versuche mit ägyptischer Baumwolle. Arbeiter sind hier allerdings knapp und teuer, dafür sind aber die Erträge vom Acre sehr hoch; ein sorgfältiger Farmer soll hier leicht $\mathrm{I} 1 / 2$ bis 2 Ballen vom Acre erzielen können, und dic Organisation der hiesigen Farmer ist eine sehr gute.

\section{Amtliche Statistik und Ernteschätzung.}

Frühzeitig hatte man die Notwendigkeit erkannt, der Preisbildung des Welthandelsartikels Baumwolle eine möglichst umfassende und zuverlässige statistische Basis zu geben. Der erste größere Bericht über Baumwollproduktion wurde dem Kongreß im Jahre 1836 von dem Schatzsekretär Levi Woodbury vorgelegt und faßte das ganze bis dahin auf Schätzungen beruhende Material zusammen. Seit Ende der 3oer Jahre des 19. Jahrhunderts nahm sich die offizielle Statistik des Ackerbau-Amtes in Washington auch der Baumwolle an. Die amtliche landwirtschaftliche Statistik für die Vereinigten Staaten beginnt mit dem Census von I840 für das Jahr I839, und außer dem alle zehn Jahre aufgenommenen Census erschienen ab 1863 auch jährliche amtliche Statistiken über den Baumwollbau durch das Ackerbau-Amt.

Das „Statistische Bureau des Ackerbau-Amtes“ gibt jährlich sieben Bulletins heraus, von Sachverständigen erstattete Gutachten und Urteile über den Erntestand im Vergleich zu früheren Jahren und über die Aussichten der heranwachsenden Ernte. Der Junibericht gibt cine Schätzung der Grüße der mit Baumwolle bestellten Ackerfläche, fünf weitere, je am ersten Tage der Monate Juni bis ()ktober erscheinende Veröffentlichungen berichten über den Stand 
der Pflanzungen, und der Dezemberbericht gibt eine Schätzung der zu erwartenden Gesamternte. Bei den fünf Monatsberichten gilt die Zahl Ion als "Normalzustand“, ein keineswegs klarer Begriff, und die veröffentlichten Vergleichszahlen bezeichnen, wenn höher, eine hervorragende, wenn unter Ioo, eine entsprechend mangelhafte Entwicklung der Pflanzen. Sonderbarerweise wird die „Normalzahl" 100 in den offiziellen Baumwollberichten überhaupt nie erreicht.

Der zur Berichterstattung in Tätigkeit tretende Apparat ist cin sehr mannigfacher. Zunächst sind, ausschließlich für Baumwolle, fünf ,s p e cial field a g e n $t s^{\prime \prime}$ tätig, je einer für eine Gruppe von Staaten, welcher beständig seinen Bezirk bereist und sich unterrichtet durch eigenen Augenschein, durch Rücksprache mit Pflanzcrn, Baumwollaufkäufern, Lieferanten von Ackerbaugeräten und Dünger, Bankiers und aus anderen zuverlässig erscheinenden Quellen; eine Reihe von Korrespondenten berichten diesem field agents monatlich. Direkte Berichte nach Washington liefern I30 ooo freiwillige, unbezahlte Korrespondenten für Grafschaften und einzelne Ortschaften, sowie einzelne Farmer und Entkernungsanstalten. Außerdem besitzt jeder Staat einen $S t a t e s t a t$ is t ic al a gent, der unter sich einen Stab von Korrespondenten hat (im ganzen Reiche sind es gegen I2 Ooo), welche verschieden sind von denen, die di r e k t nach Washington berichten. Aus all diesen Informationen wird nun in Washington der Durchschnitt gezogen und das Resultat veröffentlicht.

Der $W$ e $r \mathrm{t}$ dieser zeitweise gegebenen Sammelberichte ist aber sehr fragwürdig. Sie haben tatsächlich mehr zur Spekulation veranlaßt, als dem legitimen Geschäft gedient. Unfähigkeit, Oberflächlichkeit, persönliches Interesse und Stimmungen trüben das Urteil nicht weniger der vielen Berichterstatter; der Einfluß der Pflanzervereine ist recht bedenklich; die Regierungsbeamten sind keineswegs immer gegen Bestechungen von seiten der Interessenten gefeit gewesen, und es ist nicht selten vorgekommen, daß bei Termingeschäften, die in Kompagnie betrieben wurden, der eine Teilhaber, statt der üblichen „margin" in bar, seine ,,influence“ bei Regierungsbeamten als seinen Teil des Gesellschaftskapitals einschoß. Im Juli 1905 gab es einen öffentlichen Skandal in dieser Richtung, und es erfolgte ein Wechsel im Personal des Statistischen Bureaus im Ackerbauministerium, weil Beamte desselben an Personen, durch die sie in "cotton futures" spekulierten, Informationen über die amtlichen Baumwollberichte lieferten, bevor diese der Öffentlichkeit übergeben wurden. 
Um den Mißbrauch der gesammelten Materialien seitens einzelner Beamten unmöglich zu machen, findet seitdem eine vorsichtig berechnete $\mathrm{Tr}$ r $\mathrm{n}$ ung der Arbeit statt, welche darauf hinzielt, die volle Kenntnis der Zahlen bis zu dem Augenblick der amtlichen Veröffentlichung nur einem sehr beschränkten Kreise, und selbst diesem erst kurz vor der Veröffentlichung zu ermöglichen, wenn auch die Informationen selbst in a $1 \mathrm{te} r$ Weise gesammelt werden.

Die Dezember-Schätzung der Gesamternte seitens des Statistischen Bureaus ist so oft falsch gewesen, daß darauf keinerlei Verlaß ist; die Unterschätzungen beliefen sich auf eine Million Ballen und mehr, so daß man das ganze Werk dieses Bureaus als ,gucss work", ein Ratespiel, bezeichnet und seine gänzliche Abschaffung wiederholt, u. a. auch auf dem Internationalen Baumwollkongreß zu Atlanta im Oktober 1907 beantragt hat.

Die Erkenntnis der Unzulänglichkeit der Berichte des Ackerbau-Amtes hat dazu geführt, der statistischen Erfassung der Baumwollproduktion auch von einer anderen Seite her näherzutreten, und zwar durch das dem Department of Commerce and Labor in Washington unterstehende

Census-Bureau. Dasselbe veröffentlicht, neben den alle zehnJahre erscheinenden umfassenden Statistiken, seit dem Jahre 1899 fortlaufende Erhebungen über die Menge der in den Entkern ungsanstalten bearbeiteten Baumwolle und gibt darüber zwischen September und März zehn Berichte heraus, die sich auf die Angaben von über zoo, im Durchschnitt mit je 300 Dollars bezahlten ,field agents“ stützen. Die Zuverlässigkeit der Angaben der Entkernungsanstalten wird zwar auch bezweifelt, immerhin handelt es sich hier um einen ,,count, not a guess", und man regte deshalb auf dem Atlanta-Kongreß, vorläufig allerdings ohne Erfolg, an, daß die Census-Berichte über die Leistungen der Entkernungsanstalten nicht als Sammelberichte, sondern fortlaufend täg lich veröffentlicht werden möchten, ähnlich wie die Berichte über die Baumwollzufuhr in den einzelnen Häfen. Vorgeworfen wird dem Census-Bureau, daß es sich mehr und mehr zu einer Interessenvertretung der Pflanzer ausbilde, statt streng objektiv zu sein.

Außer den erwähnten Einzelberichten gab das Census-Bureau seit $1899 \mathrm{j}$ ä h r l i che Zusammenstellungen der Gin-Resultate heraus, an deren Stelle seit 1905 die beiden interessanten Jahresberichte: „Cotton Produktion" und "Supply and Distribution of Cotton" traten. Es wird darin über Produktion, Export und Import von Baumwolle und ihren Nebenprodukten in den Vereinigten Staaten 
berichtet, und seit 1905 ist dic Statistik auch auf den jährlichen Konsum und den Lagerbestand am 3I. August jedes Jahres nicht nur in Nordamerika, sondern auch in den Industrieländern Europas ausgedehnt worden, wobei das Census-Bureau dic Unterstützung der Internationalen Vereinigung ron Baumwollspinnern und -webern fand. Seit September I9I 2 werden diese letzteren Berichte über Baumwollkonsum, Import, Export, Stocks und arbeitende Spindelzahl sogar monatlich veröffentlicht.

Das Census-Bureau stellt außerdem alle fünf Jahre eine Statistik über die Verarbeitung von Baumwolle und Baumwollsaat auf, ein von Fabrikanten und Statistikern sehr geschätztes Werk.

Das Bureau of foreign and domestic comm c r ce, eine andere Abteilung des Department of Commerce and Labor, welches seit I9I2 die beiden früheren Bureau of Statistics und Bureau of Manufactures vereinigt, entsendet Geschäftsleute als Spezialkommissare in verschiedene Weltteile, um amerikanische Waren, darunter Baumwollprodukte, dort einzuführen.

Auch verschiedene Einzelstaaten, wie Texas, Oklahoma und Alabama haben eigene staatliche Statistik über Baumwollproduktion auf Grund der Ergebnisse der Entkernungsanstalten eingeführt.

Bei Vergleich verschiedener Statistiken Nordamerikas ist zu berücksichtigen, daß man neben dem Kalenderjahr auch das „Baumwolljahr" vom 1. September bis 3I. August, und das "Fiskaljahr" vom I. Juli bis 30. Juni hat. Mit dem I. August 1914 beginnend, ist das Geschäftsjahr für Baumwolle von Anfang August bis Ende Juli festgesetzt worden.

Schließlich sei noch der Baumwoll-Statistikerin Miß Giles gedacht, welche früher im Census-Bureau angestellt war, sich dann aber selbständig machte und seitdem mehr oder weniger beeinflußte, individuell-egoistische Berichte lieferte.

\section{Ernteaufbereitung.}

Die gepflückte $\mathrm{S}$ a a $\mathrm{t}$ b a $\mathrm{u} \mathrm{m}$ w o 11 e besteht aus Samenkernen und den mehr oder weniger fest an ihnen haftenden Samenfasern, der sogenannten Lintbaumwolle, und zwar ergeben durch die Entkernung

Ioo Pfund Upland-Saatbaumwolle 25 bis 40 Pfund und mehr, im Durchschnitt 35 Pfund Lintbaumwolle,

Ioo Pfund Sea Island-Saatbaumwolle etwa 25 Pfund Lintbaumwolle. 
Die Upland-Saat ist von grünlicher, bräunlicher oder weißer Farbe und ihre Fasern sind so innig mit dem Samen verwachsen, daß sie nur schwer von ihm zu trennen sind; auch die entfaserte Saat bleibt infolge einer besonderen kurzhaarigen Grundwolle noch filzig. Dagegen haftet die Sea I s land-Faser weit loser an ihrem schwarzen Samen, ist leicht von ihm zu trennen, und die alsdann verbleibende Saat ist nackt und glatt.

Jede Saatbaumwolle sollte vor dem Entkernen, da namentlich die zuerst gepflückte Baumwolle leicht noch grün und unreif ist, mindestens 30 Tage lang in guten Lagerräumen aufgestapelt werden, um ganz auszureifen und gut zu trocknen; hierbei wächst die unreife liaser nach, saugt vom Ól des Samens auf und bekommt dadurch gleichmäßigeren Stapel, kräftigere und geschmeidigere Faser und bessere Farbe, mithin also höheren Handelswert. Baumwolle muß, bevor sie entkernt wird, durchaus trocken und abgelagert sein, niemals grün und feucht; besonders gilt das von langstapeliger Baumwolle, die selbst nicht bei feuchtem Wetter entkernt werden darf.

Leider werden diese Vorsichtsmaßregeln meist $\mathrm{n}$ i $\mathrm{ch}$ t befolgt, sondern die Samenbaumwolle, reine und schmutzige oft gemischt, kommt in offenen Pflanzerwagen mit etwa I500 Pfund Saatbaumwolle $=500$ Pfund Lint $=$ I Ballen sofort nach der Entkernungsanstalt.

Das Entkernen. In der Jugendzeit der amerikanischen Baumwollkultur geschah die Entkernung zunächst ganz mit de r $\mathrm{H}$ a n d, wobei eine Familie neben der gewöhnlichen Haus- und Feldarbeit in der Woche nur 4 Pfund Lint fertig brachte. Man war deshalb frühzeitig darauf bedacht, ein geeignetes Gerät dafür zu verwenden und benutzte eine primitive Entkernungs w a $1 \mathrm{ze}$, wie sie in Indien schon 300 Jahre vor Christus verwandt worden war. Dabei wird die Saatbaumwolle zwischen zwei hölzernen Rollen hindurchgezogen, welche die Fasern abziehen und passieren lassen, die Kerne aber zurückhalten. Das dabei gewonnene Material wurde teilweise, auch nach indischem Muster, dann noch mit einer schnellenden Bogensehne und einem Klopfstab weiter gereinigt, und der Name „Bowed Georgia“ als Qualitätsbezeichnung galt noch lange nach Abschaffung des Verfahrens.

Die erste Entsamungsmaschine in den Vereinigten Staaten, eine Walzengin, wird im Jahre 1722 bei einem Pflanzer namens Krebs in Louisiana erwähnt. I742 wird vom Pflanzer Dubreuil in Louisiana berichtet, daß dic von ihm benutztc Walzengin die Ausdehnung des Baumwollbaus in seiner Kolonic begünstigte; näheres 
über diese Maschine ist aber nicht bekannt. Wenn für die an der Küste gezogene langstapelige Sca Island-Baumwolle dieses Walzensystem, das I 790 von einem Dr. Eve in Augusta, Georgia, verbesscrt sowie für Wasser- und Pferdebetrieb eingerichtet wurde, an und für sich auch geeignet war und immerhin fünfmal so viel liefcrte, als das Auspicken mit der Hand, so erwies es sich doch als ungeeignet für die Bearbeitung der kurzstapeligen Upland-Baumwolle, und so erreichte die Ausdehnungsmöglichkeit der Baumwollkultur schon aus diesem Grunde bald ihr Ende. Ėrst die 1793 von Eli Wh i t n e y crfundene "S äg e - G i n“ machte dic Massenerzeugung von Baumwolle für den Weltmarkt lohnend. Das System dieser Gin — das auch in Deutschland eingebürgerte Wort "Gin" ist eine Abkürzung von „Engine“, Maschine, wird heute aber ausschließlich für Entkernungsanlagen gebraucht, und zwar speziell für die SägeGin — besteht darin, daß die schräggestellten Zähne einer Reihe von Kreissägen, die einen Durchmesser von einem Fuß haben und in Abständen von je $3 / 4$ Zoll auf einer Walze befestigt sind, bei 400 bis 500 Umdrehungen in der Minute die ihnen zugeführte Samenbaumwolle durch die engstehenden Stäbchen eines eisernen Rostes hindurchziehen, wobei die erbsengroßen Samenkörner abspringen, während eine hinter der Sägewelle befindliche, mit Bürsten besetzte Walze die Baumwollfaser, den "Lint", abstreift und in einen rückwärts befindlichen Kasten befördert.

Die Säge-Gin, anfangs nur mit 200 bis 300 Umdrchungen in der Minute, aber bald mannigfach verbessert, wurde zunächst mit - Menschen- oder Wasserkraft, teilweise mit zwei bis vicr Maultieren oder Pferden, später mit kleinen Dampfmaschinen betrieben, und die Anlage war in einem einfachen Holzbau untergebracht, der in seinem seitlich offenen Unterstock die Betriebsmaschinerie, im Oberstock die Gins und unter dem Dache die zu verarbeitende Saatbaumwolle bcherbergte. Daneben diente cine zunächst hölzerne, später eiserne Schraubenpresse, dic unter einem hölzernen Schutzdach außerhalb, aber nahe bei dem Ginhaus untergebracht war, der Packung in Ballen, die damals 60 Zoll lang, 30 Zoll dick und 42 bis 46 Zoll breit waren, und die man mit Tauen schnürte. Diese einfachen Einrichtungen blieben im großen und ganzen bis gegen I875 oder I880 unverändert; nur führte man allmählich die früher überwiegend aus Holz bestehénden Hauptteile der Gin in Eisen und Stahl aus.

Vor dem Bürgerkrieg hatte jede Pflanzung von 50 Acres und mehr ihre e i g e n e, meist mit Pferde- oder Maulticrkraft betricbene 
Gin. Mit den dann folgenden Arbeiterschwicrigkeiten begann aber die Einrichtung größerer L o h n - Gins zum Allgemeingebrauch; der Pflanzer fährt dahin seine Saatbaumwolle zum Entkernen, bezahlt für Ginnen und Ballenpackung, und bringt dann beides, Lint und Saat, auf den Markt. Allmählich kauften die größeren GinAnlagen, besonders wenn sic auf Saat reflektierten, die Samenbaumwolle für e ig e n e Rechnung auf, wie das besonders in Texas mehr und mehr geschieht; jede Gin ist dann gleichzeitig Baumwollmarkt; meist aber arbeitet die Gin für den Farmer gegen einen bestimmten Preis, der für Entkernen und Packen des Ballens von 500 Pfund

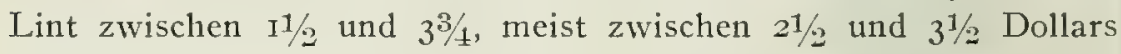
schwankt.

Die Arbeiterschwierigkeiten führten auch in den Gins dazu, allmählich eine Reihe von Einrichtungen zu treffen, welche menschliche Arbeitskraft nach Möglichkeit ausschalten, und das amerikanische Erfindungstalent ist unausgesetzt tätig, immer weitere Verbesserungen der maschinellen Anlage zu ersinnen.

Heute spielt sich der Gin-Proze $B$ meist folgendermaßen ab:

Bei Wiederaufnahme der Arbeit zu Anfang der Saison werden zunächst die Sägen geschärft, je nach Bedarf auch ausgehauen; für beide Operationen gibt es besondere Apparate. Die Saatbaumwolle wird aus dem Lagerhaus oder direkt vom Pflanzerwagen vermittels eines pneumatischen Saugrohres in einen Vakuumkasten oberhalb der Gin befördert und von dort, durch ein Gebläse getrocknet und von Sand, Erde, Blattrippen und anderen Fremdkörpern gereinigt, in einem Gerinne, dem ,Feeder“, der Gin zugeführt, welche meist 50 bis 80 Kreissägen auf der Walze aufweist. Die abgerissenen Saatkerne fallen aus der Maschine in cine Förderschraubc, die häufig mit cinem durchlöcherten Boden versehen ist, un den Sand entweichen zu lassen, und werden aus der Miihle nach cinem besonderen Lagerhaus getrieben; die Lintbaumwolle aber wird mechanisch in einem hölzernen Kanal durch einen Reinigungskasten nach dem „Condensor" oder Verdichtungsapparat geleitet, der sie, in eine fortlaufende Schicht zusammengedrückt, nach dem Preßkasten abfließen läßt.

Keine Gin vermag die Fasern von fremden Bestandteilen, wie Blatt- und Kapselrückständen, Staub usw. vollständig zu reinigen. Einige Saatkerne, namentlich die unreifen, gehen mit den Fasern durch die Maschine hindurch. Auch die Faser ist nicht immer genügend ausgereift und wird selbst in mannigfacher Weise beschädigt. Infolgedessen entsteht beim Spinnen ein anselnlicher 
Verlust, der bei amerikanischer Baumwolle etwa 8 bis $12 \%$ beträgt, bei ostindischer auf 20 bis $25 \%$ steigt. Leider nimmt auch die Vermischung von Baumwolle verschiedenen Stapels im gleichen Ballen zum Schaden der Industrie mehr und mehr zu.

In einigen Gegenden, wo die Baumwollpflanze sehr groß und dicht wächst, auch schnell reift, achten die Pflücker nicht darauf, die Faser von den Schalen der Kapseln rein zu halten. Man benutzt dann zum Entkernen die sogenannte $H$ uller $G$ in, welche durch eine mit Haken besetzte Rolle zunächst die Schalen und dann mit der Sägenwalze die Samenkerne entfernt. Die Verwendung dieser Huller Gin ist aber sehr beschränkt.

Die am besten eingeführte $\mathrm{S} \ddot{\mathrm{g} g} \mathrm{e}-\mathrm{G}$ in ist heute Mungers Patent der Continental Gin Company in Birmingham, Alabama, der größten Gin-Fabrik der Erde. Daneben seien genannt die F. H. Lummus Sons Company in Columbus, Georgia; die E. van Winkle Gin and Machine Works in Atlanta, Georgia; the Little Company Gin Machinery in Charlotte, Nord-Carolina; die Carver Cotton Gin Company in East Bridgewater, Massachusetts, deren Gins besonders häufig in den OOlmühlen zum Entfernen der "Linters" angetroffen werden; the Fuller Combing Gin Company in Charlotte, NordCarolina; the Luce Compress and Cotton Company in New-Orleans, Louisiana; Murray and Company in Dallas, Texas.

F u 11 e r liefert eine die Faser schonende $\mathrm{K}$ ä $\mathrm{m} \mathrm{m}$ - Gin, deren cinzelne verbrauchte Stellen leicht auch durch die Hand des Laien auszuwechseln sind, und die Luce-Kompagnie zeigt eine Gin an, welche die Fasern durch Aussaugung losziehen, also jedes Zerreißen und Zerschneiden der Fasern vermeiden und dabei dic verschiedenen Faserlängen sortieren soll; ein ideales Programm.

Das Bedenken bei der Säge-Gin liegt nämlich darin, daß bei zu schnellem Laufen der Sägen, oder wenn die zu entkernende Baumwolle noch feucht ist, leicht die Faser beschädigt, zerrissen oder zerschnitten wird; kauft die Gin-Anlage die Saatbaumwolle für e ige ne Rechnung auf, so pflegt sie sorgfältiger damit umzugehen, als wenn sie im L o h n für den Farmer arbeitet. Leider wird auch langstapelige Upland, die eigentlich mit Walzen entkernt werden sollte, mit Säge-Gins bearbeitet und die Faser dadurch beschädigt; zum mindesten sollte man sich dabei auf nicht mehr als 300 bis 400 Umdrehungen in der Minute beschränken.

Am beliebtesten ist die Gin mit 70 Sägen, welche bei $500 \mathrm{Um}-$ drehungen in der Minute je 6 Pfund Lint auf die Säge und Stunde liefert. Eine moderne Entkernungsanlage mit 6 Gins à 70 Sägen 
verlangt cinschliclilich des Betriebes von Kondensor und J'resse ctwa 80 Pferdekräfte und liefert täglich 60 bis 70 Ballen à 500 P'fund Lint. Im Durchschnitt zählt man auf die 7o-Säge-Gin Io bis I5 Ballen am Tage. Gewöhnlich rechnet man vie r Gins auf einen Kondensor und eine Presse; der Preis von vier Gins mit Feeder und Kondensor beläuft sich auf ungefähr ıoo Dollars, das gleichc kostet eine hydraulische Doppelkasten-Presse.

Sea Island-Baumwolle, vereinzelt auch langstapelige Upland, wird der besseren Schonung der Faser wegen auf W a 1 z e n-G in s entkernt, wie das allgemein in Agypten geschieht; auch die WalzenGins haben im Laufe der Zeit wesentliche Verbesserungen erfahren, besonders durch englische Fabrikanten, deren Hauptmarke die Mac Carthy-Maschine ist. Diese besteht im wesentlichen aus einer mit Leder überzogenen Walze, welche die Baumwolle zwischen cine schräg zur Walze stehende Metallplatte und eine auf- und abgehende zweite Platte zieht, welche die Samenkerne ausschlägt.

Trotz der wachsenden Größc der Baumwollernte ist die G c$\mathrm{s}$ a $\mathrm{m} \mathrm{tzah} 1$ der Entkernungsanstalten in den Vereinigten Staaten zurückgegangen. Nur in Texas nimmt ihre Zahl noch zu, im allgemeinen aber ist durch Zusammenlegung verschiedener älterer und Einrichtung größerer, modernerer an Stelle kleinerer, veralteter Anlagen die Gesamtzahl abnehmend. Im Jahre I9I2 zählte man im ganzen 28358 Entkernungsanstalten, wovon aber nur 25279 mit einer Durchschnittsleistung von je 535 Ballen in der Saison tätig waren. Im Jahre 1907 zählte man noch 30822 Anstalten, die aber im Durchschnitt nur je 400 Ballen lieferten. Dic 26431 a k t i ve 1 Ginnereien des Jahres I909 besaßen im ganzen 57339 einzelne Gins mit 3710000 Sägen, so daß im Durchschnitt I 40 Sägen auf die einzelne Gin-Anstalt kamen; in Texas ist diese Zahl weit größer und beträgt 500 und mehr Sägen. Dazu kamen noch 238 Anstalien, welche nur Walzen-Gins besaßen. Um für einen eventucllen Niederbruch einzelner Maschinen gerïstet $z u$ scin, pflegt man vielfach Reserven davon zu halten.

Als B etriebskraft diente im Jahre 1912 bei $90 \%$ Dampf, bei $6 \%$ Wasser, bei $3 \%$ Gasoline und bei dem restlichen I \% ticrische und elektrische Kraft.

Die Entkernungsanstalten arbeiten wegen der Ungleichmäßigkeit der Erntedauer jährlich 4 bis 6 Monate. Etwa $60 \%$ der Ernte sind von Anfang der Saison bis Ende Oktober entkernt, bis Mitte November sind $3 / 4$ der netien Ernte bearbeitet, und in der zweiten Hälfte Januar wird der Betrieb gewöhnlich eingestellt. 
Das Pressen und Packen. Die Presse, heutigentags im gleichen Gebäude wie die Gin untergebracht, ist entweder eine von oben nach unten wirkende eiserne $\mathrm{Schra}$ u b n p resse; meist aber benutzt man jetzt eine hydraulische oder mit Dampf angetriebene vertikale $\mathrm{Z}$ y 1 ind e r presse und hat im Interesse einer möglichst ununterbrochenen Arbeit das System der Doppelkas ten eingeführt, welche auf einer drehbaren Plattform stehen. Die Maße der Preßkasten sind leider nicht einheitlich, sondern bei den verschiedenen Preßsystemen verschicden. Die aus dem Kondensor abfließende Baumwollschicht wird durch eine Ramme zunächst in dem einen Kasten zusammengedrückt, und ist dieser voll, so wird er herumgedreht, so daß er über dem Preßzylinder zu stehen kommt; hier wird die mit dem Packmaterial umhüllte Baumwolle gepreßt, während der andere Kasten inzwischen vom Kondensor neu gefüllt wird. Der Druck beträgt 400 bis 600 Pfund auf den Quadratzoll.

Die Baumwolle wird in der Gin im allgemeinen nur $\mathrm{h}$ a $1 \mathrm{~b}$ gepreßt, d. h. auf eine Dichtigkeit von 8 bis 16 Pfund auf den Kubikfuß gebracht. Zur Packung nimmt man dabei 6 Yards à $13 / 4$ bis $21 / 4$ Pfund schweren, 45 Zoll breiten ordinären Jutestoff (Burlap), oder 40 Zoll breite und $5 / 8$ Pfund das Yard schwere baumwollene "Osnaburgs", und darum werden an Stelle der Taue heute sechs eiserne Bandreifen à I $1 \%$, Pfund gelegt, so daß das Gesamtgewicht der etwa 50 Cents kostenden Verpackung eines 500 Pfund schweren Ballens $2 \mathrm{I}$ bis 22 Pfund beträgt.

Das Durchschnittsgewicht des Ballens Upland-B a u mwo 11 e hat im allgemeinen ständig zugenommen; es betrug nämlich in den Jahren:

$\begin{array}{lllllllll}1790 & \text { I825 } & \text { I } 841 & \text { I860 } & \text { I875 } & \text { I890 } & \text { I895 } & \text { I905 } & 1912 \\ 225 & 312 & 409 & 461 & 444 & 478 & 484 & 503 & 508\end{array}$

In Texas, Arkansas, Louisiana, Mississippi, Oklahoma und Tennessee betrug im letzten Jahre das Bruttogewicht durchschnittlich 520 Pfund, in Alabama, Georgia und den Carolinas 490 Pfund.

Sea Island-Ballen sind leichter, wogen im Jahre I9i2 durchschnittlich 382 Pfund brutto bei to Pfund Tara und einem Mafie von $80 \times 32$ inch.

Die $\mathrm{Ma} B$ e eines Standard-Ballen von 500 Pfund Upland bei I2 Fuls Dichtigkeit weisen ungefähr $56 \times 26 \times 48$ Zoll auf, bei $161 \%$ Pfund Dichtigkeit $54 \times 27 \times 36$; die letzte Dimension variiert am stärksten, je nach Dichtigkeit und Menge, denn auch die letztere 
ist bei den einzelnen Ballen ganz verschieden und schwankt im allgemeinen zwischen 440 und $55^{\circ}$ Pfund.

Den Schluß der Verpackung bildet das Markieren der Ballen. Jeder Pflanzer wählt sich cine Marke, gewöhnlich die Anfangsbuchstaben seines Namens, die mit Schablonen aufgezeichnet werden, und zwar jedes Jahr gleichmäßig, so daß die Marken als solche im Markte bekannt werden.

Von der Gin-Station geht die halbgepreßte Baumwolle, soweit sie nicht schon von der Entkernungsanstalt aufgekauft ist, in sogenannten „Pflanzerballen“, zusammen mit der zu ihr gehörigen Baumwollsaat, an den Farmer zurück, der beide Produkte auf dem ihm geeignet erscheinenden Markt zum Verkauf bringt. Für den F er nversand ist die Batumolle in diesem Stadium aber noch nicht fertig gepackt, sondern sie bedarf dazu noch einer $\mathrm{z}$ w e i t e $n$ und stärkeren Pressung in der sogenannten

Compress. Nach diesen, meist mit größeren Lagerräumen verbundenen Lohnanstalten, die gewöhnlich an Eisenbahnzentralpunkten oder in Hafenplätzen etabliert sind, senden die Zwischenhändler die halbgepreßte Baumwolle, meist auf der Bahn in Waggons mit durchschnittlich 25 Pflanzerballen, und dort wird die Ware entladen und gelegentlich weiter bearbeitet. Unter dieser schweren Endpresse wird das Volumen des Ballens ungefähr um die Hälfte und mehr reduziert. Die alten Reifen werden um 2 Fuß verkürzt, dagegen zwei neue à $\mathrm{I} 1 / 3$ Pfund zugefügt, und sodann werden Stücke alten Sacktuchs, angeblich zum Bedecken der beim Musterziehen entstandenen Löcher, aufgenäht, im ganzen etwa 3 bis 4 Yards à $1 / 2$ bis 2 Pfund, um die Tara künstlich auf die im ,cif"-Kontrakt der Liverpooler Baumwollbörse erlaubte Höhe von $6 \%=30$ Pfund auf den Ballen von 500 Pfund Bruttogewicht $=470$ Pfund Nettogewicht hinaufzuschrauben. Tatsächlich wäre leicht mit I6 bis 22 Pfund Tara oder $4 \frac{1}{2} \%$ als Maximum auszukommen, und die a $\mathrm{merik}$ a $\mathrm{i}$ sche $\mathrm{n}$ Spinner erlauben für Tara schon jetzt nicht mehr als 22, höchstens 24 Pfund.

Zurzeit sind in Nordamerika etwas über 300 Compresses tätig. welche jährlich rund Io Millionen Dollars einnehmen; sie sind zum großen Teil als „Trusts" organisiert, stehen in enger Verbindung mit Eisenbahngesellschaften, bei denen sie Vorzüge genießen, und häufen große Mengen von Baumwolle an Hauptpunkten an. Dic drei größten Compress-Korporationen sind die im Besitz von Eisenbahngesellschaften befindlichen "Atlantic Compress Company" in Augusta, Georgia, die auf die Golf-Staaten beschränkte „Gulf Com- 
press Company" und die „Mac Fadden Company", welche in ihren Anlagen rund 20 Millionen Dollars investiert haben. Diese Trusts sind die stärksten Gegner aller Verbesserungen, die i h r e n Besitzstand an Geschäften bedrohen und ihre veralteten Einrichtungen und Methoden noch wertloser machen könnten. Technische Erfindungen in der Richtung besserer Aufbereitung der Baumwollernte folgen sich neuerdings zwar schnell, sind aber angesichts der in den alten Anstalten angelegten großen Kapitalien nicht so bald in nennenswertem Umfang einzuführen. Auch ,bagging and ties“, die Verpackungsmaterialen, Gewebe und Bandeisen, sind vertrustet und dadurch Mißbräuchen in Qualität und Preis ausgesetzt.

Der Preis der großen schweren Compresses, die teils mit hydraulischem, teils mit Dampfdruck betrieben werden, beträgt im allgemeinen 25000 bis 30000 Dollars, steigt aber bis zu etwa 50000 Dollars, und die Le istu $\mathrm{ng} \mathrm{s}$ äh ig ke it der einzelnen Presse schwankt ungefähr zwischen 50 und angeblich 150 Ballen in der Stunde.

Als bekannte Systeme seien genannt: Webbs Cotton Compress der Reading Iron Company in Reading, Pennsylvania; Moise Cotton Compress der Fulton Iron Works in St. Louis, Missouri, und die Pierce Hydraulic Press der Cleveland Compress Company in Cleveland, Ohio.

Die in den amerikanischen Compresses erreichte Dichtigkeit schwankt zwischen $I 7$ und 30 Pfund auf den KubikfuB, bei 30 FuB mift der 500-Pfund-Ballen $54 \times 20 \times 27$ Zoll. $221 / 2$ Pfund werden jetzt von verschiedenen amerikanischen Baumwollkorporationen und Reedereien als Minimum verlangt, während die Dichtigkeit in Ägypten bis 37 Pfund, in Ostindien 40 bis 42, neuerdings sogar 54 bis 56 Pfund beträgt.

Ein ostindischer Ballen von 400 Pfund $=$ Io Kubikfuß bei einer Dichtigkeit von 40 Pfund hat 8 bis io Pfund Tara.

Ein äg y p t is cher Ballen von $75^{\circ}$ Pfund $=24$ Kubikfuß bei einer Dichtigkeit von 32 Pfund hat 2 I Pfund Tara.

Ein a $\mathrm{merikanischer}$ Ballen von 500 Pfund $=22$ Kubikfuß bei einer Dichtigkeit von 22 Pfund hat 30 Pfund Tara.

Der erwünschte amerikanische $\mathrm{Standard-Ballen} \mathrm{sollte}$ nach dem Muster der viereckigen ägyptischen Ballen bei 500 Pfund Nettogewicht 35 Pfund Dichtigkeit haben, in seinen Maßen $48 \times 2$ I $\times 2$ I Zoll aufweisen, mit ro Reifen geschnürt sein und an beiden Kopfenden die Angaben von Gewicht, Klasse und Stapel tragen; als Zielpunkte bei seiner Herstellung sollten gelten: Mög- 
lichste Schontung des Inhalts, Raumersparnis und gute Verstauungsmöglichkeit in Lagerhaus, Bahnwagen und Schiff, Verringerung der Fcuersgefahr. Leider sind die amerikanischen Ballen meist noch recht weit von diesem erwünschten Zustand entfernt.

Seit einiger Zeit hat sich deshalb eine Bewegung dahin gehend geltend gemacht, die jetzige do p p e l t e Pressung der Ballen durch eine e in zige, sofort in der Entkernungsanstalt vorzunehmende Pressung zu ersetzen, welche den seemäßig verpackten Ballen fertig liefert, und es sind bislang etwa ein Dutzend verschiedener, mehr oder veniger aussichtsreicher Systeme dieser sogenannten

Gin-Compresses bereits im Betrieb oder in Vorbereitung begriffen. Teilweise wird dabei das Prinzip der a $11 \mathrm{mäh} 1 \mathrm{ich}$ en Verdrängung der Luft angewandt, indem man die Luft zunächst aus den in Tafelform gelegten Lagen auspreßt und erşt diese dann zu einem Ballen formt und der letzten Pressung aussetzt.

Es handelt sich dabei um vi e r kan tig e Ballen à 500 Pfund und um runde oder zylindrische Ballen à 250 Pfund.

Erstere werden u. a. geliefert von der Mungers Cotton Compress der Continental Gin Company in Birmingham, Alabama; der Thomas Square Lap Bale Gin House Compress in Little Rock, Arkansas; der Farmers Compress Construction Company in Philadelphia, Pennsylvania; der Luce Compress and Cotton Company in New Orleans, Louisiana; der Neely Gin Compresss Company in Chester, Süd-Carolina, und netuerdings durch die Farmers Gin Compress and Cotton Company in Memphis, Tennessee.

Die amerikanischen Gin-Compresses für vierkantige Ballen kosten etwa 4000 bis 5000 Dollars, liefern 5 bis ${ }_{5}$ Ballen in der Stunde, bei einer Dichtigkeit von 30 bis 40 Pfund und einer Tara, die durchgehend eine geringere als die sonst übliche ist, nämlich bei Luce mit 6 Reifen 9 Pfund, bei Thomas mit 5 Reifen I $_{5}$ Pfund, bei der Farmers Compress aus Memphis 12 Pfund mit 7 Reifen; die letztere kostet 4000 Dollars und liefert den $500-$ Pfund-Ballen bei einer Dichtigkeit von 30 Pfund in den Maßen von $52 \times 25 \times 20$ Zoll, während Gin-Compresses mit 40 Pfund Dichtigkeit einen Ballen von $50 \times 20 \times 20$ Zoll liefern.

En $\mathrm{g} l$ is c h e Gin-Compresses nosten etwa Iooo Pfd. St., liefern 300 Ballen am Tage und halten 20 Jahre aus, während amerikanische nur 5 Jahre dauern.

Auch von den erst in den goer Jahren des vorigen Jahrhunderts cingefürten "R un dballe n" existiert eine ganze Reihe von Systemen, von den hier die Bessonette-Ballen, die Lowry-Ballen der 
Planters Press Co. in Boston, die Swenson-Ballen der American Cotton Co. in New York und die Reagan-Ballen der Reagan Round Bale Company in S. Antonio, Texas, genannt seien; letztere Presse kostet nur I200 Dollars. Die Rundballen haben das halbe Gewicht der vierkantigen, wogen im Jahre I9I2 durchschnittlich 254 Pfund und haben bei einer Tara von nur 3 Pfund und einer Dichtigkeit von 38 Pfund $36 \times 20$ Zoll Maß.

Die Meinungen der Spinner über „Rundballen“ sind verschieden, aber weitaus die Mehrzahl von ihnen zieht vierkantige Ballen vor, und tatsächlich ist der Anteil der Rundballen an der Gesamternte von $4,6 \%$ im Jahre 1902 auf $0,3 \%$ in 1912 zurückgegangen, und während Rundballenpressen 1902 in 12 Staaten in Gebrauch waren, benutzten sie im Jahre IgI2 nur noch Alabama, Arkansas, Louisiana, Oklahoma und Texas.

Feuchtigkeit in Baumwolle. Z uf ällig durch Regen-oder Preßwasser, nicht selten aber auch in bet $r$ ii $g$ e $r$ is ch c $r$ Absicht beigefügtes Wasser beschwert die Baumwolle zuweilen bis zu $16 \%$ an Stelle der normalen 81/2\% für Texas, $9 \%$ für Uplands, welche Baumwolle aufweisen darf; der Feuchtigkeitsgrad schwankt zwischen 6 und $16 \%$

Mit Rücksicht auf die erfahrungsgemäße Zunahme von Feuchtigkeit und damit auch Gewicht der Baumwolle während der Seereise wird in Amerika auf jeden Ballen von 500 Pfund ein Zuschlagsgewicht von 5 Pfund gerechnet.

Englische Spinner haben schon seit dem Jahre 1898 den Kampf für Einrichtung a $\mathrm{m} \mathrm{t} \mathrm{licher}$ Konditionieranstalten in den Baumwoll-Ankunftshäfen aufgenommen, bislang aber keine Gegenliebe bei den Baumwollbörsen gefunden, weil die europäischen Verkäufer keine Vergütung von Amerika zurückbekommen würden; eine im Jahre 1912 von den französischen Spinnern in Havre errichtete Konditionieranstalt wird von der Havre-Baumwollbörse nicht anerkannt.

Private und gesellschaftliche Konditionieranstalten bestehen zwar vielfach, in Frankreich schon seit 50 Jahren, aber keine a $\mathrm{m} \mathrm{t}$ $1 \mathrm{ich}$ en, welche systematisch und das ganze Jahr hindurch eine wissenschaftliche Feststellung des Feuchtigkeitsgrades in der Baumwolle als Grundlage für Feuchtigkeitsvergütungen vornehmen sollten. Dic Internationale Vereinigung von Baumwollspinnern und - webern hat sich seit Anfang ihres Bestehens für Errichtung solcher amtlicher Anstalten eingesetzt. 


\section{Produktionskosten und Rentabilität.}

Die Baumwolle ist nunmehr vollständig fertig für Verkauf und Versand. Ehe wir aber hierauf eingehen, sollten wir zunächst wissen, wie hoch sich der $\mathrm{Herste} 11 \mathrm{ungspreis} \mathrm{der} \mathrm{Baumwolle}$ stellt. Das ist nun keineswegs leicht festzustellen.

Fragt man den Pflanzer, was ihn seine Baumwolle kostet, so weiß das ungefähr $\mathrm{n}$ i e m a $\mathrm{nd}$ anzugeben, selbst der intelligente Pflanzer nicht. Eine planmäßige landwirtschaftliche Buchführung ist noch von der Sklavenzeit her im allgemeinen unbekannt, es gibt nur Abrechnungsbücher für Pächter, und es ist daher meist unmöglich, ge n a $u$ zu sagen, was eine Pflanzung einbringt und was die Erstehungskosten für ein Pfund Lint-Baumwolle sind.

Eine amtliche Umfrage, die Dr. Seaman A. Knapp, der verdienstvolle Chef der Baumwoll-Versuchsfarmen, im Jahre Igo4 unter 8000 Farmern hielt, ergab im Durchschnitt folgendes Resultat betreffs der Baukosten für das Pfund Lint-Baumwolle:

$\begin{array}{lllllll}\text { Bei einem Ertrage von I } & 1 / 2 & 1 / 3 & 1 / 4 & 1 / 16 & \text { Ballen vom Acre } \\ \text { kostete das Pfund } & 4 / 2 & 7 & 9 & 12 & 32 & \text { Cents. }\end{array}$

Der höchste Ertrag und damit der billigste Einstandspreis wurde erzielt auf bestem Lande, mit sorgsam gewähiter Saat, richtig gewählter Düngung und sorgfältiger Pflege.

Nach einer aus dem Jahre 1906 stammenden Schätzung verteilten sich die Herstellungskosten im ganzen Bereich der Vereinigten Staaten für das Pfund mit:

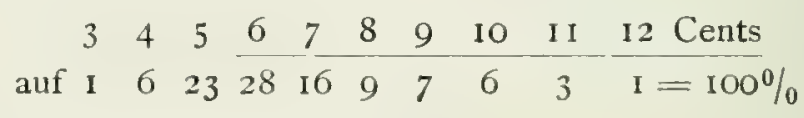

des gesamten Baumwollandes.

$\mathrm{DaB}$ Baumwolle unter besonders günstigen Bedingungen zu 3 bis 4 Cents produziert werden kann, steht außer Zweifel, aber es sind, wie obige Aufstellung zeigt, nur verhältnismäßig $\mathrm{kle}$ i ne Gebiete dazu imstande.

Im Jahre Igog wurden die Proc'uktionskosten auf durchschnittlich 8 Cents für das Pfund geschätzt.

Die State Experiment Farm in Stoneville, Mississippi, gab mir im Jahre 1907 folgende Berechnung für den Acre Baumwolland bei cinem Ertrag von einem Ballen auf, wobei Aufsicht und Abnutzung nicht in Anschlag gebracht wurden. 
A usgaben:

Landpacht .

Dollar 6,00

Landbestellung

\begin{tabular}{|c|c|}
\hline$"$ & 2,00 \\
\hline$"$ & 0,25 \\
\hline$"$ & 4,00 \\
\hline " & 5,00 \\
\hline " & 2,00 \\
\hline$"$ & 9,50 \\
\hline ", & 2,50 \\
\hline$n$ & $\mathrm{I}, \mathrm{OO}$ \\
\hline, & I, 50 \\
\hline
\end{tabular}

E in $n$ a h m en:

Aussaat.

Fünf Umackerungen

Zwei Bearbeitungen mit der Hacke

Pftücken von $1500 \mathrm{Pfd}$. Saatbaumwolle

Entkernen , 1500 ,,

Steuern .

Fracht, Kommission und Versicherung.

500 Pfd. Lintbaumwolle à I 3 Cents Dollar 65,00

I00o Pfd. Baumwollsaat à 15 Dollars die Tonne

Nettoertrag des Acre . .

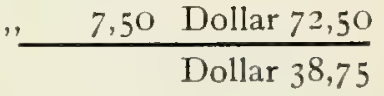

Aus neuerer Zeit, dem Jahre I9I3, stammen die folgenden, auch auf amtlichen Grundlagen von Mercier und Savely mitgeteilten Beispiele, bei denen die Produktionskosten für den Acre berechnet sind:

in Reihe A für gute Farmen auf guten Böden, mit guten Gespannen und Werkzeugen und einem Ertrag von 500 Pfund Lint,

in Reihe B für gewöhnliche Farmen auf Durchschnittsbaumwolland, mit ungenügenden Gespannen und Geräten und einem Ertrag von nur 200 Pfund Lint.

\section{Produktionskosten auf den Acre.}

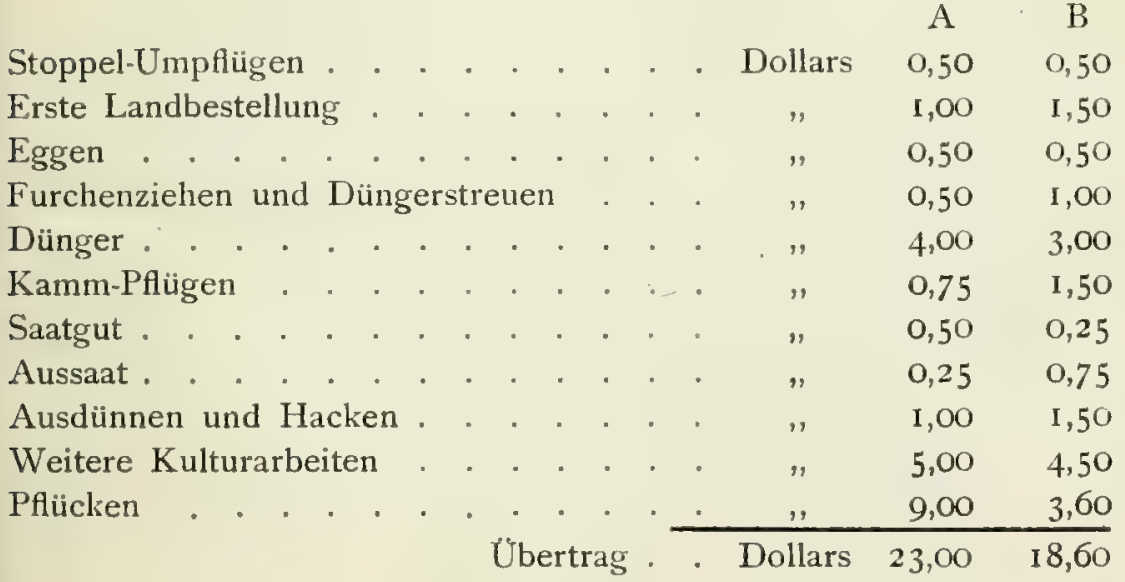


Entkernen und Packen

Übertrag . Dollars 23,00 i 8,60 Transport zu Gin und Marktplatz - " $\quad 3,00$ Landpacht .

\begin{tabular}{rrrr}
.$\quad$ & 1,50 & 0,60 \\
\hline & \multicolumn{1}{c}{$\quad 5,00$} & 3,00 \\
\hline Dollars & 32,50 & 23,40
\end{tabular}

Ertrag.

I000 Pfd. bzw. 400 Pfd. Saat à Dollar I 8 per Tonne Dollar 9,00 3.60 500 Pfd. bzw. 200 Pfd. Lint à Io Cents

Kosten

Netto Nutzen

Kosten des Pfundes Baumwolle.

\begin{tabular}{ccc}
$n$ & 50,00 & 20,00 \\
\hline Dollar & 59,00 & 23,60 \\
$n$ & 32,50 & 23,40 \\
\hline Dollar & 26,50 & 0,20 \\
\hline Cents & 4,7 & 9,9
\end{tabular}

$\mathrm{Zu}$ vorstehenden Aufstellungen treten noch einige andere Unkosten hinzu, so z. B.:

Verzinsung. Bewirtschaftet der Besitzer sein Land selbst, so muß sich das darin angelegte Kapital mit mindestens $6 \%$ verzinsen. Die übliche 20-Acres-Farm kostet niedrig gerechnet ì I5 Dollars 300 Dollars, das Maultier oder Pferd 200 Dollars, das Gerät 75 Dollars, Total 575 Dollars, oder zu $6 \%$ eine Zinsbelastung von $34 \frac{1 / 2}{12}$ Dollars.

S t e u e rn darauf betragen 3 Dollars.

A bschreibungen. Ein Pferd oder Maultier kann durchschnittlich to Jahre arbeiten, daher steht eine jährliche Abschreibung von 20 Dollars darauf; dazu für Reparaturen der Geräte und Abnutzung noch mindestens io Dollars, total 30 Dollars.

An Unterhaltungskosten des Landes und Viehbestandes auch außerhalb der eigentlichen Feldarbeiten rechnet man bei der 20-Acres-Farm jährlich etwa 45 Dollars.

Die übliche Familienfarm von 20 Acres Baumwolland würde bei dem amerikanischen Durchschnittsertrag von 200 Pfund Lint auf den Acre 4000 Pfund Lint-Baumwolle und 8000 Pfund Baumwollsaat, oder zum Preise von io Cents für Lint und I8 Dollars für Saat, einen $\mathrm{Brut}$ toe r trag von 520 Dollars im Jahre erzielen; dabei ist in Betracht zu ziehen, daß der Winter Zeit für Nebenverdienst läßt. Harvie Jordan behauptet freilich, daß eine weiße Familie mit fünf l'ersonen im Durchschnitt nur 6 Ballen $=3000$ I'fund im Jahre ernte. Man würde dabei erst recht annehmen müssen, daß ein geringerer Preis als Io Cents den Kleinfarmer zum WVegzug 
oder zum Übergang zu anderen, lolnnenderen Kulturen zwingen würde.

Ist Baumwolle doch auch die un sich e r s t $\mathrm{c}$, weil am meisten von der Witterung beeinflußte Kultur. Zuckerrohr, Reis und andere Bodenerzeugnisse werfen bei weniger Arbeit weit höheren Nutzen ab. So rechnete man im Jahre 1907 in der Nähe von Houston, Texas, folgende Bruttocrträge auf den Acre beim Anbau von: Baumwolle 50, Bohnen 150, Reis 300, Salat und Zwiebeln 350, Möhren 400, Kohl 450, Tomaten 450 bis 800 , Blumenkohl I 200 Dollars. Baumwolle bictet allerdings den g r o B e n Vorteil, j e d e r zeit leicht verkäuflich zu sein, und bei leidlichen Allgemeinbedingungen und cinem vernünftigen Grad von praktischer Erfahrung ist durchschnitlich auch von Baumwolle ein guter Nutzen zu erwarten.

\section{Baumwollsaat und Produkte daraus.}

Ist die L in t-B a u $\mathrm{m}$ wo $11 \mathrm{e}$ auch weitaus der höchstwertige Teil der Baumwollpflanze, so gibt es doch keinen Teil derselben, der nicht gleichfalls seinen Nutzwert hätte, wenn dieser teilweise auch recht spät crkannt und angewandt worden ist.

Die. R inde der W urzeln dient zu medizinischen Mitteln.

Die B 1 ätter, le eren Kapseln und Aste der Pflanze werden nach der letzten Pfliicke vom Vieh abgeweidet; dic dann noch stehen bleibenden trockenen St e $\mathrm{ng} \mathrm{e} 1$, dic man in holzarmen Ländern als Feuerungsmaterial verwendet, haben ungefähr deñ gleichen Futterwert wie Hafer- und Weizenstroh und dienen als Düngemittel. Man hat in Nordamerika aus dem B a s t e des Baumwollstengels auch eine zu Sacktuch, Matten und Teppichgarnen gut gecignete F a s e gewonnen; es fehlte bislang aber noch an einer wirklich brauchbaren, billig arbeitenden Schälmaschine; dagegen hat man mit der Benutzung der Baumwollstengel zur D r u c k p a j i crfabrikation bereits recht gute Resultate erzielt.

Weitaus das wichtigste Nebenprodukt der Baumwolle aber bildet die $\mathrm{B}$ a u $\mathrm{mw}$ oll sa at, welche in ihrem rohen Zustande heutigentags einen jährlichen Produktionswert von rund I50 Millionen Dollars repräsentiert.

Die flaumartigen, der Saat nach ihrer Entkernung noch anhaftenden, im Gegensatz zu dem langstapeligen Lint als

„Linters" bezeichneten kurzen Fasern dienen zur Herstellung von Hut- und anderen Filzen, Vigognegarnen, gewöhnlicher 
und Verbandwatte, Schicßbaumwolle, Sackmaterial, Putz- und Scheuertüchern, Bettdecken und Teppichen, Polstermaterial, Dochten, Bindfaden, Stricken und Zellulose und werden auch in der Papierfabrikation benutzt. Auch die Fasern der in der Entkernungsfabrik abfallenden ,Motes", das sind unreife Samen, werden stellenweise noch auf besonderen Maschinen gewonnen.

Die von den Samenkernen getrennten

Schale n, die "Hulls" oder ,Husks", liefern als Kleie ein gutes Futtermittel, werden als Düngemittel benutzt und hinterlassen, als Brennmaterial verwandt — was heutigentags allerdings kaum mehr geschieht - , eine an wertvollen Dungstoffen (Potasche) reiche Asche, aus der man angeblich auch Kalisalze zur Glasfärbung gewinnen kann, welche den aus Melassekohlen gewonnenen gleichen. Die geschälten

K e r n e endlich liefern, ausgepreßt, das zu den verschiedensten Zwecken verwendete $B$ a $\mathrm{um}$ o $11 \mathrm{~s}$ a a tö 1 , als Rückstand den $\mathrm{B}$ a u m wo $11 \mathrm{sa}$ a $\mathrm{tk} \mathrm{c} \mathrm{c}$ e $\mathrm{n}$, der, gemahlen, das B a m wo 11 $\mathrm{s}$ a a $\mathrm{t} \mathrm{m}$ e h 1 ergibt, beides wertvolle Futtermittel und Düngestoffe.

Die Preis e für die verschiedenen Produkte aus Baumwollsaat schwanken natürlich je nach dem Preisstand der Konkurrenzartikel; so konkurrieren Linters mit Stapelbaumwolle; Saatschalen und Ölkuchen mit anderen Futtermitteln und Düngestoffen; Baumwollöl mit Schweinespeck, Olivenöl und Seifenmaterialien.

Lange genug hat es freilich gedauert, ehe man in Amerika den hohen wirtschaftlichen Wert der Baumwollsaat erkannte.

Vor Einführung der Ölmühlen diente die Saat im allgemeinen nur zur neuen Aussaat und zu Düngezwecken, vereinzelt auch als Viehfutter. Der erschöpfte Boden der atlantischen Küstenstaaten gab die erste Veranlassung, in Nordamerika Baumwollsaat als $\mathrm{D}$ ü $\mathrm{n} \mathrm{g} \mathrm{e} \mathrm{m} \mathrm{it} \mathrm{te} 1$ zu verwenden, und man bezahlte für dicse Zwecke 6 bis 9 Dollars die Tonne; wo Düngen aber nicht nötig war, befand man sich oft in der größten Verlegenheit, was man mit der Saat anstellen sollte. Das, was man nicht zur Neuaussaat gebrauchte. wurde meist als eine $L$ as $t$ betrachtet, die man billigst möglich zu entfernen trachtete. Oft ließ man dic Saat an abgelegenen Orten verrotten, oder man übergab sie fließenden Gewässern und stelltc, um das Wegschwemmen möglichst bequem zu machen, den Entkerner häufig gleich über einen Kanal auf. Dieses System wirkte aber direkt gesundheitsschädlich, und so schritt, als die Bevölkerung dichter wurde, in verschiedenen Staaten die Gesetzgebung gegen die Verunreinigung der Flüsse mit Baumwollsat ein. 
Darin ist nun ein gewaltiger Unterschied eingetreten, seitdem man den Wert des Öls in der Baumwollsaat erkannte und mit technischen Hilfsmitteln zu gewinnen lernte. So gehen denn heute bereits $75 \%$ der gesamten Saat in die Olmühlen. Der Rest wird auch heute noch überwiegend als Düngemittel benutzt, obgleich dieses Verfahren durchaus unrationell ist, da das Öl als solches keinen Düngewert besitzt und somit im Boden ganz ungenutzt verloren geht. Auch die Verwendung der ganzen $\mathrm{S}$ a a t als Fut termittel, die früher vorkam, ist jetzt als unwirtschaftlich gänzlich aufgegeben, weil die der Saat anhaftenden Flaumhaare und andere Beigaben schädlich auf dic Tiere wirkten und die nötige Mischung mit rauhem Futter schwierig ist.

Die ganze Entwicklung geht naturgemäß dahin, mit Ausnahme der für die nächste Aussaat nötigen Mengen, das ga a 11 e Quantum von Baumwollsaat an die Ölmühlen abzuliefern.

Von der gesamten Saaternte des Jahres 1905 wurden verwandt:

$62 \%$ in den Ölmühlen,

30 , zu Düngezweken,

7,8, zur neuen Aussaat $=26$ Pfund auf den Acre,

$\frac{0,2,,}{100 \%}$ ins Ausland ausgeführt,

Seitdem ist der Anteil der Olmühlen schon bis zu $79 \%$ gesticgen, obgleich sich mit der stark wachsenden Konkurrenz deren Betrieb letzthin weit weniger lohnend als früher gestaltet hat.

Die Ölmühlen. Baumwollsaatöl wurde vermutlich zunächst zu Beleuchtungszwecken benutzt, so vor vielen Jahrhunderten in Indien, und auch in den Vereinigten Staaten um das Jahr $175^{\circ}$ bereits als Ersatz für Walfischtran in Lampen gebraucht, eine Verwendung, die um 1820 allgemeiner geworden zu scin scheint. Dic crste kleine Ölmühle wurde 1826 in Süd-Carolina, 1832 eine zweite auf den Georgia vorliegenden Inseln errichtet, und im Jahre 1843 soll es bereits 43 Ölmühlen in den Vereinigten Staaten gegeben haben. Aber die Herstellung war noch sehr teuer und der Bürgerkrieg brachte die Fabriken zum Stillstand. I867 gab es im ganzen Süden nur 4 Ölmühlen, in den Vereinigten Staaten überhaupt nur 7 . Die Vormacht in Herstellung von Baumwollöl aber war damals England, das im Jahre I870 z. B. 200000 Tonnen Saat verarbeitete, die es erst weit herholen mußte. Des Baumwollrohöls säuerlicher und bitterer Geschmack machte es anfangs für Genußzwecke wenig 
tauglich; allmählich aber gelang es der Wissenschaft, cin reines, klares und wohlschmeckendes Öl zu erzeugen, wenn diese Verbesserungen in der Herstellung von den Betreffenden zunächst auch sehr geheimnisvoll behandelt wurden. Die Zahl der Mühlen in der Union war von 26 in 1870 auf 45 in I880 gestiegen und von da ab begann die schnelle Entwicklung des Gewerbes, nachdem man endlich den Wert des Baumwollöls für die Nahrung des Menschen erkannte. Bislang hatte man das Baumwollöl überwiegend als Ersatz von Olivenöl verwandt. Erst I88 I fand man, daß Baumwollöl, mit tierischen Fetten gemischt, auch einen guten Ersatz für Speck bilde, doch bchandelte man das bei dieser Herstellung $z u$ beobachtende Verfahren zunächst ebenfalls ziemlich geheim.

Anfänglich wurde die Ölindustrie von einer großen Gesellschaft, der „American Cotton Oil Company“ kontrolliert, bald aber entstanden neue Unternehmungen. Hatte man bislang ausschließlich c $n \mathrm{~g} l \mathrm{i}$ s ch e Maschinenanlagen benutzt, so fing man ab 1884 an, in der Olindustrie a merika $\mathrm{n}$ is $\mathrm{ch}$ e Maschinen zu gebrauchen, und zwar kommen dafür heute besonders die folgenden Werke als Lieferanten in Betracht:

G. H. Bushnell Press Company in Thompsonville, Connect., besonders für kleinere Anlagen; W. P. Callahan Company und die Buckeye Iron and Brass Works in Dayton, Ohio; endlich die Cardwell Machine Company in Richmond, Virginia.

Im Jahre IgI2 war die Zahl der Ólmühlen auf 859 gestiegen, welche durchschnittlich je 533 I Tonnen Sat in der Saison bearbeiteten und sich auf die einzelnen Staaten verteilten mit 220 in Texas, I 59 in Georgia, 99 in Süd-Carolina, 79 in Alabama, 75 in Mississippi, 63 in Nord-Carolina, 55 in Oklahoma und 42 in Arkansas.

Der letzte Zensus von Ig ro gibt für die damals vorhandenen 8I7 Mühlen eine Kapitalanlage von 9I Millionen Dollars und cin Total von 185000 Pferdekräften an, bei 21 ooo Angestellten, im Durchschnitt 25 auf das Etablissement. Dic in den Ölmühlen bcschäftigten Arbeiter sind meist Farbige.

In welchem Maße die produzierte Saat in dic Mühle wanderte, zeigt folgende Tabelle:

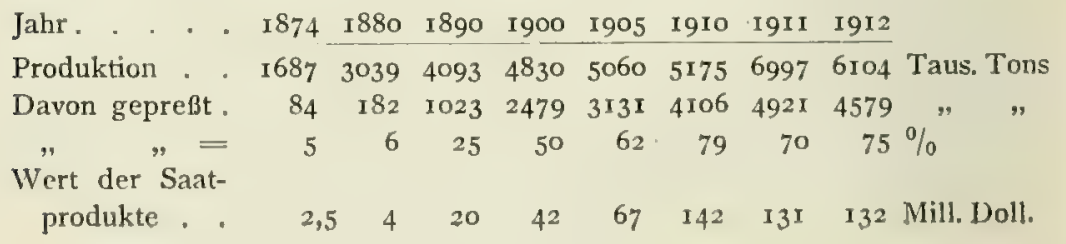


Im einzelnen ergaben die im Jahre I9I2 gepreBten 4579000 Tonnen Saat:

I85 Mill. Gallonen Öl im Werte von. . . . . . . . 69 Mill. Doll.

2 , Tonnen Kuchen und Mehl im Werte von . . 46 " "

I,54, " Schalen im Werte von .... 9 9,7 " ,

583000 Ballen à 500 Pfund netto Linters im Werte von. 7,4 , ,.

I32,I Mill. Doll.

Ein Gesamtbild über die Entwicklung der Erzeugnisse aus Baumwollsaat gibt die folgende Tabelle:

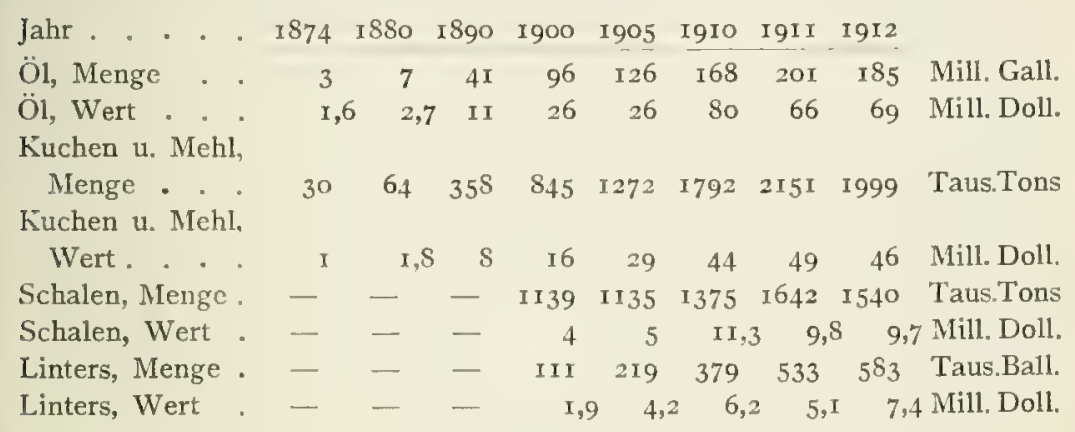

Es gibt heute zweierlei Formen von Ölmühlen:

große, an Eisenbahnknotenpunkten gelegene, auf das rationellste eingerichtet und betrieben, mit Raffinerien ausgestattet, verarbeiten in 24 Stunden I5O bis 250 Tonnen Saat, in der Saison über 20000 Tonnen; der Einkaufsradius für Baumwollsaat ist bei diesen Mühlen ein sehr großer. Daneben gibt es zahlreiche

$\mathrm{k} l \mathrm{e}$ in e Genossenschaftsmühlen in Plätzen mit ungenügender Eisenbahnverbindung, welche für ihre Saat hauptsächlich auf dic Zufuhren aus der nächsten Umgebung angewiesen sind, und in 24 Stunden 20 bis 40 , in der Saison 2000 bis 4000 Tonnen Saat verarbeiten. Die Pflanzer, welche die Genossenschaft bilden, liefern dic Saat zu billigen Preisen und sind ihrerseits wieder sichere Abnehmer von Schalen und Baumwollsaatmehl für Futter- und Düngemittel, so daß nur Baumwollöl und Linters, also I7 \% des Gesamtertrages an Gewicht, auf größere Entfernungen hin verfrachtet zu werden brauchen.

Nicht selten sind die Ölmühlen gleich den Entkernungsanstalten angeschlossen, und die nachfolgende Tabelle gibt Aufschluß über die Anlagekosten. 


\begin{tabular}{|c|c|c|c|c|c|c|c|c|c|c|}
\hline 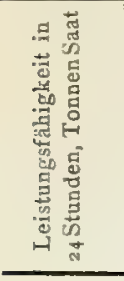 & 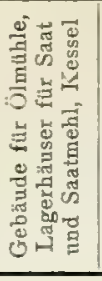 & 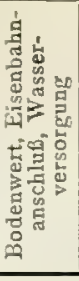 & 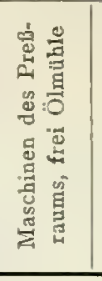 & 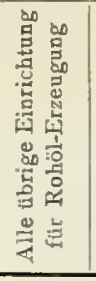 & 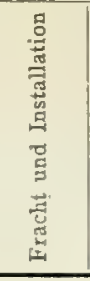 & 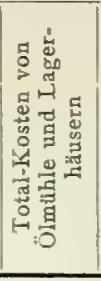 & 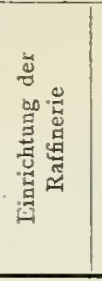 & 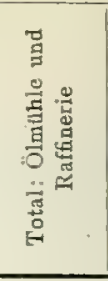 & 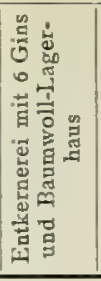 & 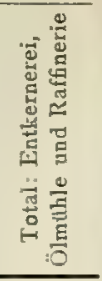 \\
\hline & \multicolumn{10}{|c|}{$\mathrm{D} \circ 1 \mathrm{lars}$} \\
\hline $20-30$ & IO 000 & 2000 & 6400 & 8500 & 4500 & 3 I 4 & II 600 & 43000 & 15000 & 58000 \\
\hline $30-40$ & 10000 & 2000 & 8200 & 10 000 & 4800 & 350 & I5 000 & 50000 & 15000 & 65000 \\
\hline $60-80$ & I 5000 & 2000 & 12500 & 22000 & 8500 & 600 & 25000 & 85000 & 15000 & 100000 \\
\hline $100-120$ & 22000 & 2500 & I8 500 & 34500 & I 2500 & 90000 & 35000 & 125000 & 15000 & 140000 \\
\hline
\end{tabular}

Während der Gin-Saison gibt es in allen Marktplätzen der Baumwollstaaten "S a a t-A g e n t e n", welche die Saat für eigene oder für Rechnung der Ölmühlen aufkaufen, teilweise liefern Pflanzer und Gin-Anstalten ihre Saat auch direkt an dic nächstc Ölmühle ab; denn die Transportkosten darauf sind, der Natur des Artikels entsprechend, verhältnismäßig sehr hohe.

Der Durchschnittspreis der Saat betrug für die Tonne von 2000 Pfund in den Jahren

\begin{tabular}{|c|c|c|c|c|c|c|c|c|c|c|c|c|c|}
\hline I899 & 1900 & I90I & 1902 & 1903 & 1904 & 1905 & 1906 & 1907 & I 908 & I909 & 1910 & 1911 & I9I2 \\
\hline \multicolumn{14}{|c|}{$\mathrm{D} 01 \mathrm{lars}$} \\
\hline I I, 60 & 16,0 & 12,50 & I 5,8 & $\mathbf{1} 7,8$ & 14,2 & I 4,9 & 13,8 & I 7,6 & I 5,6 & 27,7 & 27,4 & I 8,3 & 21,2 \\
\hline
\end{tabular}

Die Ausfuhr von g a n z e r Baumwollsaat betrug im Jahre 1906 rund 12000 Tonnen im Werte von 268000 Dollars und ging hauptsächlich nach Holland, England und Deutschland. Im Jahre IgI I betrug die Ausfuhr 32000 Tonnen.

In den Olmühlen zu L a g e r gebrachte Saat sollte durchaus trocken sein; es ist dies überaus wichtig, denn schon wenige feuchte Kerne können schnell allgemeine Erhitzung verursachen und dadurch die Qualität der Saat stark beeinträchtigen. Die Saat der ersten Pflücke enthält den meisten Saft und erhitzt sich deshalb leichter, so daß manchmal Selbstentzündung eintritt; deshalb verarbeiten die Olmühlen diese erste Saat so rasch wie möglich. Da die Saat, wie alle Ölsamen, sich überhaupt leicht erhitzt, wenn sie in Massen in einem geschlossenen Raum liegt, so muß sie auf Lager 
immer sorgfältig überwacht und $\mathrm{schnell}$ verarbeitet werden. Man kennt bislang noch kein Mittel, welches erlaubte, größere Mengen von Baumwollsaat für längere Zeit aufzubewahren.

Die $\mathrm{B}$ e a r beitung selbst geschieht nun folgendermaßen:

Durch lange horizontale Förderschrauben wird die Saat vom Lagerhaus nach der anstoßenden Mühle und hier durch BecherElevatoren nach dem Oberstock gebracht, wo man sie durch zwei S i ebung e n zunächst von beigemischten Stengeln, Blätter- und Kapselteilen, sodann von Sand, Erde und anderen kleineren Verunreinigungen befreit.

Linters. Ein Kanal führt die Saat alsdann zur „Lin terG in“. Die zur Neuaussaat bestimmte Saat braucht nicht von dem aller Upland-Saat anhängenden Flaum gereinigt zu werden, wohl aber ist dessen Entfernung in der Ölmühle wichtig, weil man damit nicht nur ein Handelsprodukt, die "Linters", gewinnt, sondern dadurch auch die Qualität des Öls und der anderen Nebenprodukte crhöht. Die Entfernung der Linters verhindert das Aufsaugen des Öls durch die kurzen Fasern und macht dic Hülsen geeigneter für Viehfutter. Die Linter-Gin, eine Säge-Gin mit enger gestellten Zähnen als in den Entkernungsanstalten, nimmt nun noch einen Teil der Fasern, dic kurzhaarigen Linters, ab, welche, vom Kondensor kommend, in deckenförmige Lagen aufgerollt und dann ebenso wie die Lint-Baumwolle in Ballen verpackt werden. Der Ertrag an Linters ist durch verbesserte Maschinen netuerdings gestiegen, betrug im Jahre I9I2 auf dic Tonne Saat im Mittel 67 Pfund, in Louisiana und Mississippi 6I, in Oklahoma 8I Pfund. Die Linters werden teilweise exportiert, ein guter Teil auch nach Deutschland. Ihr Preis schwankt, je nach Länge der Faser, zwischen I und 4 Cents für das Pfund.

Im Gegensatz zu der, wie bereits früher erwähnt, ganz nackten, glatten und haarlosen Sea Island-Saat ist die Saat der UplandBaumwolle, welche ja weitaus den Hauptteil der amerikanischen Ernte liefert, auch nach diesem zweiten Ginnen noch wollig. Neuerdings hat man deshalb an einigen Stellen angefangen, diese Baumwollsaat noch ein drittes Mal zu ginnen, und das dabei gewonnene, ganz kurzstapelige Material zur Papierfabrikation benutzt.

Von der Linter-Gin kommt die Saat nunmehr in den "Huller“ oder "Sheller" genannten Schäler, einen starken Zylinder, in dem schnell rotierende, gegeneinandergestellte Schneiden die $\mathrm{S}$ ch a l e von dem K e rn der Saat loslösen; ein Enthülser mittlerer Größe bearbeitet am Tage to bis 50 Tonnen Saat. Ein auf diesen 
Prozeb folgendes Sieben und Schütteln in Separator trennt die beiden Bestandteile voneinander, die Hulls und Husks, die Schalen, von den „Meats" oder Kernen.

Baumwollsaatschalen. Dic Schalen werden einer weitercn Bearbeitung $\mathrm{n}$ i $\mathrm{ch}$ t unterzogen, sondern durch eine mechanische Vorrichtung nach dem Lagerhaus geführt.

Die erste B en utzung der Schalen war dic als Feuerungsmaterial bei den Olmühlen, und zwar ist der Heizwert einer Tonne Schalen ungefähr demjenigen einer Viertel Tonne Kohle gleich. Dic Asche der Saat benutzte man als Dünger. Bereits eine Verarbeitung von to Tonnen Saat am Tage lieferte aber reichlich genügend Hülsen für dic Betriebsfeuerung, so daß man nach einer anderen Verwendung des nutzlosen Uberschusses dieses sperrigen und schwer zu transportierenden Artikels Umschau halten mußte.

Zwar hatte man die Schalen schon in den ersten Tagen der Ölmählen auch als F u t e r m it t e 1 benutzt, aber ihr wahrer Wert als solcher wurde erst zwischen 1885 und 1890 erkannt. Um diese Zeit begann in Südwesten der Union cine systematische Rinderfütterung im Anschluß an die Ölmühlen; große Herden von Texasvieh wurden billig aufgekauft, nahe den Ölmühlen gemästet und, wenn sie fett waren, nach den Schlachthäusern versandt. Dabei wurde der Wert der Baumwollschalen als einer Art Kleie praktisch im großen erwiesen, und so erwuchs in a lle $\mathbf{n}$ Baumwollstaaten wachsende Nachfrage danach, da sie sich als ein billiger und wirksamer Ersatz von Heu bewährten. Ungekocht und ohne jede weitere Zerkleinerung werden sie meist in der Form benutzt, daß sie nicht allein, sondern mit cinem genau ausprobierten Prozentsatz von Baumwollsaatmehl gemischt verabreicht werden. Gewölnlich rechnet man auf fünf Teile Schalen einen Teil Mehl.

Viele der Ölmühlen in den Vereinigten Staaten, besonders im Südwesten, übernehmen heute im Nebenbetrieb gegen einen bestimmten Preis für den Kopf die Fettmachung ihnen zugeführten Magerviehs, welches teils in leichten langen Schuppen, teils ganz im Freien, in Hürden, untergebracht, meist sofort enthörnt und nach drei bis vier Monaten, wenn schlachtreif, direkt und möglichst schnell nach den Verkaufsmärkten transporticrt wird.

In Texas wird das Vieh durch die Ölmühlen a us ch 1 i e B1 i e mit Baumwollhülsen und Baumwollsatmehl gemästet, ohnc irgendwelches andere Beifutter, wie man das in den Südoststaaten tut.

Die sperrige Natur der Schalen und der Umstand, daß sic lose 
auf Lager leicht der Erhitzung ausgesetzt sind, machen ihre Behandlung schwierig. Für den $\mathrm{E} \times \mathrm{p}$ or $\mathrm{t}$ sind sie durch den niedrigen Wert bei großer Raumbeanspruchung ausgeschlossen. Im Binnenland werden sie teils offen in Wagen verladen, teils in gepreßten Ballen von ungefähr je Ioo Pfund Gewicht.

Der Preis der Schalen ist zu gleicher Zeit je nach den verschiedenen Unständen der einzelnen Bezirke sehr verschieden, betrug z. B. zur Zeit meines letzten Besuchs im Herbst Iyo7 in Atlanta, Georgia, für die Tonne f. o. b. $7 \frac{1}{2}$ Dollars in bulk, d. h. lose, und IO1/4 bis 13 Dollars in Säcken, gleichzeitig in Texas aber nur 5 Dollars und weniger. Dieser große Unterschied erklärt sich daraus, daß im Staate Texas Grünfutter und Heu in großen Mengen erzeugt werden, und man die eigene Massenproduktion von Baumwollschalen nicht aufbrauchen kann; im Staate Georgia dagegen liegen die Verhältnisse gerade umgekehrt: Grünfutter und Heu werden hier wenig erzeugt, so daß Baumwollsaatschalen stark als Viehfutter benutzt werden müssen, und da diese zum größten Teile aus Texas gedeckt werden, so treten zu dem Einkaufspreis dort noch die Kosten der Bahnbeförderung, die im Durchschnitt 6 Dollars auf die Tonne betragen.

Im allgemeinen sind die Schalen beinahe soviel wie Heu wert.

Die A s c h e von Baumwollsaatschalen, als Ersatz von Kali besonders von Tabakpflanzern gesucht, ist seit I880 auf dem Markt; Wert und Preis - etwa 40 bis 50 Dollars die Tonne - wechseln sehr nach der Menge ihr beigemischter Verunreinigungen, besonders durch den gleichzeitigen Gebrauch anderer Heizmittel neben Baumwollschalen. Im übrigen werden Schalen als Heizmittel heute kaum mehr gebraucht.

ơlgewinnung. Die von den Schalen befreiten Baumwollsaatkerne, die sogenannten „Meats", kommen nunmehr zunächst in den „Crusher", vier bis fünf übereinanderliegende, schwere eiserne Rollen, welche die Olzellen brechen und ein grobes Mehl liefern, das durch einen Kanal, den "Conveyor", in einen gußeisernen D a $m$ p f k o h a p a rat gelangt, in welchem der kochende Brei bei einem Dampfdruck von 40 bis 60 Pfund mit Rührstäben mechanisch umgerührt wird. Es soll dabei das Eiweis gerinnen, das OI leicht flüssig und das in den Kernen enthaltene Wasser verdampft werden, zu welchem Zwecke die Temperatur allmählich auf $105^{\circ} \mathrm{C}$. erhöht wird. Die dafür nötige Zeit beläuft sich meist auf 20 bis 30 Minuten; bei sehr trockener Saat bedarf es nur I 2 bis I 8 Minuten. bei sehr frischer kann es bis zu 45 Minuten dauern. Die richtige 
Abwartung beim Kochen bildet den verantwortlichsten und schwierigsten Teil bei dem ganzen Verfahren.

Von dem Kochapparat gelangt der heiBe Brei in den nahebeistehenden „F o r m e r"; hier wird er in $32 \times 14$ Zoll große Kuchen geformt, die man mit Kamelhaartuch umhüllt und dann in die gegenïberstehende Press e einlegt.

Die seit dem Jahre 1882 eingeführte jetzige Form der Pressen weist übereinander I 2 bis I6 eiserne Preßkasten auf, und die darin liegenden heißen Kuchen werden I 2 bis 20 Minuten, zuweilen noch länger, einem hydraulischen Druck von 3000 bis 4000 Pfund auf den Quadratzoll ausgesetzt, wobei das B a u m w o 11 ö 1 ausgepreßt wird und seitlich langsam abfließt, während die von $21 / 2$ auf etwa $5 / 8$ Zoll Höhe reduzierten, gepreßten $\mathrm{B}$ a $\mathrm{u} \mathrm{m}$ w o $11 \mathrm{~s}$ a a $\mathrm{t} \mathrm{k} \mathrm{c} \mathrm{h}$ e $\mathrm{n}$ herausgenommen, vom Tuche befreit und 12 bis 24 Stunden zum Trocknen aufgestapelt werden; sie sind dann bretterhart.

Wenn die Kuchen die Presse verlassen, wiegen sie je I2 bis 14 Pfund. Eine Presse mit i5 Kästen repräsentiert ungefähr den Ertrag von einer viertel Tonne Saat.

Der Durchschnittsertrag von Öl, Mehl und Schalen ist in den verschiedenen Jahren und Staaten sehr verschieden, je nach der Witterung, Art und Zustand der Saat und Leistungsfähigkeit der Presse.

Laut amtlichen Berichten ergab eine Tonne von 2000 Pfund Baumwollsaat in den Jahren

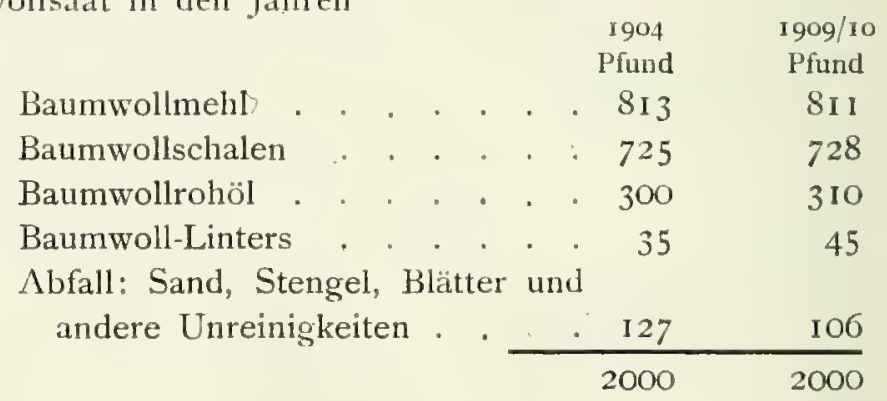

Der Durchschnittsertrag an Öl belüuft sich in Nordamerika auf ${ }_{15} \%=40$ Gallonen à 3.78 Liter oder $7 \frac{1}{2}$ Pfund. Chemischer Berechnung nach enthält die Tonne Saat allerdings 53 Gallonen Oo und tatsächlich, wenn auch nur vereinzelt, werden auch in Amerika größere Lrträge als I5\% erzielt; doch sind dies Ausnahmen, die meist nur auf Kosten der Qualität des Ols und der Ölkuchen erziclt werden; auch letztere enthalten natïlich noch einen gewissen Prozentsatz an Öl. 
$\mathrm{Da}$ man es in $\AA \mathrm{g}$ y pte $\mathrm{n}$ mit einer glattsamigen Baumwollsaat zu tun hat, so preßt man diese, sowohl in der Heimat wie auch in Hull, dem Zentrum der englischen Ölindustrie, u n geschält, und die Ölkuchen daraus enthalten also auch Saatschalen. Ägyptische Saat gibt I8 bis $20 \%$ OI, also mehr als Upland-Saat mit ihrem Durchschnitt von nur $15 \%$.

In A merika wird ungeschälte Upland-Saat nicht zur OIgewinnung benutzt, und Kuchen ohne Schalen gelten als fünfmal so nahrhaft und gesund wie solche mit Schalen.

Wohl aber wird die nackte Sea Is Iand-S a t auch in Amerika nicht geschält, sondern in Hülsen auf ơl gepreßt. Das dabei als Rückstand gewonnene Mehl enthält aber nur 3 bis $4 \%$ Stickstoff gegen 7 bis $9 \%$ bei Upland-Sorten und ist deshalb als Düngemittel weniger geschätzt als Upland-Miehl und auch als Futtermittel minderwertig.

Man hat früher auch in Nordamerika das intensivere $c h e-$ $\mathrm{m}$ is $\mathrm{c}$ h e Verfahren zur Extraktion des Ols mit Hilfe von Schwefelkohlenstoff zu betreiben gesucht, ist davon aber gänzlich wieder abgekommen, da es nicht gelang, den dabei unvermeidlichen üblen Beigeschmack des Baumwollmehls zu beseitigen; die Olgewinnung in den Vereinigten Staaten geschah also bis vor kurzem ausschließlich durch das vorstehend geschilderte mechanische Auspressen der gekochten Saatkerne.

Seit dem Jahre I905 wird zur Ölgewinnung nun aber auch ein „Kalter Prozeß“ angewandt, bei dem die Saat gewöhnlich nicht enthülst wird, die Preßrückstände ebenfalls als Kuchen bzw. Mehl verkauft werden. Man verwendet bei diesem Verfahren den selbsttätigen "A nderson Oil Expelle r" der V. D. Anderson Company in Cleveland, Ohio, eine sehr kräftig gebaute Presse von etwa 8400 Pfund Gewicht, die wenig Reparaturen ausgesetzt ist und loko Cleveland 2000 Dollars kostet. Sie besteht in der Hauptsache aus einem liegend angeordneten, aus einzelnen Hartstahlstäben gebildeten und mit Schlitzöffnungen versehenen Seiher, in dessen Zylinder von 3 Fub Länge und 7 Zoll Innendurchmesser die auf der Hauptwelle festsitzende Druckschnecke aus Hartstahl bei I4 Umdrehungen in der Minute einen allmählich bis zu 8000 Pfund auf den Quadratzoll zunehmenden Druck ausübt. Hinter der Druckschnecke befindet sich die Zuführungsschnecke, welche sich lose auf der Hauptwelle dreht. Der Antrieb der Schneckenwelle und der Druckschnecke erfolgt von der seitlich angeordneten Vorlegewelle aus durch Zahnräder. Am vorderen Ende der Schneckenwelle befindet sich ein 
verschiebbarer Kegel, der die ringförmige Austrittsöffnung verengt oder erweitert, je nachdem er vor- oder zurückgeschraubt wird.

Die A rbeits we is e ist die folgende: Die vorher gereinigte und gelinterte Saat wird durch den Speisebehälter und die Zuführungsschnecke in selbsttätig geregelter Menge zur Druckschneckc befördert. Diese drückt das Preßgut durch die ringförmige Anstrittsöffnung, die mittels des Kegels auf die der besten Olausbeute entsprechende Kuchendicke eingestellt ist. Das Öl fließt bei verhältnismäßig geringem Druck durch die Schlitze des Seihers leicht $\mathrm{ab}$; der im $O 1$ enthaltene Trub setzt sich in dem unter der Presse befindlichen, fahrbaren Behälter ab, oder er wird durch ein Schüttelsieb abgesondert, und durch ein Becherwerk gehoben, mit frischem Gut zusammen nochmals der Presse zugeführt. Die Kuchenrïckstände treten durch den ringförmigen Endspalt in Form von ctwa handgroßen, dünnen Stücken aus der Presse aus und werden durch einen Elevator direkt zum Wiegen und Einsacken befördert, falls man nicht vorzieht, den Kuchen vorher zu mahlen und in Gestalt von Mehl in den Handel zu bringen.

Gewöhnlich werden in einer Olmühle vier Expeller nebeneinander aufgestellt, und diese verarbeiten in 24 Stunden 30 Tonnen Saat.

Die Tonne Saat ergibt bei kalter Pressung etwa 70 Pfund Linters, I6oo Pfund Preßkuchen und 36 Gallonen Ö.

Die Pressung kann gänzlich kalt und ohne vorherige Offnung der Saat erfolgen; die besten Resultate werden aber auch bei diesem System dann erzielt, wenn die Saat vorher auf einer geeigneten Mühle roh aufgebrochen und dann in einem besonderen, über dem Expeller laufenden, für Dampfheizung eingerichteten Trog auf $60^{\circ} \mathrm{C}$. erwärmt wird.

Der Olertrag beim Anderson-Prozeß ergibt mit 35 bis 40 Gallonen OOl von der Tonne Saat wohl nicht ganz die behauptete gleiche Höhe wie bei dem hydraulischen Prozeß. Dagegen soll das Ól vom kalten Prozeß süßer und leichter zu raffinieren sein und beim Raffinieren geringeren Verlust, nämlich nur 4 bis $6 \%$ statt der sonst üblichen durchschnittlichen $9 \%$ ergeben.

Der dabei gewonnene $01 \mathrm{kuch}$ en enthält gewöhnlich noch ctwa 5 bis $6 \%$ Ol und soll bekömmlicher sein als der alte, da die Proteinstoffe, weil nicht gekocht, leichter verdaulich sind und die im Kuchen mit enthaltenen Schalen eher vorteilhaft, als nachteilig wirken.

Als Vorteile des Anderson-Systems werden aulerdem angeführt: 
Einfacherer Gesamtapparat mit nur einer statt sonst sieben verschiedenen Maschinen für die Ölpressung; Fortfall sämtlicher Pumpen, Ventile, Rohrleitungen und Manschetten, daher leichteste Instandhaltung der Anlage. Einfacherer Betrieb, keine erfahrenen Spezialisten benötigend; jeder Maschinist kann die durch Riemen angetriebene und sich vollständig selbsttätig vollziehende Arbeit überwachen; diese beschränkt sich auf das An- und Abstellen, so daß cin Mann für vier bis fünf Pressen genügt. Dampf dabei unnötig, da kein Kochen der Saat erforderlich, der Betrieb kann mit Wasserkraft, Motor oder Gasmaschine erfolgen und erfordert für jeden Expeller höchstens Io Pferdekräfte. Wegfall des teuren Preßtuches; Fortfall jeder Handarbeit bei der Bedienung der Presse und somit große Ersparnis an Lohn; weitere Ersparnis an Heizmaterial. Betrieb also billiger, mit angeblich 50 bis 100 Cents auf die Tonne Saat geringeren Kosten. Dazu kommt, daß die Aufstellung der Anderson-Presse sich gegenüber jeder anderen Presseart deshalb bedeutend billiger stellt, weil dazu nur sehr wenig Grundmauerwerk nötig ist. Ein Raum von $16 \times 16 \mathrm{FuB}$ bei $12 \mathrm{Fu} B$ Höhe genügt. Die Presse kann fertig zusammengebaut verschickt werden und ist in den meisten Fällen in drei bis vier Tagen betriebsfertig aufgestellt.

Der Anderson-Expeller, zunächst nur für andere Olsaaten, erst seit 1905 auch für Baumwollsaat verwandt, wird auch in Deutschland gebaut, und zwar vertragsmälig allein von dem Kruppschen Gruson-Werk in Buckau-Magdeburg, welches eine Presse mit einer stündlichen Leistung von 140 bis $160 \mathrm{~kg}$ Ol zu $8400 \mathrm{M}$. loco Magdeburg liefert.

Während in den Vereinigten Staaten im Jahre 1905 erst 6 Expeller auf Baumwollsaat liefen, zählte man deren im Jahre I9I3 bereits 327 , und zwar besonders viele in Texas.

Die amerikanischen Ömühlen arbeiten während der Saison ununterbrochen Tag und Nacht, um die zugeführte Saat nicht dem Verderb auszusetzen und um Lagerraum zu sparen; beansprucht die Tonne Saat doch 88 Kubikfuß. Dic in doppelter Schicht beschäftigten Arbeiter sind meist Farbige.

Baumwollsaatkuchen und -mehl. Da man herausfand, da. Bamwollsaat $\mathrm{meh} 1$ sich besser mit anderen Futtermitteln mischt und leichter verdaulich ist als Baumwollsaatkuchen, so wird letzterer heute in den Olmühlen meist gemahlen. $\mathrm{Zu}$ diesem $\mathrm{Z}_{\text {wecke }}$ passieren die Kuchen nach dem Trocknen zunächst einen rotierenden Brechapparat (,Cracker"), der sie in maiskerngroße, für die Mühle geeignete Stücke bricht, und die Mahlmühle mahlt letztere in ein 
feines Mehl, welches zuweilen noch gesiebt wird, um es von anhaftenden kleinen Schalenfragmenten und Fasern zu befreien. Den Wert des Mahlens der Kuchen zu Mehl fand man zuerst in De u t s h 1 a nd heraus, und die deutschen Abnehmer legen auch besonderen IVert auf feines Mahlen, weil solches Mehl leichter verdaulich ist. Größere Olmühlen haben seit einiger Zeit automatische Einrichtungen für Abwiegung und Verpackung des Mehls in Säcken getroffen.

England und andere Länder bevorzugen teilweise noch $\mathrm{K} u \mathrm{ch}$ e $\mathrm{n}$, wohl mit aus dem Grunde, weil man bei Mehl leichter Verfälschungen befürchten kann.

Das Mehl wird für Amerika ungesiebt in Säcken von Ioo Pfund, für das große Posten beziehende Deutschland fein gesiebt und in solchen zu I65 Pfund verpackt; auch dic O $1 \mathrm{k} \mathrm{u} \mathrm{ch} \mathrm{e} \mathrm{n}$ für England werden in Säcken versandt.

Manche OImühlen haben, um bestmögliche Preise für ihre Produkte zu erzielen, gleich Mischungsanlagen, in denen das stark stickstoffhaltige Baumwollsaatmehl nach Bedarf mit Kainit und Phosphaten zusammen zu D ün ge m it te $1 \mathrm{n}$ verarbeitet wird; Baumwollsaatmehl wird schon seit den joer Jahren zum Düngen benutzt. Aber da die Praxis bewiesen hat, daß der $\mathrm{H}$ a $\mathrm{u}$ twe $\mathrm{t}$ des Mehles im Füttern und nicht in seinen Dungqualitäten liegt, so ist es wohl nur eine Frage der Zeit, daß a 11 es Baumwollsaatmehl verfüttert werden und nur noch indirekt als Vichdung den Feldern wieder zugute kommen wird; künnen im Dung doch so bis $95 \%$ der in der Siat enthaltenen befruchtenden Stoffe wiedergewonnen werden.

Eine Tonne Mehl enthält I28 Pfund Stickstoff, 54 Pfund Phosphorsäure und 36 Pfund Kali.

Der frische Kuchen hat einen süßen, nußartigen Geschmack, ist hellgelb, verbleicht aber mit der Zeit. Er ist so reich an Protein $(43 \%)$ und Fett $\left(13 \frac{1}{2} \%\right)$, daB er als Vichfutter im rationellen Betrieb nur mit einem $r$ a $u$ he ren Futter gemischt dient, das reich an Kohlenhydraten ist, wie also z. B. Baumwollsaatschalen, Mais, Stroh u. a., oder aber in Verbindung mit guter Weide.

Die gan z e (ungeschälte) Baumwollsaat ist roh, geröstet, gelämpft oder gekocht schon längst als Futtermittel, besonders für Rinder, erkannt und fast vom Beginn der Baumwollkultur in Nordamerika an als solches benutzt worden; aber seit Einführung der Olmühlen ist die ganze Sat fast ibbrall durch ihre Schalen, Kuchen und Mehl ersetzt worden. 
Als Futter- und Mastmittel hat Baumwollmehl in Amerika sowohl wie auch in Europa vorzügliche Dienste geleistet bei Rindern, Milchkühen, Pferden, Maultieren, Schafen und Geflügel, dagegen hat es sich bei Kälbern und jungen Schweinen zuweilen als fatal erwiesen.

Im Jahrzehnt I 880 bis 1890 wurden im Südosten der Union, wo man allgemein dïngt, von dem gewonnenen Baumwollsaatkuchen bzw. -mehl benutzt:

$90 \%$ allein, oder mit andern Mitteln gemischt, zu Düngezwecken,

$5 \%$ für Rinderfütterung,

$5 \%$ für Export.

Im Südwesten der Union aber, wo Dung noch nicht die wichtige Rolle spielt, verwertete man schon damals

$25 \%$ für die eigene Rindermast und sandte

$75 \%$ für Futter- und Düngezwecke nach Europa.

Erst von 1883 ab hat man angefangen, Baumwollschalen und -mehl in g rößere m Maßstab und auf rationeller Basis als Vichfutter zu verwenden, und heutigen Tages ist die Viehzucht sowohl im Südosten wie im Südwesten der Union so ausgedehnt, daß man 35\% des Mehls für Futter neben 35\% für Dung im eigenen Lande selbst verwertet und etwa $30 \%$ der Gesamtproduktion zur Ausfuhr bringt.

Im Jahre 1905 wurden in den Vereinigten Staaten 900000 Rinder und 325 ooo Milchkïhe überwiegend mit Schalen und Mehl der Baumwollsaat gefüttert.

In neuester Zeit wird Baumwollsaatmehl auch mit Eirfolg in B a c k w a r e n, wie Brot, Kuchen, Biskuits und Konfekt, als Ersatz. für Weizenmehl benutzt, ist billiger als dieses und dabei sehr nahrhaft.

Der Verkaufs p re is der Tonne Baumwollsaatmehl war im Oktober 1907 in Atlanta 251/2 Dollars für Prima- und 24 Dollars für Sekundaware.

Die $A \mathrm{us} f \mathrm{uh} \mathrm{r}$ von Baumwollsaatmehl und -kuchen belief sich im Jahre Igo6 auf 555000 Tonnen im Werte von I3 Millionen Dollars und richtete sich überwiegend nach Dänemark und Deutschland mit 5 bzw. 4\% Millionen Dollars; England folgte mit I $\% 3$ Millionen Dollars. Im Jahre I9 I I war die Ausfuhr auf 646000 Tonnen gestiegen.

Baumwollsaatöl. Sehen wir nun zu, was mit dem aus der Presse träufelndem $O 1$ geschieht.

Dieses fließt zunächst in einen flachen Trog hinter der Presse, von da aus nach einem Tank unter dem Fußboden des Preßraums 
und wird von hier in große eiserne Bottiche gepumpt, in denen die Unreinigkeiten zu Boden sinken, während das obenauf schwimmende

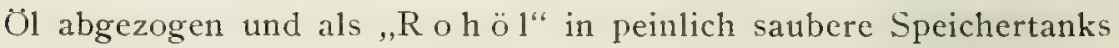
gebracht wird.

Die $\mathrm{Niederschläge} \mathrm{des} \mathrm{Rohöls} \mathrm{werden} \mathrm{entweder} \mathrm{noch-}$ mals mit dem Kernmehl zusammen gekocht, gepreßt und gereinigt oder die Rückstände werden auch direkt für die Seifen-, Waschpulver- und Kerzenfabrikation und zur Herstellung von Phonographenwalzen benutzt, ergeben außerdem Glyzerin und Olein. Die S e if e aus Baumwollöl hat sich besonders für Wollwäscherei vorzüglich bewährt, aber sie dient auch für allgemeine Haushaltzwecke und bei Zusatz entsprechender Substanzen zu feinen Phantasieseifen.

Das R o hö 1 oder „crude oil“ ist geruchlos, dunkel, braungrün und in seiner Qualität sehr verschieden, da das wechselnde Klima auch einen starken Einfluß auf die Qualität der Saat und des Öles hat; im allgemeinen ist beobachtet worden, daß das $O 1$ in feuchten Saisons von geringerer Güte ist. Da etwa $90 \%$ des jährlich in den Vereinigten Staaten gewonnenen Baumwollöls als Nahrungsmittel für die Menschen, besonders in der Form von Speckersatz, Brat- und Salatöl dienen, so bildet seine Verwendbarkeit dafür den Prüfungspunkt; was nicht dazu verwandt werden kann, ist minderwertig.

Der Preis des Rohöls war im Oktober 1907:

34 Cents die Gallone bei Tankladung,

$40 " \quad " \quad, \quad$ Verladung in Fässern zu 50 bis 52 Gallonen.

Vom September 1909 bis September I9Io stieg das rohe Tanköl von $34 \frac{3}{4}$ auf 60 Cents die Gallone.

Zunächst gilt es nun, das Rohöl noch zu $r$ affinieren.

Diese Reinigung geschieht teils in den Olmühlen selbst, meist aber verkaufen die kleineren dieser Anlagen ihr Rohöl an größere, komplett ausgestattete Mühlen mit Raffinerien, und diese Anstalten sind überwiegend in großen Trusts organisiert, unter denen an erster Stelle die älteste, die "American Cotton Oil Company", mit einem Kapital von über 30 Millionen Dollars, und die „Southern Cotton Oil Company" stehen.

Einige Mühlen haben letzthin angefangen, schon das Rohöl vor dem Versand zu filtricren; meist unterläßt man das aber, da die Ausscheidung der letzten Niederschläge beim Raffinieren erfolgt.

Früher verlud man das Rohöl in Fässern. Ab r885 aber führte zunächst der „American Oil Trust" T a n k w a g e n ein, und heute ist deren Verwendung fast allgemein. Wo das Rohöl nicht 
selbst gereinigt wird, geht es in Tankwagen von 6000 bis 7000 Gallonen nach den Raffinerien, und zwar stellen diese ihre Tankwagen den Olmühlen zur Verfügung.

Das $\mathrm{R}$ a f f in ieren selbst besteht in der Entfernung der freien Fettsäure, des braunen Farbstoffes und irgendwelcher anderen fremden Bestandteile, die sich im Rohöl finden mögen.

$\mathrm{Zu}$ diesem Zweck füllt man das Rohöl in eiserne Behälter von ctwa 5000 Gallonen, setzt ihm Io bis $15 \%$ seiner Menge in 74 prozentiger $\mathrm{k}$ a ustischer Soda zu und rührt die Mischung bei ciner Temperatur von 38 bis $55^{\circ} \mathrm{C}$ und Durchführung reiner Luft 45 Minuten lang um, worauf man sich den durch dic Alkalien gebundenen Niederschlag 6 bis 36 Stunden lang setzen läßt.

Die früher an Stelle der kaustischen Soda benutzte Sch w cf e ls ä u re, welche gleichzeitig cin gutes Blcichmittel war, ist ausgeschlossen bei Ölen, welche Speisezwecken dienen sollen.

Das im Tank obenauf schwimmende reine $O 1$ wird abgezogen und in einen im unteren Stockwerk befindlichen Läuterungstank geleitet, wo es nochmals erhitzt und umgeruhrt wird, um alles Wasser zu verdampfen, und dann läßt man das OOl sich auch hier setzen.

War bei der Bearbeitung im crsten Tank noch überschüssiges Alkali verblieben, so muß dieses im ersten oder zweiten Tank durch Wasserzusatz und Umrühren ausgewaschen werden.

Zum Schlub wird das Ól meist durch eine Filterpresse filtriert und ergibt so das sogenannte "gelbe Sommeröl". Einige Raffinerien benutzen letzthin dic Filterpresse nicht mehr, weil sic durch ruhiges Absetzenlassen cin klareres öl erzielen als beim forcierten Pressen.

Größte Rein lichkeit ist in allen Stadien der Raffineric von entscheidender Bedeutung.

Die $\mathrm{N}$ iederschläge aus dem ersten und zweiten Tank werden zur Se if e n fabrikation, ferner zu Waschpulver, Glyzerin, Kerzen, Olein und Dachteer benutzt und einzelne Raffinerien verarbeiten ihre Rückstände selbst zu gewöhnlichen Seifen. Die Verwertung der Rückstände - rein oder mit Torf gemischt — zu Heizbriketts ist in den Vereinigten Staaten nicht üblich; wohl aber wurde im Jahre rgI I berichtet, daß es der N. K. Fairbank Company in Chikago gelungen sei, aus den Baumwollsaatrückständen ein $\mathrm{Pech}$ herzustellen, welches geruchlos und unentzündbar sei.

Der Gewichtsverlust, den Prima-Rohöl beim Raffinieren erleidet, schwankt zwischen 5 und $12 \%$, steigt in schlechten Saisons aber bis zu $20 \%$. 
Prima gelbes Sommeröl wurde im Herbst 1907 verkauft zu:

38 bis 40 Cents die Gallone bei Tankladung,

50 " " $"$ in Fässern von 50 bis 52 Gallonen.

Vom September I909 bis September I9 Io stieg das raffinierte Tanköl von 43 Cents auf $761 / 2$ Cents für die Gallone; die Preise im Juni I9I4 waren bei Tankladung 45 Cents für ,,crude“ und 65 Cents für raffiniertes Öl.

Das g e l b e S o m m e r ö 1 , welches direkt zu Oleomargarine, Butterin usw. verwandt wird und die Basis zu allen weiteren Verarbeitungen bildet, ist von heller Strohfarbe, frei von Satz und Wasser, absolut neutral und, um ,prima“ zu sein, fast geschmacklos; ein leichter Beigeschmack degradicrt es zu "Butteröl“"

Das amerikanische Baumwollöl ist klarer als ägyptisches und indisches, das von Uplandsaat stammende wieder klarer als das von der Meeresküste stanmende. Auch das in England hergestellte Baumwollöl ist nicht so klar wic das amerikanische, weil die Saat dazu meist von Indien und Ägypten geliefert wird und sodann, weil man sie dort nicht schält.

Sommerö 1 kocht bei $320^{\circ} \mathrm{C}$., wird wolkig zwischen 5 bis $10^{\circ}$ und erstarrt bei $-\mathrm{I}^{\circ} \mathrm{C}$; d die Wölkung stammt von der Verdichtung des Stearins, welches mit zunehmender Festigkeit auch weißer wird.

W interöle nennt man solche, welche auch beim Gefrierpunkt noch flüssig bleiben, und zwar stellt man sie her durch Erniedrigung der Temperatur bis zu dem Punkte, wo das Stearin erstarrt, während das Olcin flüssig bleibt; bei dieser Temperatur werden die beiden Bestandteile unter der Filterpresse separiert. Das ausgeschiedene S te a rin, ungefähr $25 \%$, dient zur Kunstbutter-, Kunstspeck- und Kerzenfabrikation, das übrig bleibende

,g e 1 b e Winteröl“, hauptsächlich aus Olein bestehend, liefert ein vorzügliches Brat- und Backöl, das beim Erhitzen nicht den unangenehmen, vom Stearin herrührenden Geruch des Sommeröls hat und Speck und Butter ersetzt; es dient auch als Salat- und Speiseöl.

\section{Zur Herstellung von}

„w e i $B$ e m W in teröl“ benutzt man geringwertiges gelbes Sommeröl und bleicht dieses mit Schwefelsäure. Dieses weiße Winteröl dient, mit Petroleum gemischt, als L e u c h tö 1 der Bergwerkslampen, ungemischt auch zu pharmazeutischen Zwecken. 
„W e i B e s S o m m e r ö l" dagegen wird gewonnen, indem man gelbes Sommeröl im Tank erhitzt, mit 2 bis $3 \%$ Walkerde durchrührt und dann filtriert; es ist, so gebleicht, fast wasserhell und wird zur Herstellung von Kunstspeck benutzt. Walkerde hinterläßt einen leicht säuerlichen Geschmack, der vollständig vermieden wird, wenn man an ihrer Stelle pulverisierte Holz- oder, besser noch, Knochenkohle benutzt; die Feuergefährlichkeit dieser Stoffe läßt ihre Anwendung aber im allgemeinen nicht angebracht erscheinen.

Das ,g e l b e S o m m e rö l“ wird außer zu Oleomargarine und Butterin auch noch verwandt beim Packen von Sardinen und anderen Fischen, zu Kosmetiks, Emulsionen und bei Automobilreifen.

Da Baumwollöl schlecht trocknet, so ist es nicht als Anstreichmittel oder zum Farbenanrühren gecignet, auch nicht zur Lederzubereitung, wohl aber wird es, besonders mit anderen Fetten gemischt, als Schmieröl und zu Kitt benutzt. Mit der zunehmenden Verbesserung in der Raffinierung des Baumwollols ist auch dic Zahl seiner Verwendungsmöglichkeiten gestiegen.

Als $\mathrm{Nahrungsmittel}$ wurde Baumwollöl zunächst in Form einer Beimischung zum Temperieren von Speck für kalte Klimate benutzt. Später beseitigte man dic Flüchtigkeit des Öls durch Zusatz von Rinderfett und brachte diese Mischung als compound, hogless oder refined lard = Kunstspeck auf den Markt. Die Art der Mischungen von Schweinespeck, Rinderfett und raffiniertem Baumwollöl, welche schmackhafte und billige Nahrungsmittel, besonders Kunstspeck, liefern, ist mannigfaltig, meist freilich segelt das Produkt bislang unter irreführender Flagge; nur das "Cottolene", ein erstklassiges Nahrungsmittel aus Oleostearin und bestem raffinierten Baumwollöl gemischt, macht davon eine Ausnahme. Aber $90 \%$ des in den Vereinigten Staaten verkauften „Olive nö $1 \mathrm{~s}$ " sind in der Tat Baumwollöl.

Auch bei pharma ze ut is chen Mitteln bildet Baumwollöl Ersatz für Olivenöl und wird außerdem ähnlich wie Lebertran verwandt.

Soweit das raffinierte $O 1$ in Packhäusern zu Kunstprodukten weiter verarbeitet wird, versendet man es in Tankwagen.

Im Herbst 1907 verkaufte man in den Vereinigten Staaten die Hauptprodukte aus rafiniertem Baumwollöl wie folgt:

B r atö 1 in Fässern zu 400 Pfund

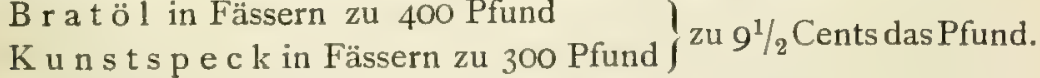

Sa latö 1 in Kisten mit 12 Blechdosen à 2 Pfund netto zu 4,20 Dollars die Kiste $=17 \frac{1}{2}$ Cents das Pfund. 
W a sch pulver lose in Fässern à 300 Pfund zu $3^{1 / 2}$ Cents das Pfund.

Im März 19 Io kosteten Butter und Speck 40 bzw. I4 $3 / 4$ Cents das Pfund, während die aus Baumwollöl hergestellten Ersatzstoffe Oleomargarine und Kunstspeck nur 23 bzw. Io Cents kosteten, also cine für billigere Haushalte sehr wesentliche Ersparnis ermöglichten. Damit hängt auch der wachsende Konsum zusammen.

Während die Vereinigten Stạaten im Jahre I879 nur $30 \%$ des dort erzeugten Baumwollöls selbst konsumierten, den größeren Teil aber ausführten, ist der eigene Gebrauch heute auf über das Doppelte gesticgen und im Jahre IgI I z. B. wurden nur noch $25 \%$ der Gesamtproduktion, nämlich 53 Millionen Gallonen, ausgeführt. Hauptabnehmer dafür ist Holland, dann folgen England, Mexiko, Kanada, Italien, Deutschland und Norwegen. Holland bezieht bestc Qualität zur Margarinefabrikation, dic anderen Länder benutzen das Öl als Ersatz und zur Fälschung von Olivenöl und zur Seifenfabrikation. In Hamburg notierte man Baumwollsaatöl im Juni 1914 mit 59\% Mark für $100 \mathrm{~kg}$. Ist dic Olausfuhr auch im Verhältnis zur Gesamterzeugung gesunken, so weisen die absoluten Ausfuhrziffern, entsprechend der großartigen Entwicklung der Olindustrie, doch eine gewaltige Steigerung auf, wie folgende Liste zeigt:

$\begin{array}{cccccc}\text { I875 } & \text { I880 } & \text { I890 } & \text { I895 } & \text { I900 } & \text { I9II } \\ \text { O,3 } & 3,4 & \text { I I } & 20 & 49 & 53 \text { Millionen Gallonen, }\end{array}$

während die Gesamtprodultion in diesen Jahren betrug:

$3,3 \quad 7,3 \quad 4 \mathrm{I} \quad 57 \quad 96 \quad 202$ Millionen Gallonen.

\section{Baumwollhandel.}

Baumwoll-Aufkauf und -Handel. Kehren wir nach Betrachtung der Nebenprodukte zum Hauptprodukt, der Baumwolle, zurück.

Bevor die amerikanische Baumwolle ihren Weg vom Pflanzer zum Konsumenten findet, hat sie durch viele Hände zu gehen. Der Verkauf der Baumwolle seitens der Pflanzer erfolgte vor dem Bürgerkrieg meist an ein Kommissionshaus im nächsten größeren Orte, das in Gegenrechnung auch die der Plantage nötigen Dinge lieferte. $\mathrm{N} \mathrm{a} \mathrm{ch} \mathrm{dem} \mathrm{Kriege} \mathrm{war} \mathrm{der} \mathrm{verschuldete} \mathrm{Farmer} \mathrm{vielfach}$ ganz in den Händen solcher Händler oder „Faktoren“, und die von diesen berechneten hohen Zinsen auf gewährte Vorschüsse ließen viele Pflanzer lange Jahre hindurch auf keinen grïnen Zweig 
kommen. Dic Faktoren kaufen nämlich Batumwolle nicht nur für eigene Rechnung auf oder verkaufen sie in Kommission gegen $21 / 2 \%$ Vergiitung, sondern sic geben gegen Hypothek und hohe Zinsen auch Vorschüsse auf die kommende Ernte, gewöhnlich to Dollars auf den Ballen und mehr und sichern sich dadurch das Anrecht auf dic ihnen damit verpfändete Ernte. Ohne diese Beihilfe würde es vielen Farmern unmöglich sein, Samen, Dünger, Vieh, Futter und Ackergeräte zu beschaffen und zu unterhalten. Ist die Ernte cingebracht, so geht sie an den Faktor, der durch ihren Verkauf scine Vorschüsse deckt.

Mit der allmählichen finanziellen Kräftigung des Südens und dem Ausbau des Eisenbahnnetzes ist das Faktorwesen aber in den meisten Gegenden eingeschränkt worden oder ganz verschwunden; im allgemeinen kauft und verkauft der Farmer heute gegen Bargeld im nächsten Marktplatz, wo man während der Saison jeden Morgen Reihen von Pflanzerwagen mit je 2 bis I 2 Ballen Baumwolle antrifft, die auf offener Straße von den Käufern untersucht und an den Meistbietenden verkauft werde11, nicht immer mit gerechter W Wurdigung von Klasse und Grad. Unpraktisch ist im allgemeinen das fast ausschließlich am westlichen Ende des Baumwollgürtels übliche System, die Baumwolle nicht erst nach Entkernung, sondern schon als Saatbaumwolle zu verkaufen, denn der bessere Pflanzer erzielt für seine ertragreicheren Arten dabei auch nur den Durchschnittspreis. Wird die Ware im Lagerhaus gelagert, so betragen die Gesamtkosten für Lagern, Feuerversicherung und Verkauf I bis 2 Dollars für den Ballen. Daß die Zahl der öffentlichen Lagerhäuser letzthin ganz gewaltig zugenommen hat, ist bereits im Abschnitt über die Pflanzervereinigungen ausgeführt. Auch die Rcgierungen verschiedener Einzelstaaten haben sich letzthin der Sache angenommen.

So nahm die 33. Legislaturperiode des Staates Texas das „Permanent Warehouse and Co-operative Marketing Law" an und gliederte dem staatlichen Versicherungs- und Bankdepartement eine besondere Lagerhausabteilung an zu dem Zwecke, damit eine Besserung in der Entkernung und Packung von Baumwolle zu fördern.

Ein großartiges Projekt zur Errichtung moderner Lagerhäuser für Baumwolle ist ferner $\mathrm{z}$. $\mathrm{Z}$. in $\mathrm{New} \mathrm{Orleans}$ in Ausführung begriffen. Nachdem die Hafenbehörde die gesetzliche Ermächtigung erhalten hat, für diesen Zweck 3 Millionen Dollars 5prozentige Bonds auszugeben, werden an der Flußfront des Mississippi eine Anzahl Lagerhäuser mit neuesten Preßeinrichtungen erstellt, welche 
für den Umsatz von 3 Millionen Ballen in einer Saison ausreichen sollen und jeden einzelnen Ballen nach den Standards der amerikanischen Regierung klassifizieren und bezeichnen. Das Unternehmen ist Eigentum des Staates Louisiana, steht unter Aufsicht der Port Commissioners und soll plangemäß zum Beginn der Baumwollsaison 1915/16 voll funktionieren.

Ist der nächste Handelsplatz, an dem sich Aufkäufer befinden. zu weit entfernt, als daß er bequem mit Wagen zu erreichen sei, so wird die Baumwolle mit der Bahn verladen oder, wo brauchbare Wasseradern vorhanden sind, zu Schiff.

Die Handelsplätze für Rohbaumwolle im Binnenlande befördern die Ware entweder unmittelbar in die Spinnereien der Baumwollstaaten oder in die Fabriken des Nordens oder nach den Ausfuhrhäfen, welche die großen Handelsplätze an der Küste bilden. Dadurch, daß Amerika bereits ein Drittel seiner Baumwolle zur Verarbeitung im eigenen Lande behält, hat sich letzthin ein großer Umschwung in der Verteilung vollzogen; früher bedeutende Plätze sind zurückgegangen, andere in die Höhe gekommen.

Von den Handelsplätzen im Innern wird über etwa 30 cinc regelmäßige jährliche Statistik geführt; die wichtigsten sind Houston, Memphis, St. Louis, Dallas, Shreveport, Augusta, Cincinnati und Little Rock, während die bedeutendsten Baumwollhäfen Galveston, Savannah, New Orleans, New York und Wilmington sind. Hauptmärkte für Sea Island-Baumwolle sind Charleston und Savannah.

Der Handel mit Baumwolle ist ein Saisongeschäft von etwa sechs Monaten Dauer und richtet sich in wesentlichen nach der Erntezeit. Im Juli und August erscheinen die ersten Vorposten der neuen Ernte, während das Gros von September an nachrückt und der Schwerpunkt auf die Nonate Oktober bis Dezember entfällt, welche zusammen durchschnittlich \% der Ernte dem Handel übergeben. Von da an beginnt das Geschäft abzunehmen und versiegt im Mai fast vollständig, um erst im August allmählich wicder aufzuleben.

Immerhin ist die Verteilung der Ernte jetzt gleichmäßiger als friiher, wie folgende zwei Beispiele zeigen:

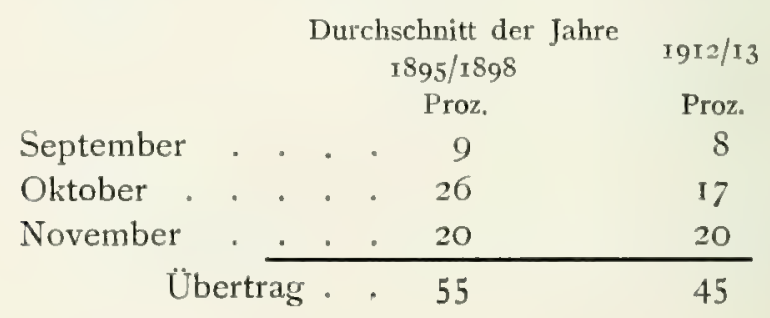




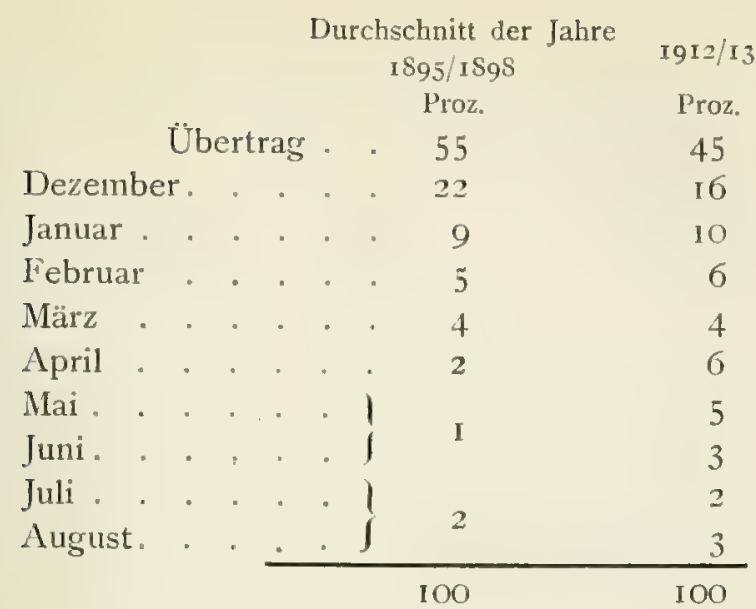

Der Exporteur (buyer) kauft seine Ware entweder im offenen Markte auf Proben hin, die er selbst priift, oder an Binnenplätzen vom "interior merchant" nach Beschreibung (,description“). Diesc Zwischenhändler, welche vom l'flanzer, vom Faktor oder von Händlern in Binnen- und Hafenplätzen kaufen, bringen so größere Verkaufsmengen zusammen, die sie lagern, klassifizieren, bemustern und weiter verkaufen, wobei sic atuch Versicherung und Versand besorgen. Dic Pflanzervereinigungen streben zwar eine möglichste Ausschaltung des Zwischenhandels an, doch scheint es bei einer eventuellen direkten Verbindung zwischen Pflanzer und Spinner schr fraglich, ob letzterer auf Empfang der ihm nötigen $\mathrm{K} 1$ a s s e Baumwolle sicher rechnen kann. Auf dem Liverpooler Baumwollmarkt findet jeder Spinner für seinen Spezialbedarf genau passendes Material.

Vor der Zeit des Kabels pflegten europäische Spinner ihre Agenten zum Aufkauf nach Amerika zu schicken. Später kauften Handelshäuscr den Artikel auf Spekulation auf und die Spinner kauften bei ilmen auf spätere Lieferung. Daran schlossen sich seit Anfang der yoer Jahre Terminbörsen in New York (1870), Liverpool ( 1873 ) und New Orleans ( 1880 ), dic teils dem legitimen Warengeschäft, teils mehr oder weniger wilden Spekulationen dienen.

Die in Batumwolle abgeschlossenen Kontrakte beziehen sich auf Menge, Qualität, Stapel, korrektes Brutto- und Nettogewicht und die Lieferung in guter innerer und äußerer Verfassung.

Schließt der „Buyer“ nach dem Ausland ab, so sind für Klasse und Gewicht die Bestimmungen der Börsen in Liverpool, Bremen und Havre maßgebend; der amerikanische Export richtet sich also 
nach den europäischen Börsengebräuchen. Licfert der Buyer jedoch innerhalb der Vereinigten Staaten, so unterliegen seine Kontrakte ausschlicßlich den Usancen der Börsen in diesem Lande, die für Verkäufer und Käufer bindend sind.

Baumwollbörsen. Zur Sicherung und Durchführung des legitimen Geschäfts deckt sich der Verkäufer oder Exporteur gewöhnlich durch Termingeschäfte ein, welche in den Vereinigten Staaten durch die beiden ,futures"-Börsen in New York und New Orleans kontrolliert werden, die beide für diese "paper contracts" ihre bestimmten Regeln haben.

Preise werden in Cents und Punkten $=1 / 100$ Cents notiert; als Basis für Termingeschäft gilt dic Klasse „Upland middling“, doch ist der Verkäufer nicht verpflichtet, auch wirklich nur ,middling“ zu liefern, sondern er kann jeden Grad, nur nicht unter ,good ordinary" oder "low middling" liefern; e r hat die Wahl hinsichtlich des Grades, nicht aber der Käufer. Der Verkäufer gibt den Käufer „Notiz“, daß er zur Lieferung bercit ist, und letzterer muli innerhalb von fünf Tagen regulieren. Die P'reisdifferenzen, welche bei der nun erfolgenden effektiven Licferung für andere Grade als „middling“ zu zahlen sind, wurden bislang durch börsenmäBig, früher in New Iork jeweilig für cin ganzes Jahr, seit 1912 jährlich zweimal festgestellte ,differences above and below middling " bestimmt. Bei diesem Geschäft läuft der Käufer allerdings bei effektiver Andienung die in letzter Zeit zunehmende Gefahr, ein sehr minderwertiges Produkt zu erhalten.

Die jährlichen Durchschnittspreise für ein englisches Pfund amerikanische middling-Baumwolle in New York waren dic folgenden :

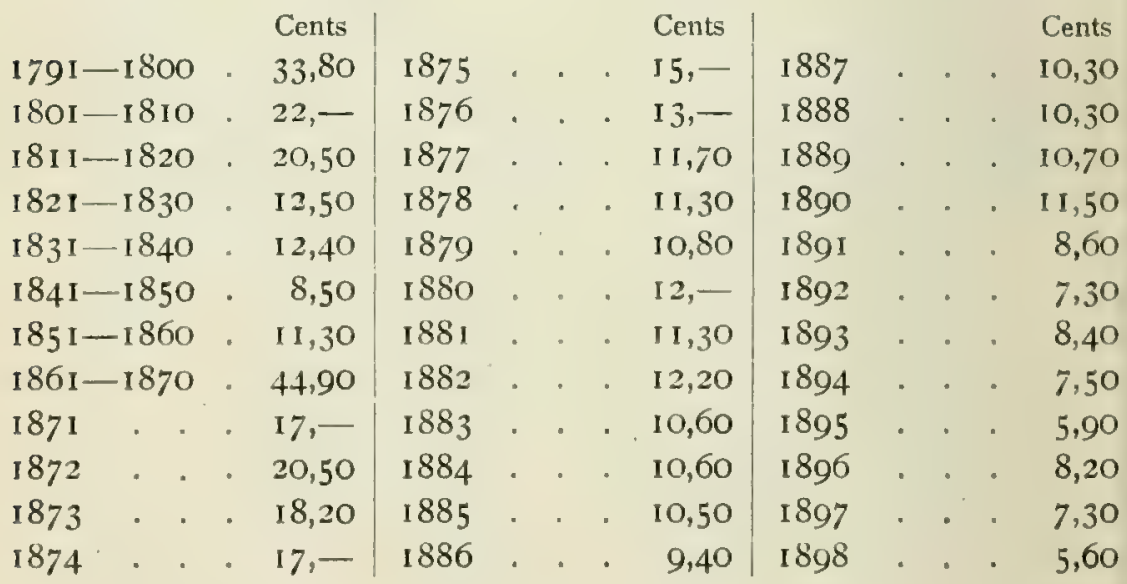




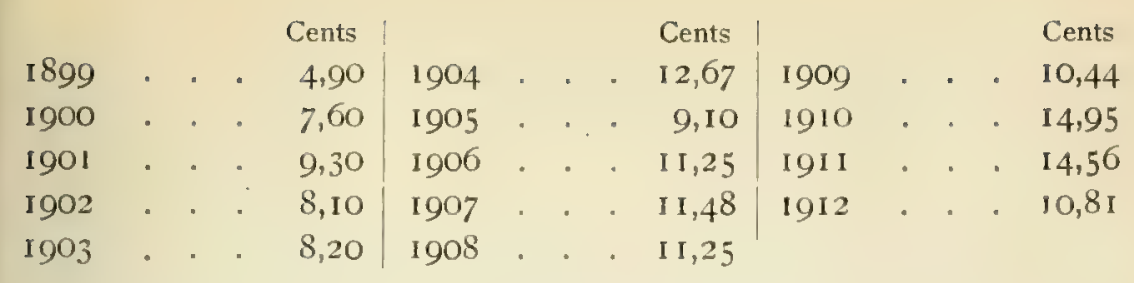

Neben den großen Baumwollbörsen in New York und New Orleans, die Effektiv- und Termingeschäfte betreiben, bestehen Baumwollbörsen auch noch in einer ganzen Reihe weiterer Baumwollmärkte, so in Galveston, Memphis, Dallas, St. Louis, Mobile, Vicksburg, Macon, Charleston, Little Rock, Natchez, Oklahoma u. a. Hier werden aber nur Effektivgeschäfte abgeschlossen; Termingeschäfte in allen Ackerbauprodukten sind auf Betreiben der Farmervereinigungen durch von ihnen durchgedrückte ,anti-futures laws" seit Igo6 in den Baumwollstanten Nord- und Süd-Carolina, Georgia, Alabama, Arkansas und Texas verboten, und das Bestreben der Farmervereinigungen geht in lebhafter Bewegung dahin, auch die Terminbörsen in New York und New Orleans zu unterdrücken.

Nachdem in den gesetzgebenden Körperschaften wiederholt Bills eingebracht, aber gescheitert waren, hat der I'räsident der Vereinigten Staaten unter dem 18. August I9I4 ein Gesetz unterzeichnet, welches die Bezcichnung „United States Cotton Futures Act" trägt und den Terminhandel in Baumwolle regelt. Das Gesetz ist nach langen Beratungen und vielen Abänderungen aus zwei Gesetzentwürfen, von denen der eine vom Senat und der andere vom Repräsentantenhause ausging, zusammengestellt worden. Das nach seinem Haupturheber als ,Lever-Bill" bezeichnete Gesetz gibt genaue Vorschriften über Inhalt und Form der Kaufs- und Verkaufsverträge für zukünftige Lieferung von Baumwolle. Es setzt eine Steuer von 2 Cents für ein Pfund = Io Dollars für den Ballen fest für alle Termingeschäfte, die nicht in allen l'unkten den Vorschriften entsprechen, gleichviel, ob die Geschäfte an amerikanischen Börsen allein oder zwischen amerikanischen und ausländischen Baumwollbörsen abgeschlossen sind. Die Kontrakte, die nicht den Bestimmungen des Gesetzes entsprechen, sind bei den Gerichten der Vereinigten Staaten nicht einklagbar. Strafen von roo bis 20000 Dollars oder Gefängnis von 60 Tagen bis zu 3 Jahren sind für Ubertretungen festgesetzt. Auherdem kann von den Vereinigten Staaten auf eine Zusatzstrafe von zoon Dollars geklagt werden, wovon die 
Hälfte der Person, welche die Verletzung des Gesetzes anzeigt oder zur Überführung der Schuldigen beiträgt, zugesprochen wird. Effektivgeschäfte in Baumwolle werden von dem Gesetz nicht betroffen.

Das am I8. Februar 1915 in Kraft getretene Gesetz verfolgt den Zweck, den börsenmäßigen Terminhandel durch Bestimmungen über die den Kontrakten zugrunde zu legenden Baumwollqualitäten, die vom Bundesackerbauamt nach Standardmustern festgesetzt werden, und über den Ausgleich bei Ablieferung möglichst festzulegen und dadurch einzuschränken. An Stelle der früheren Klassendifferenzen treten nunmelır wirkliche Marktwertdifferenzen, womit die Interessen des Käufers besser als bislang gewahrt sind.

Zweifellos haben die Terminbörsen und besonders die New Forker manche bedauerliche und zu bekämpfende Auswüchse gezeitigt, die in den heftigen Preisschwankungen des letzten Jahrzehnts zum Ausdruck kamen, aber daneben erfüllen sie doch ihren legitimen Hauptzweck der Sicherung des solide n Geschäfts, das auf Basis von Terminnotierungen für Rohbaumwolle entsprechend langfristige Abschlüsse in Garnen und Geweben macht; sie wirken ausgleichend.

Während in New Orleans jeder einzelne Ballen Baumwolle nacn seinem Grade klassifiziert und durch ein Etikett bezeichnet wird, stellt man in New York für ein "Lot" von roo Ballen nur e in Zertifikat aus, das angibt, wieviel Ballen der einzelnen Grade in dem Lot vorlanden sind.

Die amerikanischen Spinner kaufen Baumwolle nach Bruttogewicht, mit einer Tara von 22 Pfund für den viereckigen Ballen Upland, ro Pfund für den Ballen Sea Island und 3 Pfund für den Rundballen.

Der Verkauf nach Europa erfolgt entweder: „fob“, d. h. frei an Bord in amerikanischem Hafen; oder, wie meist, ,cif", d. h. Kosten, Fracht und Versicherung bis europäischem Hafen einschließend und mit Zubilligung einer Tara von $6 \%$; über die Unbilligkeit dieser Tara ist schon im Kapitel über Verpackung gesprochen worden und man strebt eine Fakturierung auf Basis von Nettogewicht an.

Eine Gewichtsdifierenz bis zu I \% am Bestimmungsort, die sogenannte "Franchise", gilt als zulässig. 


\section{Versand.}

Werfen wir nun einen Blick auf die Verkehrsmittel in Nordamerika.

Landstraßen. Abgesehen von wenigen Kunststraßen in dem alt besiedelten Osten und einzelnen Minendistrikten des Westens, ist der Ausbau der Landstraßen in der Union noch recht rückständig, da Herstellung und Unterhaltung der öffentlichen Verkehrswege nicht Aufgabe der Bundesregierung, sondern den kleinsten Verwaltungseinheiten der Counties und Townships, sowie privaten Wegebaugenossenschaften vorbehalten ist. Der Zustand der Wege ist dementsprechend besonders zur Winter- und Regenzeit ein so schlechter, dab der Verkehr von der Farm zu der durchschnittlich 7 bis 12 Meilen von ihr entfernten Verladestation oft schwierig ist. In neuerer Zeit haben aber auch Bund und Staat angefangen, sich der Verbesserung der Landstraßen anzunehmen.

Wasserstraßen. Vor der Vorherrschaft der Eisenbahnen im Transportwesen der Vereinigten Staaten widmete man dem Kanalbau und Ausbau schiffbarer Flüsse zum Transport von Massengütern zu billigen Frachtsätzen großes Interesse, und die Blütezeit des nordamerikanischen Kanalbaus fällt in die Jahre 1827 bis 1837 . Bis zum Sezessionskrieg bildete die Flußschiffahrt das Haupttransportmittel der Baumwolle in Süden, und seit 1816 wurde auf dem Mississippi regelmäßige Dampfschiffahrt betrieben. Die scharfe Konkurrenz der Bahnen führte aber zu cinem Niedergang der amerikanischen Binnenschiffahrt, und erst neuerdings sucht man sie wieder zu beleben und in ihr cinen Regulator der Eisenbahntarife zul schaffen. Während im Baumwollgürtcl die texanischen Flüsse für die Schiffahrt einstweilen nicht in Betracht kommen, spielt der Riesenstrom des Mississippi für den Verkehr eine hervorragend wichtige Rolle, die allerdings eingeschränkt wird durch die häufigen Veränderungen des Strombetts, den starken Wasserstandswechsel und durch die schwere Zugänglichkeit seiner Ufer an vielen Stellen. Des niedrigen Wasserstands wegen wird Baumwolle auf dem Mississippi und Red River meist nur in Deckladung auf einer Art von verbesserten Riesenflößen verladen. Von den übrigen Golfzuflüssen bildet der Alabama eine der besten seiner Schiffahrtsstraßen, und die atlantischen Flüsse des Baumwollgebiets sind für den Verkehr von ganz geringer Bedeutung.

Eisenbahnen. Die Eisenbahnbauten der Amerikaner sind zweifelsohne nach ihrem Umfang und nach ihren Wirkungen für die 
nationale und wirtschaftliche Entwicklung des weiträumigen Staates die größte Leistung, die je ein Volk auf diesem Gebiet vollbracht hat, und haben wesentlich dazu beigetragen, die außerordentlich günstigen Bedingungen gewaltiger natürlicher Hilfskräfte des Landes auszunutzen. Der Süden freilich blieb zunächst in der Entwicklung dieses wichtigen Verkehrsmittels weit zurück. Zwar waren schon I83 I in New Orleans und 1833 in Süd-Carolina kleine Versuchsstrecken eröffnet worden, aber vielfach hielt man noch bis I860 die Wasserstraßen für ausreichend. Erst 1843 wurde nach schweren Kämpfen die erste Eisenbahnkonzession in Nord-Carolina vergeben, und das nördliche Kapital, von dem der Süden für alle scine Zwecke mehr oder weniger abhing, zog nördliche Eisenbahnlinien vor und konnte in einzelnen Fällen nur durch Landschenkungen und andere Staatshilfen herangezogen werden. So entfielen im Jahre 1860 von den 28000 Meilen Eisenbahnen des ganzen Landes nur 6185 auf den Süden. Nach dem Kriege machte man sich daran, dic zerstörten Linien wieder in den Stand zu setzen und das Netz zu erweitern, da der Streit inzwischen endgültig zugunsten der Eisenbahnen ausgefallen und der Kanalbau überall eingestellt war. Im Jahre I895 besaßen die Südstaaten 37 ooo von den I79 0oo Meilen Eisenbahnen des ganzen Landes. Unterstützt wurde der Bahnbau durch die im allgemeinen günstige Bodengestaltung. Im Jahre Ig Io verfügte die Union über ein Eisenbahnnetz von rund $388000 \mathrm{~km}$ betriebsfähiger Länge (Deutschland 6 I 000, Europa etwa 334000 , die ganze Erde rund eine Million Kilometer).

Auch die Südstaaten sind heute mit Eisenbahnverbindungen wohl versorgt, wenngleich die Linien bei Entwicklung neuer Gebicte zunächst so billig wie möglich angelegt wurden und erst allmählich verbessert werden. Dic Hauptgesellschaften interessieren sich auch stark für die Besiedlung und wirtschaftliche Entwicklung det von ihnen bedienten Gebiete, und unterhalten zu diesem Zwecke zahlreiche Agenten, teilweise, wie die Southern Railway, sogar in Europa. Manche Mängel im Betriebe, besonders auch in bezug: auf Frachtverkehr und dessen Tarife, werden von der I887 geschaffenen und I906 in ihren Befugnissen erweiterten ,Interstate Commerce Commission" scharf kontrolliert.

In allgemeinen sind ciie amerikanischen Eisenbahntarife die billigsten der Welt, z. B. nur ein Bruchteil der englischen, obgleich die Löhne in den Vereinigten Staaten reichlich doppelt so hoch wic durchschnittlich in Furopa sind; die Frachtsätze bedürfen deshalb dringend einer Aufbesserung. 
Die Kosten der Baumwollversendung vom Ursprungsgebiet bis zum Bestimmungsort sind sehr wechselnd nach den beständig schwankenden Frachtverhältnissen; Konkurrenzlinien, Wassertransport und Durchgangsfrachten komplizieren die Frage. Die Durchschnittsfracht von der Farm zum Verladungsplatz beträgt etwa I6 Cents, von dort zum Ausfuhrhafen 40 Cents für Ioo Pfund. Die Durchgangsfracht von Memphis nach Fall River, Mass., ist fast dieselbe wie nach Liverpool, nämlich etwa 55 Cents für Ioo Pfund.

Weit billiger sind allerdings noch die Frachten für Mais und Weizen, die in Waggonladungen einen Tarif genießen, der nur den dritten Teil von demjenigen für Baumwolle ausmacht.

Ausfuhrplätze. Während früher die Baumwolle ausschließlich von den Häfen des Atlantischen Ozeans und des Mexikanischen Golfs verschickt wurde, nimmt neuerdings auch die pazifische Küste daran teil, und ein Quantum geht jährlich über den Rio Grande del Norte. Von den pazifischen Häfen, wie S. Francisco, S. Diego, Portland, Tacoma und Seattle, geht die Baumwolle nach Japan und China, aus Grenzplätzen, wie Eagle Pass und Laredo, nạch Mexiko. Auch unter den alten Baumwollverschiffungsplätzen machen sich mancherlei Verschiebungen geltend: New Orleans, lange Zeit hindurch der größte Baumwollausfuhrhafen der Welt, ist seit Anfang unseres Jahrhunderts von Galveston iberholt; ungebrochen in ihrer Unternehmungslust durch die furchtbare Sturmflut des Jahres I9oo, welche die ganze niedrige Insel wegzuschwemmen drohte, hat die Stadt seit jener Zeit ihre Einrichtungen für Verschiffung von Baumwolle in mustergültiger Weise ausgebaut. Auch New York und Boston haben nicht mehr die gleiche Bedeutung wic früher, und für den Eigenbedarf übertrifft die Versorgung auf dem Landivege mittels der Eisenbahn heute den Seeverkehr.

Der Export im Baumwolljahr 191I/I2 ging über folgende Hauptplätze :

\begin{tabular}{|c|c|c|c|}
\hline & $\begin{array}{c}\text { Tausend } \\
\text { Ballen }\end{array}$ & & $\begin{array}{c}\text { Tausend } \\
\text { Ballen }\end{array}$ \\
\hline Galveston & . 3700 & Übertrag & 8616 \\
\hline Savannah & . I 786 & Mobile & 292 \\
\hline New Orleans & I 600 & Pensacola, Flor.. & 216 \\
\hline New York & 655 & Puget Sound & 213 \\
\hline Wilmington, N. C. & 502 & S. Francisco & 212 \\
\hline Brunswick, Geo. & 373 & Diverse. . . . &.$\quad 1132$ \\
\hline Ubbertrag & 8616 & Zusammen & I0 68 I \\
\hline
\end{tabular}


Von der Compress geht die Baumwolle in - während der Saison oft knappen - Eisenbahnwaggons mit je 50 bis 60 Ballen nach dem Hafen, wo der Verschiffer die Ballen im Schiffe selbst noch durch Schraubenapparate näher aneinander pressen läßt, um Raum zu sparen, wobei Packung und Signum häufig weiter beschädigt werden, nachdem die Ballen bereits auf der Farm, auf den Märkten der offenen Straße, auf Entkernungs- und Eisenbahnstationen und endlich auch am Hafenplatz selbst nicht selten allen Unbilden, wie Feuchtigkeit, Feuersgefahr, Diebstahl und Beschädigungen aller Art, gänzlich ungeschützt ausgesetzt waren, und dadurch häufig die sogenannte „, o u n try d a ma g e“ aufweisen. Obgleich in den letzten Jahren viele Millionen für Einrichtung von Iagerhäusern ausgegeben wurden, reichen diese doch erst für einen Bruchteil der Ėrnte aus, und der Rest liegt wochenlang ungeschützt auf offenerStraße herum. Die Einführung von Zetteln an jedem einzelnen Ballen, mit Angabe von Pflanzernamen, Entkernungs- und Compressstation und Brutto- und Nettogewicht wird der Verminderung von ,country damage" durch die alsdann mögliche Kontrolle sehr dienlich sein.

Bislang ist der meist aufgerissene amerikanische Baumwollballen, von Wasser, Schmutz und Signierfarbe beschädigt, nicht selten mit abgerissenem Signum, so daß seine Identität unter Umständen schwer festzustellen, geradezu ein Hohn auf jede moderne l'ackung, und es gibt wohl iberhaupt keinen zweiten Handelsartikel der Erde, dessen Packung so nachlässig ist wie diejenige der anerikanischen Baumwolle. Bezeichnete doch selbst Richter O g d e $n$ gelegentlich der Baumwollkonvention zu Washington im Mai 1906 den amerikanischen Baumwollballen als einen ,schmutzigen, beschädigten, unansehnlichen, wassergetränkten, liederlichen, raumverschwenderischen, ungestalteten, schildkrötenähnlichen und lı̈̈chst feuergefährlichen Packen". Kein Wunder, daßi die europäischen Feuerversicherungs-Gesellschaften 12 bis $25 \%$ höhere Raten für amerikanische als für die so viel besser verpackte indische und ägyptische Baumwolle nehmen.

Jedenfalls sind auf dem Wege der Baumwolle vom Felde bis in die Spinnerei noch viele Verbesserungen möglich.

\section{Baumwollexport.}

Die amerikanischen Märkte notieren Bammwolle für das amerikanische Pfund in Cents und Fracht in Pence plus $5 \%$ Primage; Anstellungen durch Agenten in Europa nach Deutschland erfolgen 
stets für das amerikanische Pfund in Pence, ,cif“ Bremen oder Hamburg mit $6 \%$ Tara, und die Fakturierung erfolgt in englischem Gewicht. Rembours in 90 oder 60 Tage Sicht-Tratten auf ein Haus in London oder einen deutschen Platz. Die Frachtraten nach Europa schwanken sehr in den einzelnen Jahren; im April I9I4 notierte man für Ioo Pfund Baumwolle nach Liverpool oder Bremen 20 Cents ab New York und 35 Cents ab Galveston.

Nicht unbedenklich hat sich bei der amerikanischen Baumwollverladung der Umstand erwiesen, daß anf Grund der Konnossementsklausel: „Failing shipment by said steamer, in and upon a following steamer" eine gekaufte Partie von Ioo Ballen zuweilen auf sechs verschiedene Dampfer und über vier Monate und mehr verteilt wird, während die Tratte gegen den Gesamtbetrag sofort gezogen und längst honoriert war, ehe der letzte Ballen endlich amerikanischen Boden verließ.

Im Sommer 1910 wurden von Amerika aus gefälschte Konnossemente äber große Quantitäten Baumwolle in den Handel gebracht, ohne daß die betreffende Ware selbst ïberhaupt existierte. Die schweren Verluste, welche dadurch Liverpool, Bremen und Havre trafen, veranlaßten den Baumwollhandel zur Forderung von Garantien seitens der Eisenbahnen und Dampfergesellschaften, und die Verhandlungen mit diesen seitens der Händler und Banken haben immerhin einigen Erfolg gehabt.

Die Entwicklung des amerikanischen Haumwollexports weist folgende Zahlen auf:

\begin{tabular}{|c|c|c|c|c|c|c|c|}
\hline Jahr & \begin{tabular}{|c|} 
Menge \\
Tausend Ballen \\
à soo Pfund
\end{tabular} & $\begin{array}{l}\text { Wert } \\
\text { Millionen } \\
\text { Dollars }\end{array}$ & $\begin{array}{l}\text { Preis } \\
\text { Cents das } \\
\text { Pfund }\end{array}$ & Jahr & $\begin{array}{c}\text { Menge } \\
\text { Tausend Ballen } \\
\text { à 5oo Pfund }\end{array}$ & $\begin{array}{l}\text { Wert } \\
\text { Millionen } \\
\text { Dollars }\end{array}$ & $\begin{array}{l}\text { Preis } \\
\text { Cents das } \\
\text { Pfond }\end{array}$ \\
\hline 1790 & 0,379 & 0,05 & 26 & I 88I & $43^{8 I}$ & 247 & I 2 \\
\hline 1800 & $4 \mathrm{I}$ & 9,2 & 44 & I $\$ 85$ & 3783 & 202 & 9,4 \\
\hline ISIO & 124 & 9,6 & 16 & 1890 & 4943 & $25 \mathrm{I}$ & 8,6 \\
\hline I 820 & 250 & 17,8 & 14 & 1895 & 7034 & 205 & 8,2 \\
\hline I 830 & 597 & 29 & 10 & 1896 & 4670 & 190 & 7,3 \\
\hline I 840 & 1487 & 64 & 9,5 & 1898 & 7700 & 230 & 4,9 \\
\hline 1850 & $127^{\circ}$ & 72 & 12 & 1900 & 6200 & 242 & 9.3 \\
\hline I855 & 2017 & 88 & IO & 1902 & $700 I$ & $29 I$ & 8,2 \\
\hline 1860 & 3535 & 102 & I3 & I904 & 6126 & 371 & 8,7 \\
\hline I 86 I & 615 & 34 & $3 I$ & 1907 & 9036 & $48 \mathrm{I}$ & II, 5 \\
\hline I 862 & IO & I & 67 & 1908 & 7634 & $4^{8} 3$ & 9,2 \\
\hline I 863 & 23 & 6,6 & $\operatorname{IOI} 1 / 2$ & 1909 & 8896 & $4 I 7$ & 14,3 \\
\hline I 864 & 24 & IO & $8_{3}$ & 1910 & 6413 & $45^{\circ}$ & 14,7 \\
\hline I 865 & I3 & 6,8 & 43 & I9I I & 8067 & 585 & 9,7 \\
\hline 1866 & I3OI & $28 I$ & 32 & 1912 & 10 675 & 565 & 12 \\
\hline 1870 & 1917 & 227 & 17 & 1913 & 8725 & 547 & I 2,5 \\
\hline 1875 & 2520 & 191 & I 3 & & & & \\
\hline
\end{tabular}


Die Ausfubr von Sea Is 1 a n d-Baumwolle, in obigen Zahlen inbegriffen, belief sich in den Jahren:

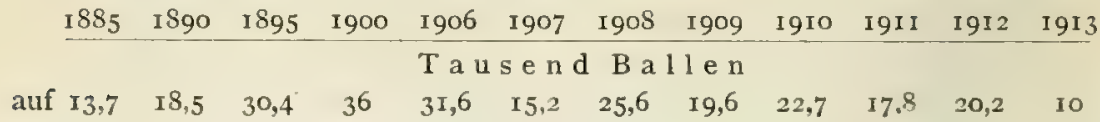

und die Durchschnittspreise waren für das Pfund:

\begin{tabular}{|c|c|c|c|c|c|c|c|c|}
\hline & & & & & & $\begin{array}{c}\text { Georgia } \\
\text { Cents }\end{array}$ & $\begin{array}{c}\text { Florida } \\
\text { Cents }\end{array}$ & $\begin{array}{l}\text { Süd-Carolina } \\
\text { Cents }\end{array}$ \\
\hline 1902 & . & . & . & . & 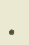 & I7 & 20 & 25 \\
\hline I906 & . & . & . & . & . & 28 & 28 & 36 \\
\hline 1908 & . & • & . & . & " & I 8 & 18 & 23 \\
\hline I9IO & . & . & 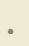 & . & . & 27 & 27 & 36 \\
\hline 1912 & . & . & . & . & . & 19,5 & 19,5 & 25 \\
\hline
\end{tabular}

Die besseren Sea Island-Sorten werden durch Schwankungen im Preise kurzstapeliger Uplands nur wenig beeinflußt, wohl aber beeinflussen Erntemenge und Güte der langstapeligen Uplands ernstlich die niedrigen Klassen von Sea Island-Baumwolle.

Der Gesam twert der Baumwollausfuhr ist mehr von den jeweiligen Prei se n, als von der Menge abhängig; kleinere Ernten ergeben zuweilen höheren Ertrag. Der niedrigste vorgekommenc Jahresdurchschnitt vor dem Kriege war I843/44 mit 5 Cents; der Bürgerkrieg brachte ein phänomenales Aufschnellen bis zu einem Maximum von I90 Cents in 1866; von da ab sanken die Preise erst schnell, dann langsam, bis sie 1898 mit 4,9 Cents ihren niedrigsten Sitand erreichten. Seitdem ist eine kräftige Erholung eingetreten.

Damit das stolze Wort amerikanischer Redner: „Cotton is King" wahr bleibe, muß Baumwolle freilich billig und dadurch populär bleiben, denn es handelt sich hier immerhin auch um eine beschränkte Monarchie.

Maßgebend für die Preisbildung sind die Börsen in New York und Liverpool, und die Schwankungen der Preise vollziehen sich von Stunde zu Stunde je nach Angebot und Nachfrage. Amerikanische Upland-Baumwolle ist maßgebend für das gesamte Baumwollgeschäft der Welt; ihrer Preisbewegung schließen sich alle anderen Sorten Baumwolle mehr oder weniger an. Ein Rückgang in den Erträgen der amerikanischen Ernte pflegt ohne weiteres die Baumwollpreise auf der ganzen Linic emporzutreiben, und umgekehrt bringt eine reichliche amerikanische Ernte in der Regel auch für die anderen Baumwollsorten eine Ermäßigung des Preises. 
Im Verglcich zum G es a m t export der. Vereinigten Staten nimmt Baumwolle folgende Stelle ein:

Fiskaljahr * . $1880 \quad 1890 \quad 1900 \quad 1910 \cdot 1912$

Total. . . . $835 \quad 857 \quad 1394 \quad 1744 \quad 2204$ Millionen Dollars Davon Baumwolle 2 I I $250 \quad 241 \quad 450 \quad 565 \quad$ "

Die Länder, nach denen sich die nordamerikanische Baumwollausfuhr richtet, waren:

$$
\text { I9II/12 I9I2/I3 }
$$

Tausend Ballen Tausend Ballen

\begin{tabular}{|c|c|c|c|c|c|c|}
\hline England. & . & - & - & . & $. \quad+197$ & 3563 \\
\hline Deutschlan & & . & . & $\cdot$ & . 3053 & 2351 \\
\hline Franlireich & & . & . & . & . $\quad I$ ISI & I Or 5 \\
\hline Italien & 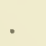 & . & . & . & 612 & 479 \\
\hline Spanien . & . & . & . & . & 297 & 298 \\
\hline Belgien . & . & . & . & . & 202 & I if \\
\hline Rußland . & . & . & . & . & 107 & 71 \\
\hline Österreich & . & . & . & . & 120 & 109 \\
\hline Holland . & . & . & . & . & 35 & I 4 \\
\hline Rest von $F$ & & pa & & . & 81 & 52 \\
\hline Japan . & . & • & . & . & 458 & 375 \\
\hline Kanada . & . & . & . & . & 175 & I 48 \\
\hline Mexiko . & . & . & . & . & I 5 & 20 \\
\hline Diverse . & . & • & . & . & . 142 & I 5 \\
\hline & & & & & 10675 & \\
\hline
\end{tabular}

Die 20000 Ballen Se a I 1 a nd des Jahres 1912 gingen mit I 4 Soo Ballen nach England, 4900 Ballen nach Frankreich und nur I78 Ballen nach Deutschland.

Der Hauptbaumwollmarkt der Welt ist L i v e r p o o l, wo sich aus der I84I gegründeten „Liverpool Cotton Association“ die Baumwollbörse entwickelte. An dieser können folgende Geschäfte abgeschlossen werden:

I. Verkauf von in Liverpool lagernder Ware (,,spot" ${ }^{64}$,

2. Verkauf von Baumwolle auf Ankunft (, to arrive"),

3. „cf." $=$ Kostfracht und „,if" $=$ Kost, Assekuranz und Frachtverkäufe,

4. Termingeschäfte, ,futures“, auf Basis von Upland middling, nichts unter low middling, in Partien von Ioo Ballen und dem mehrfachen davon,

5. Geschäfte auf Abruf (,on call“"), letzthin sehr zugenommen, wobei der Preis auf Grund der Terminnotierung und einer Prämie 
endgültig bei dem vom Käufer zu bestimmenden Abnehmetermin festgestellt wird.

Der größte Baumwollplatz des Kontinents ist B remen, wo man I872 die „Bremer Baumwollbörse“ gründete zur Abschätzung und Klassierung der gehandelten Baumwolle durch beeidigte und von den Parteien unabhängige Klassierer und zur Bildung von Schiedsgerichten. Diese Einrichtungen bewährten sich ausgezeichnet, und im Jahre 1886 erfolgte die Vereinigung der deutschen Spinnerei mit der Bremer Baumwollbörse, um Bremen zu einem großen nationalen Baumwollmarkt auszubauen. Im Februar 1914 eröffnete der „Bremer Verein für Terminhandel in Baumwolle" seine Tätigkeit mit Abschlüssen auf Partien von Ioo Ballen oder dem Mehrfachen in der bei den anderen Terminbörsen üblichen Weise, Basis middling, nichts unter ,good ordinary“. Das Geschäft vollzieht sich auch hier auf Grund der Liverpooler Standards und beim Effektivhandel in folgenden fünf Formen:

I. Verkäufe von Loco-Baumwolle,

2. Verkäufe auf Lieferung mit einer bestimmten Lieferzeit,

3. Verkäufe auf Ankunft,

4. Verkäufe mit der Klausel ,franco Waggon“",

5. Verkäufe nach Kostfracht-Bedingungen.

Um einen Begriff von dem Preisverhältnis zwischen den verschiedenen Klassen zu geben, folgt hier als Beispiel dic Noticrung der Bremer Baumwollbörse vom I7. April I9I4:

Amerikanische Baumwolle. Preise in bar ohne Abzug, für $1 / 2 \mathrm{~kg}$.

\begin{tabular}{|c|c|c|c|c|c|c|c|c|}
\hline $\begin{array}{l}\text { Middling } \\
\text { fair }\end{array}$ & $\begin{array}{c}\text { Fully good } \\
\text { middling }\end{array}$ & $\begin{array}{c}\text { Good } \\
\text { middling }\end{array}$ & $\begin{array}{c}\text { Fully } \\
\text { middling }\end{array}$ & Middling & $\begin{array}{l}\text { Fully low } \\
\text { middling }\end{array}$ & $\begin{array}{c}\text { Low } \\
\text { midaling }\end{array}$ & $\begin{array}{c}\text { Good } \\
\text { ordinary }\end{array}$ & Ordinary \\
\hline \multirow[t]{2}{*}{$\begin{array}{c}\text { Pf. } \\
74^{1} / 4\end{array}$} & $\begin{array}{c}\text { Pf. } \\
7 \mathrm{I}^{3} / 4\end{array}$ & $\begin{array}{c}\text { Pt. } \\
70^{1} / 4\end{array}$ & $\begin{array}{c}\text { Pf. } \\
67^{1} / 4\end{array}$ & $\begin{array}{c}\mathrm{Pf} . \\
64^{1} / 4\end{array}$ & $\begin{array}{c}\text { Pf. } \\
6 I^{3} / 4\end{array}$ & $\begin{array}{c}\text { Pf. } \\
58^{1} / 4\end{array}$ & $\begin{array}{c}\text { Pf. } \\
52^{1 / 4}\end{array}$ & $\begin{array}{l}\text { Pf. } \\
46^{1} / 4\end{array}$ \\
\hline & \multicolumn{4}{|c|}{ 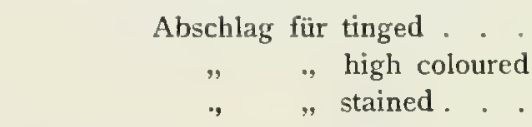 } & 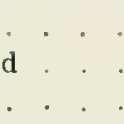 & $\begin{array}{l}3 \text { Pf. } \\
4, \\
5\end{array}$ & & \\
\hline
\end{tabular}

\begin{tabular}{|c|c|c|c|c|c|c|c|c|}
\hline & $28 \mathrm{~mm}$ & $28 / 29 \mathrm{~mm}$ & $28 / 30 \mathrm{~mm}$ & $29 \mathrm{~mm}$ & $29 / 30 \mathrm{mIn}$ & $30 \mathrm{~mm}$ & $30 / 32 \mathrm{~mm}$ & $32 \mathrm{~mm}$ \\
\hline $\begin{array}{l}\text { Good middling und hö- } \\
\text { here Grade }\end{array}$ & $1 / 4$ & $1 / 2$ & $I^{1} / 4$ & $2^{1 / 4}$ & 5 & $8^{1 / 4}$ & ca. $12^{1 / 3}$ & ca. I9 \\
\hline Fully middling . . & $1 / 8$ & $3 / 8$ & I & $I^{3} / 4$ & $41 / 4$ & 7 & ca. Io & ca. I 5 \\
\hline Middling und darunter & $1 / 8$ & $1 / 4$ & $5 / 8$ & $1 / 8$ & $23 / 4$ & $4^{3} / 4$ & ca. $71 / 2$ & ca. II \\
\hline
\end{tabular}


Obige Differenzen gelten für good color und fair color. Für alle farbigen Qualitäten kommen nur die Stapeldifferenzen von middling und darunter in Betracht.

Unter ,good staple“ versteht man ctwa $27 \mathrm{~mm}$ Stapellänge.

Die gleichzeitigen Notierungen für das englische Pfund ,middling“ waren in Liverpool 7,30 Pence, in New York 13 , Io Cents.

Linters, in gelbliche und grünliche Sorten und in die sechs Klassen: Fancy, Choice, A, B, C, D eingeteilt, notierten Mitte April I9I4 in Bremen für das 1/2 $\mathrm{kg}$ gutstapelig A 29 Pfennige in gelblich, 27 Pfennige in grünlich, und die Wertdifferenzen gegen die anderen Klassen betrugen zwischen Fancy Linters und

$$
\begin{aligned}
& \text { Choice, A gutstapelig, A rein, aber kurzstapelig, B C D }
\end{aligned}
$$

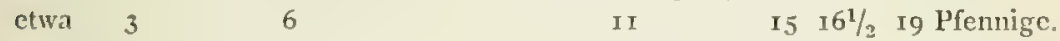

Ha m b rg spielt im Baumwollhandel hauptsächlich einc Kolle im Terminmarkt. Die Termingeschäfte in Baumwolle werden dort durch die "Waren-Liquidationskasse" abgeschlossen in Mengen von 100 Ballen und dem Vielfachen dieses Minimalsatzes.

Havre und scit I9I4 Gent in Belgien sind die weiteren Terminplätze in Europa für Baumwolle.

A rbitration ist bei Baumwollieferungen sehr läufig. Sic erfolgt

in Bremen durch beeidigte unparteiische Klassierer der Baumwollbörse,

in $\mathrm{H}$ a $\mathrm{mburg}$ auf Basis der Liverpooler Standards von Maklern der beiden Seiten, welche nur dann, wenn sie sich nicht einigen können, einen Dritten als Obmann wählen, besorgt.

in Liverpool wird die Arbitration durch die Makler

\section{Baumwollverbrauch in den Vereinigten Staaten.}

Ein großer Teil der amerikanischen Baumwollernte bleibt heute im Lande selbst. Waren die Vereinigten Staaten während vieler Jahrzehnte ganz überwiegend Lieferanten von Rohmaterial für im A us 1 and gelegene Fabriken, so ist in der Letztzeit, besonders auch im Süden der Union, ein großartiger Aufschwung der amerikanischen Baumwollindustrie eingetreten, so zwar, daß sie bereits heute, nach Großbritannien, den zweiten Platz in der Baumwoll- 
industrie der Welt iberhaupt cinninme und von allen lndustricländern die gröbte Menge Rohbaumivolle verarbeitet.

Geschichtliches. Sichon frühzeitig hatten die Kolonisten NeuEnglands, Engländer wie Holländer, sich auch der Schafzucht, dem Flachs- und Hanfbau gewidmet, und die Produkte daraus, ebenso wie die aus Westindien bezogene Baumwolle, versponnen und verwebt. Trotzdem man im merkantilen England der Entwicklung dieser Dinge durchaus feindlich gegenüberstand, nahm sie ihren lortgang, und zwar überwiegend in den nördlichen Gebieten zwischen Philadelphia und Boston. Im Siiden dagegen waren es die Sklaven, wclche unter Leitung der Frauen Gewebe für die häusliche Tracht und für die Dienstboten herstellten, und die ersten dortigen ,spinncreien" waren die Wolnnungen der Farmer, wo Sklavinnen mit Spinnen und Weben beschäftigt wurden. Der Gebrauch ron Spinnrad und Handwebstuhl zur Verarbeitung von Baumwolle war in allen Teilen des Landes schon vor der Revolution weit verbreitet, und dic in Nordamerika gebaute Baumwolle wurde in der Kolonialzeit fast ausschlieblich im Lande selbst verbraucht. Bis zur Arckwrightschen Erfindung bestand auch in Amerika die Kette solcher Gewebe immer aus Leinen oder Wolle, und Baumwolle diente nur als Einschlag. In Jahre i720 wurde in Boston eine besondere Spinnschule eingerichtet, 1753 folgte Charleston darin nach, und noch lange Zeit nach dem Beginn von Fabriken wurde die Baumwollverarbeitung von den Frauen als Hausindustric betrieben.

Bereits I775 war in Philadelphia eine Spinn-Jenny mit $2+$ Spulen in Betrieb gesetzt worden. Die erste kleine Baumwollweberei mit Pferdebetrieb entstand 1787 bei Charleston, eine etwas größere Baumwollspinnerei I787/88 in Beverly, Mass, und bald folgten deren weitere an verschiedenen Orten entlang der Ostgrenze des Landes, besonders in Pawtucket und Providence, Rh. I.; Boston, Mass., New Haven und Norwich, Conn.; New York City und Paterson, N. Y, ; Philadelphia, Penns, und Statesburg, S. Ca. In diesen Fabriken wurde Baumwolle mit Maschinen gekardet und gesponnen, während das Weben bis I8I5 noch ausschließlich auf Handstühlen erfolgte; erst in diesem Jahre wurde die erste mechanische Weberei in Waltham, Mass., errichtet. Mehr als irgendein anderer Faktor bestimmte das Vorhandensein von W asser$\mathrm{k} r \ddot{a} \mathrm{ften}$ die Lokalisierung der Baumwollindustric, und für viele Jahre wurde als Betriebskraft ausschließlich Wasser verwandt, wenn kleinere Anlagen auch zuweilen mit tierischer Kraft betrieben 
wurden. Der Schwerpunkt der Baumwollindustrie lag von vornherein in den Neu-England-Staaten, und besonders in Massachusetts.

Im Jahre 1809 waren im ganzen 62 Baumwollfabriken mit einem Total von 3 I 000 Spindeln im Betrieb, I83 I I I24 000 Spindeln und 33000 Webstühle.

Georgia war der zweite $\mathrm{S}$ ü $\mathrm{d} \mathrm{sta}$ a $\mathrm{t}$, der mit fabrikmäßiger Bearbeitung von Baumwolle begann; 1809 wurde in Louisville die erste Weberei mit Pferdebetrieb eröfnet. I818 folgte die erste Weberei in Nord-Carolina, im ganzen aber war die Entwicklung der Baumwollindustrie in den Südstaaten eine langsame. Die Fabriken hier wurden teils mit schwarzen Sklaven, teils mit freien weißen Arbeitskräften betrieben. Ein kurz vor dem Bürgerkrieg genommener Anlauf wurde durch den Krieg und seine Folgen unterbrochen, und man stand im Süden im allgemeinen auf dem Standpunkt, die Baumwolle zu produzieren, ihre Verarbeitung aber anderen Gegenden zu überlassen. Der alte Süden war eben fast ausschlieBlich Ackerbaustaat.

Der während des Sezessionskrieges eingetretene „Baumwollhunger" machte sich natürlich auch in den Nordstaaten fühlbar, aber doch nicht in so hohem Maße, als man meinen sollte; die notigen Betriebseinschränkungen wurden durch höhere Verdienste wettgemacht.

Im Jahre 1880 besaßen die Süstaaten erst $7 \%$ der in Nordamerika laufenden Spindeln und Webstühle; nachdem die wirtschaftliche Stagnation, die dem Bürgerkrieg zunächst folgte, überwunden war, trat aber auch im Süden, besonders in den beiden Carolinas und in Georgia, ein rapider Aufschwung der Baumwollindustrie ein, so dab die Baumwollstaaten im Jahre I890: i \%, I900: $24 \%$, I9 Io fast $40 \%$ der gesamten Baumwollindustrie der Vereinigten Staaten repräsentierten.

Während in den Jahren 1900 bis 1913 der Baumwollkonsum in den Neu-England-Staaten nur um I6\% zunahm, steigerte er sich in den Südstaaten um $94 \%$.

Die Baumwollindustrie in den Vereinigten Staaten entwickelte sich mit Hilfe hoher Schutzzölle immer größer und mannigfaltiger, die Einfuhr von Baumwollwaren wurde entsprechend herabgedrückt, in vielen Artikeln ganz verhindert, und schließlich konnte man selbst zum Export übergehen. So ist die Baumwollindustrie heute nicht nur eine der ältesten, sondern auch eine der wichtigsten der Vereinigten Staaten überhaupt. 
Statistik. Die Entwicklung der Industrie wird durch folgende Zahlen der mit dem Zensus von I840 einsetzenden amtlichen Statistik illustriert:

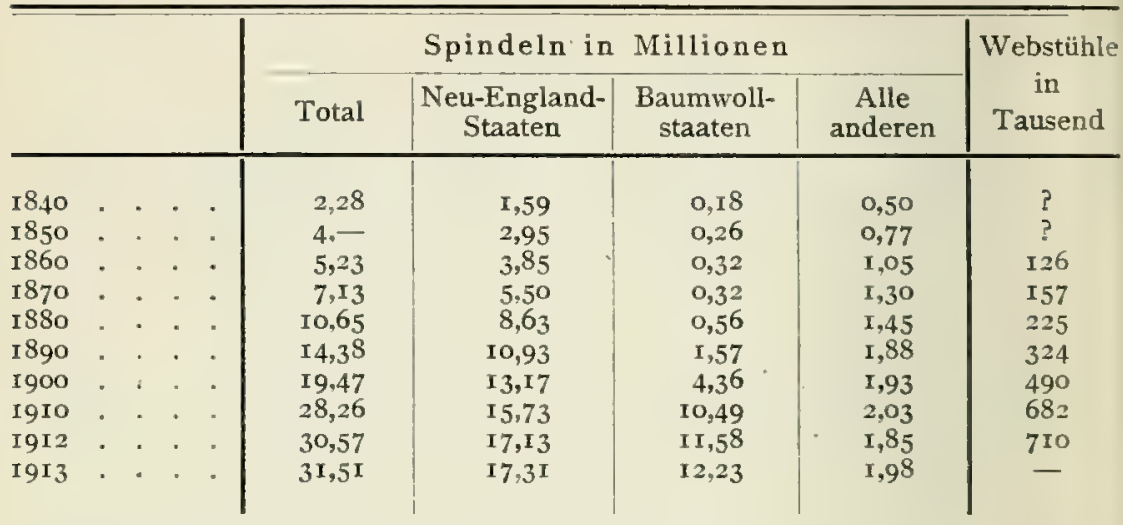

Zur Ergänzung diene folgende Tabelle:

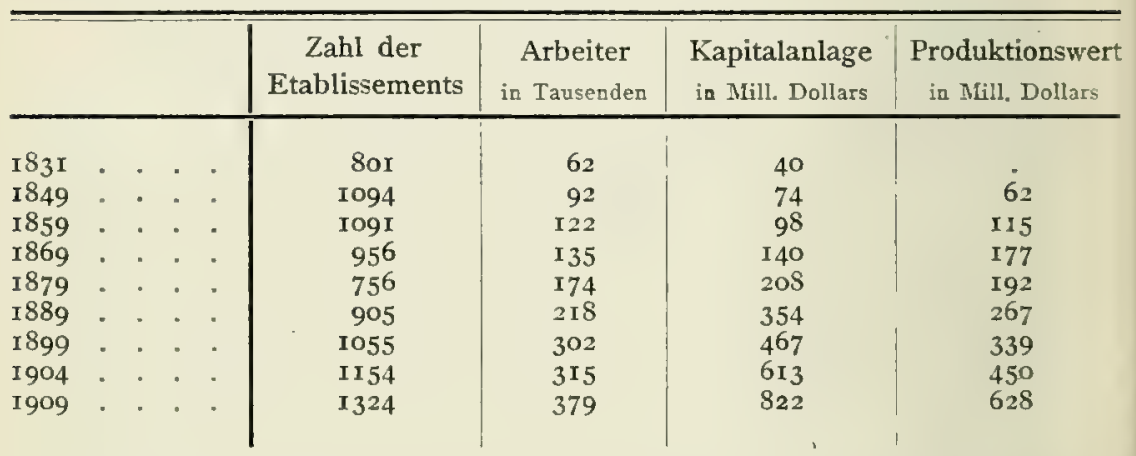

Bei den Produktionswerten ist allerdings zu bemerken, daß sie zahireiche Wiederholungen einschließen, wie z. B. bei Garn und Geweben.

Von den I909 vorhandenen 1324 Etablissements der Baumwollindustrie waren $16 \%$ in Privatbesitz, $84 \%$ in Gesellschaftsform organisiert, und nach ihrem jährlichen Produktionswert entfielen auf

Produktion bis 20000 Dollars. . . . . . $6 \%$

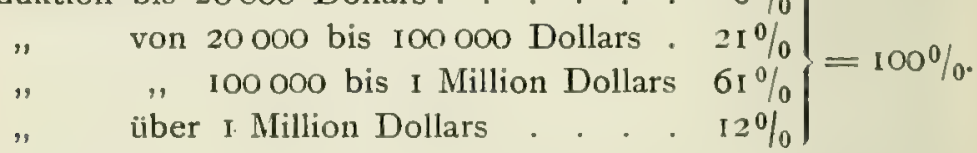

Die $\mathrm{Z}$ ah 1 der aktiven Spindeln, in Tausenden ausgedrückt, verteilte sich im Jahre I9I3 auf die Staaten 
Von den 633000 Stühlen des Census von 1909 liefen 473000 auf glatte Rohware in Breite

$\begin{array}{cccc}\text { von bis } 28 & 28-31 & 32-36 & \text { über } 36 \text { Zoll } \\ \text { mit } 41 & 130 & 102 & 200 \text { Tausend Stühlen, }\end{array}$

und zwar sind darunter am stärksten zunehmend die breitesten.

Im allgemeinen werden Spinnerei und Weberei in den Vereinigten Staaten meist zusammen und nicht getrennt betrieben; auch Appretur, Aufmachung und Packung der Ware wird gleich in der Weberei besorgt.

Von den 1077 Baumwollfabriken des Census von 1905 vereinten 590 Spinnerei und Weberei, während 295 nur Spinnerei, I69 nur Weberei, 23 eine andere Tätigkeit betrieben. Tatsächlich, nach der Zahl der Spindeln und Webstühle berechnet, war das Übergewicht der kombinierten Betriebe aber noch größer, als es die vorstehenden Ziffern erscheinen lassen, denn die 590 gemischten Betriebe umfaßten mit durchschnittlich je 32000 Spindeln $83 \%$ aller dieser, und mit durchschnittlich je 885 Webstühlen sogar $97 \%$ aller Webstühle der Vereinigten Staaten. Das Zentrum der reinen Weberei in der Union ist Philadelphia.

Fünfundzwanzig Gesellschaften haben mehr als je 4000 Webstühle; siebzehn Gesellschaften besitzen jede über 200000 Spindeln und 5000 Webstühle. Die größte ist die Amoskeag Manufacturing Company mit 620000 Baumwollspindeln und 22000 Baumwollwebstühlen, neben 50000 Kammgarnspindeln und 2200 Tuchwebstühlen; weitere große Baumwollfabriken sind die Fall River Iron Works u. a. Die wichtigsten Baumwollindustrieorte sind Fall River und Lowell in Massachusetts.

Die Qualität der hergestellten Baumwollstoffe ist im allgemeinen grob und mittelfein, wenn auch allmählich zunehmend an Feinheit und Mannigfaltigkeit, so daß sie den überwiegenden Teil der Landesbedürfnisse decken.

Schwierigkeiten bietet aber auch hier wieder die Frage der

Arbeiter. Der Census von 1909 führt 379000 Arbeiter in den Baumwollfabriken auf, und davon waren

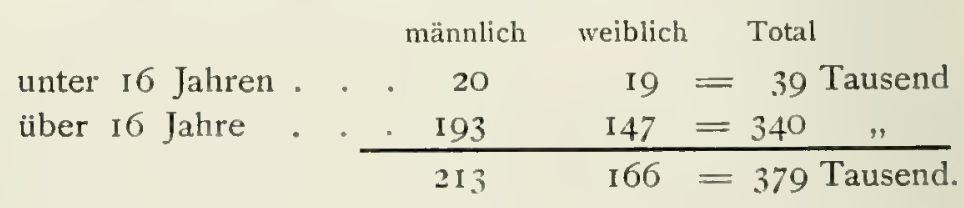


Die Arbeitszeit der Woche verteilt sich auf 48 bis 54, 54 bis 60,60 bis 72 Stunden bei 3000,3 I0 000, 65000 Arbeitern.

In den $\mathrm{Neu}-\mathrm{Eng} \mathrm{l}$ and-Staaten sind die Arbeiter gut organisiert und meist fremder Geburt; den Irländern folgten französische Kanadier, Italiener, Griechen, Litauer und andere ungelernte Einwanderer aus Ost- und Südeuropa. Die erwünschte und nötige Einwanderung geschulter Arbeitskräfte aus Europa verhindern die amerikanischen Arbeiterorganisationen, welche die I.cbenshaltung möglichst hoch halten wollen, und die von ihnen beeinflußten scharfen Einwanderungsgesetze, so daß mangels genügender Arbeitskräfte regelmäßig eine ganze Reihe von Spindeln und Webstühlen im Lande außer Tätigkeit ist. Kinderarbeit ist in den Nordstaaten nicht vertreten.

In den $\mathrm{S} \ddot{u} \mathrm{dsta}$ a ten entstammen die Fabrikarbeiter der Baumwollindustrie meist der Klasse der sogenannten „Armen Weißen" aus den Bergländern, vielfach Analphabeten, die aber unter beständiger Kontrolle der Aufseher in bemerkenswert kurzer Zeit Gutes leisten. Immerhin sind sie durchschnittlich weniger leistungsfähig als die Arbeiter der Nordstaaten und bislang noch nicht organisiert; Kinderarbeit ist hier häufig. Der Neger hat sich für die feine Maschinenarbeit als ungeeignet erwiesen, und ist deshalb in Baumwollfabriken nur in Außenarbeit und auf dem Lager zu beschäftigen; für die Hauptarbeit kommen nur W e i Be in Frage.

Auch in der Baumwollindustrie Nordamerikas hat sich das Bestreben gezeigt, die teure und an Zahl unzulängliche mensch$1 \mathrm{iche}$ Arbeitskraft weitestgehend durch $\mathrm{Masch}$ inen zu ersetzen, und tatsächlich sieht man in den Arbeitssälen der Spinnereien und Webereien verblüffend wenig Menschen: Ein Mädchen bedient I200 Ringspindeln, ein Mann angeblich bis zu 32, nicht selten 16 bis 20 Northrop-Webstühle. Die Censusaufnahme rom Jahre 1909 weist allerdings nur einen Durchschnitt von 407 Spindeln auf die Spinnerin und von $61 / 2$ Webstühlen auf den einzelnen Weber auf. Die Northrop-Webstühle, von einem Yorkshiremann in den Vereinigten Staaten erfunden, 1892 in England, später auch in Deutschland eingeführt, werden von der Draper Company in Hopdale, Mass., hergestellt, finden gerade wegen ihrer Leistungsfähigkeit bei den Arbeitern der Neu-England-Staaten Opposition, sind aber im Süden überwiegend vertreten, wie denn überhaupt der erst seit kurzem industrialisierte Süden durchweg mit den neuesten Maschinen und Einrichtungen ausgestattet und nicht mit veraltetem 
Material belastet ist. Der Ersatz alter Maschinenanlagen durch neue hat, neben der meist durch Vergrößerung a 1 te r Spinnereien und Webereien erfolgten Ausdehnung der Industrie, auch im Norden die Produktionsfähigkeit vergrößert.

Nicht alle diese amerikanischen Maschinen eignen sich auch für Europa; in Amerika mit seinen hohen Löhnen - Wochenlohn im Süden 8 bis 9 Dollars für die Spinnerin, 9 bis I4 Dollars für den Veber; im Norden bis doppelt so hoch bei einer um ein Drittel größeren Arbeitsleistung — ist durch Lohnersparnis die Amortisation der Maschinen leichter und schneller möglich als bei uns, obgleich die finanziellen Ergebnisse der amerikanischen Baumwollindustrie seit Jahren vielfach auch unbefriedigend sind.

Im allgemeinen scheint Europa von amerikanischen Baumwollspinnereien kaum etwas lernen zu können; darin ist noch inmer England Meister und Vorbild. Wohl aber bietet die amerikanische Baumwoll weberei sehr nachahmungswerte Einrichtungen, deren Tendenz, neben weitgehender Ausschaltung der Handarbeit, dahin geht, die Elastizität des Fadens durch bessere Vorbereitung und Führung möglichst zu schonen.

Bislang ist in der amerikanischen Baumwollindustrie die $\mathrm{D}$ a $\mathrm{mp} \mathrm{f} \mathrm{kraft}$ noch weit überwiegend; von den in ihr arbeitenden I 296000 Pferdekräften im Jahre 1909 stammten $67 \%$ von Dampf-, $23 \%$ von Wasser-, $8 \%$ von elektrischer und $2 \%$ von anderer Kraft. Die Ausnutzung vorhandener reicher Wassermengen für Gewinnung elekt rische $r$ Kraft steht erst im Anfangsstadium. Allein im $\mathrm{s} \ddot{\mathrm{u}} \mathrm{d} \mathrm{l}$ i chen Industriebezirk rechnet man dabei auf 9 Millionen Pferdekräfte, von denen bislang erst I Million in den Dienst der verschiedenen Industrien gespannt ist; der Preis der Pferdekraft bei 66 Arbeitsstunden in der Woche beträgt jährlich etwa 20 Dollars. Im Süden weisen die beiden Carolinas die größte Benutzung elektrischer Kraft auf, welche die vorhandenen Wasserläufe billig liefern. Im Norden genügt allein der theoretisch mit $7 \frac{1}{2}$ Millionen Pferdekräften berechnete Niagarafall, um den ganzen Osten der Vereinigten Staaten und Kanadas mit elektrischer Kraft zu versorgen; auch davon ist bislang nur ein sehr kleiner Bruchteil eingefangen, und der Preis für eine Pferdekraft beträgt bei 24 Arbeitsstunden im Tage auch hier nur 20 Dollars im Jahre; größere Anlagen grenießen bedeutende Ermäßigung und bezahlen bei einer Abnahme von Iooo Pferdekräften für jede nur io Dollars im Jahre. Unter den Industriestaaten des Nordens macht Massachusetts den größten Gebrauch von elektrischer Kraft. 
Der Baumwollterbrauch der Vereinigten Staaten betrug in den Jahren

\begin{tabular}{|c|c|c|c|c|c|c|c|c|c|c|c|c|}
\hline & 1840 & I85o & 1860 & 1870 & 1880 & 1890 & 1900 & 1905 & 1909 & 1911 & $19 \times 2$ & {$[9]$} \\
\hline & & & & Tau & asend & Balle & en à & 500 & Pfund & d & & \\
\hline avo & 236 & 575 & & 796 & & & & & & 4704 & & \\
\hline $\begin{array}{l}\text { Export von Rohbaum- } \\
\text { wolle }\end{array}$ & & $\begin{array}{r}70 \\
1271\end{array}$ & 93 & & 188 & 539 & 1523 & \begin{tabular}{|}
2140 \\
8610
\end{tabular} & 8596 & $\mid \begin{array}{l}2328 \\
8068\end{array}$ & 712 & \\
\hline
\end{tabular}

Weitaus der Hauptteil der verbrauchten Baumwolle ist einheimische Upland, dazu konsumiert Amerika auch den größten Teil seiner Sea Island-Baumwolle, im Jahre ${ }^{1912 / 1}$ I3 z. B. 42000 von den geernteten 56000 Ballen à 500 Pfund; sie dient hauptsächlich zu Nähgarnen, Automobilreifen, Schläuchen für Hochdruck usw: Weiter wurden von frem der Rohbaumwolle im Jahre 19I2/I3 e ingef üh rt IgI ooo Ballen à 500 Pfund, wovon $84 \%$ aus Agypten stammten, der Rest aus China, Peru, Indien und Mexiko.

Der Gesamt produktionswert amerikanischer Baumwollfabrikate - einschließlich der bereits erwähnten Wiederholungen - ist im Fiskaljahr I9I2/I3 auf rund 700 Millionen Dollars geschätzt worden.

Den In landabsat z amerikanischer Baumwollwaren vermitteln große Kommissionshäuser, die an Engros- und Detailhändler verkaufen; den Export besorgen Handelsgesellschaften, welche ihren Bedarf durch Vermittlung von Maklern decken.

Die Entwicklung des Exports amerikanischer Baumwollwaren weist folgende Zahlen auf im Fiskaljahr

$\begin{array}{cccccccccc}1900 & 1905 & 1906 & 1907 & 1908 & 1909 & 1910 & \text { I9II } & 1912 & 1913 \\ 24 & 50 & 53 & 32 & 25 & 32 & 33 & 4 I & 51 & 54 \\ \text { Mill. Doll. }\end{array}$

Besondere Erwartungen hatte man auf die Entwicklung des Handels mit dem fernen Osten und in erster Linie auf China gesetzt, wohin man 1905/06 für 30 Millionen Dollars absetzte; infolge des Boykotts amerikanischer Waren ging der Betrag aber schon im Nächstjahr auf 6 Millionen zurück, und ist seitdem ungefähr auf diesem niedrigen Stand geblieben.

Der Export rom Jahre I9I2/13 mit 533/4 Millionen Dollars verteilt sich auf $4+4$ Millionen Quadratyard Gewebe im Werte von 32 Millionen Dollars, II Millionen Dollars Wirkwaren und andere Kleidungsstücke, 4 $1 \frac{2}{2}$ Millionen Baumwollabfälle, 3/4 Millionen Garn und $63 / 4$ Millionen Terschiedenes. Die Hauptstärke des amerikani- 
schen Exports in Baumwollwaren liegt in ungebleichten starkfädigen Sheetings und Drills, bei denen das G e w i c h t des Amerika ja billiger einstehenden Rohmaterials die Kalkulation zugunsten der Union wesentlich beeinfluBt.

Die Ausfuhr:I912/I3 richtete sich nach

\begin{tabular}{|c|c|c|c|c|c|c|c|c|}
\hline & & $\begin{array}{r}\text { Mill } \\
\text { Do }\end{array}$ & $\begin{array}{l}\text { lionen } \\
\text { llars }\end{array}$ & & & & \multicolumn{2}{|c|}{$\begin{array}{l}\text { Millionen } \\
\text { Dollars }\end{array}$} \\
\hline Kanada & . . & mit & 10,5 & Übertrag & & & & 26,0 \\
\hline Úbriges & und & & & China . & & & mit & 5,8 \\
\hline Mittel-Amerika & . & , &,+ 5 & Philippinen . & & & , & 7,0 \\
\hline Westindien . . & . & :, & 3,6 & Übriges Asien & & & $"$ & 5,3 \\
\hline Kuba . . . . & . & , & 2,9 & Afrika . . & & & , & 1.6 \\
\hline Südamerika . . & - &, & 4,5 & Europa & & & $n$ & 84 \\
\hline Übertrag & 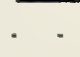 & & 26,0 & zusammen & & & & 53,7 \\
\hline
\end{tabular}

Die $\mathrm{E}$ in $\mathrm{fuhr}$ von $\mathrm{f} r \mathrm{~m}$ de $\mathrm{n}$ Baumwollwaren in den Vereinigten Staaten betrug dagegen in den Fiskaljahren

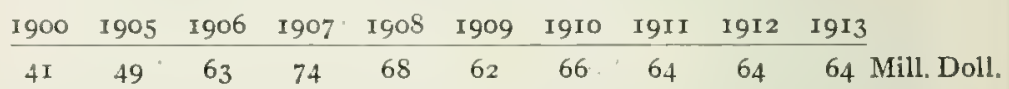

und besteht in den Hauptwerten aus Stickereien und Spitzen, Geweben, Garnen und Wirkwaren, welche IgI2/I3 werteten 353/4, 8 , $t^{1 / 2}$ und 3 . Iillionen Dollars. $95 \%$ der Einfuhr entfielen im letzten Jahre auf die vier Staaten:

England Deutschland Frankreich Schweiz

mit $20 \quad$ I6 12 I I 1/2 Millionen Dollars,

Japan war mit I Million vertreten.

\section{Zukunft des amerikanischen Baumwollbaus.}

Rückblick und Ausblick. Die Südstaaten behaupten mit Recht, daß ihr Land von der Natur begünstigt sei. Sie haben ein Klima, das für den Anbau fast aller Kulturpflanzen geeignet ist; ihr Boden besitzt große Fruchtbarkeit, und weite Flächen bislang unbebauten Landes warten nur darauf, unter Pflug genommen zu werden und den Arbeiter reich zu belohnen; ausgedehnte Kohlen-, Eisen- und Ölfelder bieten der Industrie bequeme Hilfsmittel. Geld ist in Menge da, und nur an Arbeitskräften fehlt es. Der hohe Preis der Baumwolle hat die Pflanzer in eine unabhängige Lage gesetzt, und die gewaltige Entwicklung in Öl, Eisen, Kohlen, Holz, Eisenbahnen, Landwirtschaft jeder Art und Industrie hat die Bevölkerung schr

1) Davon England 4,8, Deutschland 1,3. 
bereichert. Löhne, Produktenpreise und Bodenwerte haben seit Anfang des Jahrhunderts eine starke Steigerung erfahren, und dabei haben, trotz der Flut eines beispiellosen Wohlstandes, die sich über das Land ergiebt, die Farmpreise das Niveau der Tage vor dem Kriege noch nicht wieder erreicht. An Stelle der Hoffnungslosigkeit und Schwäche, die noch vor einem Menschenalter herrschte, ist mit den gewonnenen Erfahrungen und dem angesammelten Kapital ein starkes Macht- und Kraftbewußtsein getreten. Bei dieser wunderbaren Entwicklung, von den Tagen der Armut und der Unruhe an, welche noch lange nach dem Bürgerkrieg anhielten, bis auf die Gegenwart mit ihrem verhältnismäßigen Reichtum und ihrer Unabhängigkeit hat die $\mathrm{B}$ a u $\mathrm{m}$ w o $1 \mathrm{l}$ e die Hauptrolle gespielt. Der mittellose Farmer, welcher auf den reichen Pflanzer der Sklavenzeit folgte, war gezwungen, Baumwolle zu bauen, denn nur für dieses Produkt konnte er jederzeit bares Geld erhalten. Seine Sucht nach alljährlichen großen Baumwollernten führte freilich zu einer Verschlechterung seines Landes, das keine Erholung in Fruchtwechsel fand, auch mußte er die notwendigen Lebensbedürfnisse zu erpresserischen Preisen kaufen. Aber jener Zustand kann heute als überholt gelten. Geld ist auch im Süden reichlich geworden, dem Farmer wird gelehrt, Baumwolle mit anderen Produkten abwechselnd zu bauen und seine eigene Farm zur Befriedigung seiner Bedürfnisse auszunutzen, während das Entstehen großer Städte, die Entwicklung der Eisenbahnen und die Verwendung von Kühlwagen, dirch welche seine dem Verderb ausgesetzten landwirtschaftlichen Erzeugnisse in gutem Zustande nach gut lohnenden Märkten geschafft werden können, ihn viel weniger als bisher von der Baumwolle abhängig machen. Früher wurde Baunwolle um jeden Preis gebaut; wenn aber jetzt Baumwolle unter einem lohnenden Preis sinken sollte, kann der Farmer leicht Geld für andere Ernten bekommen, und so hat die Baumwolle heute Rivalen in der Gunst des Farmers. Dazu kommen noch die Bestrebungen der Pflanzervereinigungen, die Vorräte ihrem Einfluß zu unterwerfen. Reich geworden, gut organisiert und letzthin auch mit zahlreichen Lagerhäusern ausgerüstet, ist denn der Farmer auch keineswegs geneigt, Baumwolle billig zu verkaufen; lieber schränkt er ihren Anbau zugunsten anderer und besser lohnender Kulturen ein.

Die Weltproduktion in Baumwolle verteilte sich im Jahre I9I2 auf:

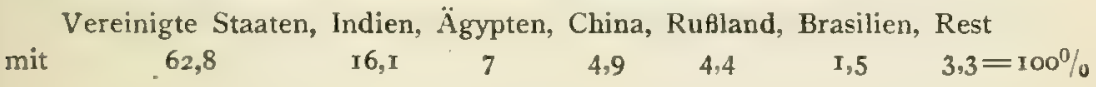


Die S p inde $1 z$ ah 1 der Welt ist gestiegen von Io 5 Millionen im Jahre 1900 auf It4 im Jahre I9I3, der Ba umwollver$\mathrm{br}$ a $\mathrm{uch}$ in gleicher Zeit von I5, I auf 2I, $\mathbf{5}$ Millionen Ballen. Dabei ist der Weltverbrauch an Baumwolle in fortwährendem Steigen begriffen, und es liegt die Frage nahe, ob die Vereinigten Staaten a 11 e in diesen Mehrbedarf auf die Dauer zu decken vermögen?

Meine persönlichen Eindrücke habe ich auf Grund einer Studienreise im Jahre 1907 damals wie folgt zusammengefabt:

Es ist durchaus $m \ddot{g} \mathrm{gl} \mathbf{i} \mathrm{ch}$, daß die Vereinigten Staaten von Nordamerika, soweit die für Baumwollbau geeigneten Flächen in Betracht kommen, weit größere Mengen von Baumwolle als bislang erzeugen können; angesichts der jetzt schon vorhandenen Schwierigkeiten, die beim Baumwollbau vielfach, besonders beim Pflücken unentbehrliche Handarbeit zu beschaffen, ist es aber we n ig w a h r schein 1 ich, daß für die Nächstzeit eine wesentliche Produktionssteigerung zu erwarten sei, und es ist sicher. $\mathrm{d} a \mathrm{~B}$ die Vereinigten Staaten einen immer größeren Teil ihrer Baumwollernte für ihre eigene wachsende Industrie in Anspruch nehmen werden, da ihre Tendenz ausgesprochenermaßen dahin geht, an Stelle von Rohbaumwolle mehr und mehr Baumwollfabrikate auszuführen.

Die Sachlage ist noch heute genau dieselbe.

Solange der Bedarf in gleich hervorragendem Maße wie bislang auf die Produktion eines einzelnen Landes angewiesen ist, bleiben die schroffsten Preisschwankungen ein unvermeidliches Übel. Die Vergewaltigung der natürlichen Preisbewegung des Rohmaterials durch Börsenspekulationen erfolgt bei keinem Welthandelsartikel in so wilder Weise wie bei Baumwolle. Nichts kann die europäische Industrie aus dieser drückenden Abhängigkeit von dem amerikanischen Monopol befreien, als größerer Anbau von Baumwolle a u B e r h a l b der Vereinigten Staaten, und alle darauf gerichteten Bestrebungen verdienen deshalb die eifrigste Förderung.

Als Beihefte zum „Tropenptlanzer" früher erschienen:

\section{Moritz Schanz:}

Die Baumwolle in Ägypten und im Englisch-Ägyptischen Sudan. Die Baumwolle in Ostindien.

Die Baumwolle in Russisch-Asien. 


\section{Quellen.}

The Cotton Plant. Bulletin Nr. 3o. U. St. Agricultural Department. Washington I 896. Cotton Produktion. Jährliche Berichte des Census-Bureau. Washington bis I9r3. Supply and distribution of Cotton des Census Bureau. Washington bis rgr3. Yearbooks. U. St. Agricultural Department. Washington bis I9I3.

Thirteenth Census of the United States. Washington I9Io.

D. A. Tompkins, Cotton and Cotton Oil. Charlotte r 90 I.

Report of the Lancashire Private Cotton Investigation Commission. Manchester rgo6. W. B. Mercier \& H. E. Savely, The Knapp Method of Cotton Growing. Washington I9I3.

Max Sering, Die landwirtschaftliche Konkurrenz Nordamerikas in Gegenwart und Zukunft. Leipzig 1887 .

Ernst von Halle, Baumwollproduktion und Pflanzungswirtschaft in den nordamerikanischen Südstaaten, Teil I u. II. Leipzig 1897 u. I906.

Max Augstin, Die Entwicklung der Landwirtschaft in den Vereinigten Staaten von Nordamerika. Leipzig Igr4.

Heinrich Semler, Die tropische Agrikultur. Wismar I903.

A. Oppel, Die Baumwolle. Leipzig I902.

C. Heine, Die Baumwolle. Leipzig I9o8.

Moritz Schanz, Die Baumwolle in den Vereinigten Staaten von Nordamerika. Berlin Igos.

Moritz Schanz. Der Neger in den Vereinigten Staaten von Nordamerika. Essen I9I r. H. Escherich, Die angewandte Entomologie in den Vereinigten Staaten. Berlin 1913. Nachrichten für Handel, Industrie und Landwirtschaft, herausgegeben vom Reichsamt des Innern. Bis I9I4.

u. a. 
Gedruckt in der Königlichen Hotbuchdrackerei von E. S.Mittlex \& Sohn, Berlin SW68, Kochstr.68-7r. 

Pressboard

Pamphlet

Binder

Gaylord Bros., Inc

Makers

Syracuse, N. Y.

PAT. JAM 21. 1908

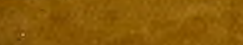




\section{UNIVERSITY OF ILLINOIS-URBANA}

338.15CH1682 COOA
BAUMWOLL-ANBAU, HANDEL UND INDUSTRIE IN

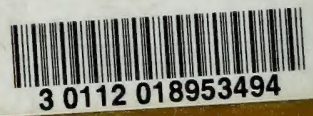

